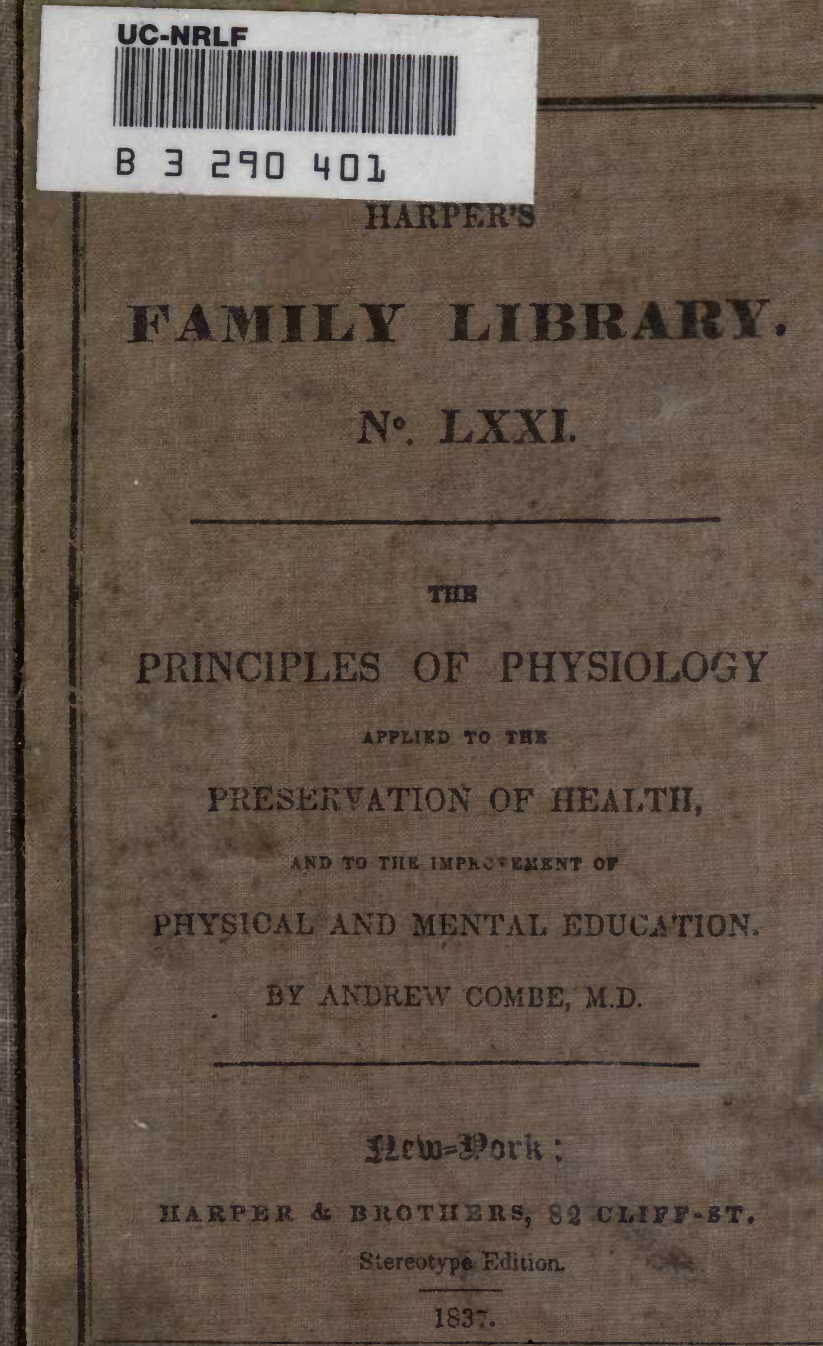




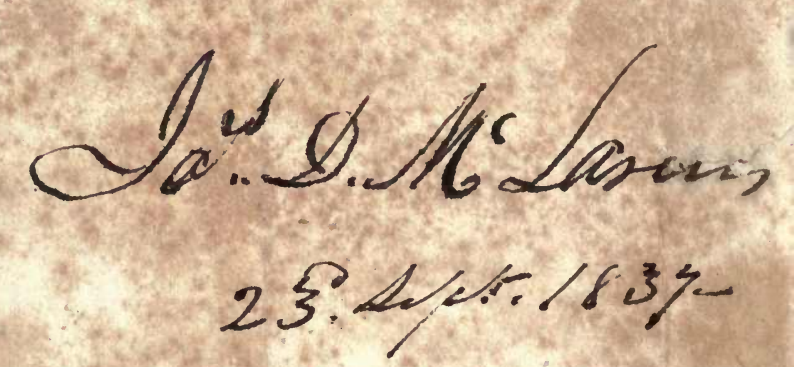



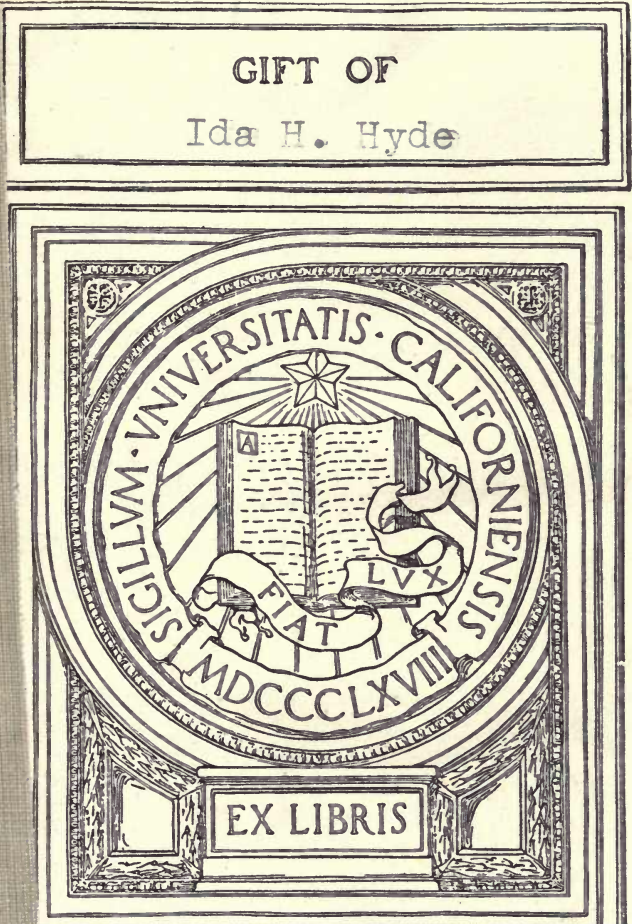

Bologr

HERARY 






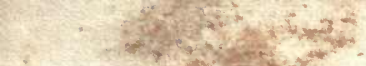

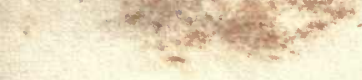




\section{PRINCIPLES OF PHYSIOLOGY}

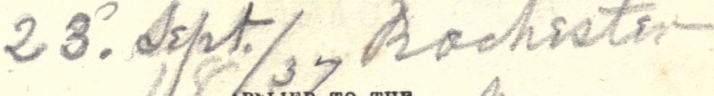

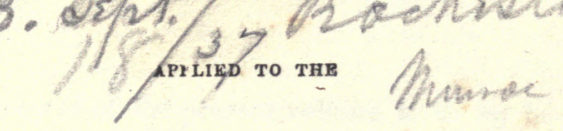

PRESERVATION OF HEALTH,

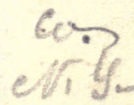

AND TO THE IMPROVEMENT OF

PHYSICAL AND MENTAL EDUCATION.

\section{BY ANDREW COMBE, M.D.}

1)

FELLOW OF THE ROYAL COLLKGE OF PYYCICUANS OF EDINBURAY,

NEW-YOR K :

HARPER \& BROTHERS-82 CLIFF.STREET.

1836. 
QP34

C58

MOLOEP

UIRAPY

$$
\operatorname{lda} \text { H. Hyds }
$$




\section{PREFACE.}

THE object of the present volume is to lay before the public a plain and intelligible description of the structure and uses of some of the more important organs of the human body, and to show how information of this kind may be usefully applied both to the preservation of health and to the improvement of physical and mental education. In selecting the functions to be treated of, I have preferred to examine those which are at once most influential in their operation on the general system, and at the same time least familiarly known. Some, accordingly, whose sphere of action is comparatively subordinate, I have not even named; and to others of essential consequence in the animal economy, such as that of digestion, I have merely alluded. To include the first would have added to the difficulties of the reader, by the multiplicity of unimportant details; and to treat of the latter would have been, in a great measure, a work of supererogation, as treatises on the digestive organs are already in extensive circulation.

In offering practical rules for the guidance of the reader, it has been my constant endeavour to exhibit the relation subsisting between them and the

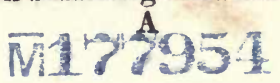


particular laws of the organization, according to which their influence is exerted, that the recommendation given may rest, as far as possible, on the foundation of nature, and not on the doubtful authority of any individual. Many of the valuable treatises which have already appeared on the subjects of health and of education seem to me to have failed in making an adequate impression on the public mind, chiefly from this basis not having been brought sufficiently into view; and thus not only have the evils arising from defective education been unjustly and invidiously charged against education itself, but the most opposite methods have been advocated and practised, with equal earnestness and plausibility, where a direct reference to the laws of the organization would at once have dissipated doubt and placed truth in its clearest light.

It is not uninstructive to remark, that, in the case of the lower animals, the necessity of modifying the method of cultivation according to the peculiarities of constitution which they present, has been long perceived and consistently acted on, and with such success as to afford us good reason for applying the same rule to our own species, and for regarding every mode of education as erroneous and inefficient which is not in harmony with the higher nature of man. The extent, indeed, to which, by following this plan, we can carry our influence over the lower animals, and secure the development and efficiency of almost every organ, has often been the theme of admiration and surprise : and there can 
scarcely be a doubt that were the same principle followed in the cultivation of the physical, moral, and intellectual powers of man, and were no rule received which is not in accordance with the laws of his constitution, a much higher degree of success would reward our exertions than we have ever yet experienced or anticipated.

The little regard which has hitherto been paid to the laws of the human constitution, as the true basis on which our attempts to improve the condition of man ought to rest, will be obvious from the fact, that, notwithstanding the direct uses to which a knowledge of the conditions which regulate the healthy action of the bodily organs may be applied, in the prevention, detection, and treatment of disease, there is scarcely a medical school in this country in which any special provision is made for teaching it; the pupil being left to elaborate it for himself from amid information communicated to him for other purposes. In some of the foreign universities, chairs have been instituted for this purpose ; and, in France, a journal of Hygiène has existed for a short time. But, in this country, with the exception of Sir John Sinclair's elaborate Code of Health, and one or two other publications of a late date, the subject has never been treated with any thing like the regard which it assuredly deserves. In one point of view, indeed, the omission is not so extraordinary as it may at first sight appear. The prominent aim of medicine being to discriminate and to cure disease, both the teacher and the student naturally fix upon that as their chief 
object; and are consequently apt to overlook the indirect but substantial aid which an acquaintance with the laws of health is calculated to afford in restoring the sick, as well as in preserving the healthy from disease.

It is true, that almost every medical man, sooner or later, works out this knowledge for himself; but, in general, he attains it later than he ought to do, and seldom so completely as he would have done had it been made a part of his elementary education, to which he saw others attach importance. In my own instance, it was only when entering upon practice that I had first occasion to feel and to observe the evils arising from the ignorance which prevails in society in regard to it. Impressed afterward more deeply than ever with the interest and utility of the study, I contributed two or three articles on the subject to one of our periodical journals, and resolved to make them the basis, at some future time, of a more detailed and connected exposition. This I have now attempted; and, if the result prove useful, in any degree, to the general reader or professional student, my object will be attained. The volume being of a purely elementary character, and admitted truths of a useful kind being, in every instance, preferred to novelty or ingenious speculation, the experienced practitioner will meet with little to interest him in the perusal ; but for him it was never intended.

There is a tendency in the minds of many, when a new subject is presented to them, to run away with a part of a proposition, or with an individual 
illustration, and to condemn the principle to which it applies as unsound, because they happen to know facts which are at variance with the particular example brought forward. In this way, there is perhaps no one rule which I have advanced to which some individual case may not be plausibly opposed. But it does not necessarily follow that the principle or rule is thereby disproved. An example may be badly chosen, and yet the truth it is meant to convey may be as much a truth as before. Insteaa, therefore, of at once condemning a proposition on account of a single apparent exception, it will be better to extend the inquiry, and discover whether any peculiarity of situation or constitution has interfered to modify the result, and to condemn only when evidence of inaccuracy is obtained. Thus, because some drunkards have enjoyed good health, and lived to an unusually old age, we are by no means entitled to infer that drinking was the cause of the good health, and that if we would all drink as freely, we should all live as long. An example of this kind, far from disproving the principle that ardent spirits are prejudicial to the human frame, only establishes the fact that individuals exist who, from some idiosyncrasy, are better able than others to resist their bad effects; and, in like manner, when I state, as a general proposition, that severe muscular exertion is hurtful during rapid growth, I do not consider it as any argument against the fact to say, that A. B. underwent great exertion when growing without being injured by it. The general principle obviously remains unaffected by any such instances. 
Various repetitions occur in the course of the work, which to some may seem unnecessary, and for which I ought to solicit the indulgence of the reader. These have arisen chiefly from the intimate manner in which the different functions are connected with each other, rendering it impossible to explain one without constantly referring to the rest. Occasionally, also, the novelty and importance of the subject have led me to risk repetition, in order to ensure attention, but I trust that these faults, if felt as such, will be forgiven.

Those who desire to obtain further information of a popular nature in regard to the structure of man, will find an excellent treatise on Animal Physiology, in four of the earlier numbers of the Library of Useful Knowledge. It is understood to be from the pen of an able physician in London, with whose sentiments on the subject now before us, as expressed in the following extract from his concluding page, I need hardly say I entirely concur :-

"The obvious and peculiar advantages of this kind of knowledge are, that it would enable its possessor to take a more rational care of his health; to perceive why certain circumstances are beneficial or injurious; to understand, in some degree, the nature of disease, and the operation as well of the agents which produce it as of those which counteract it ; to observe the first beginnings of deranged function in his own person; to give to his physician a more intelligible account of his train of morbid sensations as they arise; and, above all, tc cooperate with him in removing the morbid state on 
which they depend, instead of defeating, as is now through gross ignorance constantly done, the best concerted plans for the renovation of health. It would likewise lay the foundation for the attainment of a more just, accurate, and practical knowledge of our intellectual and moral nature. There is a physiology of the mind as well as of the body ; both are so intimately united, that neither can be well understood without the study of the other; and the ohysiology of man comprehends both. Were even what is already known of this science, and what might be easily communicated, made a part of general education, how many evils would be avoided, how much light would be let in upon the understanding, and how many aids would be afforded to the acquisition of a sound body and a vigorous Inind;-pre-requisites more important than are commonly supposed to the attainment of wisdom and the practice of virtue." 


$$
5
$$




\section{CON'TENTS.}

\section{CHAPTER I.}

Physiology, vegetable, comparative, and human-Animate and inanimate Bodies - Objects of Physiology - Usefulness of Physiological Knowledge-Illustrations-Evils of Ignorance -Error in separating Anatomy and Physiology from their practical Applications-Object of the present Publication 13

CHAPTER II.

The Skin-Composed of three Layers-The Cuticle-Its Structure and Uses - The mucous Coat-The Seat of Colour-The true Skin-Its Structure-The Seat of Perspiration-Its Nature-Consequences of suppressed Perspiration-Sympathy between the Skin and other Organs-The Skin a Regulator of Animal Heat-The Seat of Absorption-Touch and Sensation -Connexion between the Skin and Nervous System - 30

\section{CHAPTER III.}

Mortality in Infancy from Cold-Animal Heat lowest at that Age-Too little and too much Clothing equally bad-Rules for Dress-Advantages of Flannel, exemplified in H. M. S. Valorous-Ventilation of Beds and Clothing-Influence of Light-Importarce of Ablution and Bathing-Cold, Tepid, and Warm Bath-Sponging with diluted Vinegar-Friction of the Skin-Vapour-bath and Warm Bath useful in preventing and curing Nervous Diseases and Liability to Cold-Sailing and Riding useful by acting on the Skin - . - . 62

\section{CHAPTER IV.}

Muscles-Their Structure, Attachments, and Conditions of Ac tion-Necessity of Arterial Blood and of Nervous InfluenceIllustrations-Muscles act by alternate Contraction and Relaxation-Fatigue consequent on continuing the same Attitude explained-Injuries of Spine from Neglect of this Law, and from sedentary Occupations in School-The Mind ought to be 
engaged in Exercise as well as the Body-Superiority of cheerful Play and amusing Games-A dull Walk the least useful Exercise-Influence of Mental Stimulus illustrated by Examples-Exercise to be proportioned to Strength-Laws of Exercise - . . . . . . . . . - 88

\section{CHAPTER V.}

Effects of Muscular Exercise on the principal Functions of the Body explained-Shampooing a Substitute for ExerciseEvils of deficient Exercise-Best Time for taking ExerciseAlways to be taken in the open Air-Different KindsWalking-Riding-Dancing - Gymnastics - Fencing-Shuttlecock-Reading aloud-Case illustrative of the Principles of Exercise-Involuntary Muscles - . - . . - 121

\section{CHAPTER VI.}

The Bones essential to Motion, and to the Security of the Vital Organs-The Skeleton-Bones are composed of Animal and of Earthy Matter-The Animal Part the Seat of their Vitality - The Proportions between these vary at different Periods of Life-Vessels, Nerves, Life, Growth, and Decay of BonesAdvantages of their Vitality and Insensibility-Their Adaptation to contained Parts-Conditions of Health-Necessity of Exercise - ................. 140

\section{CHAPTER VII.}

Respiration-Arterial and Venous Blood-Nature of Respiration -Structure of the Lungs-Conditions required for Healthy Respiration-Sound original Constitution-Iufluence of $\mathrm{He}$ reditary Predisposition-Of wholesome Food, and good Digestion-Of the free expansion of the Lungs-Of exercise of the Muscles and Voice-Of Cheerfulness and Depression of Mind - Of Pure Air and Ventilation-Examples of the bad effects of Vitiated Air-Respiration the source of Anima! Heat-Causes of deficient Generation of Heat-Removal of such CausesDirect and Indirect Exercise of the Lungs-Beneficial Effects of, and Rules for, Exercise-Precautions to be observed in Diseases of the Lungs, and in Persons predisposed to Consumption -................. 164

\section{CHAPTER VIII.}

Nervous System-Structure of the Brain-Its FunctionsConnexion between the Mind and Brain-Conditions of Health in the Brain-Hereditary Predisposition-Influence 
of the Blood on the Brain-Influence of Exercise on the Brain-Effects of insufficient Exercise-Effects of excessive Exercise at different Ages-Case of Sir H. Davy-Rules for the proper Exercise of the Brain-Best Time for Mental Exertion-Regularity essential-Repetition-Every Mental Power to be exercised directly on its own Objects-Illustrations-Influence of the Nervous System on the general Health-Examples - .... . . . . - 206

\section{CHAPTER IX.}

Causes of Bad Health-Not always the Result of moral or immoral Conduct-Nor of Accident-But of the Infringement of the Laws of Organization-Proofs from past History-Dimin. ished Mortality from Increase of Knowledge, and better fulfilment of the Conditions of Health-The Expeditions of Anson and Cook contrasted-Gratifying Results of the Sanatory Arrangements of Ross, Parry, and Franklin-Pulmonary Diseases in the Channel Fleet, from Ignorance of PhysiologyRates of Mortality in different Ages and Countries-Causes of late Improvements-Condition of Wealthier and Poorer Classes compared-Good done by the Apprehension of Cholerz-Influence of Habit-Neglect of Organic L2ws in Recruiting Service-Examples-Conclusion - . - 264 


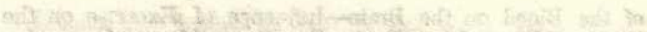

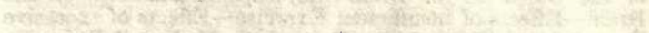

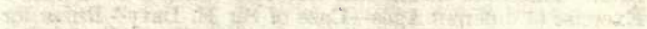

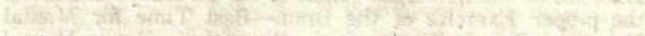

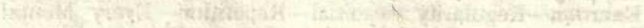

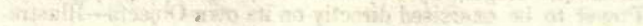

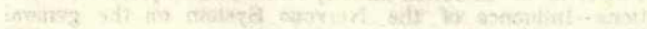

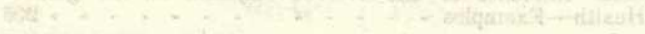

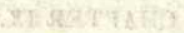

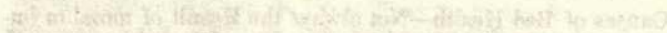

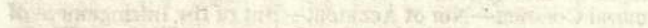

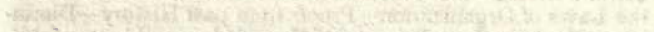

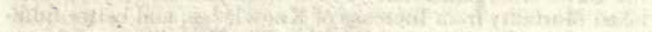

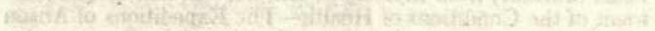

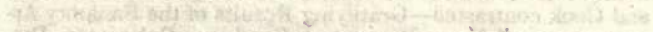

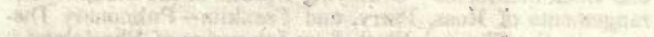

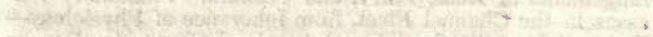

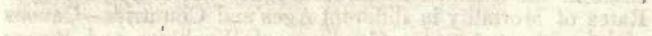

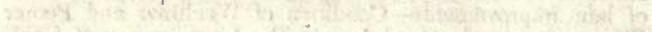

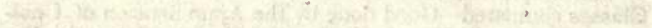

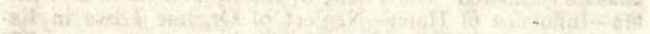

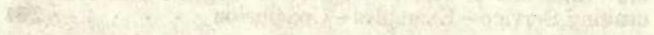




\section{THE}

\section{PRINCIPLES OF PHYSIOLOGY.}

\section{CHAPTER I.}

Thysiology, vegetable, comparative, and human-Animate an inanimate Bodies - Objects of Physiology-Usefulness of Physiological Knowledge-1Hustrations-Evils of Ignorance -Error in separating Anatomy and Physiology from their practical Applications-Object of the present Publication.

Physiology, from фvsis nature, and doyos discourse, signifies literally a discourse about natural powers, but, as now used, it applies exclusively to the doctrine of the uses or functions of the different constituent parts of beings endowed with the principle of life. As applied to the vegetable kingdom, it is called Vegetable Physiology; to the lower animals, Comparative Physiology; and to man, Human Physiology. In all these instances, however, the objects of physiology are the same, viz. the exposition of the mechanism and laws by which the various functions which characterize living bodies are carried on, so as to fit each individual for the particular sphere in which the Creator intended it to exist.

The grand mark of distinction between animate and inanimate bodies is to be found in the different relations in which they stand to the ordinary laws of the material world. Inanimate or unorganized bodies have no internal power of action, and of themselves can effect no change. Possessed of 
certain fixed and invariable properties, they stand uniformly in the same relation to each other, and act invariably according to the same general laws, so that what is once ascertained of them can be predicted with certainty to hold true for ever after; and, therefore, in conducting our investigations, we know that the same effects will always follow the same causes with mathematical precision. But when the same elementary material becomes part of a living body, this rule no longer holds : the laws of chymical and physical action are greatly modified, or, for a time, counteracted, and the now organized matter obeys the laws of vegetable or animal life, and is not again subjected to those of chymical action, either till eliminated from the body, or till life is extinct ; and, in point of fact, the putrefaction which instantly follows the extinction of the vital principle is neither more nor less than the ordinary laws of inanimate matter resuming their dominion when no longer opposed by a higher power.

An example or two will render the difference more apparent. All bodies gravitate towards the earth, according to a well-known and invariable law. But animals are able to resist this law, so far as to preserve an attitude at variance with its tendency, or even to rise, like the eagle, many thousand feet in the air in opposition to their natural weight; but, on the extinction of life, they lose this power, and again become subject to the full influence of gravitation. In the same way, many anin.als preserve an -elevated and steady temperature, whether exposed to severe cold or to excessive heat ; but when life ceases, rapidly assume that of the objects by which they are surrounded. A human being may, for instance, be exposed to the intensest cold of the Polar Regions without having his own internal temperature reduced by a single degree so long as life endures; but from the moment he ceases to exist, his body begins to part with its heat, and ere long it 
becomes frozen and stiff like the inanimate masses by which it is surrounded.

Here, then, is a grand boundary-line dividing the organized from the inorganized, the animate from the inanimate body. Chymistry and natural philosophy investigate the laws and conditions which regulate the action and movements of inanimate or inorganized objects; but, from what we have seen of the power of the vital principle in modifying these, it will be manifest that, however extensive and accurate our knowledge of the properties of the elementary materials of living bodies may be, considered separately, we can thence infer nothing in regard to the qualities of the animal compound when endowed with life, but must resort to observation and study for the discovery of the conditions by which life is characterized, and under which it is carried on.

Physiology, or the history of the functions which characterize living beings, is thus a subject of peculiar inter est; and human physiology, or that which is about to engage our attention, is as important in its practical consequences as it is attractive to rational curiosity. In its widest sense it comprehends an exposition of the functions of the various organs of which the human frame is composed; of the mechanism by which these are carried on; of their mutual relations to each other; of the means of improving their development and action; of the purposes to which they ought severally to be directed; and of the manner in which exercise ought to be conducted, so as to secure for the organ the best health, and for the function the highest efficiency. A true system of physiology comes thus to be the proper basis, not only of a sound physical, but of a sound moral and intellectual education, and of a rational hygiene; or, in other words, it is the basis of every thing having for its object the physical and mental health and improvement of 
man ; for, so long as life lasts, the mental and moral powers with which he is endowed manifest themselves through the medium of organization, and no plan which he can devise for their cultivation, that is not in harmony with the laws which regulate that organization, can possibly be successful.

But, besides the power of resisting the operation of the ordinary chymical and physical laws, living bodies are distinguished by other properties peculiar to themselves. Unlike inorganized matter, which exists in the same form from the beginning, bodies endowed with the principle of life derive their origin from previously existing living bodies of the same nature as themselves: these, in their turn, give birth to others, and in this way the succession is kept up. Unlike the inert material which retains its properties unaltered throughout endless ages, the living body is constantly undergoing changes from the first to the last moment of its existence; and these are exemplified, on the large scale, in the great stages of youth, maturity, old age, and death. Unlike inorganized matter, which neither grows nor decays, living bodies require a constant supply of nourishment to admit of their growth in youth, and to replace the worn-out particles which are regularly thrown off at every period of life ; and, unlike inanimate objects, the relations and properties of which never alter, living bodies cease at last to exist, and their component elements, deprived of the principle of life, again become subject to the ordinary laws of matter, and are speedily decomposed and scattered about as if life had never been. These properties, it may be observed, are common to vegetable and animal life; but animals possess others peculiar to themselves. Among the most remarkable of these are sensation, thought, voluntary motion, and the faculty of communicating to each other their own thoughts and feelings, through the medium of natural or artificial language. These 
are great marks of distinction, and, considered in a general point of view, amply suffice to divide the two great classes of animated beings; and while some animals exhibit individual powers in greater perfection, man stands far their superior, not only in combining in his own body all the senses and faculties possessed among them, but in being endowed with moral and intellectual powers which are denied to them, and which place him at once at the head of the living creation, and constitute him a moral, religious, intelligent, and responsible being.

So numerous and important are the various organs of which the human frame is composed, and so closely are they linked with each other in their action, that, in treating of them, it is difficult, or rather impossible, to follow any arrangement which shall not involve considerable repetition. On the present occasion, however, a systematic mode of proceeding is not essential, my object being merely to communicate a general knowledge of a few of the more important functions, partly with a view to the direct practical purposes to which such information may be applied, and partly for the sake of rousing public attention to the necessity of including this branch of science in every plan of what is called a liberal education.

Let it not be said that knowledge of this description is superfluous to the unprofessional reader; for society groans under the load of suffering inflicted by causes susceptible of removal, but left in operation in consequen':e of our unacquaintance with our Jwn structure, and of the relations of the different parts of the system to each other and to external objects. Every medical man must have felt and lamented the ignorance so generally prevalent in regard to the simplest functions of the animal system, and the consequent absence of judicious cooperation of friends in the care and cure of the sick. From unacquaintance with the commonest 


\section{USEFULNESS OF PHYSIOLOGICAL KNOWLEDGE.}

facts in physiology, or incapability of appreciating their importance, men, of much good sense in every other respect, not only subject themselves unwittingly to the active causes of disease, but give their sanction to laws and practices destructive equally to life and to morality, which, if they saw them in their true light, they would shrink from countenancing in the slightest degree.

For proof of this 1 need only refer to the evidence on the Factories Regulation Bill, which lately occupied so much of public attention.* The law then in operation authorized the working of children between the years of eight and sixteen, in the close, heated atmosphere of a cotton-mill, for twelve hours a day; and, as a great boon, the period has been, with much difficulty, reduced from twelve to eight hours for the younger children. Had our legislators been instructed in anatomy and physiology so far as to obtain even the most general notion of the constitution of the human body, and had they followed without bias the conclusions to which such knowledge would have led every reflecting mind, they would never have sanctioned such a law as that which formerly disgraced the statute-book, nor would they have shown any reluctance to modify its provisions when its unfitness was pointed out to them. Had such knowledge been familiar to their minds, and morality been their aim, I doubt whether, instead of objecting to the reduction when it was proposed, any one would have been found hardy enough to affirm that even the present amount of labour is not too much for ungrown children. It may be that the evidence in the printed report was partially got up; but it contains a multitude of facts so entirely in accordance with the soundest and best understood principles in physiology, which no counter-evidence can rebut, that one can only lament the ignorance

* [In Great Britain.] 
which prevented many able and benevolent but prejudiced men from perceiving its true character, and yielding at once to the imperious dictates of nature and of duty. That there were great difficulties in the way of every alteration is quite true; but surely no question of mere gain to any or to every class ought to be allowed to stand for ever in the way, when the lives and happiness of multitudes of our fellow-creatures are at stake; and unless we begin somewhere, how can any improvement be accomplished?

Another instance of the dangers of ignorance lately presented itself. In the Edinburgh Advertiser of the 1st March, 1833, we are informed that " a distressing occurrence was discovered on Wednesday forenoon, on board t'ie Magnus Troil, Shetland trader, Captain Ganson, lying at Leith. The master and mate, who are brothers, went as usual on Tuesday night to sleep in the cabin of the vessel, but not appearing at the eustomary hour in the morning, the crew thought they had merely slept beyond their time. A little time having elapsed, they were repeatedly called, but no answer being returned, one of the men went into the cabin, where he found the two brothers almost dead through suffocation. It is thought that they had shut the companion and skylights so close, that they had during the night exhausted the whole of the vital air necessary for respiration contained in their confined situation. Medical aid was procured, and hopes are entertained of their recovery. Both were much respected." Captain Ganson, however, did not recover, but died convulsed on Thursday morning.

Since the publication of the preceding statement, doubts have been entertained whether the catastrophe resulted simply from confined air, or from the stove not having been extinguished, or from impure air proceeding from the bilge-water. The cause, however, to which it ray be ascribed is not of much 
consequence to our argument, for it is quite certain that had Captain Ganson and his brother possessed the slightest acquaintance with the nature of the atmosphere, and the relation of its elements to the function of respiration, neither of their lives would ever have been lost in such a way as that described. A constant supply of pure air is indispensable to the formation of proper blood in the lungs, and consequently to the preservation of life and the well-being of the whole body; but formerly, when this condition was as little known or regarded as it was by Captain Ganson, many persons were shut up together in small ill-ventilated rooms in schools, jails, and hospitals, and the natural result was a degree of mortality from fevers and other diseases, which, now that the laws of respiration are better known and more attended to, is never heard of.

From the same hurtful absence of knowledge, a law exists, or lately existed, in France, by which infants must be taken within a very short time after being born to the office of the Maire, if it is wished to have their births registered. But there is another and higher law, made by the Creator, with which this enactment is at variance ; and that law renders the infant incapable of bearing exposure to a low temperature without injury. The consequence is, that in winter, especially in places where the Maire resides at a distance, and where consequently there is much exposure, a greater mortality takes place than is observed among infants placed under more favourable circumstances. Had the nature of the living functions been generally understood by the framers of such a law, it is obvious that it could never have been enacted, for to have done so knowingly would have been in substance to legalize infanticide.

One additional example may be given. It is well understood among professional men, that in speaking singing, and playing on wind-instruments, the 
lungs are called into play as powerfully as in running or any other species of severe muscular exercise. From not adverting to this fact, a strongly constituted individual, who brought on spitting of blood by bodily labour to which he had not been accustomed, conceived himself perfectly safe, and even cautious, when he gave up the spade, and confined himself to talking a great deal, which he did daily to numerous visiters in explanation of favourite views then occupying all his thoughts. The consequence was, that the medical treatment resorted to was without effect, and a fatal illness was brought on. When the action of the lungs was subsequently explained to this individual, he saw at once the error into which he had fallen, and lamented the ignorance which had led to it, but too late to derive any advantage from his knowledge.

We are constantly meeting with anomalies in practical life, in the case of individuals little accustomed, when in health, to observe or reflect on the influence of external circumstances and modes of life in disturbing the action of the various animal functions, but at the same time easily and deeply impressed by all extraordinary occurrences affecting them. Thus, when any one is taken ill, his relatives or friends become extremely anxious to have his room properly ventilated; his body-clothes frequently changed and carefully aired; his food properly regulated in quantity and quality; his skin cleaned and refreshed; his mind amused and tranquillized; his sleep sound and undisturbed; and his body duly exercised;-and they state as the reason for all this care, and most justly, that pure air, cleanliness, attention to diet, cheerfulness, regular exercise, and sound sleep are all highly conducive to health And yet such is the inconsistency attendant on ignorance, that the patient is no sooner restored, than both he and his guardians are often found to become as careless and indifferent in regard to all 
the laws of health, as if these were entirely without influence, and their future breach or observance could in no way affect him! Just as if it were not better by a rational exercise of judgment to preserve health when we have it, than first to lose it, and then pay the penalty in suffering and danger, as an indispensable preliminary to its subsequent restoration!

One cause of such anomalous conduct is the dangerous and prevalent fallacy of supposing, that because glaring mischief does not instantly follow every breach of an organic law, no harm has been done. Thus, what is more common than to hear a dyspeptic invalid, who seeks to gratify his palate, say, that vegetables, for example, or pastry, or heavy puddings, do not disagree with him, as he ate them on such a day, and felt no inconvenience from them? and the same in regard to late hours, heated rooms, insufficient clothing, and all other sources of bad health, every one of which will, in like manner, be defended by some patient or other, on the ground that he experienced no injury from them on a certain specified occasion; while all will readily admit the abstract fact, that such things are, and must be, very hurtful to every one else.

Happy would it often be for suffering man could he see beforehand the modicum of punishment which his multiplied aberrations from the laws of physiology are sure to bring upon him. But as, in the great majority of instances, the breach of the law is limited in extent, and becomes serious by the frequency of its repetition rather than by a single act; so is the punishment gradual in its infliction, and slow in manifesting its accumulated effect; and this very gradation, and the distance of time at which the full effect is produced, are the reasons why man, in his ignorance, so often fails to trace the connexion between his conduct in life and his broken health. But the connexion subsists although ho 
does not regard it, and the accumulated consequences come upon him when he least expects them.

Thus, pure air is essential to the full enjoyment of health; and reason says, that every degree of vitiation must necessarily be proportionally hurtful, till we arrive at that degree at which, from its excess, the continuance of life becomes impossible. When we state this fact to a delicately constituted female, who is fond of frequenting heated rooms, or crowded parties, theatres, or churches, and call her attention to the hurtful consequences which she must inflict on herself by inhaling the vitiated air of such assemblies, her answer invariably is, that the closeness and heat are very disagreeable, but that they rarely injure her: by which she can only mean, that a single exposure to them does not always cause an illness serious enough to send her to bed, or excite acute pain; although both results are admitted sometimes to have followed. An intelligent observer, however, has no difficulty in perceiving that they do hurt her, and that although the effect of each exposure to their influence is so gradual as not to arrest attention, it is not the less progressive and influential in producing and maintaining that general delicacy of health by which she is characterized, and from which no medical treatment can relieve her, so long as its active causes are left in operation.

The debility so generally complained of in spring by invalids and persons of a delicate constitution, and which renders that season of the year so formidable in prospect, and in reality so fatal, seems to result more from the accumulated effects of the preceding winter months than from any thing directly inherent in the season itself. At the commencement of winter, such persons feel comparatively strong from the beneficial influence of exposure to the open air, light, and exercise, during the 
preceding months of summer and autumn. But in proportion as they are deprived of these advantages by the advance of winter, and are subjected to the evil influence of confinement to close rooms, deficient exercise, cold damp air, and deprivation of the stimulus of light, the stamina of the constitution become impaired, and debility and relaxation begin to be felt, and make progress from day to day, till on the arrival of spring they have reached their maximum, and either give rise to positive disease, or gradually disappear at the return of the invigorating influence of longer and warmer days. This principle, however, will not apply where pulmonary or other disease pre-exists ; for in such cases, the east winds prevalent in spring are directly injurious.

If the above view be correct, it is obvious that the hurtful cause is not, as is commonly supposed, so much any positive quality of spring as the accumulated mass of the winter infuences then reaching their maximum ; and this is not perceived, only because the operation of the cause from day to day, although perfectly real, is too small to attract notice, while the aggregate of the many days composing winter is striking enough. The fact that those who are sufficiently robust to undergo the necessary exposure in winter suffer much less in spring, seems to corroborate the above explanation.

We must not suppose, then, that because a single excess of any kind does not produce a direct attack of disease, it is, therefore, necessarily harmless; for it is only when the noxious agent is very powerful indeed that its deleterious influence on the system becomes instantly sensible. In the great majority of situations to which man is exposed in social life, it is the continued or the reiterated application of less powerful causes which gradually, and often imperceptibly, unless to the vigilant eye, effects the change, and ruins the constitution before danger is dreamed of And yet this great truth is 
so little known, that, if no glaring mischief has followed any particular practice, within at most twentyfour hours, nine out of ten individuals will be found to have come to the conclusion that it is perfectly harmless, even where it is capable of demonstration that the reverse is the fact.

It is this apparent but unreal separation of the effect from its cause which has given rise to the variety of opinions entertained in regard to the qualities of the same agents, and which has, perhaps, tended more than any thing else to discourage rational regard to the means of preserving health; and yet this very variety is a proof at once of the absence of sound views of our own nature, and of the urgent necessity of possessing them. In society, accordingly, nothing is more common than to hear the most opposite opinions expressed in regard to the evils or advantages of particular kinds of clothing, food, and exercise. One person will affirm with perfect sincerity that flannel is pernicious, because it irritates the skin, and uniformly causes an eruption over the whole body; and that linen or cotton is an excellent article of dress, because it produces no such consequences. Another will tell you with equal truth that flannel is a capital thing, because it is pleasant to the feeling, and affords protection from cold and rheumatisn, which linen does not. One will affirm that a long walk or violent muscular exercise is an excellent tonic, because it gives a keen appetite, and a vivacity and alertness which are delightful. But another will declare that a long walk or severe exercise is exceedingly injurious and debilitating, because it destroys his appetite, and unfits him for exertion of mind or body, and always gives him headache. One will, in like nanner, praise vegetables as the best diet, and another animal food as infinitely superior, and so on through the whole range of physical objects which ret upon the human frame, and the natural conse- 
quence of these apparent anomalies and contradic. tions is, that when in health, we come practically to look upon the effects of air, food, exercise, and dress as very much matters of chance, subject to no fixed rule, and therefore little worth attending to, except when carried to palpable extremes, or in the cure of disease ; and in this way, man, instead of being able to protect his children by the results of his own experience in his journey through life, goes on from generation to generation, groping a little, then seeing a little, and then groping again, till he arrives, often prematurely, at the end of his existence, when he stumbles into his grave, leaving his posterity to pass unaided through the same series of experiments, and arrive at the same termination as himself.

This unnatural result must arise either from the laws which regulate the animal functions and the operations of external objects being variable and ever changing, or from the conditions of the living body on which they act being different in different persons, or in the same person at different ages or seasons ; and it is not difficult to determine to which of these it is to be ascribed. It cannot be to the first, for the laws of nature are invariable and unbending. The food which to-day nourishes and sustains the body, and which to-morrow, when sickness is present, raises the pulse and excites the heart to febrile action, has not altered its qualities or changed its relation to the healthy body. It is the state of the body that has changed and caused the apparent discrepancy of effect. In judging, therefore, of the propriety, advantages, or evils of exercise, food, and clothing, we must take into consideration, not only the kind of exercise, the kind of food, and the kind of clothing, but also the age, health, and kind of constitution of the individual who uses them, and adapt each to the degree in which it is required; and then we may rest assured that many of our difficulties will vanish, and certainty and consistency come proportionally into view. 
In cultivating, and especially in teachıng, medical science, the different branches of which it is composed are habitually too much dissevered from each other, and from the practical consequences to which they lead. The anatomist teaches structure, and structure only, and refers to the physiologist for an account of the uses to which it is subservient. The physiologist, on the other hand, expounds functions, but scarcely touclies upon the instruments by which they are executed. The consequence is, that the student often becomes disgusted with what he considers the dry details of anatomical structure, when perhaps nothing would interest him more deeply were the purposes which they fulfil in the animal economy taught to him at the same time. Many, in like manner, fail to take any pleasure in the study of physiology, who would be truly delighted to hear the truths of which it treats expounded more generally in connexion with peculiarities of structure, and with more frequent reference to their practical applications. The anatomist and physiologist err, in short, in limiting themselves too exclusively to the objects of their respective departments, and devoting too little attention to the relations which these bear to each other and to the great unit,- - the living being, of which they form a part.

The result of this system is, that the young practitioner is educated without having made himself sufficiently familiar with the conditions on which the healthy action of the animal economy depends, or having even rightly appreciated the importance of such knowledge : and that, consequently, in common with his patient, he sometimes unwittingly allows the operation of morbid causes to go on without interference, where, by a timely warning on his part, serious illness might have been averted; or unconsciously permits the gradual ripening of hereditary tendencies into active disease, which rational precautions, early resorted to, might have 
kept in subjection throughout a long period of existence.

The general diffusion of a knowledge of physiology among the intelligent classes of society will be attended with this great advantage, that more attention will be paid to the preservation of health and the prevention of disease than is at present practicable. The medical man will then be able to advise with increased effect, because he will be proportionally well understood. It is a very different thing to comply blindly with the directions which come to us simply on the authority of a man like ourselves, and to comply intelligently with those which claim our obedience on the authority of the Creator.

It cannot be too constantly kept in view by medical men, that their true province is to preserve as well as restore the health of those who intrust themselves and their families to their care; and that it behooves them to turn their knowledge to account, in giving the greatest degree of security to their employers which their circumstances and situation in life will admit of, as well as in prescribing for actual disease. The day is, perhaps, not very far distant, when, in consequence of the improvements both in professional and in general education now in progress, a degree of importance will become attached to this application of medical science, far surpassing what those who have not reflected on the subject will be able to imagine as justly belonging to it, but by no means exceeding that which it truly deserves.

Some professional men are of opinion, that it is best, in all cases, to leave the patient in ignorance of his own structure and functions, and to assign no reasons for any thing recommended; while others maintain, that advice is never so.willingly attended to as when the reason of the patient is addressed and a general explanation of the case given, so far 
as it can be easily understood. There are some persons, indeed, who prefer being simply told what they are to do, and are more manageable when dictated to than reasoned with; and there are also many things in practice for which it would be puzzling to assign a valid reason, but, generally speaking, those whose reason is enlightened will be found to co-operate more effectually in the measures required for their recovery than those who are left in the dark.

In acute diseases, of course, explanation of any kind is often precluded. Here the professional man must act, and act with decision. But the great majority of ailments are of a chronic character, in the cure of which the steady co-operation of the patient is almost indispensable. And even when the malady is acute, a patient will submit to severe measures much more readily when ordered by an adviser who has been in the habit of addressing his reason when opportunity occurred, than when prescribed by one who has adopted an opposite course.

My object, accordingly, in submitting the following pages to the public, is not to supersede the physician, by making "every man his own doctor," or by recommending the general perusal of professional treatises, for both practices induce many more ailments than they cure ; but simply to assist in diffusing such a general acquaintance with the structure and functions of the human body, as will enable individuals to adopt the best means for developing their mental and bodily powers; to protect themselves from the more common causes of disease, and to co-operate with effect in the recovery of themselves or their friends when sick. In endeavouring partially to fulfil this object, I have the general reader alone in view, and do not pretend to offer any thing new to the profession, for the subjects treated of must be familiar to every practitioner. At the same time, I am not without C 2 
hope that the method followed of connecting details with practical applications may be found useful to the student, and help to direct him in his future inquiries.

\section{CHAPTER II.}

The Skin-Composed of three Layers-The Cuticle-Its Struc ture and Uses-The mucous Coat-The Seat of. Colour-The true Skin-Its Structure-The Seat of Perspiration-Its Nature-Consequences of suppressed Perspiration-Sympathy between the Skin and other Organs - The Skin a Regulator of Animal Heat-The Seat of Absorption-Touch and Sensation -Connextion between the Skin and Nervous System.

In selecting the subjects of the following essays, I shall be guided partly by the intrinsic importance of the functions of which they treat to the well-being of the animal economy ; and partly by the comparative ignorance which prevails in regard to them. Hitherto the digestive functions have formed the most prominent topic of popular disquisition, and a great mass of information has, from time to time, been laid before the public, with a view to induce greater attention to the regulation of diet and regimen; and the action of digestive order in deranging the general health and modifying the progress of disease has also been sedulously pointed out. But there are other organs and functions, of nearly equal interest, which have been much less attended to than they deserve, and with which the general reader is very little familiar. Among these-the skin, the muscles, the bones, the lungs, and the nervous system may be mentioned as most worthy of notice, and I shall accordingly endeavour to give such an account of them in succession as will be 
both intelligible and of direct practical utility to every one. I shall commence with an explanation of the structure and functions of the skin.

The skin is that membranous covering which is spread over the whole surface of the body, and which serves to bind together, and to protect from injury, the subjacent and more delicate textures. In different animals, and at different parts of the body, it assumes different appearances. It is smooth, soft, and delicate in youth, and in females; firmer and more resisting in middle age, and in males; flabby and wrinkled in old age, and after disease ; puckered or disposed in folds in places that admit of extensive flexion, as over the finger-joints, and in the palm of the hand; and thick and horny where it is subjected to the influence of pressure, as in the soles of the feet.

The structure of the skin, like that of every other part of the aninial frame, displays the most striking proofs of the transcendent wisdom and beneficence of its great Creator. Though simple in appearance and in design, it is a compound of many elements, and the seat of as great a variety of functions. It is composed of three layers of membrane, viz. the thin scarf-skin or cuticle, the mucous coat, and the thick true skin, as it is called, which immediately encompasses the body. These distinctions should be kept in view, for, as it is a general law of the animal economy that every part has a use or function peculiar to itself, the various uses of the compound can be understood only by attending to those of the simple elements.

The epidermis, cuticle, or scarf-skin, is the outermost of the three layers, and is that which is raised in blisters. It is a thin continuous and insensible membrane, has no perceptible blood-vessels or nerves, and consequently neither bleeds nor feels pain when cut or abraded. Being homogeneous in structure, 
it is supposed by many to be merely an exudation of albuininous mucus; and although depressions are obvious un its surface, and exhalation and absorption are proved to be carried on through its substance, it is still in dispute whether it be actually porous or not. Probability is in favour of the affirmative, and the circumstance of the pores not being visible is no proof to the contrary, for the cuticle is so elastic that it may be perforated by a needle, and yet the hole not be discernible even under the microscope. The question is, however, one of little moment, provided it be remembered that its texture, whether perforated or not, is such as to admit of exhalation and absorption taking place through its substance.

The structure of the cuticle is in admirable harmony with its uses. Placed as an insensible intermedium between external objects and the delicate nervous expansion on the surface of the subjacent true skin, it serves as a physical defence against friction; and while, by impeding evaporation, it preserves the true skin in that soft and moist state which is essential to its utility, it also, by impeding absorption, enables man to expose himself without injury to the action of numerous agents, which, but for its protection, would immediately be absorbed, and cause the speedy destruction of health and life. This is remarkably exemplified in several trades, where the workman is unavoidably exposed to an atmosphere loaded with metallic and poisonous vapours, or obliged to handle poisonous substances, and where, without the obstruction of the cuticle, the evil to which he is subjected would be aggravated a hundred fold. Being destitute of nerves, the cuticle is not hurt by the direct contact of external bodies, and being very thin, it blunts without impairing the distinctness of the impression made on the nerves of sensation. The necessity of this latter provision becomes verv abvious when the 
cuticle is abraded or removed by vesication. The surface below is then found to be too tender and irritable for the exercise of touch, and conveys to the mind scarcely any other sensation than that of pain. For the same reason, those parts of the skin which are most exposed to pressure and friction, such as the palms of the hands and soles of the feet, are provided with a thicker cuticle to defend them from injury.

The greater thickness of the cuticle in such situations is manifestly the intentional work of the Creator, for it is perceptible even at birth, before use can have exercised any influence. Indeed; were the tender skin not so protected, every violent contraction of the hand upon a rough and hard surface, and every step made on uneven ground, would cause pain, and disable us for exertion.

By another beneficent provision, calculated to afford increased protection according to the necessities of the individual, it happens that, when a part is much used, the cuticle covering it becomes thicker and thicker within certain limits, till in extreme cases it becomes as thick, hard, and resisting as horn. It is this thickening of the epidermis on the lady's finger that alone enables her to wield with impunity that important instrument the needle. And it is the same thickening that fits the blacksmith and the mason, the stone-breaker and the boatman, to ply their trades, without that painful blistering which the young apprentice or unaccustomed labourer so regularly undergoes, and which must have continued to recur for ever, had the cuticle been organized with blood-vessels and nerves, or not subjected to this law of becoming thicker wherever increased protection is required.

Another modification of the cuticle to suit a modification of circumstances is that observed in the nails. These belong to the scarf-skin, and separate with it; and, like it, they have neither blood-vessels 


\section{4}

nor nerves, and may be cut or bruised without pain. When the hand or foot is macerated in water, the nails and the cuticle show their identity of organization, by separating together from the dermis or true skin below. The nails, like the cuticle, serve chiefly to protect the subjacent parts from injury; and, accordingly, in those lower animals whose manner of life subjects their feet to continual pressure, and requires no nice exercise of touch, Nature has provided horny and resisting hoofs for their pro tection, instead of a merely thickened epidermis.

To produce thickening of the cuticle, exercise must be gradual, and not too severe. If, for example, a person takes a very long walk, rows a boat, or makes use of a heavy hammer for a few hours, without having been accustomed to such an effort, there is no time for the cuticle to thicken, and defend itself from the unusual friction. The parts below, being inadequately protected, become irritated and inflamed, and throw out a quantity of watery fluid or serum on their surface, which raises up the cuticle in blisters, and by making it painful to continue the pressure, obliges the person to desist from an exercise which, if continued, would evidently soon alter the structure of the sentient nervous filaments, and for ever unfit them for their proper uses : so that even in this result beneficence and wisdom are prominently displayed.

Immediately beneath the scarf-skin, and between it and the true skin, is the mucous coat, rete mucosum, or mucous network, which is remarkable chiefly as being the seat of the colouring matter of the skin. It is seen with difficulty on dissection except in Negroes, in whom it is thick. It is exceedingly attenuated in albinos, and is in fact thick in proportion to the depth of colour. It is destitute of bloodvessels and nerves, but, like the epidermis, is permeable by other bodies. The colouring matter is said to be the same as that of the blood; Davy and Blumenbach, however, regard it as carbon. 
From all that is known regarding the mucous coat, it may be viewed generally as merely a thin soft covering, placed between the outer and the inner skin, to protect the nerves and vessels of the latter and give them their requisite softness and pliancy. Being of a dark colour in the Negro, it has been supposed to diminish the heating influence of the sun's rays in tropical climates by the higher radiating power which is possessed by a black than by a light surface; but there is reason to doubt the soundness of the theory at least, for black is well known to excel in absorbing, as well as in radiating, heat; and late experiments on the coast of Africa seem to show, that the temperature of the Negro is actually about two degrees higher than that of the European under the same circumstances.

The mucous coat is the seat of the beautiful and variegated colouring observed in the skins of many fishes and other animals, in which it has often a high and almost metallic splendour.

The third or inmost layer, called the true skin, dermis, or corion, constitutes the chief thickness of the skin, and is by far the most important of the three, both in structure and functions. Unlike the cuticle and mucous coat, which are homogeneous in their whole extent, and apparently without organization, the true skin, or simply, as we shall call it for brevity's sake, the skin, is very delicately organized, and endowed with the principle of life in a very high degree. Not only is it the beautiful and efficacious protector of the subjacent structures, but it is the seat of sensation and of touch, and the instrument of a very important exhalation, viz. perspiration, the right condition or disturbance of which is a most powerful agent in the preservation or subversion of the general health. The dermis is a dense, firm, and resistant tissue, possessed of great extensibility and elasticity, and of a colour more or less red in proportion to the quantity of blood it receives and con- 
tains. Its looser internal surface, which is united to the cellular membrane in which the fat is deposited, presents a great number of cells or cavities, which penetrate obliquely into the substance, and towards the external surface, of the skin, and also contain fatty matter. These areolæ or cells are larger on some parts of the body than on others: they are very small on the back of the hand and foot, the forehead, and other places where fat is never deposited and the skin is very thin; while they are large in the palm of the hand and sole of the foot, where the skin is consequently thicker and fat abounds. These cells are traversed by innumerable blood-vessels and filaments of nerves, which pass through to be ramified on the outer surface of the skin, where they show themselves in the form of numerous small papillæ or points, which are very visible on the surface of the tongue, and on the fingers and palm of the hand. These papillæ constitute the true organs of touch and sensation, and are therefore most thickly planted where these senses are most acute.

The true skin is so abundantly supplied with blood and nervous power, that, for practical purposes, it may almost be regarded as composed of vessels and nerves alone; and it is important to notice this fact. The universal and equal redness of the skin in blushing is itself a proof of great vascularity; but a still stronger consists in our being unable to direct the point of the finest needle into any spot without puncturing a vessel and drawing blood. The same test proves the equal abundance of nervous filaments in the skin, for not a point can be punctured without transfixing a nerve and causing pain; and it is well known, that in surgical operations and accidental wounds, the chief pain is always in the skin, because it is profusely supplied with nerves on purpose to serve as the instrument of feeling. From these examples, the skin may be truly considered as 
a network of blood-vessels and nerves of the finest conceivable texture; and, taking the vast extent of its whole surface (estimated to exceed in a man of average size 2500 square inches) into account, we can easily understand how these minute ramifcations may really constitute a larger mass of nervous matter than is contained in the original trunks of the nerves from which they are incorrectly said to arise, and also how so large a proportion of the whole blood may be circulating through the skin at one time.

To understand the important purposes of the true skin, we must distinguish between its constituent parts, and consider it, in virtue of each of them,1st, As an exhalant of waste matter from the system; 2 d, As a joint regulator of the heat of the body; $3 \mathrm{~d}$, As an agent of absorption; and, 4th, As the seat of sensation and touch.

Besides performing the mechanical office of a shield to the parts beneath, the skin is admirably fitted, by the great supply of blood which it receives, for its use as a secreting and excreting organ. The whole animal system is in a state of constant decay and renovation; and while the stomach and alimentary canal take in new materials, the skin forms one of the principal outlets or channels by which the old, altered, or useless particles are eliminated from the body. Every one knows that the skin perspires, and that checked perspiration is a powerful cause of disease and of death; but few have any just notion of the real extent and influence of this exhalation, such as we shall attempt to exhibit it. When the body is overheated by exercise in warm weather, a copious sweat soon breaks out, which, by carrying off the superfluous heat, produces an agreeable feeling of coolness and refreshment. This is the higher and more obvious degree of the function of exhalation; but, in the ordinary state, the skin is 
constantly giving out a large quantity of waste materials by what is called insensible perspiration, a process which is of great importance to the preservation of health, and which is called insensible, because the exhalation, being in the form of vapour, and carried of by the surrounding air, is invisible to the eye ; but its presence may often be made manifest even to sight by the near approach of a dry cool mirror, on the surface of which it will soon be condensed so as to become visible.

Many attempts have been made to estimate accurately the amount of exhalation carried off through the skin; but so many difficulties stand in the way of obtaining precise results, and the difference in different constitutions and even in the same person at different times is so great, that we must be satisfied with an approximation to the truth. Sanctorius, who carefully weighed himself, his food, and his excretions, in a balance, every day for thirty years, came to the conclusion that five out of every eight pounds of substance taken into the system passed out of it again by the skin, leaving only three to pass off by the bowels, the lungs, and the kidneys. The celebrated Lavoisier and M. Seguin afterward entered on the same field of inquiry, and with greater success, as they were the first to distinguish between the cutaneous and pulmonary exhalations. M. Seguin shut himself up in a bag of glazed taffetas, which was tied over his head and provided with a hole, the edges of which were glued to his lips with a mixture of turpentine and pitch, so that the pulmonary exhalation might be thrown outwards, and the cutaneous alone be retained in the bag. He first weighed himself and the bag in a very nice balance, at the beginning of the experiment; then at the end of it, when he had become lighter in proportion to the quantity of exhalation thrown out by the breathing ; and, lastly, he weighed himself out of the bag, to ascertain how much weight he had lost in all; and 
by subtracting the loss occasioned by the lungs, the remainder of course exhibited the amount carried off by the skin. He attended ninutely also to the collateral circumstances of diet, temperature, \&c. ; and allowance being made for these, the results at which he arrived were the following:-

The largest quantity of insensible perspiration from the lungs and skin together amounted to thirtytwo grains per minute; three ounces and a quarter per hour; or five nounds per day. Of this the cutaneous constituted two-thirds, or sixty ounces in twenty-four hours. The smallest quantity observed amounted to eleven grains per minute, or one pound eleven and a half ounces in twenty-four hours, of which the skin furnished about twenty ounces. The medium or average amount was eighteen grains a minute, of which eleven were from the skin, making in twenty-four hours about thirty-three ounces. When the extent of surface which the skin presents is considered, these results do not seem extravagant. But even admitting that there may be some unperceived source of fallacy in the experiments, and that the quantity is not so great as is here stated, still, after making every allowance, enough remains to demonstrate that exhalation is a very important function of the skin. And although the precise amount of perspiration may be disputed, still the greater number of observers agree that the cutaneous exhalation is more abundant than the united excretions of both bowels and kidneys ; and that, according as the weather becomes warmer or colder, the skin and kidneys alternate in the proportions of work which they severally perform; most passing off by the skin in warm weather, and by the kidneys in cold, and vice versa. The quantity exhaled increases after meals, during sleep, in dry warm weather, and by friction or whatever stimulates the skin; and diminishes when digestion is impaired, and in a moist atmosphere 
What we have considered relates only to the $i n$. sensible perspiration. That which is caused by great heat or severe exercise is evolved in much greater quantity; and by accumulation at the surface, it becomes visible, and forms sweat. In this way, a robust man may lose two or three pounds' weight in the course of one hour's severe exertion; and if this be suddenly checked, the consequences in certain states of the system are often of the most serious description. When the surface of the body is chilled by cold, the blood-vesesls of the skin become contracted in their diameter, and hinder the free entrance of the red particles of the blood, which are therefore of necessity collected and retained in greater quantity in the internal organs, where the heat varies very little. The skin consequently becomes pale, and its papillæ contract, forming by their erection what is called the goose's skin. In this state it becomes less fit for its uses; the sense of touch can no longer nicely discriminate the qualities of bodies, and a cut or bruise may be received with comparatively little pain. From the oppression of too much blood, the internal organs, on the other hand, work heavily: the mental faculties are weakened, sleepiness is induced, respiration is oppressed, the circulation languishes, and digestion ceases; and if the cold be very intense, the vital functions are at last extinguished without pain, and without a struggle. This is a picture of the extremes; but the same causes which in an aggravated form occasion death produce, when applied in a minor degree, effects equally certain, although not equally marked or speedy in their appearance.

According to Thenard, the cutaneous exhalation is composed of a large quantity of water and a small portion of acetic acid, of muriates of soda and potass, of an earthy phosphate, a little oxide of iron, and some animal matter; but Berzelius considers the acid as lactic, and not the acetic. Some car. 
bonic acid and oily matter also are excreted. It is probable, however, that the composition of the perspiration varies both at different ages and on different parts of the skin, as is presumable from the peculiarity of odour which it exhales in some situations. The armpits, the groins, the forehead, the hands, and the feet perspire most readily, in consequence of their receiving a proportionally larger supply of blood. Every thing tends to show that perspiration is a direct product of a vital process, and not a mere exudation of watery particles through the pores of the skin.

Taking even the lowest estimate of Lavoisier, we find the skin endowed with the important charge of removing from the system about twenty ounces of waste matter every twenty-four hours; and when we consider that the quantity not only is great, but is sent forth in so divided a state as to be invisible to the eye, and that the whole of it is given out by the very minute ramifications of the blood-vessels of the skin, we perceive at once why these are so extremely numerous that a pin's point cannot touch any spot without piercing them; and we see an ample reason why checked perspiration should prove so detrimental to health,-because for every twenty-four hours during which such a state continues we must either have twenty ounces of useless and hurtful matter accumulating in the body, or have some of the other organs of excretion grievously overtasked, which obviously cannot happen without disturbing their regularity and wellbeing. People know the fact and wonder that it should be so, that cold applied to the skin, or continued exposure in a cold day, often produces a bowel complaint, a severe cold in the chest, or inflammation of some internal organ; but were they taught, as they ought to be, the structure and uses of their own bodies, they would rather wonder that it did not always produce one of these effects. 
In tracing the connexion between suppressed perspiration and the production of individual diseases, we shall find that those organs which possess some similarity of function sympathize most closely with each other. Thus the skin, the bowels, the iungs, the liver, and the kidneys sympathize readily, because they have all the common office of throwing waste matter out of the system, each in a way peculiar to its own structure ; so that if the exhalation from the skin, for example, be stopped by long exposure to cold, the large quantity of waste which it was charged to excrete, and which in itself is hurtful to the system, will most probably be thrown upon one or other of the above-named organs, whose function will consequently become excited; and if any of them, from constitutional or accidental causes, be already weaker than the rest, as often happens, its health will naturally be the first to suffer. In this way, the bowels become irritated in one individual, and occasion bowel complaint ; while in another it is the lungs which become affected, giving rise to catarrh or common cold, or perhaps even to nflammation. When, on the other hand, all these organs are in a state of vigorous health, a temporary increase of function takes place in them, and relieves the system, without leading to any local disorder; and the skin itself speedily resumes its activity, and restores the balance between them.

One of the most obvious illustrations of this reciprocity of action is afforded by any convivial company seated in a warm room in a cold evening. The heat of the room, the food and wine, and the excitement of the moment, stimulate the skin, cause an afflux of blood to its surface, and increase in a high degree the flow of the insensible perspiration; which thus, while the heat continues, carries off an undue share of the fluids of the body, and leaves the kidneys almost at rest. But the moment the company goes into the cold external air, a sudden re. 
version of operations takes place; the cold chills the surface, stops the perspiration, and directs the current of the blood towards the internal organs, which presently become excited,-and, under this excitation, the kidneys, for example, will in a few minutes secrete as much of their peculiar fluid as they did in as many of the preceding hours. The reverse of this, again, is common in diseases obstructing the secretion from the kidneys; for the perspiration from the skin is then altered in quantity and quality, and acquires much of the peculiar smell of the urinary fluid.

When the lungs are the weak parts, and their lining membrane is habitually relaxed, accompanied by an unusual amount of mucous secretion from its surface, cold applied to the skin throws the mass of the blood previously circulating there inward upon the lungs, and increases that secretion to a high degree. Were this secretion to accumulate, it would soon fill up the air-cells of the lungs, and cause suffocation; but to obviate this danger, the Creator has so constituted the lungs, that any foreign body coming in contact with them excites the convulsive effort called coughing, by which a violent and rapid expiration takes place, with a force sufficient to hurry the foreign body along with it, just as peas are discharged by boys with much force through short tubes by a sudden effort of blowing. Thus, a check given to perspiration, by diminishing the quantity of blood previously circulating on the surface, naturally leads very often to increased expectoration and cough, or, in other words, to common cold.

The lungs excrete, as we shall afterward see, a large proportion of waste materials from the sys. tem: and the kidneys, the liver, and the bowels have in so far a similar office. In consequence of this alliance with the skin, these parts are more intimately connected with each other in healthy and 


\section{RECIPROCAL ACTION BETWEEN THE SKIN}

diseased action than with other organs. But it is a general law, that wherever an organ is unusually delicate, it will be more easily affected by any cause of disease than those which are sound. So that, if the nervous system, for example, be weaker than other parts, a chill will be more likely to disturb its health than that of the lungs, which are supposed in this instance to be constitutionally stronger; or, if the muscular and fibrous organizations be unusually susceptible of disturbance, either from previous illness or from natural predisposition, they will be the first to suffer, and rheumatism will ensue; and so on. And hence the utility to the physician of an intimate acquaintance with the previous habits and constitutions of his patients, and the advantage of adapting the remedies to the nature of the cause, when it can be discovered, as well as to the disease itself. A bowel complaint, for instance, may arise from over-eating as well as from a check to perspiration; but although the thing to be cured is the same, the means of cure ought obviously to be different. In the one instance, an emetic or laxative to carry off the offending cause, and in the other a diaphoretic to open the skin, will be the most rational and efficacious remedies. Facts like this well expose the glaring ignorance and effrontery of the quack, who affirms that his one remedy will cure every form of disease. Were the public not equally ignorant with himself, their credulity would cease to afford to his presumption the rich field in which it now revels.

In noticing this connexion between the suppression of perspiration and the appearance of internal disease, I do not mean to affirm, that the effect is - produced by the physical transference of the suppressed exhalation to the internal organ. In many instances, the chief impression seems to be made on the nervous system; and the manner in which it gives rise to the resulting disease is often extremely 
obscure. Our knowledge of the animal functions is, indeed, still so imperfect, that we daily meet with many occurrences of which we can give no explanation. But ii is nevertheless of high utility to make known the fact that a connexion does exist between two orders of phenomena, as it calls attention to their more accurate observation, and leads to the adoption of useful practical rules, even when their mode of operation is not understood. Nothing, indeed, can be more delusive than the rash application of merely physical laws to the explanation of the phenomena of living beings. Vitality is a principle superior to, and in continual warfare with, the laws which regulate the actions of inanimate bodies; and it is only after life has become extinct that these laws regain the mastery, and lead to the rapid decomposition of the animal machine. In studying the functions of the human body, therefore, we must be careful not to hurry to conclusions, before taking time to examine the influence of the vital principle in modifying the expected results.

It is in consequence of the sympathy and reciprocity of action existing between the skin and the internal organs, that burns and even scalds of no very great extent prove fatal, by inducing internal, generally intestinal, inflammation. By disordering or disorganizing a large nervous and exhaling surface, an extensive burn causes not only a violent nervous commotion, but a continued partial suspension of an important excretion; and when death ensues at some distance of time, it is almost always in consequence of inflammation being excited in the bowels or sympathizing organ. So intimate, indeed, is this connexion, that some surgeons of great experience, such as Baron Dupuytren of the Hôtel Dieu, while they point to internal inflammation as in such cases the general cause of death, doubt whether recovery ever takes place, when more than one-eighth of the surface of the body is severely 
burnt ; and whether this estimate be correct or not the facts from which it is drawn clearly demonstrate the importance of the relation subsisting between the skin and the other excreting organs.

In some constitutions, a singular enough sympathy subsists between the skin and the bowels. Dr. A. T. Thomson, in his work on Materia Medica (p. 42), mentions, that he is acquainted with a clergyman who cannot bear the skin to be sponged with vinegar and water, or any diluted acid, without suffering spasm and violent griping of the bowels. The reverse operation of this sympathy is exemplified in the frequent production of nettle-rush and other eruptions on the skin, by shell-fish and other substances taken into the stomach. Dr. Thomson tells us, that the late Dr. Gregory could not eat the smallest portion of the white of an egg, without experiencing an attack of an eruption like nettle-rush. According to the same author, even strawberries have been known to cause fainting, followed by a petechial efflorescence of the skin.

We have seen that the insensible perspiration removes from the system, without trouble and without consciousness, a large quantity of useless materials, and at the same time keeps the skin soft and moist, and thereby fits it for the performance of its functions as the organ of an external sense. In addition to these purposes, the Creator has, in his omniscience and foresight, and with that regard to simplicity of means which betokens a profoundness of thought inconceivable to us, superadded another purpose scarcely less important, and which is in some degree implied in the former; I mean the proper regulation of the bodily heat. It is well known, that in the polar regions and in the torrid zone, under every variety of circumstances, the human body retains nearly the same temperature, however different that of the air may be by which it is surrounded. This is a property peculiar to life, and, in consequence of 
it, even vegetables have a power of modifying their own temperature, though in a much more limited degree. Without this power of adaptation, it is obvious that man must have been chained for life to the climate which gave him birth, and even then have suffered constantly from the change of seasons; whereas; by possessing it, he can enjoy life in a temperature sufficiently cold to freeze mercury, and is able, for a time, to sustain, unharmed, a heat more than sufficient to boil water, or even to bake meat. Witness the wintering of Captain Parry and his companions in the Polar Regions; and the experiments of Blagden, Sir Joseph Banks, and others, who remained for many minutes in a room heated to $260^{\circ}$, or about $50^{\circ}$ above the temperature of boiling water. The chief agents in this wonderful adaptation of man to his external situation are undoubtedly the skin and the lungs, and in both the power is intimately connected with the condition of their respective exhalations: but it is of the skin alone, as an agent in reducing animal heat, that we have at present to speak.

The sources of animal heat are not yet demonstrably ascertained; but that it is constantly generated and constantly expended has been long known; and if any considerable disproportion occurs between these processes, it is at the immediate risk of health. During repose, or passive exercise, the surplus heat is readily carried off by the insensible perspiration from the lungs and skin, and by the contact of the colder air; but when the amount of heat generated is increased, as during active exercise, an increased expenditure becomes immediately necessary : this is effected by the skin and lungs being excited to higher action; by the latter sending out the respired air loaded with vapour, and the former exhaling its fluid so rapidly as to form sweat. Accordingly, we find that in cold countries, and in frosty weather, the superabundant heat being rapidly car- 
ried off by contact with a cooler air, the exhalation from the skin is reduced to a very moderate amount and that, in warm climates, where the heat is no: carried off in this way, the surface is constantly bedewed with perspiration, and a corresponding appetite exists for liquids by which the perspiration may be kept up to a sufficient degree. Every one must have experienced the grateful effects of this pro vision, in passing from the dry, restless, and burn ing heat, like that of fever, to the soft and pleasant coolness which follows the breaking out of the sweat.

Attention to the order of events affords the requisite knowledge of the means employed for carrying off the increased heat which is produced, when a person is exposed to a warm air and powerful sun, or engaged in severe exercise. At first the body is actually felt to be warmer, the skin becomes dry and hot, and the unpleasant sensation of heat is soon at its maximum. By-and-by, a slight moisture is perceived on the surface, followed by an immediate increase of comfort. In a short time afterward, this moisture passes into free and copious perspiration; and if the heat or exertion be still kept up, the sweat becomes profuse, and drops from the body, or wets the clothes which envelop it. A decrease of animal heat unavoidably accompanies this, because, independently of any vital action contributing to this effect, as is most probable, the mere physical evaporation of so much fluid is itself sufficient to carry off a large quantity of caloric. The curious experiments of Edwards tend to show that evaporation is really the only means required for reducing animal heat to its proper degree; but the results obtained by him require to be confirmed, and the experiments varied and carried farther, before the inquiry can be considered as completed. The sagacity of Franklin led him to the first discovery of the use of perspiration in reducing the heat of the body, 
and to point out the analogy subsisting between this process and that of the evaporation of water from a rough porous surface, so constantly resorted to in the East and West Indies, and other warm countries, as an efficacious means of reducing the temperature of the air in rooms, and of wine and other drinks, much below that of the surrounding atmosphere. The quantity of fluid evaporated from the skin during profuse sweat so far exceeds that given out during the highest insensible perspiration, that two pounds in weight have been lost by this means in a couple of hours, - an amount evidently sufficient to carry off the largest quantity of superfluous animal heat which can ever be present. In the performance of this function the skin is, indeed, assisted by the exhalation from the lungs; but as both act on the same principle, the explanation is not affected by this circumstance.

Bearing in mind the preceding explanation of the functions of the skin, the following remarks from Dr. Thomson's work* will be read with interest. "Dr. Davy, in his Travels in Ceylon, states, from his personal observation, that, on first landing in a tropical climate, the standard heat of the body of a European is raised two or three degrees, and febrile symptoms occur, which require temperance, the avoiding every cause of excitement of the vascular system, and the use of aperient medicines. All authors, and indeed every observing person who has visited the torrid zone, agree that with the languor and exhaustion resulting from the high temperature of the atmosphere, there is a greatly increased mobility of the nervous system. The action of the cutaneous vessels amounts to disease, and produces that eczematous or vesicular eruption of the skin, known by the name of prickly heat, which occurs in Europeans who visit the West Indies, on their first

- Page $6 a$ 
landing. On the other hand, this function of the skin is so much weakened, almost paralyzed, when the climate from which a person is passing is dry and bracing, and that into which he has passed is humid and relaxing, that congestions of blood take place in the larger vessels, the body becomes suss ceptible of the least impression of marshy exhalations, and agues and similar diseases are produced. ${ }^{x}$

We shall now be able to understand why in ummer we suffer most from heat in what is called moist close weather, when no air is stirring; and why warm climates, which are at the same time moist, are proverbially the most unwholesome. The chief reason is the diminished evaporation from the skin which such a condition of the atmosphere produces, partially shutting up the natural outlet of the superfluous heat of the body ; and as it at the same time checks the exit of the waste matter which ought to be thrown out, and which is known to be as injurious to the system as an active poison taken into the body from without, the hurtful consequences of such weather and climates, and the fevers, dysenteries, and colds to which they give rise, are partly accounted for. This is one powerful reason why night air is so unwholesome, particularly in malaria districts, which are loaded with moisture and miasma ; for, when the air is dry as well as hot, and free evaporation takes place, little or no inconvenience is felt, and health oftener remains uninjured. Delaroche has established this point conclusively by experiment. He exposed animals to a very high temperature in a dry air, and found them to sustain no mischief; but when he exposed them in an atmosphere saturated with moisture, to a heat only a few degrees above that of their own bodies, and greatly lower than in the former instance, they very soon died. Here we see the reason also why, in ague and other fevers, the suffering, restlessness, and excitement of the hot stage can never be abated 
till the sweat begins to flow, after which they rapidly subside; and why the remedies which, given in the hot stage, added to the excitement and distress, may now be productive of the best effects.

The function next to be noticed, viz. Absorption, is, in some measure, the opposite of the last. By its instrumentality, substances placed in contact with the skin are taken up and carried into the general circulation, either to be appropriated to some new purpose, or to be subsequently thrown out of the body.

In the vaccination of children to protect them from small-pox, we have a familiar example of the process of absorption. A small quantity of cowpox matter is inserted under the cuticle on the surface of the true skin, and there left. In a short time it is acted upon, and taken into the system, by the absorbent vessels. In like manner, mercurial preparations rubbed on the skin for the cure of liver complaint are absorbed, and affect the constitution precisely as when received into the stomach. Many even of the common laxatives, such as rhubarb and croton oil, have of late been successfully adminis tered in the same way, and the rapid absorption of poisons from bites of rabid animals and wounds in dissection through the same channel, is familiar to every one. It is from the active principle of the Spanish flies used in blisters being taken up by the cutaneous absorbents, that irritation of the kidneys and urinary organs so often attends the employment of that remedy.

The process of absorption is carried on by vessels fitted for the purpose, which are thence named absorbent vessels, or simply absorbents. In the skin they are so exceedingly small and numerous, that when injected with mercury the surface is said by Dr. Gordon to resemble a sheet of silver. In health they are of too small a size to admit the red particles of the blood, and hence, from their contents 
being nearly transparent, they are sometimes named ymphatics.

Some ascribe great, and others very little, importance to cutaneous absorption. In some diseases, as in diabetes, in which, occasionally for weeks in succession, the urinary discharge exceeds, by many ounces daily, the whole quantity of food and drink, without the body losing proportionably in weight, we can account for the system being sustained only by supposing moisture to be extensively absorbed from the air by the skin and lungs. The ancients, indeed, believed that, when food could not be retained in the stomach, a person might be nourished by placing him in a bath of strong soup or milk ; but recent experiments serve to show that, in such circumstances, absorption is too trifling in amount for any such result. Some indeed deny that any absorption would take place at all, because it is observed as a general fact that the body does not gain in weight by immersion in a warm bath. But the inference is not well founded, for occasionally weight is gained; and even when it is not, as much water must have been absorbed as would make up the loss sustained during immersion by perspiration, which is believed to go on more rapidly in warm water than in the open air.

That animals absorb copiously when immersed in water has been amply proved by Dr. Edwards and other physiologists. Dr. Edwards selected lizards as the subjects of experiment, because he regarded heir scaly skins as unfavourable for absorption. After reducing the bulk of a lizard by several days' exposure to a dry air, he immersed its tail and hind legs in water, and found that absorption took place to such an extent as to restore the original plumpness of all parts of the body. The same result attended a variety of other trials, so that the fact does not admit of doubt. In man, absorption from the surface is greatly retarded by the intervention of the 
euticle; and it is universally admitted that when this obstacle is removed, the process goes on with great vigour. Thus arsenic applied to cancerous sores, and strong solutions of opium to extensive burns in children, have been absorbed in quantities sufficient to poison the patients. Colic in its severest forms has followed similar external applications of the salts of lead. Mercury, also, in the form of fumigation, has often been used where rapid action was required, because in the state of vapour it is very speedily taken up by the cutaneous absorbents.

It is quite certain, then, that the skin does absorb. The only doubt is as to what extent the cuticle operates in preventing or modifying that action. When friction accompanies the external application, the cuticle, as we see exemplified in the use of mercurial and other liniments, is not an efficient obstacle. But when friction is not resorted to, and the substance applied is of a mild unirritating nature, such as oil, it may remain in contact with the skin for a long time without being taken into the system in appreciable quantities. If, however, it is irritating, like Spanish flies, absorption speedily begins, and is carried on through the cuticle, as is proved by the effects produced on the urinary organs.

When the perspiration is brought to the surface of the skin, and confined there either by injudicious clothing or by want of cleanliness, there is much reason to suppose that its residual parts are again absorbed, and act on the system as a poison of greater or less power, according to its quantity and degree of concentration, thereby producing fever, inflammation, and even death itself; for it is established by observation, that concentrated animal effluvia form a very energetic poison. The fatal consequences which have repeatedly followed the use of a close water-proof dress by sportsmen and others, and the heat and uneasy restlessness which E 2 
speedily ensue where proper ventilation is thus pre. vented, seem explicable only on some such principle.

It is believed by many, that marsh miasmata and other poisons are absorbed by the skin, and Bichat considered the fact as established in regard to the effuvia of dissecting-rooms. There are many reasons for concurring in this belief. The plague, for instance, is known to be much more readily communicated by contact than by any other means, and this can happen only through the medium of absorption. Again, it is certain that flannel and warm clothing are extremely useful in preserving those who are unavoidably exposed to the action of malaria and of epidemic influences; and these manifestly act chiefly by protecting the skin. A late writer on the Malaria of Rome strongly advocates this opinion, and expresses his conviction that the ancient Romans suffered less from it, chiefly because they were always enveloped in warm woollen dresses. This opinion, he says, is justified by the observation, that since the period at which the use of woollen clothing came again into vogue, intermittent fevers have very sensibly diminished in Rome. Even in the warmest weather the shepherds are now clothed in sheep-skins. Brocchi, who experimented extensively on the subject, obtained a notable quantity of putrid matter from the unwholesome air, and came to the conclusion, that it penetrated by the pores of the skin rather than by the lungs. Brocchi ascribes the immunity of the sheep and cattle, which pasture night and day in the Campagna, to the protection afforded them by their wool.* These remarks deserve the serious attention of observers, - particularly as, according to Patissier, similar means have been found effectual in preserving the health of labourers digging and excavating drains and canals in marshy grounds, where, previous to the employment

* Edir, Phil, Joturn. January, 1833. 
of these precautions, the mortality from fever was very considerable.

It is a general law, that every organ acts with increased energy when excited by its own stimulus; and the application of this law to the different functions of the skin may help to remove some of our difficulties. The skin exhales most in a warm dry atmosphere, because the latter dissolves and carries off the secretion as fast as it is produced; and the same condition is unfavourable to absorption, beeause nothing is present upon which the absorbents of the skin can act. In a moist atmosphere, on the other hand, the absorbents meet with their appropriate stimulus, and act powerfully; while exhalation is greatly diminished, because the air can no longer carry off the perspiration so freely. Apparently from this extensive absorption, we find the inhabitants of marshy and humid districts remarkable for the predominance of the lymphatic system, as has long been remarked of the Dutch; and as malaria prevails chiefly in situations and seasons in which the air is loaded with moisture, and is most energetic at periods when absorption is most active and moistare is at its maximum, the probability of its being received into the system chiefly by cutaneous absorption is greatly increased, and the propriety of endeavouring to protect ourselves from its influence by warm woollen clothing becomes more striking. In the army and navy, accordingly, where practical experience is most followed, the utmost attention is now paid to enforcing the use of flannel and sufficient clothing, as a protection against fever, dysentery, and other diseases, particularly in unhealthy climates. In the prevention of cholera, flannel was decidedly useful.

From grouping all the constituent parts of the skin into one whole, and perceiving so niany operations connocted with that tegument, some may be apt to 
suppose it an exception to the principle laid down, that no single part can execute more than a single. direct function. In reality, however, it is only by taking the guidance of this principle that we can extricate ourselves from the apparent confusion. We have already seen that exhalation, and the regulation of heat and absorption, are each connected with distinct textures in the skin. On further examination, we shall find the office of Touch and Sensation intrusted exclusively to another constituent part, the nervous; for, in serving as the instrument of feeling, the skin acts in no other way than by affording a suitable surface for the distribution and protection of the nerves which receive and transmit to the brain and mind the impressions made on them by external bodies. In this respect the skin resembles the other organs of sense; in all of which the nerve is the true instrument of the sense, and the eye, the ear, the nose, and the skin are simply structures fitted to bring the nerve into relation with the qualities of colour, sound, smell, roughness, or smoothness, by which they are respectively affected;-and they differ from each other, because sound differs from colour, colour from smell, and smell from roughness or smoothness; and because sound or colour can be taken cognizance of by its own nerve only when the latter is provided with an apparatus fit to be acted upon by the vibrations of the air, or by the rays of light. In every instance, it is the external object acting upon a nerve which gives rise to the mpression received from the organs of sense.

Every part of the skin, however remote, is provided with filaments from the nerves of sensation, in order that we may become inmediately sensible of the presence and action of external bodies. If any part were destitute of this property, its texture and vitality might be destroyed without our consciousness of the fact ; whereas, in consequence of this provision of sensitive nerves, no object can 
touch the skin without our being instantly made aware of its presence and properties.

While, however, sensation is common to the whole surface of the body, there are parts of the skin more inmediately destined by Nature for the exercise of 'Touch, and for the better appreciation of all the qualities of which it is cognizant. Such are the hands and tongue in man, the proboscis in the elephant, the tail in some of the monkey tribe, and the tenticula in fishes. Now, in accordance with the explanation given of the dependence of sensation upon nervous endowment, it is remarkable that all the parts destined for this special exercise of Touch receive the most abundant supply of sensitive nerves. Thus the nerves going to the hand and arm, the most perfect instruments of Touch and Sensation in man, are at their dorsal roots five times larger than those which are destined for its motion; and, in like manner, the nerve supplying the tactile extremity of the proboscis of the elephant exceeds in size the united volume of all its muscular nerves. On the other hand, in animals covered with hair or feathers, whose Touch and Sensation are comparatively defective, the muscular nerves far exceed in size those of Sensation; and wherever Nature has endowed any particular part with high sensitive powers, she is invariably found to have distributed to that part, and to it alone, a proportionally higher nervous endowment. In man, the innumerable nervous papillæ destined for the exercise of Touch may be distinctly seen in parallel irregular rows on the fingers and palm of the hand, and everybody knows how acute the sense is in these parts. In fishes, on the other hand, no nervous papillæ can be detected on the surface of the skin; but many of them have tentacula or projections generally about the mouth, for the special purpose of exercising Touch, and these are always plentifully supplied with branches from the fifth pair of nerves. 
The nervous tissue of the skin is thus not only an important instrument for receiving and conveying to the mind accurate impressions in regard to th 3 properties of external objects, but it is even essential to our continued existence. The pain which is caused by injuries is no doubt very disagreeable, but in its uses it is a positive blessing, in warning us against the danger, and even certain destruction which would speedily overtake us if we had no such monitor at hand. If we had no nerves on the sur face to communicate to us a lively impression of cold, we might inadvertently remain inactive in a temperature which would not only suspend perspiration, but benumb the powers of life; or we might, on the other hand, approach so near the fire or boiling fluids as to have the organization destroyed before we knew : whereas, by the kind interposition of the nerves, we cannot, when perspiring freely, be exposed to the cold air without an unpleasant sensation being experienced, impelling us to attend to our safety, and to keep up our heat either by additional clothing or by active exercise. When the nervous and vascular parts of the skin are both in healthy action, a pleasant soft warmth is felt over the body, which is in itself a delight, and which gives to the mind a lightness and hilarity, or pleasant consciousness of active existence, the very opposite of the low and languid depression which so generally accompanies continued defective action in the skin, and which forms a marked feature in many nervous affections.

For the due exercise of Sensation, the nerves must be in a proper state of health. If, for example, the cuticle protecting the nervous papillæ be abraded, or removed by vesication, the naked nerves are too powerfully stimulated by the contact of external bodies, and instead of receiving and transmitting the usual impressions of heat, cold, figure, and hardness they communicate scarcely any feeling except that 
of gam; while, if the cuticle become thickened by hard labour, the impression made on the nerves is proportionally lessened, and little information is conveyed by them to the mind.

A due supply of arterial blood is another requisite for the action of the nerves of sensation. If they be deprived of this, as by exposing the body to a degree of cold sufficient to drive the blood from the surface, the nerves become almost insensible, and severe wounds may be received in this state without tho individual being conscious of the accident, or feeling the slightest pain. For the same reason, severe cold, after a certain time, ceases to be painful, and death ensues like deep sleep and without suffering. But when a frozen limb is thawed, and the retur ning circulation begins to set the nerves in action, then suffering commences, and the overaction is in danger of leading to inflammation. The same phenomena, in an inferior degree, must be familiar to every one, in the prickling and tingling so commonly complained of on heating cold hands or feet too rapidly at a good fire, and which arise from the return of the blood stimulating the nerves to undue action.

It is the nervous tissue of the skin which takes cognizance of the temperature of the bodies by which we are surrounded, and imparts to the mind the sensation of warmth or coldness. In the healthy state, the sensation is a correct index of the real temperature; but, in disease, we often complain of cold and shivering when the skin is positively warmer than natural. In this way, those whose digestion is weak, and whose circulation is feeble, complain habitually of cold, and of cold feet, where others, differently constituted, experience no such sensations. Exercise dissipates this feeling and increases heat, by exciting the circulation of the blood, throwing more of it to the surface, and thereby 
increasing the action of the cutaneous vessels and nerves.

Some mental emotions operate upon the skin, and impair its functions much in the same way as cold. Grief, fear, and the depressing passions, by diminishing the afflux of arterial blood, render the skin pale, and at the same time diminish perspiration and nervous action; while rage, and other violent passions, by augmenting the afflux of blood, elevate the temiperature of the skin, and give rise to the red flush, fulness, and tension so characteristic of excitement. Facts like these establish a connexion between the brain and the nervous system and the skin, which it is imporiant not to overlook. The brain is readily admitted, by reflecting minds, to exercise much influence on the general system, because the nervous substance of which it is composed is collected into one focus, and, thus united, is seen to constitute a large mass. In reality, however, the nervous matter, spread out on the surface of the body for the purposes of sensation, is so great that many anatomists consider it as even exceeding the mass of the brain, and hence its reverse influences might be expected to be, as it actually is, of much importance to health.

We see this exemplified on exposure to intense cold. The first sensation of chill on the nervous surface of the skin is speedily succeeded by that of numbness and insensibility. The impression is thence communicated to the brain, which in its turn becomes affected, as is shown first by confusion of mind, as noticed by Captain Parry, and afterward by the total suspension of the mental powers, and the extinction of life itself. When, on the other nand, as in tropical climates, the surface is relaxed by excessive heat, the brain speedily participates in the relaxation, and the mind is unfitted for sustained or vigorous action.

Invalids and literary men often suffer severely 
from excess of action in the brain, and deficiency of activity in the nerves of the skin and remoter organs. The nervous stinulus, which is essential to digestion and to the health and warmth of the skin, cannot be provided when the brain is too exclusively exercised in thinking or feeling; and for want of this stimulus, the tone of the digestive and cutaneous or. gans is greatly reduced,-the surface of the body becomes cold, shrunk, and uncomfortable, and the individual subject to annoyance and painful sensations from trifles which formerly gave pleasure. Bad digestion and deficient warmth of surface are thus proverbially complained of among literary and sedentary persons, and can be removed only by exciting the nervous and vascular functions of the skin, and diminishing those of the brain.

Such are the direct and important uses of the skin. But in addition to the parts already noticed, there are numerous small follicles contained in its substance, more abundant where hairs are implanted, and in the vicinity of the orifices of natural canals, than in other regions, but existing in all parts except the palms of the hands and soles of the feet. They are about the size of a millet seed, and the skin which contains them is thin, reflected on itself, and very vascular. Their cavities are filled with an oily humour susceptible of concretion and consistence, and each opens by an orifice at the external surface of the skin. It is this oily matter which prevents water from penetrating easily and relaxing the cuticle, and the absence of which, when it has been removed by the soda used in washing, allows the skin of the hands and fingers to assume that wrinkled and shrivelled appearance which is common among washerwomen. 


\section{CHAP'TER III.}

Iortality in Infancy from Co!d-Animal Heat lowest at tha Age-Too little and too much Clothing equally bad-Rules for Dress-Advantages of Flannel, exemplified in H. M. S. Valurous-Ventilation of Beds and Clothing-Influence of Light-Importance of Ablution and Bathing-Cold, Tepid, and Warm Bath-Sponging with diluted Vinegar-Friction of the Skin-Vapour-bath and Warm Bath useful in preventing and curing Nervous Diseases and Liability to Cold-Sailing and Riding useful by acting on the Skin.

As it is only in its useful applications to the improvement and happiness of man that knowledge truly becomes power, we proceed, in accordance with this principle, to point out some of the advantages derivable from that which we have attempted to communicate.

It appears from the London Bills of Mortality, that between a fourth and a fifth of all the infants baptized die within the first two years of their existence. This extraordinary result is not a part of the Creator's designs; it does not occur in the lower animals, and must therefore have causes capable of removal. One of these, to speak only of what is related to the present inquiry, is unquestionably the inadequate protection afforded, especially among the poorer classes, to the new-born infant, against the effects of the great and sudden transition which it makes in passing at once from a high and almost unvarying temperature in the mother's womb, to one greatly inferior and constantly liable to change. At birth, the skin is delicate, extremely vascular, and highly susceptible of impressions; so much so, that cases have occurred 
in which a leech-bite has caused a fatal hemorrhage. The circulation is, in fact, cutaneous ; for the lungs, the stomach, the liver, and the kidneys are as yet new to life, and feeble in their functions. If the infant, then, be rashly exposed to a cold atmosphere, the mass of blood previously circulating on the surface of the body is immediately driven inwards by the contraction of the cutaneous vessels, and, by over-stimulating the internal organs, gives rise to bowel complaints, inflammations, croup, or convulsions, which sooner or later extinguish life. This shows the inexpressible folly of those who bathe infants daily in cold water even in winter, and freely expose them to the open air, or to currents from open doors or windows, with a view to harden their constitutions; when it is quite certain that no more effectual means could be resorted to in the earlier months of life to undermine the general health and entail future disease on the unhappy subjects of the experiment.

This hurtful practice has perhaps arisen in some degree from the prevalent error of supposing that infants have naturally a great power of generating heat and resisting cold. That the very opposite is the fact has been established by the experiments of Dr. Milne Edwards, which show that "the power of producing heat in warm-blooded animals is at its minimum at birth, and increases successively to adult age," and that instead of young animals being warmer than adults, they are generally a degree or two older, and part with their heat more readily. In en healthy infants, from a few days to two hours old, the mean temperature was observed by Dr. Edwards to be only $94^{\circ} .55 \mathrm{Fahr}$., that of adults being $97^{\circ}$ or $98^{\circ}$; and in a seven months' child, three hours after birth, he found the temperature so low as $89^{\circ} .6$, although the child was well clothed and near a good fire. That exposure to cold is really so injurious in infancy is unhappily proved by a 
multitude of facts. In France, as already alluded to in the first chapter, it is the custom to carry every infant, soon after birth, to the office of the maire that its birth may be registered. Suspecting that the exposure consequent upon such a practice must be pernicious to health, especially in winter, and where the distance is great, Dr. Edwards made inquiry, and on consulting the returns made to the Minister of the Interior, found that the proportion of deaths within a very limited period after birth was much greater in winter than in summer, and in the northern than in the southern departments; and on further inquiry he discovered that the mortality was greater in parishes where the inhabitants were scattered at a distance from the maire, than where they were congregated near him; so that the number of deaths in infancy seemed to be influenced by the degree and duration of the exposure to the cold air. What more striking proof than this can be required of the evils arising from the ignorance of our legislators in regard to the constitution of the human body? No man who understood physiology could ever have sanctioned a law, the practical effect of which is to consign annually so many victims to an untimely grave.

Many parents, from over-anxiety to avoid one form of evil, run blindfold into another scarcely less pernicious, and not only envelop infants in innumerable folds of warm clothing, but keep them confined to very hot and close rooms. It would be well for them to recollect, however, that extremes are always hurtful, and that the constitution may be enfeebled, and disease induced, by too much heat and clothing and too close an atmosphere, as effectually as by cold and currents of air. The skin thus opened and relaxed perspires too easily, and is readily affected by the slightest variations of temperature; whence arise colds and other ailments, which it is the chief intention to guard against: and 
the internal organs, being at the same time deprived of their fair proportion of blood, become enfeebled, and afford inadequate nourishment and support to the rest of the body.

The insensible perspiration being composed of a large quantity of water, which passes off in the form of vapour and is not seen, and of various salts and animal matter, a portion of which remains adherent to the skin, the removal of this residue by washing becomes an indispensable condition of health, the observance of which, particularly in early life, when waste and nutrition are both very active, prevents the appearance of cutaneous and other diseases common in infancy. Not only, therefore, is daily washing of the body required at that age, but a frequent change of clothing is essential, and every thing in the shape of dress ought to be loose and easy, both to allow free circulation through the vessels, and to permit the insensible perspiration to have a free exit, instead of being confined to and absorbed by the clothes, and held in contact with the skin, as often happens, till it gives rise to irritation.

In youth, the skin is still delicate in texture and the seat of extensive exhalation and acute sensation, but it is at the same time more vigorous in constitution than it was in infancy; and the several animal functions being now more equally balanced, it is less susceptible of disorder from external causes, and can endure with impunity changes of temperature which, at either an earlier or more advanced age, would have proved highly injurious. The activity and restless energy of youth keep up a free and equal circulation even in the remotest parts of the body, and this free circulation in its turn maintains an equality of temperature in them all. Cold bathing and lighter clothing may now be resorted to with a rational prospect of advantage; but when, from a weak constitution or unusual susceptibility, the skin is not endowed with sufficient vitality to F2 
originate the necessary reaction, which alone renders these safe and proper,-when they produce an abiding sense of chillness, however slight in degree,-we may rest assured that mischief will inevitably follow at a greater or shorter distance of time. Many young persons of both sexes are in the habit of going about in winter and in cold weather with a dress light and airy enough for a northern summer, and they think it manly and becoming to do so ; but those who are not very strongly constituted suffer a severe penalty for their folly. The necessary effect of deficient circulation and vitality in the skin is to throw a disproportionate mass of blood inwards; and when this condition exists, insufficient clothing perpetuates the evil, until internal disease is generated, and health irrecoverably lost. Insufficient clothing not only exposes the wearer to all the risk of sudden changes of temperature, but it is still more dangerous (because in a degree less marked, and therefore less apt to excite attention till the evil be incurred), in that form which, while it is warm enough to guard the body against extreme cold, is inadequate to preserving the skin at its natural heat. Many youths, particularly females and those whose occupations are sedentary, pass days, and weeks, and months without ever experiencing the pleasing glow and warmth of a healthy skin, and are habitually complaining of chillness of the surface, cold feet, and other symptoms of deficient cutaneous circulation. Their suffering, unfortunately, does not stop here, for the unequal distribution of the blood oppresses the internal organs, and too often, by insensible degrees, lays the foundation of tubercles in the lungs, and other maladies, which show themselves only when arrived at an incurable stage. Young persons of a consumptive habit will generally be found to complain of this increased sensibility to cold, even before they become subject to those slight catarrhal attacks which are so often the immediate precur- 
sors, or rather the first stages, of pulmonary consumption. All who value health, and have common sense and resolution, will therefore take warning from signs like these, and never rest till equilibrium of action be restored. For this purpose, warm clothing, exercise in the open air, sponging with vinegar and water, the warm bath, regular friction with a flesh-brush or hair-glove, and great cleanliness, are excellently adapted.

But while sufficiency of clothing is attended to, excessive wrapping up must be as carefully avoided. Great differences in the power of generating heat and resisting cold exist in different individuals, and it would be absurd to apply the same rules to those who never feel cold as to those who are peculiarly sensitive. The former may be benefited by cold bathing and degrees of exposure which would be fatal to the latter. The rule is, therefore, not to dress in an invariable way in all cases, but to put on clothing in kind and quantity sufficient in the individual case to protect the body effectually from an abiding sensation of cold, however slight. Warmth, however, ought not to be sought for in clothing alone. The Creator has made exercise essential as a means; and if we neglect this, and seek it in clothing alone, it is at the risk or rather certainty of weakening the body, relaxing the surface, and rendering the system extremely susceptible of injury from the slightest accidental exposures, or variations of temperature and moisture. Many good constitutions are thus ruined, and many nervous and pulmonary complaints brought on, to imbitter existence, and to reduce the sufferer to the level of a hot-house plant.

Female dress errs in one important particular, even when well suited in material and in quantity. From the tightness with which it is made to fit on the upper part of the body, not only is the insensible perspiration injudiciously and hurtfully confined, but that free play between the dress and the skin which 
is so beneficial in gently stimulating the latter by friction on every movement of the body is altogether prevented, and the action of the cutaneous nerves and vessels, and consequently the heat generated, rendered lower in degree than would result from the same dress worn more loosely. Every part and every function are thus linked so closely with the rest, that we can neither act wrong as regards one organ without all suffering, nor act right without all sharing in the benefit.

We can now appreciate the manner in which wet and cold feet are so prolific of internal disease, and the cruelty of fitting up schools and similar places without making adequate provision for the welfare of their young occupants. The circumstances in which wet and cold feet are most apt to cause disease are where the person remains inactive, and where, consequently, there is nothing to counterbalance the unequal flow of blood which then takes place towards the internal parts: for it is well known that a person in ordinary health may walk about or work in the open air with wet feet for hours together without injury, provided he put on dry stockings and shoes immediately on coming home. It is therefore not the mere state of wetness that causes the evil, but the check to perspiration and the unequal distribution of blood to which the accompanying coldness gives rise. Wet and damp are more unwholesome when applied to the feet than when they affect other parts, chiefly because they receive a large supply of blood to carry on a high degree of perspiration, and because their distance from the heart or centre of circulation diminishes the force with which this is carried on, and thus leaves them more susceptible of injury from external causes. They are also nore exposed in situation than other parts of the skin; but cold or wet applied anywhere, as to the side for instance, either 
by a current of air or by rain, is well known to be pernicious.

The advantages of wearing flannel next the skin are easily explicable on the above principles. Being a bad conductor of heat, flannel prevents that of the animal economy from being quickly dissipated, and protects the body in a considerable degree from the injurious influence of sudden external changes. From its presenting a rough and uneven though soft surface to the skin, every movement of the body in labour or in exercise gives, by the consequent friction, a gentle stimulus to the cutaneous vessels and nerves, which assists their action, and maintains their functions in health; and being at the same time of a loose and porous texture, flannel is capable of absorbing the cutaneous exhalations to a larger extent than any other material in common use. In some very delicate constitutions, it proves even too irritating to the skin; but, in such cases, fine fleecy hosiery will in general be easily borne, and will greatly conduce to the preservation of health. Many are in the custom of waiting till winter has fairly set in before beginning to wear flannel. This is a great error in a variable climate like ours, especially when the constitution is not robust. It is during the sudden changes from heat to cold, which are so common in autumn, before the frame has got inured to the reduction of temperature, that protection is most wanted, and flannel is most useful.

The advantages of flannel as a preservative from disease in warm as well as in cold climates are now so well understood, that in the army and navy its use is cogently, and with great propriety, insisted on. Captain Murray, late of H. M. S. Valorous, told me that he was so strongly impressed from former experience with a sense of the efficacy of the protection afforded by the constant use of flannel next the skin, that when, on his arrival in England in December, 1823, after two years' ser- 
vice amid the icebergs on the coast of Labrador, the ship was ordered to sail immediately for the W'est. Indies, he ordered the purser to draw two extra flannel shirts and pairs of drawers for each man, and instituted a regular daily inspection to see that they were worn. These precautions were followed by the happiest results. He proceeded to his station with a crew of 150 men; visited almost every island in the West Indies, and many of the ports in the Gulf of Mexico; and, notwithstanding the sudden transition from extreme climates, returned to England without the loss of a single man, or having any sick on board on his arrival. In the letter in which Captain Murray communicates these facts, he adds, that every precaution was used, by lighting stoves between decks and scrubbing with hot sand, to ensure the most thorough dryness, and every means put in practice to promote cheerfulness among the men. When in command of the Recruit gun-brig, which lay about nine weeks at Vera Cruz, the same means preserved the health of his crew, when the other ships of war anchored around him lost from twenty to fifty men each.

That the superior heath enjoyed by the crew of the Valorous was attributable chiefly to the means employed by their humane and intelligent commander is shown by the analogy of the Recruit; for although constant communication was kept up between the latter and the other ships in which sickness prevailed, and all were exposed to the same external causes of disease, yet no case of sickness occurred on board the Recruit. Facts like these are truly instructive, by proving how far man possesses the power of protecting himself from injury, when he has received necessary instruction, and chooses to adapt his conduct to his situation.

The exhalation from the skin being so constant and extensive, its bad effects, when confined, suggest another rule of conduct, viz. that of frequently 
changing and airing the clothes, so as to free them from every impurity. It is an excellent plan, for instance, to wear two sets of flannels, each being worn and aired by turns, on alternate days. The effect is at first scarcely perceptible, but in the course of time its advantages and comfort become very manifest, as the writer has amply experienced. For the same reason, a practice common in Italy merits universal adoption. Instead of beds being made up in the morning the moment they are vacated, and while still saturated with the nocturnal exhalations which, before morning, become sensible even to smell in a bed-room, the bed-clothes are thrown over the backs of chairs, the mattresses shaken up, and the window thrown open for the greater part of the day, so as to secure a thorough and cleansing ventilation. This practice, so consonant to reason, imparts a freshness which is peculiarly grateful and conducive to sleep, and its real value may be inferred from the well-known fact, that the opposite practice, carried to an extreme, as in the dwellings of the poor, where three or four beds are often huddled up with all their impurities in a small room, is a fruitful source of fever and bad health, even where ventilation during the day and nourishment are not deficient. In the abodes of the poor Irish residing in Edinburgh, I have seen bedding for fourteen persons spread over one floor not exceeding twelve feet square, and when mornin came, the beds were huddled above one another to make sitting-room during the day, and at night were again laid down, charged with accumulated exhalations. If fever were not to appear in such circumstances, it would be indeed marvellous; and we ought to learn from this, that if the extreme be so injurious, the lesser degree implied in the prevalent practice cannot be wholesome, and ought, therefore, not to be retained when it can be so easily done away with 
The salutary influence of the solar light as a stimulus to the skin has been much overlooked, and yet it must be obvious to every one after a moment's reflection. Those who live in mines or dark caves, and who are rarely exposed to the light of day, present a pale relaxed sallowness of skin, which contrasts with the ruddy freshness of country people and others living much in the open air. The inhabitants of towns may be known by the light colour and delicacy of skin which confinement induces. Part of the effect is owing, no doubt, to the agency of the external air, in the constitution of which the skin seems to produce changes analogous to those which take place in the lungs during respiration; but much is also attributable to deprivation of the stimulus of light. Even vegetables become pale, watery, and feeble in the dark; and, in like manner, men who work during the night and sleep during the day never present the vigorous look of health, which distinguishes well-fed daylabourers. The squalid paleness and depression of the poor population, resident in the dark lanes of large and crowded cities, show the necessity of consulting the wants of nature more than is generally done, when erecting new streets and manufactories, and providing play-ground for the young.

When the saline and animal elements left by the perspiration are not duly removed by washing or bathing, they at last obstruct the pores and irritate the skin. And it is apparently for this reason that, in the eastern and warmer countries, where perspiration is very copious, ablution and bathing have assumed the rank and importance of religious observances. Those who are in the habit of using the flesh-brush daily are at first surprised at the quantity of white dry scurf which it brings off; and those who take a warm bath for half an hour at long intervals cannot fail to have noticed the great amount of impurities which it removed, and the 
grateful feeling of comfort which its use imparts. The warm, tepid, cold, or shower bath, as a means of preserving health, ought to be in as common use as a change of apparel, for it is equally a measure of necessary cleanliness. Many, no doubt, neglect this, and enjoy health notwithstanding ; but many, very many, suffer from its omission; and even the former would be benefited by employing it. The perception of this truth is gradually extending, and baths are now to be found in fifty places for one in which they could be obtained twenty years ago. Even yet, however, we are far behind our continental neighbours in this respect. They justly consider the bath as a necessary of life, while we still regard it as a luxury.

When we consider the importance of the exhalation performed by the skin, the extent to which ablution and bathing of every description are neglected in charitable institutions, in seminaries for the young, and even by many persons who consider themselves as patterns of cleanliness, is almost incredible. Mr. Stuart, in speaking of the North Americans, states in his remarks, that "the practice of travellers washing at the doors, or in the porticoes or stoops, or at the wells of taverns and hotels once a day, is most prejudicial to health; the ablution of the body, which ought never to be neglected, at least twice a day, in a hot climate, being altogether inconsistent with it. In fact," he adds, "I have found it more difficult, in travelling in the United States, to procure a liberal supply of water at all times of the day and night in my bedchamber than to obtain any other necessary. A supply for washing the face and hands once a day seems all that is thought requisite."* But, bad as this is, I fear that numbers of sensible people may be found much nearer home, who limit their ablutions to the visible

* Three Years in America, vol. u. p. 440. 
parts of their persons, and would even express surprise if told that more than this is necessary to health. Certain it is, that many never wash their bodies at all, unless they happen to be at sea-bathing quarters in summer, or are oppressed with heat, when they will resort to bathing as a means of comfort, but without thinking at all of its efficacy as a means of cleanliness in preserving health. In many public charities and schools, in like manner, bathing or ablution is never thought of as a proper or practicable thing, except for the sick; and yet, it is obviously of great importance to every one, especially to the young.*

For general use, the tepid or warm bath seems to me much more suitable than the cold bath, especially in winter, and for those who are not robust and full of animal heat. Where the constitution is not sufficiently vigorous to secure reaction after the cold bath, as indicated by a warm glow over the surface, its use inevitably does harm. A vast number of persons are in this condition; while, on the contrary, there are few indeed who do not derive evident advantage from the regular use of the tepid bath, and still fewer who are hurt by it.

Where the health is good, and the bodily powers are sufficiently vigorous, the cold bath during summer, and the shower-bath in winter, nay serve every purpose required from them. But it should never be forgotten, that they are too powerful in

* While revising these pages, a friend has mentioned to me a case strikingly illustrative of the necessity of attending to the condition of the skin, and of the sympathy subsisting between it and the bowels. A lady, who is in other respects very cleanly in her habits, has never been accustomed to the use of the bath or to general ablution of any kind, and in consequence the skin acts very imperfectly. As a substitute, however, for its exhalation, she has all her life been affected with bowel complaint, which no treatment directed to the bowels has been able to remove. It is probable that the natural course of the exhalation could not now be restored. 
their agency to be used with safety by every one, especially in cold weather. In proportion as cold bathing is influential in the restoration of health when judiciously used, it is hurtful when resorted to without discrimination; and invalids therefore ought never to have recourse to it without the sanc tion of their professional advisers.

Even where cold bathing is likely to be of service when judiciously employed, much mischief often results from prolonging the immersion too long, or from resorting to it when the vital powers are too languid to admit of the necessary reaction-before breakfast, for example, or after fatigue. For this reason, many persons derive much benefit from bathing early in the forenoon, who, when they bathe in the morning before taking any sustenance, do not speedily recover their natural heat and elasticity of feeling.

For those who are not robust, daily sponging of the body with cold water and vinegar, or salt water, is the best substitute for the cold bath, and may be resorted to with safety and advantage in most states of the system; especially when care is taken to excite in the surface, by subsequent friction with the flesh-brush or hair-glove, the healthy glow of reaction. It then becomes an excellent preservative from the effects of changeable weather. When, however, a continued sensation of coldness or chill is perceptible over the body, sponging ought not to be persisted in : dry friction, aided by the tepid bath, is then greatly preferable, and often proves highly serviceable in keeping up the due action of the skin.

For habitual use, the tepid or warm bath is certainly the safest and most valuable, especially during the autumn, winter, and spring, and for invalids. A temperature ranging from $85^{\circ}$ to $98^{\circ}$, according to the state of the individual, is the most suitable; and the duration of the immersion may vary from fifteen minutes to an hour, or more, according to circum. 
stances. As a general rule, the water ought simply to be warm enough to feel pleasant, without giving a positive sensation of heat: the degree at which this happens varies a good deal according to the constitution and state of health at the time. Sometimes, when the generation of animal heat is great, a bath at $95^{\circ}$ will be felt disagreeably warm and relaxing; while, at another time, when the animal heat is produced in deficient quantity, the same temperature will cause a chilly sensation. The rule, then, is to avoid equally the positive impressions of heat and of cold, and to seek the agreeable medium. A bath of the latter description is the reverse of relaxing; it gives a cheerful tone and activity to all the functions, and may be used every day, or on alternate days, for fifteen or twenty minutes, with much advantage.

A person in sound health and strength may take a bath at any time, except immediately after meals. But the best time for valetudinarians is in the forenoon or evening, two or three hours after a moderate meal, when the system is invigorated by food, but not oppressed by the labour of digestion. When the bath is delayed till five or six hours after eating, delicate people sometimes become faint under its operation, and, from the absence of reaction, are rather weakened by the relaxation it then induces. As a general rule, active exertion ought to be avoided for an hour or two after using the warm or tepid bath; and, unless we wish to induce perspiration, it ought to be taken immediately before going to bed; or, if it is, it ought to be merely tepid, and not of too long duration.

These rules apply of course only to persons in an ordinary state of health. If organic disease, headache, feverishness, constipation, or other ailment exist, bathing ought never to be employed without medical advice. But that it is a safe and valuable preservative of health in ordinary circumstances, and 
an active remedy in disease, is most certain. Instead of being dangerous by causing liability to cold, it is, when well managed, so much the reverse, that the author of these pages has used it much and successfully for the express purpose of diminishing such liability, both in himself and others with whom the chest is delicate. In his own instance, in particular, he is conscious of having derived much advantage from its regular employment, especially in the colder months of the year, during which he has uniformly found himself most effectually strengthened against the impression of cold, by repeating the bath at shorter intervals than usual.

In many manufactories where warm water is always obtainable, it would be a very great advantage to have a few baths erected for the use of the operatives. Not only would these be useful in promoting health and cleanliness, but they would, by their refreshing and soothing influence, diminish the craving for stimulus which leads so many to the ginshop; and, at the same time, calm the irritability of mind so apt to be induced by excessive labour. Where the trade is dirty, as many trades necessarily are, it is needless to say how conducive to health and comfort a tepid bath would be on quitting it for the day.

On the Continent, the vapour and hot air-baths are had recourse to, both as a means of health and in the cure of disease, to an infinitely greater extent than they are in this country. Their use is attended by the very best effects, particularly in chronic ailments, and there can be no question that their action is chiefly on the skin, and through its medium on the nervous system. As a means of determining to the surface, promoting cutaneous exhalation, and equalizing the circulation, they are second to no remedy now in usc; and consequently, in a variety of affections which the encouragement of these processes is calculated to relieve, they may be emG 2 
ployed with every prospect of advantage. The prevalent fear of catching cold, which deters many from using the vapour-bath, even more than from warm bathing, is founded on a false analogy between its effects and those of profuse perspiration from exercise or illness. The latter weakens the body, and, by diminishing the power of reaction, renders it susceptible of injury from sudden changes of temperature. But the effect of the vapour-bath properly administered is very different. When not too warm or too long continued, it increases instead of exhausting the strength, and, by exciting the vital action of the skin, gives rise to a power of reaction which enables it to resist cold better than before. This I have heard many patients remark; and the fact is well exemplified in Russia and the north of Europe, where, in the depth of winter, it is not uncommon for the natives to rush out of a vapour-bath and roll themselves in the snow, and be refreshed by doing so; whereas, were they to attempt such a practice after severe perspiration from exercise, they would inevitably suffer. It is the previous stimulus given to the skin by the vapourbath which is the real safeguard against the coldness of the snow.

Common experience affords another illustration of the same principle. Jf, in a cold winter day, we chance to sit for some time in a room imperfectly warmed, and feel in consequence a sensation of chillness over the body, we are much more likely to "catch cold on going out than if we had been sitting in a room comfortably warm. In the latter case, the cutaneous circulation and nervous action go on vigorously; heat is freely generated, and the vital action of the skin is in its full force. The change to a lower temperature, if accompanied with exercise to keep up this vitality, is then felt to be bracing and stimulating rather than disagreeable. But it is widely different when the surface is already chilled 
before going out. The vitality of the skin being diminished, reaction cannot follow additional exposure ; the circulation leaves the surface, and becomes still more internal; and, if weakness exists in the throat or chest, cold is the almost certain result. Many suffer from ignorance of this principle.

The vapour-bath is thus calculated to be extensively useful, both as a preservative and as a reme dial agent. Many a cold and many a rheumatic attack arising from checked perspiration or long exposure to the weather might be nipped in the bud. by its timely use. In chronic affections, not only of the skin itself, but of the internal organs with which the skin sympathizes most closely, as the stomach and intestines, the judicious application of the vapour-bath is productive of great relief. Even in chronic pulmonary complaints, it is, according to the continental physicians, not only safe, but very serviceable; particularly in those affections of the mucous membrane which resemble consumption in so many of their symptoms. Like all powerful remedies, however, the vapour-bath must be administered with careful regard to the condition and circumstances of the individual.

It happens occasionally, either from some peculiarity of constitution, or from some unusual condition of the skin, indicated by great dryness and a liability to erysipelatous and scaly eruptions, that the moisture of the water or vapour-bath is at first rather prejudicial and unpleasant, and becomes grateful only in proportion as the skin regains its healthy state. In such cases, the warm air-bath is said to be remarkably successful, and is gaining ground very rapidly in the metropolis.

Although the preceding remarks apply specially to the skin considered as an exhalant, yet most of them are equally applicable to it when viewed as the seat of an important nervous function. For so intimately and beautifully are all the parts of the frame 
connected with each other, that what is really good for one rarely if ever fails to be beneficial to the rest. Thus while exercise, adequate clothing, the bath, friction, and cleanliness are very efficacious in promoting the insensible perspiration and equalizing the circulation, they are almost equally influential in promoting the vital action of the innumerable nervous filaments ramified on the skin, and the tone of which is as essential as that of the bloodvessels to the proper discharge of the cutaneous functions. In the large and afflicting class of nervous and mental diseases, attention to the skin becomes therefore almost a sine qua non of successful treatment. - As a preservative, too, it is influential. In most nervous ailments, languor and inaction of the skin show themselves simultaneously with the earliest dawn of mental uneasiness, and often attract notice before the morbid feelings of the mind have acquired either permanence or strength. At this early period, the use of the bath will frequently prove very efficacious in restoring health.

Many imagine the tepid and warm bath to be weakening, but experience shows that they are so only when abused. When not too warm, and not prolonged beyond fifteen or twenty minutes, the tepid bath may be employed daily with perfect safety and advantage by persons in health; while invalids, whose condition requires its use, are often strengthened by a much longer and equally frequent immersion. I have seen it resorted to for an hour daily, for months in succession, by nervous invalids, with much benefit to health and strength; and in France it is employed to an infinitely greater extent. At the immense hospital of Salpetriere at Paris, and also at Charenton, M. Esquirol has for many years directed it to be extensively used for two, three, and even five or six hours a day, and with excellent effect. When I visited the hospital for the insane at Charenton, and M. Esquirol's admirable private 
asylum at Ivry in September, 1831, that gentleman spoke to me in very strong terms of the benefits resulting from the practice, and declared that he had ever found it, when used with ordinary prudence, a safe and valuable remedy; and that, in reality, it failed to do good in some cases more from the patient remaining in it too short a time, than from its want of power to relieve.

In the Medico-Chirurgical Reviews for January and April, 1833, a very interesting outline is given of an article published in the Revue Medicale, illustrative of the efficacy of the tepid bath and the affusion of cooler water on the head during the last few minutes of immersion, in the cure of a variety of nervous and head affections of considerable obstinacy and severity. Dr. Johnson, the editor of the Review, adds his testimony to the success of the practice, and the results obtained agree entirely, with my own experience; but, as these papers relate to the treatment of disease, it would be out of place to do more here than recommend them to the attention of the professional reader. I may mention, however, that Dr. Recamier frequently orders the bath to be repeated two, three, or even four times in a day. So little reality is there in its supposed debilitating effect.

I mention these facts to show, that attention to the health of the skin is really infuential in preserving the tone of the nervous system, and in contributing to mental and bodily comfort, and not for the purpose of inducing persons in bad health to have recourse to the bath of their own accord, which they ought never to do, as they may chance to suffer from using it unseasonably. No rules of universal application can be laid down, and this is not the place for a professional disquisition.

If the bath cannot be had at all places, soap and water may be obtained everywhere, and leave no apology for neglecting the skin; or, as already men. 
tioned, if the constitution be delicate, water and vinegar, or water and salt, used daily, form an excellent and safe means of cleansing and gently stimulating the skin: to the invalid, they are highly beneficial, when the nature of the indisposition does not render them improper. A rough and rather coarse towel is a very useful auxiliary in such ablutions. Few of those who have steadiness enough to keep up the action of the skin by the above means: and to avoid strong exciting causes, will ever suffer from colds, sore throats, or similar complaints ; while, as a means of restoring health, they are often incalculably serviceable. If one-tenth of the persevering attention and labour bestowed to so much purpose in rubbing down and currying the skins of horses, were bestowed by the human race in keeping themselves in good condition, and a little attention were paid to diet and clothing,-colds, nervous diseases, and stomach complaints would cease to form so large an item in the catalogue of human miseries. Man studies the nature of other animals, and adapts his conduct to their constitution; himself alone he continues ignorant of, and neglects. He considers himself as a being of a superior order, and not subject to the laws of organization which regulate the functions of the inferior animals; but this conclusion is the result of ignorance and pride, and not a just inference from the premises on which it is ostensibly founded.

The writer of these remarks has, unfortunately for himself, had extensive experience, in his own person, of the comnexion between the state of the skin and the health of the lungs ; and can therefore speak with some confidence as to the accuracy of his observations, and the benefit to be derived from attending to the condition of the skin in chronic pulmonary complaints. Many affections of a consumptive character are preceded or begin by a deficiency 
of vital action in the skin and extremities, and a consequent feeling of coldness in the feet and on the surface, and susceptibility of catarrhal affections from apparently inadequate causes, often long before any pressing symptom, directly connected with the lungs, occurs to attract notice. In this state, means systematically directed to restoring the cutaneous circulation will frequently be successful in warding off consumption; and even when the disease is formed, the same means will help to prolong life and relieve suffering, while they will go far to effect a cure in those chronic affections of the bronchial membrane which simulate consumption and are sometimes undistinguishable from it, and which, when mismanaged, are equally fatal.

The two remedies which have the oldest and most general reputation in the successful treatment of pulmonary and consumptive disease have this quality in common, that both owe much of their influence to their exciting the cutaneous functions, and equalizing the circulation. I allude to sailing, and riding on horseback. Many authors speak of both in the highest terms, and Sydenham is well known to have considered the latter as almost a specific. Dr. Rush, of Philadelphia, too, extols it with nearly equal force. So far as my observation goes, these exercises are productive of advantage, chiefly in proportion as they determine the blood to the surface, which squeamishness, sea-sickness, and riding all do in a powerful manner. Riding seems to have this effect, partly from the bodily exercise giving general vigour to the circulation, and partly from the continued gentle friction between the skin and the clothes stimulating the cutaneous vessels and nerves. This latter effect is of more importance than many believe. Those, accordingly, who are proof against sea-sickness, derive least benefit from the voyage; while those who suffer under it long are compensated by the amelioration which it 
induces in the more serious malady. The writer of these remarks became ill in the month of January, 1820 , and soon presented many of the symptoms of pulmonary consumption. In spite of the best advice, he continued losing ground till the month of July, when he went by sea to London, on his way to the south of France; but, finding himself unable for the journey, he was obliged to return from London also by sea. Being extremely liable to seasickness, he was squeamish or sick during the whole of both voyages-so much so as to be in a state of gentle perspiration for a great part of the time. After this he became sensible for the first time of a slight improvement in his health and strength, and of a diminution of febrile excitement. Some weeks afterward, he embarked for the Mediterranean, and encountered a succession of storms for the first four weeks, two of which were spent, in the month of November, in the Bay of Biscay, in a very heavy sea. For more than three weeks he was generally very sick, and always in a state of nausea; and during the whole time, although his bed was repeatedly partially wetted by salt water, and the weather cold, the flow of blood towards the skin was so powerful as to keep it generally warm, always moist, and often wet with perspiration, forced out by retching and nausea. The result was, that, on entering the Mediterranean at the end of a month, and there nieeting fine weather, he found himself, though still more reduced in flesh and very weak, in every other respect decidedly improved; and on his arrival in Italy at the end of seven weeks, recovery fairly commenced, after about ten months' illness, and by great care it went on with little interruption, till the summer of 1821 , when he returned home.

To carry on what was so well begun, riding on horseback in the country was resorted to, and that exercise was found to excite the skin so beneficially, ns to keep it always pleasantly warm, and generally 
bedewed with moisture, even to the extremities of the toes; and in proportion to this effect was the advantage derived from it, in relieving the chest, increasing the strength, and improving the appetite. A second winter was spent in the south with equal benefit; and in the summer of 1822 , riding was resumed at home, and the health continued to improve. The excitement given to the skin by riding was sufficient to keep the feet warm, and to prevent even considerable changes of temperature from being felt : and rain was not more regarded, although special attention was of course paid to taking off damp or wet clothes the moment the ride was at an end. Strength increased so much under this plan, combined with sponging, friction, and other means, that it was persevered in through the very severe winter of $1822-3$, and with the best effects. For nine years thereafter the health continued good, under the usual exposures of professional life: but in 1831 it again gave way, and pulmonary symptoms of a suspicious character once more made their appearance. The same system was pursued, and the same results have again followed the invigoration of the cutaneous functions and of the general health, by a seavoyage, horseback exercise, and the regular use of the bath. These, as formerly, have proved beneficial in proportion to their influence in keeping up the warmth and moisture of the surface and extremities.

In thus insisting upon the advantages of maintain ing the healthy action of the skin, I must not be supposed to ascribe the whole benefit to that circumstance alone. So beautifully is the animal economy constituted, that it is impossible to use rational means for the invigoration of one organ or function, without good being done to all; and so closely are the various parts allied to each other, that, to describe fully the functions and sympathies of any one, we would require to make the circle of 
the whole. From this appears the fallacy of those who select the derangements of any one organ as the origin and source of all existing diseases. Some functions are no doubt more important, and their disorders exercise a wider influence over the general health than others; but no one who knows the structure of the human body and the relations of its parts, or has carefully observed the phenomena of disease, can be satisfied with such exclusive reasoning. The stomach, the bowels, the liver, and the nervous system have each had their patrons, and the derangement of each has been specially held out as the grand fountain of human misery. Each doctrine, too, has been denionstrated, by cases and cures, to be superior to all the rest, and each has proved successful in its turn, where the others had been tried and failed. Far, however, from proving the propriety of exclusiveness in favour of any one organ, such facts, rightly considered, demonstrate the reverse, and show that successful practice requires views and remedies founded on a careful examination of every function; and afford a strong presumption that the man who traces every illness to the liver, the stomach, or the nerves will be at least as often strikingly wrong, as strikingly right.

In saying, therefore, that attention to the state of the skin is influential in preserving and restoring health, we wish to represent it as an important, but by no means exclusive condition, and to ascribe to the means used for invigorating its functions their due share of action upon other organs and functions. Sailing, for example, is useful in pulmonary complaints, not only because its accompanying nausea causes a healthful flow of blood from the internal parts to the surface, but because the gentle and constant exercise occasioned by the movement of the ship is admirably adapted to a debilitated state of the system, when other exercise cannot be taken without hurrying the breathing or inducing fatigue; 
and because pure, fresh, bracing air is of infinite importance in all, and especially in pulmonary affections. Attention to the skin must, therefore, never be considered for a moment as superseding attention to the other functions. That were a pernicious mistake. It must be regarded as a part only, though an important part, of a rational and consistent treatment, and its efficacy will often depend, in no small degree, on the care which is taken to support its effects by a scrupulous attention to the necessitics of the rest of the system.

When these pages were passing through the press in the form in which their substance first appeared in a periodical journal, I was surprised and gratified on seeing a work advertised, on the same subject and with almost the same title, by Dr. Wood of Newry. On afterward procuring the book, I was much pleased to perceive the extent to which our views harmonized, and to find that Dr. Wood, as well as myself, had felt the want of popular information on the functions of the animal economy, and come to the conclusion, that, even by medical men, the influence of the skin on the general health and in the treatment of disease is too much overlooked. 


\section{CHAPTER IV.}

Muscles-Their Structure, Attachments, and Conditions of Action-Necessity of Arterial Blood and of Nervous InfluenceIllustrations-Muscles act by alternate Contraction and Re. laxation-Fatigue consequent on continuing the same Attitude explained-Injuries of Spine from Neglect of this Law, and from sedentary Occupations in School-The Mind ought to be engaged in Exercise as well as the Body-Superiority of cheerful Play and amusing Games-A dull Walk the least useful Exercise-Influence of Mental Stimulus illustrated by Examples-Exercise to be proportioned to Strength-Laws of Exercise.

Having examined the nature and uses of the skin, we may next proceed to consider the important system of organs, lying almost immediately under it, viz. the Muscles; which, although in constant activity during our waking hours, and of indispensable necessity to man in every movement which he makes, are perhaps less familiarly known than almost any other part of the body. As the study of the nuscular system involves an exposition of the principles which ought to regulate exercise, it can scarcely fail to excite the attention of the general reader, and especially of those who, as parents or teachers, are interested in the education of the young.

The muscles are those distinct and compact bundles of fleshy fibres which are found in animals immediately on removing the skin and subjacent fat; and which, although perhaps not known to all under their generic or scientific name, are faniliar to every one as constituting the red fleshy part of meat.

Fvery muscle, or separate bundle of fleshy substance, is composed of innumerable small fibres or 
threads, each separated from, and at the same time loosely connected with, the others by a sheath of cellular membrane, enveloping it, but which is so thin as not to obscure the colour of the fibre, or attract notice unless specially looked for. Each muscle is in its turn separated from the neighbouring muscles by thicker layers or sheaths of the same membrane, in some of the cells of which fat is deposited, especially where the interval between the muscles is considerable; and hence the elegantly rounded form of the limbs, which without this fat would present the rigid, sharp, and prominent outline which we see occasionally in strong persons of a spare habit of body. From the loose texture of the connecting cellular membrane, the muscles enjoy perfect freedom of motion during life, and admit of being easily separated from each other after death, either by the knife, or by simply tearing the cellular tissue.

Muscles, speaking generally, may be divided into three parts, of which the middle fleshy portion, called the belly, is the most conspicuous and important. The other two are the opposite ends, commonly called the origin and insertion of the muscle. The belly is the bulky and fleshy part, by the contraction or shortening of the fibres of which the two ends are brought nearer to each other, while the belly itself swells out in a lateral direction. When we attempt to lift a heavy weight in the hand, or to overcome any resistance, the muscles which bend the arm may be seen and felt to start out, rigid and well defined in their whole extent, while their extremities tend powerfully to approach each other, and of course to carry along with them the bones to which they are attached. In consequence of this tendency, if the weight be unexpectedly knocked out of the hand before we have time to obviate the result, the muscles, having then no resistance to overcome, will contract violently, and throw the H 2 
hand up with a sudden jerk. Voluntary motion is, in fact, effected by the contraction of muscles acting upon and changing the relative positions of the bones or solid support of the system, and therefore almost all muscles are attached to one bone by their origin, and to another by their insertion; the former being merely the fixed extremity, towards which the opposite and more moveable end, called the insertion, is carried by the shortening of the intervening belly of the muscle.

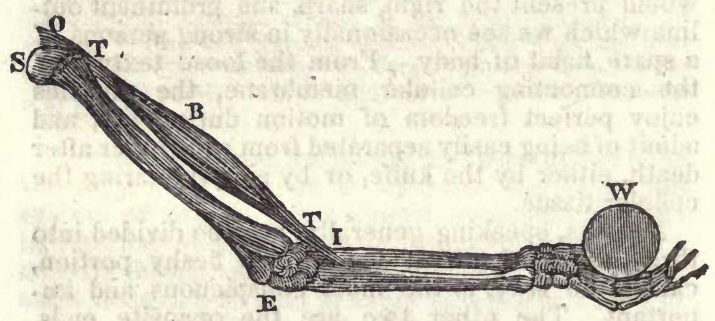

The figure represents the bones of the arm and hand, having all the soft parts dissected off except one inuscle O B I, of which the function is to bend the arm. O the origin of the muscle. $\mathrm{B}$ the belly. I the insertion. T T the tendons $\mathbf{S}$ the shoulder-joint. $\mathbf{E}$ the elbow. When the belly contracts, the lower extremity of the muscle, I, is brought nearer to the origin or fixed point $\mathrm{O}$, and, by thus bending the arm at the elbow-joint, raises up the weight $W$ placed in the hand.

If the muscles must be attached to bones, it may be asked,-how can the bones, which present comparatively so small a surface, afford space enough for the attachments of muscles, which are so much larger, and which eren appear in successive layers above each other? This difficulty is obviated in two ways. In the first place, the heads and other parts of bones to which muscles are attached are 
enlarged so as to present a greater surface than the body of the bone, and form what are called processes, for the obvious purpose of affording greater room; and, secondly, instead of all the fleshy fibres of a muscle being prolonged to its points of attachment at the bone, they, with few exceptions, terminate gradually, as they proceed from the belly, in a white shining tendon, of a much smaller size than the muscle, but of great strength, which is inserted into the bone. These tendons, or sinews as they are occasionally named, conduce greatly to symmetry, elegance, and freedom of motion ; and may be traced under the skin on the back of the hand, and in the very powerful specimen at the heel, called the tendon of Achilles. The hamstrings are another obvious example, and may be easily felt becoming tight when an effort is made to bend the knee. There are a few muscles not attached to bones by either extremity, and also a few which have no tendons. Those which surround the eyebrows, the mouth, the gullet, and some of the other natural passages are of the former description; as is also the heart. Some of the muscles of the trunk have no tendons, but these are few in number, and may at present be considered exceptions to the general rule.

In man, and in most of the animals with which we are familiar, the muscles are of a red colour. This, however, depends entirely on the blood which they contain; for so far is the colour from being essential to their constitution, that it may be destroyed by washing out the blood which produces it, the muscular substance remaining in other respects unchanged. Hence the colour of the muscles varies with that of the blood,-is dark where it is dark, pale where it is pale, and white where it is white. The true characteristic of muscular fibre is contractility, or the power of shortening its substance 
on the application of stimuli, and again relaxing when the stimnulus is withdrawn.

The direction in which the fleshy fibres run determines the direction of the motion effected by their contraction. In some muscles the fibres are nearly parallel, and act consequently in a straight line. In others they run obliquely, producing a corresponding obliquity of motion; while in others they are disposed like feathers in relation to a quill, and are, therefore, styled penniform. A few are circularly disposed round openings, and contract towards a common centre, like the mouth of a purse closed by its strings. When the direction varies, it is always to effect a particular kind of action. Remarkable contrivances appear for this end : one muscle of the lower jaw, for example, is divided into two distinct fleshy bellies by an intermediate thin strong tendon, which passes through and plays in a pulley adapted for its reception; its two portions being by this means enabled to operate with full effect almost at right angles to each other. A similar arrangement is found in the trochlearis or pulleymuscle of the eyeball; and modifications of a different kind occur in other muscles, as in those of the fingers and toes, wherever a particular object is to be accomplished.

The chief purpose of the muscles is obviously to enable us to carry into effect the various resolutions and designs-or volitions, as they are termed by philosophers - which have been formed by the mind. But while fulfilling this grand object, their active exercise is at the same time highly conducive to the well-being of many other important functions. By muscular contraction, the blood is gently as. sisted in its course through the smaller vessels and more distant parts of the body, and its undue accumulation in the internal organs is prevented. The important processes of digestion, respiration, secretion, absorption, and nutrition are promoted, and 
the health of the whole body immediately influenced. The mind itself is exhilarated or depressed by the proper or improper use of muscular exercise ; and it thus becomes a point of no slight importance to establish general principles by which that exercise may be regulated.

The first requisite for healthy and vigorous muscular action is the possession of strong and healthy muscular fibres. In every part of the animal economy, the muscles are proportionate in size and structure to the efforts required from them; and it is a law of nature, that whenever a muscle is called into frequent use, its fibres increase in thickness within certain limits, and become capable of acting with greater force and readiness; and that, on the other hand, when a muscle is little used, its volume and power decrease in a corresponding degree. When in a state of activity, the quantity of blood which muscles receive is considerably increased; and, in consequence, those which are much exercised become of a deeper red colour than those which are less used. The reason of this will be evident, when we recollect that to every organ of the body arterial blood is an indispensable stimulus, and that its supply is, during health, always proportioned to the extent and energy of the action. When any part, therefore, is stinted of its usual quantity of blood, it very soon becomes weakened, and at last loses the power of action, although every other condition required for its performance may remain unimpaired.

It is the infringement of this condition that entails so much misery upon our young manufacturing population, and even upon many of the inmates of our boarding-schools. Wasted by excessive labour, long confinement, and miserable diet, the muscular system is stinted in growth, and weakened in structure; and the blood, impoverished by insufficiency of nourishing food and by a vitiated atmosphere, is 
no longer capable of repairing the waste conseyuent upon exercise, or of affording a healthy stimulus to the vessels and nerves which animate the muscles. Languor, debility, and exhaustion of mind necessarily follow; and the individual is left susceptible of no stimulus but that of ardent spirits or of excited or reckless passion.

In youth, not only must the waste of materials be replaced, but an excess of nourishment must be provided, to admit of the continued growth which is the chief function of our earlier years. If this be denied, the development of the bodily organs often receives a check which no subsequent treatment can remedy, and a foundation is laid for diseases of debility which afterward imbitter and endanger life. From pretty extensive inquiry, I am satisfied that in boarding-schools, especially for females, this important principle is often disregarded; while the conductors are at the same time without the least suspicion of the evil they are producing, and even take credit to themselves for only checking sensual appetites, and promoting temperance in eating as well as in drinking. Youth requires the best and most nutritious food, and such ought regularly to be provided. Weak broth, twice-cooked hashes, and quantities of vegetables and watery milk, are not sufficient sustenance for a young and growing frame. Can we be surprised that, with such a diet, worm-powders and stomachic medicines are in constant demand, and that, even with the assistance of these, the girl shoots up thin, pale, and fleshless ? Let it not be supposed that I wish to make a god of the belly : my object is the reverse of this, and I am sure that no better means can be used to effect it than to give a sufficiency (not an excess) of wholesome and nourishing food, which alone will satisfy the stomach, and obviate the constant craving which is a frequent and painful concomitant of deficiency of food. Let it be considered how soon, in 
cases of shipwreck for example, men previously well fed are wasted away by bodily labour when deprived of a full allowance of food, and it will not be difficult to form some conception of the importance of this condition to the well-being of the mus- . cular system.

Something more than mere muscle, however, is required for the production of regulated or voluntary motion. The muscle itself, though perfect in strength and in structure, would otherwise remain inert. A stimulus is required to put it into activity, and to direct its contraction; and this stimulus is conveyed to it by the nerves. As we write, the muscles which move the fingers and guide the per obviously follow the commands of the will; and the moment the will is withdrawn they cease to oper. ate. If the will be feeble and undecided, the muscular movements will be equally weak and irresolute; whereas, if the mind be powerfully excited and the will energetic, strength, rapidity, and decision will equally characterize all the movenients of the body. Under the intense excitement and headlong fury of madness, the muscular action of an otherwise feeble man acquires a force often exceeding all our powers of control.

It will be at once perceived from this description, that, in effecting voluntary motion, we must have in operation, first, The brain, or organ of mind, as the source of the will; secondly, The nerves, which convey the intimations of the will to the muscles; and, thirdly, The muscles themselves, by whose contractile powers motion is produced. It will be understood, also, why the number and size of the nerves distributed to a muscle are in proportion, not simply to its volume, but to the variety, frequency, and vivacity of the movements required from it; and why some small muscles employed in many combinations are therefore supplied with a greater 
variety of nerves than others double their size, but with more simple functions.

Muscular power is (other circumstances being equal) proportioned to the size of the muscle; but it often happens that great power is required where bulk of muscle would be inconvenient or cumbersome. In such cases, it is supplied with an increased endowment of nervous filaments, which make up by the strength of stimulus what the muscle wants in bulk of fibre. Many birds, for example, require great muscular power to sustain them in their long and rapid flights through the air, and owe its possession chiefly to the strong stimulus imparted to moderate-sized muscles by large nerves, which add nothing, or next to nothing, to their weight; whereas, had the greater power been obtainable only from an augmentation of fleshy fibres, the consequent addition of weight would, from the greatly increased difficulty the animal must have felt in raising and sustaining itself in the air, have gone far to counterbalance any advantage gained on the side of power. But in fishes, which float without effort in their own element, size produces no such inconvenience, and their strength, accordingly, is made to depend more on the volume of the muscle than on its nervous endowment,-showing a beautiful adaptation to the mode of life and wants of the animal.

As voluntary motion depends as much on nervous stimulus as on muscular agency, it happens that whatever interrupts the action of the nerves puts a stop to motion as effectually as if the muscular fibre itself were divided. Injuries and diseases of the brain, whence the will emanates, are well known to be accompanied with palsy, or want of power in the muscles, although in their own structure the latter remain sound. Sleep and narcotics, too, suspend voluntary motion, solely in consequence of their action on the nervous system. Ardent spirits, in 
like manner, disturb the regularity of muscular action, solely by previously disordering the brain; and

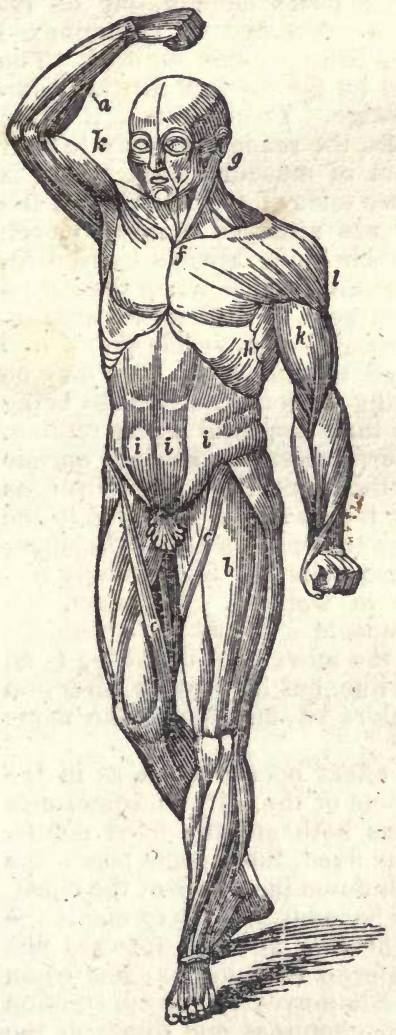

hence the unsteady gait and faltering elocution of a semi-intoxicated person are sometimes removed in an instant by some powerful mental impression being suddenly made, sufficient to restore the brain to its natural state, and thereby to give unity and steadiness to the nervous impulse proceeding from it to the muscles.For the same reason, although the brain and muscles be perfectly sound, yet if the comimunication between them be impaired or destroyed by the compression or division of the nerves, the muscles cease to act. The muscles of the human body are upwards of 400 in number, and form several layers lying over each 
other. That some conception may be formed of their arrangement and distribution, the superficial layer, or that which appears immediately on removing the skin, is represented in the annexed woodcut, taken from a little volume entitled "The Physician," published by the Society for the Diffusion of Useful Knowledge. To understand th e uses of the various muscles, the reader has only to bear in mind that the object of muscular contraction is simply to bring the two ends of the muscle and the parts to which they are attached nearer to each other, the more moveable being always carried towards the more fixed point. Thus, when the sternomastoid muscle $f \mathrm{~g}$ contracts, its extremities approximate, and the head being the moveable point, it is pulled down and turned to one side. This may be easily seen in the living subject, the muscle being not less conspicuous than beautiful in its outline. Again, when the powerful rectus or straight muscle $b$ on the front of the thigh contracts with force, as in the act of kicking, its lower end attached to the knee-pan and leg tends to approximate to the upper or more fixed point, and pulls the leg strongly forwards. This occurs in walking. But when the sartorius or tailors' muscle $c$ is put in action, its course being oblique, the movement of the leg is no longer in the straight line, but in a cross direction like that in which tailors sit, and hence the name sartorius.

Another variety of effect occurs when, as in the rectus, or straight muscle of the belly $i i$, sometimes one end and sometimes both are the fixed points. When the lower end is fixed, the muscle bends the body forward and pulls down the bones of the chest. When, as more rarely happens, the lower end is the moveable point, the effect is to bring forward and raise the pelvis and inferior extremities; and when both ends are rendered immoveable, the contraction of the muscle tends to compress and diminish the 
size of the cavity of the belly, and thus not only assists the natural evacuations, but co-operates in the function of respiration.

In contemplating this arrangement, it is impossible not to be struck with the consummate skill with which every act of every organ is turned to account. When the chest is expanded by a full inspiration, the bowels are pushed downwards and forwards to make way for the lungs; when the air is again expelled, and the cavity of the chest diminished, the very muscies $i i$, which effect this by pulling down the ribs, contract upon the bowels also, and push them upwards and inwards, as can be plainly perceived by any one who attends to his own breathing. By this contrivance, a gentle and constant impulse is given to the stomach and bowels, which is of great importance to them in contributing to digestion and in propelling their contents; and one cause of the costiveness with which sedentary people are so habitually annoyed is the dininution of this natural motion in consequence of bodily inactivity.

From the preceding exposition, the action of the muscles $a, k, l$, which bend the arm and forearm, will be easily understood, and some notion may be formed of the innumerable combinations into which a system composed of upwards of 400 pieces may be thrown, in effecting all the movements required from the human frame. In some of the operations in which we engage, nearly the whole, and in others only a part, of the muscles are thrown into action at one time. The simultaneousness of action which obtains in such instances, and which occurs in almost every act of life, however simple, and without which no dictate of the will could be harmoniously and successfully obeyed, depends solely on the distribution and connexions of the nerves which animate the muscles. Every individual fibre of every muscle is supplied with nervous filaments, and different fibres of the same muscle are indebted for 
the simultaneousness of their excitement to the connexion established between each of them by these filaments. Wherever many muscles combine to execute an important movement, they are uniformly found to be provided with, and connected by, branches from the same system of nerves; as, without this means, simultaneousness of action could not be ensured. Thus the muscles which cover the upper part of the chest co-operate in the voluntary movements of the arm, and at the same time in the respiratory movements of the chest; but these, being two distinct purposes, require different combinations of the muscles among themselves. To effect these combinations, two sets of nerves are provided, as has been shown by Sir Charles Bell; the one regulating the respiratory, and the other the purely voluntary movements of the muscles. This is the true reason why the same muscle sometimes receives nerves from $t$ wo or three different quarters; a circumstance which, before the principle was discovered, and when all nerves were considered alike, was altogether inexplicable, and seemed a work of mere supererogation.

The influence of the nervous agency may be still further illustrated. When the trunk of a muscular nerve is irritated by the contact of an external body, or by the electric spark, the muscles which it supplies instantly contract, but without either harmony or permanency of action: the contraction is like the violent and ill-regulated start of convulsion. It is the influence of the brain and mind in the equal diffusion of the required stimulus to each muscle, in the exact proportion needful, that characterizes healthy and sustained voluntary motion, as opposed to the irregular convulsive start. Nothing can be more wonderful than the accuracy with which, in the most delicate movements, this stimulus is adjusted and apportioned to such a variety of parts, particularly where practice, or, in other words, edu- 
cation, has rendered the combination of powers easy and certain. Not to mention the more obvious and graceful movements of dancing, fencing, and riding, we discover, in the management of the hand and fingers by engravers, seulptors, watchmakers, jugglers, and other artists and mechanics, a minute accuracy of muscular adjustment to effect a given end, which is the more surprising the more we consider the complicated means by which it is effected.

In consequence of the co-operation of both nerve and muscular fibre being required to effect motion, excess of action in each is followed by results peculiar to itself. If the NERVES preponderate, either constitutionally or from over-exercise, - as they are apt to do in highly nervous temperaments, - their excessive irritability renders them liable to be unduly excited by ordinary stimuli ; and hence, as in hysteric and nervous females, a proneness to sudden starts, cramps, and convulsions, from causes which would scarcely affect an individual differently constituted. Such pérsons have little muscular power, except under excitement; they then become capable of great efforts, of short duration, but sink proportionally low when the stinsulus is past. If, on the other hand, the muscLes predominate, as in athletic strong-built men, the nervous system is generally dull and little susceptible of excitement, and the muscles which it animates are consequently little prone to the rapid and vivacious action which accompanies the predominance of the nervous func tions. Great strength and capability of bodily labour are then the characteristics.

Great muscular power and intense nervous action are rarely conjoined in the same individual; but when they do happen to meet, they constitute a perfect genius for muscular exertion, and enable their possessor to perform feats of strength and agility which appear marvellous to those who are deficient 
in either condition. The most successful wrestlers and gladiators among the ancients seem to have owed their superiority chiefly to the possession of both endowments in a high degree; and among the moderns, the most remarkable combination of the two qualities is exhibited by some of our harlequins, clowns, rope-dancers, and equestrian performers, and also by those who display their strength and power of equilibrium by balancing wheels, ladders, or other heavy bodies, on the chin; and whose performances require from the small muscles of the jaw and neck a force of contraction which, when reduced to calculation, almost exceeds belief. Bel. zoni combined both conditions in a high degree.

From the general resemblance which characterizes the different nerves, a similarity of function was long ascribed to them all, and no explanation could be given why one muscle sometimes received filaments from a variety of nervous trunks. Recently, however, the labours of Sir Charles Bell and Magendie have clearly established, that, in such cases, each nerve serves a distinct purpose, in combining the movements of the particular muscle with those of others necessary to effect a given end, -and that without this additional nerve such a combination could not have been produced. The muscular nerves must not be confounded with those which we have seen ramified on the skin for the purposes of sensation. The former are provided for the purposes of motion and not of feeling, and hence muscles may be cut or injured with little pain, compared to what is felt by the skin. Weariness is the kind of sensation recognised by the muscular nerves.

So uniformly is a separate instrument provided for every additional function, that there is every reason to regard the muscular nerves, although running in one sheath, as in reality double, and performing distinct functions. Sir Charles Bell has 
the merit of this discovery, if such it shall ultimately prove to be. In his work on the Nervous System, he endeavours to show, that one set of nervous fibres conveys the mandate from the brain to the muscle, and excites the contraction; and that another conveys from the muscle to the brain the peculiar sense of the state of the muscle, by which we judge of the fitness of the degree of contraction which has been produced to accomplish the end desired, and which is obviously an indispensable piece of information to the mind in regulating the movements of the body. Sir Charles has shown, that many of the sensations supposed to be derived from the sense of touch and the skin, arise from the muscular sense, and are wholly imperceptible to the skin, without the co-operation of muscular contraction.

"The muscles have two nerves," says Sir Charles, "which fact has not hitherto been noticed, because they are commonly bound up together. But whenever the nerves, as about the head, go in a separate course, we find that there is a sensitive nerve and a motor nerve distributed to the muscular fibre, and we have reason to conclude that those branches of the spinal nerves which go to the muscles consist of a motor and a sensitive filament.

"It has been supposed hitherto, that the office of a muscular nerve is only to carry out the mandate of the will, and to excite the muscle to action, but this betrays a very inaccurate knowledge of the action of the muscular system ; for, before the muscular svstem can be controlled under the influence of the will, there must be a consciousness or knowledge of the condition of the muscle.

"When we admit that the various conditions of the muscle must be estimated or perceived, in order to be under the due control of the will, the natural question arises, Is that nerve which carries out the mandate of the will capable of conveying, at the 
same moment, an impression retrograde to the course of that influence which is going from the brain to the muscle? If we had no facts in anatomy to proceed upon, still reason would declare to us that the same filament of a nerve could not convey. a motion, of whatever nature that motion may be, whether vibration or motion of spirits, in opposite directions at the same moment of time.

"I find that, to the full operation of the muscular power, two distinct filaments of nerves are necessary, and that a circle is established between the sensorium and the muscle; that one filament or single nerve carries the influence of the will towards the muscle, which nerve has no power to convey an impression back wards to the brain; and that another nerve connects the muscle with the brain, and, acting as a sentient nerve, conveys the impression of the condition of the muscle to the mind, but has no operation in a direction outwards from the brain towards the muscle, and does not therefore excite the muscle, however irritated."*

This consciousness of the state of the muscles, or muscular sense, as it may be truly called, is of great importance both to man and to animals, as it is necessarily by information thence derived that every subsequent exertion is directed and apportioned in intensity to the effort required to be made. If we had no such sense, the delicate and welldirected touches of the engraver, painter, and sculptor, or of the ingenious mechanic, would be at the mercy of hazard; and a single disproportioned movement might ruin the successful labour of months, supposing success in reality to be compatible with chance. Without this sense, man could not deliberately proportion the muscular efforts to his real wants; and, even in walking, his gait would be unsteady and insecure, because there would be no

- Bell's Anatomy seventh edition. vol ii p. 372. 
harmony between effort and resistance. The loss of equilibrium, and the concussion and disturbance of the system consequent on taking a false step, as it is called, are a specimen of what we would always be subject to without the guidance of the muscular sense. When we imagine we have one step more of a stair to descend than really exists, we are placed nearly in the same circumstances as if we had no muscular sense to direct the extent of our intended movement; because the sense is then misled by an erroneous impression, and, accordingly, we make an effort grievously unsuited to the occasion: and yet, so habitually are we protected from this error by the assistance of the sense alluded to, and so little are we conscious of its operation, that it is only after mature reflection that we perceive the necessity of its existence.

In chewing our food, in turning the eyes towards an object looked at, in raising the hand to the mouth, and, in fact, in every variety of muscular movement which we perform, we are guided by the muscular sense in proportioning the effort to the resistance to be overcome; and where this harmony is destroyed by disease, the extent of the service rendered us becomes more apparent. The shake of the arm and hand which we see in drunkards, and their consequent incapability of carrying the morsel directly to the mouth, are examples of what would be of daily occurrence, unless we were directed and assisted by a muscular sense.

Life and the nervous stimulus are essential to muscular power. Separated from the body, and deprived of both, the muscle which formerly contracted with a power equal to 100 pounds would be torn asunder by a weight of ten. This fact is of itself sufficient to give a tolerable notion of the extent to which muscular contraction depends on other causes than the mere structure of the fleshy fibres, for these continue the same after death, or 


\section{EVRS RESULTING FROM INACTIVITY}

after the nervous communication has been suspended, as in recent paralysis; and yet how feeble s the power of resistance which the muscle then possesses!

The required movement having been once effected by the nervous impulse stimulating the muscular fibre to contraction, relaxation speedily follows, and is in its turn succeeded by a fresh contraction proportioned to the object in view. Muscular action, therefore, consists properly in alternate contraction and relaxation of the fleshy fibres. A state of permanent contraction is both unnatural and impossible; and, accordingly, the most fatiguing muscular employment to which a man can be subjected is that of remaining immoveable in any given attitude. To an unreflecting person it may seem a very easy and pleasant service to stand for half a day in the attitude of an Apollo or a gladiator, as a model to a statuary ; but, on trying it, he will find, to his astonishment, that stone-breaking or the tread-mill are pastimes in comparison: in the one case, the muscles which preserve the attitude are kept incessantly on the strain; while in the other, they enjoy that play and variety of motion for which they were destined by nature. We may easily put the fact to the test, by attempting to hold the arm extended at right angles to the body for the short space of ten minutes. He whose muscles, if indeed capable of the exertion, do not feel sore with fatigue at the end of that time, may think himself peculiarly fortunate in being blessed with a powerful constitution.

The principle just stated explains very obviously the weariness, debility, and injury to health which invariably follow forced confinement to one position or to one limited variety of movement, as is often witnessed in the education of young females. Alternate contraction and relaxation, or, in other words, exercise of the muscles which support the trunk of the body, are the only means which, ac: 
cording to the Creator's laws, are conducive to muscular development, and by which bodily strength and vigour can be secured. Instead of promoting such exercise, however, the prevailing system of female education places the muscles of the trunk, in particular, under the worst possible circumstances, and renders their exercise nearly impossible. Left to its own weight, the body would fall to the ground, in obedience to the ordinary law of gravitation: in sitting and standing, therefore, as well as in walking, the position is preserved only by active muscular exertion. But if we confine ourselves to one attitude, such as that of sitting erect upon a chair-or, what is still worse, on benches without backs, as is the common practice in schools, - it is obvious that we place the muscles which support the spine and trunk in the very disadvantageous position of permanent instead of alternate contraction; which we have seen to be in reality more fatiguing and debilitating to them than severe labour. Girls thus restrained daily for many successive hours invariably suffer-being deprived of the sports and exercise after school-hours which strengthen the muscles of boys, and enable them to withstand the oppression. The muscles being thus enfeebled, they either lean over insensibly to one side, and thus contract curvature of the spine; or, their weakness being perceived, they are forthwith cased in stiffer and stronger stays - that support being sought for in steel and whalebone which Nature intended they should obtain from the bones and muscles of their own bodies. The patient, finding the maintenance of an erect carriage (the grand object for which all the suffering is inflicted) thus rendered more easy at first welcomes the stays, and, like her teacher fancies them highly useful. Speedily, however, their effects show them to be the reverse of beneficial. The same want of varied motion, which was the prime cause of the muscular weakness, is still 
further aggravated by the tight pressure of the stays interrupting the play of the muscles, and rendering them in a few months more powerless than ever. In spite, however, of the weariness and mischief which result from it, the same system is persevered in ; and, during the short time allotted to that nominal exercise, the formal walk, the body is left almost as motionless as before, and only the legs are called into activity. The natural consequences of this treatment are, debility of the body, curvature of the spine, impaired digestion, and, from the diminished tone of all the animal and vital functions, general ill health:-and yet, while we thus set Nature and her laws at defiance, we presume to express surprise at the prevalence of female deformity and disease!

It would be easy, were it required, to prove that the picture here drawn is not over-charged. A single instance, from a note appended by Dr. Forbes to an excellent treatise on "Physical Education," by Dr. Barlow of Bath, will suffice. After copying the programme of a boarding-school for young ladies, which exhibits only one hour's excrcise, consisting of a walk, arm in arm, on the high road, and that only when the weather is fine at the particular hour allotted to it, in contrast with nine hours at school or tasks, and three and a half at optional studies or works,-Dr. Forbes adds :- "That the practical results of such an astounding regimen are by no means overdrawn in the preceding pages is sufficiently evinced by the following fact, a fact which, we will venture to say, may be verified by inspection of thousands of boarding-schools in this country. We lately visited in a large town a boardingschool containing forty girls; and we learned on close and accurate inquiry, that there was not one of the girls who had been at the school two years (and the majority had been as long) that were not more or less CRooked: Our patient was in this predicament; and we could perceive (what all may perceive who meet that 
most melancholy of all processions,-a boardingschool of young ladies in their walk) that all her companions were pallid, sallow, and listless. We can assert, on the same authority of personal observation, and on an extensive scale, that scarcely a single girl (more especially of the middle classes) that has been at a boarding-school for two or three years, returns home with unimpaired health; and for the truth of the assertion, we may appeal to every candid father, whose daughters have been placed in this situation."*

Dr. Barlow justly remarks, that the superintendents of such schools cannot generally be blamed for indifference about the welfare of their pupils; that most of them are extremely anxious to do their utmost to improve those under their charge; and that it is ignorance alone which misleads them as to the proper means : he might have adverted also to the ignorance of parents, who insist on so many hours a day being dedicated to the study of accomplishments for which their children have neither taste, capacity, nor use. From similar ignorance, the young girls in a public hospital in this country used to be shut up in the hall and school-room during play-hours, from November till March, and no romping or noise, or, in other words, no real play, relaxation, or exercise allowed; and in 1830-31, from fear of typhus fever, they were seldom, if ever, out of doors, except at church, from November to April-than which a more efficient method of infringing all the laws of health could scarcely have been devised. Here, too, the object was unquestionably benevolent, but the method was radically bad; and, in consequence, a great deal of sickness prevailed.

The sedentary and unvaried occupations which follow each other for hours in succession in many of our schools have also been the cause of needless sufiering to thousands; and it is high time that a

* Cyclopædia of Practical Medicine, article Physical Educetion; vol. i. p. 698. 
sound physiology should step in to root out all such erroneous and hurtful practices. Taken in connexion with the long confinement, the custom of causing the young to sit on benches without any support to the back, and without any variety of motion, cannot be too soon exploded. If the muscles of the spine were strengthened by the exercise which they require, but which is so generally denied,- and if the school employments were varied or interrupted at reasonable intervals, to admit of change of position and of motion,-nothing could be better adapted for giving an easy and erect carriage than seats without backs, because the play of the muscles necessary for preserving the erect position would give them activity and vigour; and, accordingly, the want is scarcely, if at all, felt in infant-schools, for the very reason that such variety of motion is, in them, carefully provided for. But it is a gross misconception to suppose that the same good result will follow the absence of support, when the muscles are weakened by constant straining and want of play. The ineessant and fidgety restlessness observable after the second or third hour of common sehool confinement shows the earnest call of nature for a little wholesome exercise ; and the quiet that ensues when it is granted indicates clearly enough that the restlessness springs even more from bodily than from mental weariness. It is, in fact, a degree of what we all feel when kept long standing on our feet, or sitting at a desk. We become wearied and uneasy from the continued strain on the same muscles, and feei at once relieved by a walk, a drive, or any change whatever. The same principle explains the fatigue so often complained of, as experienced in " shopping," or in an exhibition-room. We saunter about till the muscles become sore from the fatigue of being always in the same attitude, and we are refreshed by a walk or a dance, or any thing which alters the position The same languor of the mus- 
cles is felt after witnessing a pantomime, or other continuous spectacle, by which we are induced to keep the neck for a long time in a constrained and unvaried position.

Instead, therefore, of so many successive hours being devoted to study and to books, the employments of the young ought to be varied and interrupted by proper intervals of cheerful and exhilarating exercise, such as is derived from games of dexterity, which require the co-operation and society of companions. This is infinitely preferable to the solemn processions which are so often substituted for exercise, and which are hurtful, inasmuch as they delude parents and teachers into the notion that they constitute in reality that which they only counterfeit and supersede. We have already seen what an important part the mental stimulus and nervous impulse perform, in exciting, sustaining, and directing muscular activity; and how difficult and inefficient nuscular contraction becomes, when the mind, which directs it, is languid, or absorbed by other employments. The playful gambolling and varied movements which are so characteristic of the young of all animals, mian not excepted, and which are at once so pleasing and so beneficial, show that, to render it beneficial in its fullest extent, nature requires amusement and sprightliness of mind to be combined with, and be the source of, muscular exercise; and that, when deprived of this healthful condition, it is a mere evasion of her law, and is not followed by a tithe of the advantages resulting from its real fulfilment. The buoyancy of spirit and comparative independence enjoyed by boys when out of school prevent them suffering so much from this cause as girls do; but the injury inflicted on both is the more unpardonable, on account of the ease with which it might be entirely avoided

Facts illustrative of the influence of mental, cooperating with and aiding muscular, activity, must 
be familiar to every one; but as the principle on which they depend is not sufficiently attended to, I shall add a few additional remarks.

Everybody knows how wearisome and disagreeable it is to saunter along, without having some object to attain; and how listless and unprofitable a walk taken against the inclination and merely for exercise is, compared to the same exertion made in pursuit of an object on which we are intent. The difference is simply, that, in the former case, the muscles are obliged to work without that full nervous impulse which nature has decreed to be essential to their healthy and energetic action; and that, in the latter, the nervous impulse is in full and harmonious operation. The great superiority of active sports, as a means of exercise, over mere measured movements, is referable to the same principle. Every kind of youthful play interests and excites the mind, as well as occupies the body; and by thus placing the muscles in the best position for wholesome and beneficial exertion, enables them to act without fatigue, for a length of time which, if occupied in mere walking for exercise, would utterly exhaust their powers.

The elastic spring, bright eye, and cheerful glow of beings thus excited form a perfect contrast to the spiritless and inanimate aspect of many of our boarding-school processions; and the results in point of health and activity are not less different. So powerful, indeed, is the nervous stimulus, that examples have occurred of strong mental emotions having instantaneously given life and vigour to paralytic limbs. This has happened in cases of shipwrecks, fires, and sea-fights, and shows how indispensable it is to have the mind engaged and interested along with the muscles. Many a person who feels ready to drop from fatigue, after a merely mechanical walk, would have no difficulty in subse. quently undergoing much continuous exertion in active play or in dancing; and it is absurd, there. 
fore, to say that exercise is not beneficial when in reality proper exercise has not been tried.

The amount of bodily exertion of which soldiers are capable is well known to be prodigiously increased by the mental stimulus of pursuit, of fighting, or of victory. In the retreat of the French from Moscow, for example, when no enemy was near, the soldiers became depressed in courage and enfeebled in body, and nearly sank to the earth through exhaustion and cold; but no sooner did the report of the Russian guns sound in their ears, or the gleam of their bayonets flash in their eyes, than new life seemed to pervade them, and they wielded powerfully the arms which, a few moments before, they could scarcely drag along the ground. No sooner, however, was the enemy repulsed, and the nervous stimulus which animated their muscles withdrawn, than their feebleness returned. Dr. Sparrman, in like manner, after describing the fatigue and exhaustion which he and his party endured in heir travels at the Cape, adds,- " yet, what even now appears to me a matter of wonder is, that as soon as we got a glimpse of the game, all this languor left us in an instant." On the principle already mentioned, this result is perfectly natural, and in strict harmony with what we observe in sportsmen, cricketers, golfers, skaters, and others, who, moved by a mental aim, are able to undergo a much greater amount of bodily labour than men of stronger muscular frames, actuated by no excitement of mind or vigorous nervous impulse. We have heard an intelligent engineer remark the astonishment often felt by country people, at finding him and his town companions, although more slightly made, withstand the fatigues and exposure of a day's surveying better than themselves; but, said he, they overlooked the fact, that our employment gives to the mind as well as to the body a stimulus which they were entirely without, as their only object was to afford us bodily $\mathrm{K} 2$ 
aid, when required, in dragging the chains or carrying our instruments. The conversation of a friend is, in the same way, a powerful alleviator of the fatigue of walking.

The same important principle was implied in the advice which the Spectator tells us was given by a physician to one of the Eastern kings, when he brought him a racket, and told him that the remedy was concealed in the handle, and could act upon him only by passing into the palms of his hands when engaged in playing with it, and that as soon as perspiration was induced, he might desist for the time, as that would be a proof of the medicine being received into the general system. The effect, we are told, was marvellous ; and, looking to the principle just stated, to the cheerful nervous stimulus arising from the confident expectation of a cure, and to the consequent advantages of exercise thus judiciously managed, we have no reason to doubt that the fable is in perfect accordance with nature.

The story of an Englishman who conceived himself so ill as to be unable to stir, but who was prevailed upon by his medical advisers to go down from London to consult an eminent physician at Inverness who did not exist, may serve as another illustration. The stimulus of expecting the means of cure from the northern luminary was sufficient to enable the patient not only to bear, but to reap benefit from, the exertion of making the journey down; and his wrath at finding no such person at Inverness, and perceiving that it was all a trick, sus. tained him in returning, so that on his arrival at home he was nearly cured. Hence also the superiority of battledore and shuttlecock, and similar games, which require society and some menta] stimulus, over mere listless exercise. It is, in fact, a positive misnomer to call a solemn procession exercise. Nature will not be cheated; and the 
healthful results of complete cheerful exertion will never be obtained where the nervous impulse which animates the muscles is denied.

It must not, however, be supposed that a walk simply for the sake of exercise can never be beneficial. If a person be thoroughly satisfied that exercise is requisite, and perfectly willing, or rather desirous, to obey the call which demands it, he is from that very circumstance in a fit state for deriving benefit from it, because the desire then becomes a sufficient nervous impulse, and one in perfect harmony with the muscular action. It is only where a person goes to walk, either from a sense of duty or at the command of another, but against his own inclination, that exercise is com. paratively useless.

The advantages of thus combining harmonious mental excitement with muscular activity have not escaped the sagacity of the late Dr. Armstrong, who thus notices them in his frequently reprinted poem on the Art of Preserving Health, but without giving the physiological explanation:-

In whate'er you sweat

Indulge your taste. Some love the manly toils,

The tennis some, and some the graceful dance;

Others more hardy range the purple heath,

Or naked stubble, where from field to field

The sounding covies urge their lab'ring flight,

Eager amid the rising cloud to pour

The gun's unerring thunder; and there are

Whom still the meed of the green archer charms.

He chuses best whose labour entertains

His vacant fancy most; THE TOIL YOU HATE

Fatigues you soon, AND sCarce improves your limbs.

Book III.

This constitution of Nature, whereby a mental impulse is required to excite and direct muscular action, points to the propriety of teaching the young to observe and examine the qualities and arrangements of external objects. The most pleasing and 
healthful exercise may be thus secured, and every step be made to add to useful knowledge and to individual enjoyment. The botanist, the geologist, and the natural historian experience pleasures in their walks and rambles of which, from disuse of their eyes and observing powers, the multitude is deprived. 'This truth is acted upon by many teachers in Germany. In our own country, too, it is beginning to be felt, and one of the professed objects of infant education is to correct the omission. It must not, however, be supposed that any kind of mental activity will give the necessary stimulus to muscular action, and that, in walking, it will do equally well to read a book or carry on a train of abstract thinking, as to seek the necessary nervous stimulus in picking up plants, Kammering rocks, or engaging in games. This were a great mistake; for in such cases the nervous impulse is opposed rather than favourable to muscular action. Wherever the mind is absorbed in reading or in abstract speculation, the active will to set the muscles in motion must necessarily be proportionally weakened, and the action of the nuscles be reduced to that inanimate kind I have already condemned as almost useless. For true and beneficial exercise, there must be harmony of action between the moving power and the part to be moved. The will and the muscle must be bolh directed to the same end and at the same time, otherwise the effect will be imperfect. The force exerted by strong muscles, animated by strong nervous impulse or will, is prodigiously greater than when the impulse is weak; and as inan was made not to do two things at once, but to direct his whole powers to the one thing he is performing at the time, he has ever excelled most when he followed this law of his nature.

When a physician urges the necessity of exercise, it is very usual for him to be told by persons of an indolent or sedentary habit, that even a short walk 
fatigues them so much as to render them unfit for every thing for some days after, and that they are never so well as when allowed to remain in the house. But if, in perfect reliance on the regularity of the Creator's laws, we seek out the cause of this apparent exception, we shall almost uniformly find, that, instead of beginning with a degree of exertion proportioned to the weakened state of the system, such persons have (under the notion that it was not worth while to go out for a short time) forced their muscles, already weakened by inactivity and confinement, to perform a walk to which only regularly exercised muscles were adequate. The amount of exertion which is always followed by exhaustion is thus, through mere impatience and ignorance, substituted for that lesser degree which always gives strength; and because the former is followed by headache and debility, it is argued that the latter also must be prejudicial! Many sensible people delude themselves by such puerile plausibilities as this ; and it is only by the diffusion of a knowledge of the laws of exercise as part of a useful education that individuals can be enabled to avoid such mistakes.

The effects of exercise upon the organs employed are very remarkable, and useful to be known. When any living part.is called into activity, the processes of waste and renovation, which are incessantly going on in every part of the body, proceed with greater rapidity, and in due proportion to each other. To meet this condition, the vessels and nerves become excited to higher action, and the supply of arterial or nutritive blood and of nervous energy becomes greater. When the active exercise ceases, the excitement thus given to the vital functions subsides, and the vessels and nerves return at length to their original state.

If the exercise be resumed frequently, and at moderate intervals, the increased action of the blood. 
vessels and nerves becomes more permanent, and does not sink to the same low degree as formerly; NUTRITION rather exceeds waste, and the part GaINS consequently in size, vigour, and activity. But if the exercise be resumed too often, or be carried too far, so as to fatigue and exhaust the vital powers of the part, the results become reversed: WASTE then exceeds nutrition, and a Loss of volume and of power takes place, accompanied with a painful sense of weariness, fatigue, and exhaustion. When, on the other hand, exercise is altogether refrained from, the vital functions decay from the want of their requisite stimulus; little blood is sent to the part, and mutrition and strength fail in equal proportion. A limb which has been long in disuse becomes weak and shrivelled from this cause, and its muscles present an unusual paleness and flabbiness, strongly contrasting with the florid redness and rigid fulness of the muscles of a well-exercised limb.

Even sensation gives a faithful notice of these changes, and therefore serves as a guide to exercise. When muscular employment is neglected, the body becomes weak, dull, and unfit for powerful efforts, and all the functions languish. When exercise is taken regularly and in due proportion, a grateful sense of activity and comfort prevails, and we feel ourselves fit for every duty, both mental and bodily. Lastly, when we are subjected to excessive exertion, a painful sense of weariness and exhaustion ensues, which is not relieved by rest, and which for a long time prevents sleep. A person who has greatly over-fatigued himself in walking, for example, is feeble and restless; and, on lying down, either cannot sleep at all, and rises in the morning weak in body and languid in mind, or has uneasy and disturbed sleep till the exhaustion is partially recovered from, after which he may enjoy sound and refreshing repose.

From this exposition of the effects of exercise in 
its difierent stages, it becomes easy to deduce rules applicable to all, for jromoting the healthy development of the musculir system, and to trace the errors by which indolent people are accustomed to maintain that exercise is hurtful to their constitutions. The second slage of exercise, or that in which, by its frequency, moderalion, and regularity. nutrition and vigour are preserved at their highest pitch, is of course to be aimed at; but the quantity of exercise which corresponds to it must vary according to the constitution and previous habits of the individual, as is well exemplified in training for pedestrian feats, for the ring and for racing. The assertion made by many, that exercise hurts them, arises entirely from overlouking this circumstance.

A person accustomed to daily activity will feel invigorated by a walk of four or five miles in the open air; whereas the same distance will weaken another, who has not been in the habit of walking at all. But instead of inferring from this, as is often done, that exercise in the open air is positively hurtful to the latter, reason and experience coincide in telling us, that he has erred only by exceeding the powers of his system, and that to acquire strength and activity, he ought to have begun with one mile, and to have gradually extended his walk in proportion as the muscles became invigorated by the increased nutrition consequent on well-regulated exercise. A person recovering from fever begins by walking across his room perhaps ten times in a day, and gradually extends to twenty or thirty times, till he gains strength to go into the open air. On going out, a walk of ten minutes proves sufficient for him at first, but by degrees his strength and flesh increase, and his exercise is prolonged till he arrives at his usual standard. Such is the order of Nature; but many sedentary people have no patience for such slow progress, and when urged to take exercise, they grudge the trouble of going out 
for a short time, and think that, if a walk of half a mile does them good, one of a whole mile will do more; and when they suffer from the error, they shelter their ignorance under the general assumption that exercise does not agree with them! And the same persons who argue thus would think themselves entitled to laugh at the Irishman who, finding himself relieved by five pills taken at night, inferred that he would necessarily be cured if he took the whole box full at once, and on doing so narrowly escaped with his life.

From these principles it follows, first, that, to be beneficial, exercise ought always to be proportioned to the strength and constitution, and not carried beyond the point, easily discoverable by experience, at which waste begins to succeed nutrition, and exhaustion to take the place of strength : secondly, that it ought to be regularly resumed after a sufficient interval of rest, in order to ensure the permanence of the healthy impulse given to the vital powers of the muscular system: and, lastly, that it is of the utmost consequence to join with it a mental and nervous stimulus. Those who go out only once in four or five days are always at work but never ađváncing; for the increased action induced by the previous exercise has fully subsided long before the succeeding effort is begun: and so far as increased nutrition and greater aptitude for exertion are concerned, no progress whatever is made. 


\section{CHAPTER V.}

Effects of Muscular Exercise on the principal Functions of the Body explained-Shampooing a Substitute for ExerciseEvils of deficient Exercise-Best Time for taking ExerciseAlways to be taken in the open Air-Different KindsWalking-Riding-Dancing-Gymnastics-Fencing-Shut tlecock-Readmg aloud-Case illustrative of the Principles of Exercise-Involuntary Muscles.

WE have seen that exercise is necessary for de. veloping and improving the health of the muscular system ; but it still remains for us to explain how it acts in imparting tone and strength to the rest of the body, and to mention the circumstances by which its employment ought to be regulated.

Man being intended for a life of activity, all his functions are constituted by Nature to fit him for this object, and they never go on so successfully as when his external situation is such as to demand the regular exercise of all his organs. It is, accordingly, curious to observe the admirable manner in which each is linked in its action and sympathies with the rest. When the muscular system, for example, is duly exercised, increased action in its vessels and nerves takes place, as already observed; but the effect is not by any means limited to the mere organs of motion. The principal blood-vessels in all parts of the body lie imbedded among muscles, for both the protection and aid which the latter afford them. Every contraction of the muscles compresses the diameter of the vessels; and as the blood contained in them cannot retrograde in its course, it is propelled in the arteries from the heart towards the ex- 
treme parts, and in the veins from the latter towards the heart, with greater force and velocity than before. This will be better understood on

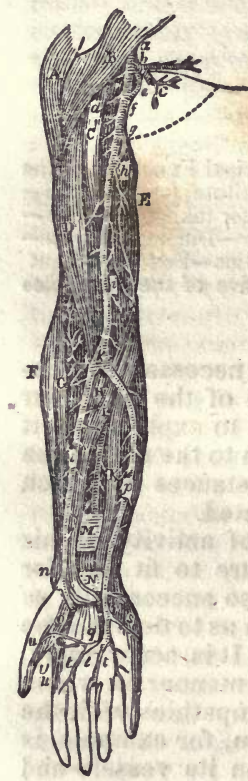
examining the annexed engraving of the blood-vessels of the arm, copied Trom Fyfe's Anatomy. The letters A, B, C, D, E, represent the principal muscles of the arm ; and $\mathrm{F}, \mathrm{G}, \mathrm{H}, \mathrm{I}, \mathrm{K}, \mathrm{M}, \mathrm{N}$, those of the forearm; but as the preparation is dried, and the muscles consequently much shrunk, they do not appear in their natural situation. The letters in italics refer to the humeral artery, which is seen dividing at the elbow into two branches. The one, called the radial artery, passes on the outer side of the forearm towards the thumb, and is the branch in which the pulse is generally felt ; the other, called the ulnar, passes along the inner side of the forearm.

In the natural state, these bloodvessels are covered and protected in almost their whole course by the adjacent muscles. In consequence of this position, the muscles cannot contract without at the same time compressing the blood-vessels, and propelling their contents. The assistance afforded to the circulation of the blood by this arrangement is familiarly exemplified in the operation of bloodletting from the arm. When the blood stops or flows slowly, it is customary to put a ball or other hard body into the hand of the patient, and desire him to squeeze and roll it about. The success of this action depends simply on the muscles of the arm 
compressing the interjacent blood-vessels, and forcing onwards the current of the contained blood by their successive contractions. Muscular action is, indeed, one of the powers provided for effecting a regular circulation. And hence when its assistance is neglected, as it is by those who take no active exercise, the blood begins to flow less freely, till at last it finds some difficulty in returning against the law of gravitation from the depending parts, which then gradually swell. People engaged for years in sedentary professions are thus very subject to varicose or dilated veins and swelled feet.

The chain of connexion among all the living functions is nowhere more visible than in this relation between muscular exercise and the circulation of the blood. Action requires the presence of arterial blood; and in the case of the muscles, the very circumstance of their being active favours the circulation and increases the supply. This increase, in its turn, enables the parts to which it is sent to act with greater energy and effect, aud the augmented action is attended by corresponding waste and exhalation. To replenish the blood thus exhausted of its nutritive principle, a greater quantity of food is required; and, to prompt us to attend to this condition, the appetite becomes keener and more imperative, and the powers of digestion proportionally vigorous. The food taken is more speedily converted into chyle, its absorption from the surface of the intestines and transmission into the circulating current more rapid; and that the blood thus improved may be properly and quickly animalized in the laboratory of the lungs, respiration becomes deeper and more frequent, thus admitting a larger quantity of air and freer circulation through them than before; and the blood, thus renewed and re-endowed with the pabulum of life, imparts fresh nutriment and vigour to all the organs of the body, and fits them for that active exertion which the proper discharge of his 
duties imperatively requires from every member of the human race.

Considered in this point of view, the hurried breathing and quickened circulation, of which we are so apt to complain when engaged in muscular exercise, instead of being evils, are, in fact, the beneficent means by which we become fitted to continue the exertion. Without a more than usually rapid flow of blood to the part in use, the necessary stimulus to its vessels and nerves could not take place, and its action could not be sustained. But were the blood-vessels not so situated among the muscles as to have their contents propelled more quickly by the compression to which every muscular contraction necessarily subjects them, it is obvious that no increase of circulation could take place. And if respiration, on the other hand, were not to become accelerated, so as to oxygenate the venous blood more quickly as it arrived at the lungs, it is obvious, that the requisite stimulus must again have failed, as, in that case, the blood must either have accumulated in the lungs and caused death, or have passed through them imperfectly prepared, and extinguished life more slowly, but not less certainly.

It is from this effect of muscular compression in promoting the flow of blood through the arteries and veins, that shampooing, which consists in a kind of kneading of the flesh, is so successfully resorted to in the warm climates of the East, and among the richer class of invalids in our own country, as a substitute for active exercise. Shampooing furnishes from without that impulse to the circulation which the Creator had destined it to receive from active muscuiar exertion; and the principle of its action being the same, we cannot wonder that it should prove indisputably useful in promoting circulation, strength, and nutrition, in cases where active. exercise cannot be enjoyed.

It is a commori observation, that sedentary persons 
are habitually subject to costiveness and its attendant evils. The reason is the same. In the natural state, the contents of the bowels are propelled partly by the successive contractions of the muscles which form the walls of the belly, and separate that cavity from the chest; and partly by the contraction of the muscular fibres, which constitute an important part of the structure of the intestinal canal. If, however, exercise be refrained from, and the same position be preserved for many hours a day, as in sitting at a desk, the bowels are necessarily deprived of one important source of power; and thus weakened, they are unable to act upon and propel their contents with the same regularity as when assisted by exercise. A slowness of action ensues, which no course of medicine, and scarcely any modification of diet, can overcome, so long as sedentary habits are indulged in; but which also may often be relieved by daily pressing over the region of the abdomen with a kind of kneading motion, imitating, though feebly, the effects of muscular action. Females suffer much from intestinal debility caused by sedentary habits.

The evils arising from deficiency of exercise to all the functions of the nind and body will now be equally evident and intelligible, for they are the converse of what we have seen to be the advantages of adequate exercise. The circulation, from want of stimulus, becomes languid, especially in the extreme vessels; the feebleness of action occasions little waste of materials; the appetite and digestion consequently become weak ; respiration heavy and imperfect; and the blood so ill-conditioned, that, when dist ributed through the body, it proves inadequate to communicate the stimulus requisite for healthy and vigorous action. The concatenation of causes and consequences thus exhibited cannot fail, when the principle connecting them is perceived, to interest and instruct every thinking mind.

The time at which exercise ought to be taken is L 2 
of some consequence in obtaining from it beneficial results. Those who are in perfect health may engage in it at almost any hour, except immediately after a full meal; but those who are not robust ought to confine their hours of exercise within narrower limits. To a person in full vigour, a good walk in the country before breakfast may be highly beneficial and exhilarating; while, to an invalid or delicate person, it will prove more detrimental than useful, and will induce a sense of weariness, which will spoil the pleasure of the whole day. Many are deceived by the current poetical praises of the freshness of morning, and hurt themselves in summer by seeking health in untimely promenades.

In order to be beneficial, exercise must be resorted to only when the system is sufficiently vigorous to be able to meet it. This is the case after a lapse of from two to four or five hours after a moderate meal, and, consequently, the forenoon is the best time. If exercise be delayed till some degree of exhaustion from the want of food has occurred, it speedily dissipates instead of increases the strength which remains, and impairs instead of promotes digestion. The result is quite natural ; for exercise of every kind causes increased action and waste in the organ; and if there be not materials and vigour enough in the general system to keep up that action and supply the waste, nothing but increased debility can reasonably be expected.

For the same reason, exercise immediately before meals, unless of a very gentle description, is injurious, and an interval of rest ought always to intervene. Muscular action causes an afflux of blood and nervous energy to the surface and extremities, and if food be swallowed whenever the activity ceases, and before time has been allowed for a different distribution of the vital powers to take place, the stomach is taken at disadvantage, and, from want of the necessary action in its vessels and nerves, is 
unable to carry on digestion with success. This is very obviously the case where the exercise has been severe or protracted, and the consequence is so well known, that it is an invariable rule in the management of horses, never to feed them immediately after work, but always to allow them an interval of rest proportioned to the previous labour. Even instinct would lead to this conduct, for appetite revives after repose.

Exercise ought to be equally avoided immediately after a heavy meal. In such circumstances, the functions of the digestive organs are in their highest state of activity; and if the muscular system be then called into considerable action, the withdrawal of the vital stimuli of the blood and nervous influence from the stomach to the extremities is sufficient almost to stop the digestive process. This is no supposition, but demonstrated fact; and accordingly, there is a natural and marked aversion to active pursuits after a full meal. In a dog, which had hunted for an hour or two directly after eating, digestion was found on dissection to have scarcely begun; while in another dog, fed at the same time, and left at home, digestion was nearly completed.

A mere stroll, which requires no exertion, and does not fatigue, will not be injurious before or after eating; but exercise beyond this limit is hurtful at such times. All, therefore, whose object is to improve or preserve health, and whose occupations are in their own power, ought to arrange these, so as to observe faithfully this important law, for they will otherwise deprive themselves of most of the benefits resulting from exercise.

When we know that we shall be forced to exertion soon after eating, we ought to make a very moderate meal, to avoid setting the stomach and muscles at variance with each other, and exciting feverish disturbance. In travelling by a stage-coach, where no repose is allowed, this precaution is invaluable. If 
we eat heartily as appetite suggests, and then enter the coach, restlessness, flushing, and fatigue are inevitable; whereas, by eating sparingly, the journey may be continued for two or three days and nights, with less weariness than is felt during one-fourth of the time under full feeding. I observed this when traivelling as an invalid on rather low diet, and was surprised to find myself less fatigued at the end of seventy-two hours than I had previously been when in health and living fully, with half the journey ; and 1 have heard the same remark made by others, also from experience.

It is the custom in many families and schools, apparently for the purpose of saving time, to take young people out to walk about the close of the day, because there is not light enough to do any thing in the house. Nothing can be more injudicious than this plan, for, in the first place, exercise once a day is very insufficient for the young, and even supposing that it were enough, the air is then more loaded with moisture, colder, and proportionably more unhealthy than at any other time; and the absence of the beneficial stimulus of the solar light diminishes not a little its invigorating influence. For those, consequently, who are so little out of doors as the inmates of boarding-schools and children living in towns, and who are all at the period of growth, the very best times of the day ought to be chosen for exercise, particularly as in-door occupations are, after nightfall, more in accordance with the order of nature.

By devoting part of the forenoon also to exercise, another obvious advantage is gained. If the weather prove unfavourable at an early hour, it may clear up in time to admit of going out later in the day: whereas, if the afternoon alone be allotted to exercise, and the weather proves bad, the day is altogether lost. In winter, indeed, it is not unusual for girls to be thus confined from Sunday to Sunday, 
simply because the weather is rainy at the regular hour of going out. When the muscular system is duly exercised in the open air early in the day, the power of mental application is considerably increased; while, by delaying till late, the efficiency of the whole previous mental labour is diminished by the restless craving for motion which is evinced by the young of all animals; and which, when unsatisfied, distracts attention, and leads to idleness in school. It would be well to copy in this respect the practice adopted in the infant-schools, where the children are turned out to play for a few minutes, as soon as the wandering of mind and restlessness of body indicate that the one has been too much and the other too little exerted. After such an interval, work goes on briskly again, and every one is alive.

To render exercise as beneficial as possible, particularly in educating the young, it ought always to be taken in the open air, and to be of a nature to occupy the mind as well as the body. Social play and active sports of every kind, cricket, bowls, shuttlecock, the ball, archery, quoits, hide-and-seek, and similar recreations well-known to the young, are infinitely preferable to regular and unmeaning walks, and tend in a much higher degree to develop and strengthen the bodily frame, and to secure a straight spine and an erect and firm but easy and graceful carriage. A formal walk is odious and useless to many girls, who would be delighted and benefited by spending two or three hours a day in spirited exercise.

Let those mothers who are afraid to trust to Nature for strengthening and developing the limbs and spines of their daughters attend to FACTs, and their fears will vanish. It is notorious that a majority of those girls who, in opposition to the laws of nature, are encased in stays, and get insufficient exercise, become deformed; an occurrence which is, on the other hand, comparatively rare in boys, 
who are left, in conformity with the designs of nature, to acquire strength and symmetry from free and unrestricted muscular action. In a seminary for young ladies, for example, containing forty pupils, it was discovered on examination, by Dr. Forbes, that only two out of those who had been resident in it for two years had straight spines; while out of an equal number of boys, imperfect as their exercise often is, it would be difficult to discover as many whose spines were not straight. Here, then, is ample proof that stays and absence of exercise, so far from contributing to an elegant carriage, are directly opposed to its acquisition; and that the absence of stays and indulgence in exercise, even when not carried so far as the wants of the system require, so far from being hurtful to the spine, contribute powerfully to its strength and security. Yet such is the dominion of prejudice and habit, that, with these results meeting our observation in every quarter, we continue to make as great a distinction in the physical education of the two sexes in early life, as if they belonged to different orders of beings, and were constructed on such opposite principles, that what was to benefit the one must necessarily hurt the other.

Different kinds of exercise suit different constitutions. The object, of course, is to employ all the muscles of the body, and to strengthen those especially which are too weak; and hence, exercise ought to be often varied, and always adapted to the peculiarities of individuals. Speaking generally, walking agrees well with everybody, but as it exercises chiefly the lower limbs and the muscles of the loins, and affords little scope for the play of the arms and muscles of the chest, it is insufficient of itself to constitute adequate exercise; and hence the advantage of combining with it movements performed by the upper half of the body, as in many 
useful sports, and in fishing. Such exercises have the additional advantage of animating the mind, and, by increasing the nervous stimulus, making exertion easy, pleasant, and invigorating.

Pedestrian excursions, in pursuit of mineralogical or botanical specimens, or in search of scenery, combine in their results all the advantages which well-conducted exercise is capable of yielding, and are much resorted to in the German seminaries, for the purpose of developing the mental and bodily powers. In summer, walking excursions to the Highlands of Scotland are common among the youth of our cities, and when proportioned in extent to the constitutions and previous habits of the individuals, nothing can be more advantageous and delightful. But not a season passes in which health is not sacrificed and life lost by young men imprudently exceeding their natural powers, and undertaking journeys and excursions for which they are totally unfitted. It is no unusual thing for youths still weak from rapid growth, and perhaps accustomed to the desk, to set out in high spirits at the rate of twenty-five or thirty miles a day, on a walking excursion, and (in consequence of carrying exercise, for days in succession, to the third degree, or that in which waste exceeds nutrition) to come home so much worn out and debilitated that they never recover. Young soldiers, whose growth is scarcely finished, are well known to die in great numbers, when exposed to long and heavy marches, particularly when food is at the same time scanty. Even a single day of excessive fatigue will sometimes suffice to produce permanent bad health; and I know one instance of a strong young man, who brought on a severe illness and permanent debility, by a sudden return to hard exercise for a single day, although some years before he had been accustomed to every species of muscular exertion in running, leaping, and swimming. Many voung men 
hurry on the premature development of consumption by excessive fatigue during the shooting season, in cases where, by prudent management, they might have escaped it for years, if not altogether. The principle already laid down, of not exceeding the point at which exercise promotes nutrition and increases strength, will serve as a safe guide on all occasions, and indicate the rate at which it may be extended. Old sportsmen know the rule by expe. rience, and generally prepare themselves for the moors by several weeks of previous training.

Since writing the preceding remarks, I have been made acquainted by a friend with a melancholy but instructive proof of their general accuracy. He says, "A young gentleman, whom I knew, was employed as a clerk in one of the banks in Edin. burgh. He was closely confined to his desk during the summer, and, towards the end of July, had become weak and emaciated, from deficient exercise in the open air. His strength continued to decline till Friday the 12th of August, when he went to shoot on Falkirk Moor. On Friday and Saturday he was much fatigued by excessive and unusual exertion, and on Sunday evening was feverish and heated, and perspired very much during the night. In this condition he rose about three or four o'clock on Monday morning, and returned to Edinburgh on the top of a coach. When he reached home he felt very unwell, but went to the bank. At two o'clock he became so sick as to be unable to sit at his desk. He was then bled by a medical gentleman, but without much effect; and after passing three months in a feverish and sleepless condition, he died in the beginning of November. He was previously of a healthy constitution." It is more than probable that this young man's life became a sacrifice to his ignorance of the structure and functions of the human body.

Riding is a most salubrious exercise, and, where 
the lings are weak, possesses a great advantage over walking; as it does not hurry the breathing. It calls into more equal play all the muscles of the body, and at the same time engages the mind in the management of the animal, and exhilarates by the free contact of the air and more rapid change of scene. Even at a walking pace, a gentle but universal and constant action of the muscles is required to preserve the seat, and adapt the rider's position to the movements of the horse; and this kind of muscular action is extremely favourable to the proper and equal circulation of the blood through the extreme vessels, and to the prevention of its undue accumulation in the central organs. The gentleness of the action admits of its being kept up without accelerating respiration, and enables a delicate person to reap the combined advantages of the open air and proper exercise, for a much longer period than would otherwise be possible.

From the tendency of riding to equalize the circulation, stimulate the skin, and promote the action of the bowels, it is also excellently adapted as an exercise for dyspeptic and nervous invalids.

Dancing is a cheerful and useful exercise, but has the disadvantage of being used within doors, in confined air, often in dusty rooms, and at most unseasonable hours. Practised in the open air, and in the day-time, as is common in France, dancing is certainly an invigorating pastime; but in heated rooms and at late hours it is the reverse, and often does more harm than good.

Gymnastic and callisthenic exercises have been in vogue for some years, for the purpose of promoting muscular and general growth and strength, but they are now rather sinking in public estimation; entirely, I believe, from overlooking the necessity of adapting the kind and extent of them to the individual constitution; the consequence of which has been, that some of the more weakly pupils have M 
been injured by exertions beyond their strength, and discredit has thus been brought upon the system. It is certain, indeed, that many of the common gymnastic exercises are fit only for robust and healthy boys, and not at all for improving those who are delicately constituted, and who stand most in need of a well-planned training. It is impossible to enter minutely into this subject at present, but again the general principle comes to our assistance;viz. carefully to avoid great fatigue, and always to adapt the kind, degree, and duration of every gymnastic exercise, so as to produce the desired results of increased nutrition and strength; and to remember that the point at which these results are to be obtained is not the same in any two individuals, and can be discovered only by experience and careful observation.

For giving strength to the chest, fencing is a good exercise for boys, but the above limit ought never to be exceeded, as it often is, by measuring the length of a lesson by the hour-hand of a clock, instead of its effects on the constitution. Shuttlecock, as an exercise which calls into play the muscles of the chest, trunk, and arms, is also very beneficial, and would be still more so were it transferred to the open air. After a little practice, it can be played with the left as easily as with the right hand, and is, therefore, very useful in preventing curvature, and giving vigour to the spine in females. The play called the graces is also well adapted for expanding the chest, and giving strength to the muscles of the back, and has the advantage of being practicable in the open air.

Dumb-bells are less in repute than they were some years ago, but when they are not too heavy, and the various movements gone through are not too eccentric or difficult, they are very useful. They do harm occasionally, from their weight being disproportioned to the weak frames which use them; in 
which case they pull down the shoulders by dint of mere dragging. When this or any other exercise is resorted to in the house, the windows ought to be thrown open, so as to make the nearest possible approich to the external air.

Reading aloud and recitation are more useful and invigorating muscular exercises than is generally imagined, at least when managed with due regard to the natural powers of the individual, so as to avoid effort and fatigue. Both require the varied activity of most of the muscles of the trunk to a degree of which few are conscious, till their attention is turned to it. In forming and undulating the voice, not only the chest but also the diaphragm and abdominal muscles are in constant action, and communicate to the stomach and bowels a healthy and agreeable stimulus; and, consequently, where the voice is raised and elocution rapid, as in many kinds of public speaking, the muscular effort comes to be -ven more fatiguing than the mental, especially to nose who are unaccustomed to it, and hence the ropious perspiration and bodily exhaustion of popuar orators and preachers. When care is taken, sowever, not to carry reading aloud or reciting so far at one time as to excite the least sensation of soreness or fatigue in the chest, and it is duly repeated, it is extremely useful in developing and giving tone to the organs of respiration, and to the general system. To the invigorating effects of this kind of exercise, the celebrated and lamented $\mathrm{Cu}$ vier was in the habit of ascribing his own exemption from consumption, to which, at the time of his appointment to a professorship, it was believed he would otherwise have fallen a sacrifice. The exercise of lecturing gradually strengthened his lungs, and improved his health so much that he was never afterward threatened with any serious pulmonary disease. But, of course, this happy result followed only because the exertion of lecturing was not too 
great for the then existing condition of his lungs. Had the delicacy of which he complained been further advanced, the fatigue of lecturing would only have accelerated his fate, and this must never be lost sight of in practically applying the rules of exercise.

It appears, then, from the foregoing remarks, that the most perfect of all exercises are those sports which combine free play of all the muscles of the body, mental excitement, and the unrestrained use of the voice; and to such sports, accordingly, are the young so instinctively addicted, that nothing but the strictest vigilance and fear of punishment can deter them from engaging in them the moment the restraint of school is at an end. Many parents, absorbed in their own pursuits, forgetful of their own former experience, and ignorant that such are the benevolent dictates of Nature, abhor these wholesome outpourings of the juvenile voice, and lay restrictions upon their children, which, by preventing the full development of the lungs and muscles, inflict permanent injury upon them in the very point where in this climate parents are most anxious to protect them. In accordance with this, we find that what are called wild romping boys or girls, or those who break through all such restrictions, often turn out the strongest and healthiest; while those who submit generally become more delicate as they grow older.

Enough has, I trust, been said to enable any rational parent or teacher to determine the fitness of the different kinds of muscular exercise, and to adapt the time, manner, and degree of each to every individual under his care : but before taking leave of the subject, and with a view to impress the more deeply upon the mind of the reader the practical importance of the principles inculcated in the preceding pages, I cannot refrain from subjoining a case which affords an extremely apposite illustration of almost every 
one of them. The particulars were furnished to me by a young friend who was allowed to peruse the manuscript of these pages, and who, as himself the subject of the case, was struck with the perfect ac. cordance between his own experience and the doctrines here expounded. It is proper to keep in view that at the time of this experiment, my friend was about seventeen years of age, and growing rapidly.

After having passed the winter, closely engaged in a sedentary profession, and unaccustomed to much exercise, he was induced by the beauty of returning spring to dedicate a day to seeking enjoyment in a country excursion; and for that purpose set off one morning in the month of May, without previous preparation, to walk to Haddington by way of North Berwick,-a distance of thirty-four miles. Being at the time entirely unacquainted with physiology, he was not aware that the power of exerting the muscles depended in any degree upon the previous mode of life, but thought that if a man was once able to walk thirty miles, he must necessarily continue to possess the same power, under all circumstances, while youth and health remained. The nervous stimulus arising from his escape from the desk, and from the expected delights of the excursion, carried him briskly and pleasantly over the ground for the first twelve miles, but then naturally began to decrease. Unfortunately the next part of the road lay through a dull, monotonous and sandy tract, presenting no object of interest to the mind, and no variety of any description; so that the mental stimulus, already greatly impaired in intensity, became still weaker. Being alone, his intellect and feelings could not be excited by the pleasures of companionship and conversation: weariness consequently increased at every step; and long before his arrival at North Berwick (twenty-five miles), " every vestige of enjoyment had disappeared, time seemed to move at a marvellous tardy pace. and every mile appeared doubled inlength. M 2 
Not being aware that excessive exercise without a succeeding period of repose is equally unfavourable to sleep and digestion, and having a lively recollection of the pleasures and refreshment consequent upon eating a good dinner with an appetite whetted by a proper degree of bodily labour in the open air, he looked forward with confidence to some recompense and consolation for his toils when dinner should make its appearance. In this, however, he was doubly disappointed; for from having started with too light a breakfast, and walked so far, his digestive organs were, in common with every part of his system, so much impaired, that he looked upon the viands placed before him almost without appetite; and as they were in themselves not remarkably nutritive or digestible, he infringed still further that condition of muscular action which consists in a full supply of nourishing arterial blood, made from plenty of nutritious food, - a condition which I have stated to be especially important in youth and during growth.

After a rest of two hours, and taking a moderate allowance of wine, which, however, he says, "seemed to have lost its ancient virtue of imparting cheerfulness to the human heart," he set out to complete the remaining ten miles to Haddington. The country was far more beautiful and varied, but the charms of nature had, by this time, lost all attractions, for our pedestrian was "now wholly occupied in counting the tedious miles yet to be traversed, and in making a pious vow that this pleasure-excursion, though not the first, should certainly be the last in his life." Being reduced to the utmost degree of exhaustion, it required an extraordinary effort to persevere; but at last he arrived at Haddington, in a state of exquisite misery. Unable to read from fatigue, and having nobody to converse with, he sought refuge in bed at an early hour, in the expectation that "tired Nature's sweet restorer, balmy sleep," would visit 
his such and bring him relief. But in accordance wid I what is mentioned on page 118 , he tossed and tun.t ed incessantly till four in the morning, a period of se ren hours, after which sleep came on. Next day $n_{1} y$ youthful friend returned home in the stagecoach, wiser, at least, if not the happier, for his pleasure-excursion; and now makes the observation, that if he had been instructed in the least degree in the nature of the human constitution, he would never for a moment have entertained an expectation of enjoyment from a proceeding so utterly in defiance of all the laws of exercise, as that of which he reaped the unpalatable fruits. He adds justly, that the number of young men who suffer in a similar way is by no means small, and that he has reason to be thankful that he has not, like some of his companions, carried his transgression so far as permanently to injure health, or even sacrifice life.

My aim being practical utility, I have said nothing in this place on the subject of what are called the Involuntary Muscles, or those over which the will has no power, in contradistinction to the Voluntary, or those which obey the direction of the will. Most of the involuntary muscles are the agents of important vital functions, which are carried on by them unconsciously to ourselves, and which it would have been dangerous to leave under our control. The chief of them is the heart, which goes on in one unvarying round of alternate contraction and relaxation from the commencement till the termination of existence. The next in importance are those connected with respiration, which, like the heart, continue to act by night and by day for the whole period of a long life without weariness and without interruption. The muscular fibres of the stomach, bowels, bladder, and other viscera are excellent examples of the same class; and the beneficence of Providence in withdrawing them from our control cannot be sufficiently admired.-Had the action of 
the heart and respiratory muscles depended on the will, as that of the muscles of locomotion do, the circulation of the blood and the process of breathing would both have ceased whenever sleep or any other cause overcame the power of attention, and life would in consequence have been extinguished.

From the different constitution of the voluntary and involuntary muscles, it is clear that the former were designed for alternate activity and repose. Had it so pleased the Creator, He could as easily have rendered the one set of muscles incapable of fatigue, as he has actually rendered the other; but then the powers of man would not have been in harmony with the purpose of his existence. Incessant muscular activity would not only have been incompatible with the highest human enjoyment,that arising from the gratification of the moral and intellectual faculties,-but it would have lacked objects on which to expend itself usefully, and, unguided by intellect, would only have served to overturn and destroy the best provisions of nature for our happiness,

\section{CHAPTER VI.}

The Bones essential to Motion, and to the Security of the Vital - Organs-The Skeleton-Bones are composed of Animal and of Earthy Matter-The Animal Part the Seat of their Vitality -The Proportions between these vary at different Periods of Life-Vessels, Nerves, Life, Growth, and Decay of BonesAdvantages of their Vitality and Insensibility - Their Adaptation to contained Parts-Conditions of Health-Necessity of Exercise.

THe hardness, strength, and insensibility which form the distinguishing properties of healthy bones fit them in a remarkable degree for serving as a basis 
of support to the softer and more active textures of the body. By their means, the human frame is enabled to unite the most finished symmetry of form with the most perfect freedom of motion and security to life.

Some of the bones, such as those which compose the scull and the socket for the eye, are designed exclusively for the protection of important organs contained within then. But by far the greater number are constructed with a direct reference to voluntary motion, and only incidentally serve for the purposes of protection.

In proportion to the variety of movements which any piece of mechanism is required to perform, its component parts must be numerous and varied.

Considered in this light, the animal frame is the most wonderful of all combinations of machinery. No production of art can be compared with it for the multiplicity and nicety of-its evolutions, and yet all these are executed simply by muscular power, acting upon the bones, and changing their relative positions.

The incalculable variety of movements required from man is the reason why the bones composing the skeleton are so numerous, and each so admirably connected with the others by articulations, constructed so as to admit of precisely that kind of motion which the animal requires from it, and of no other. The advantages of this arrangement are not less obvious than admirable. Had the osseous framework consisted of one entire piece, not only would man and animals have been incapable of motion, but every external shock would have been communicated undiminished to the whole system: whereas, by the division of its parts, and by the interposition of the elastic cartilages and ligaments constituting the joints, free and extensive motion is secured, and the impetus of every external shock is deadened in its force, and diffused over the body, in 
the same way as to a person riding in a carriage, the jolt of the wheel passing over a stone, is diminished by being diffused over the whole vehicle, in consequence of the elasticity of the springs. The safety inparted by this arrangement to the delicate and important vital organs is apt to be lost sight of, from the very smoothness with which it enables us to move along; but it will be perceived if we reflect on the shock given to the whole system by taking a single false step in going up or down a stair. The parts have then no time to adapt themselves to the exigencies of the moment, and to put the proper springs in play for the equal distribution of the impetus. Death has been occasioned by accidents of this kind.

The fabric resulting from the connexion of all these pieces in their natural order of arrangement is called the Skeleton. When the connexion is maintained by means of the ligaments which bound the pieces together during life, the whole is called a natural skeleton; but if the place of the ligaments be supplied by wires, the skeleton is then said to be artificial. The bones entering into the composition of the human skeleton exceed 200 in number. Each is separate from, but intimately connected with, the rest ; and of a shape, size, and construction in exact harmony with the kind and extent of motion which it is destined to exercise. Dry and uninviting as such a subject may seem at first sight, there are found, nevertheless, on closer examination, many points of inquiry both interesting and instructive, to which I shall briefly advert.

The three great divisions of the skeleton recognised by anatomists are, the head, trunk, and extremities. The first is well known; the second includes the two great cavities, the thorax or chest, and the abdomen or belly; and the third comprises the arms and legs, or upper and lower extremities.

Fach of these presents a structure beautifully 
adapted to the purposes for which it is destined The head consists of the scull and bones of the face. The scull affords complete protection to the brain

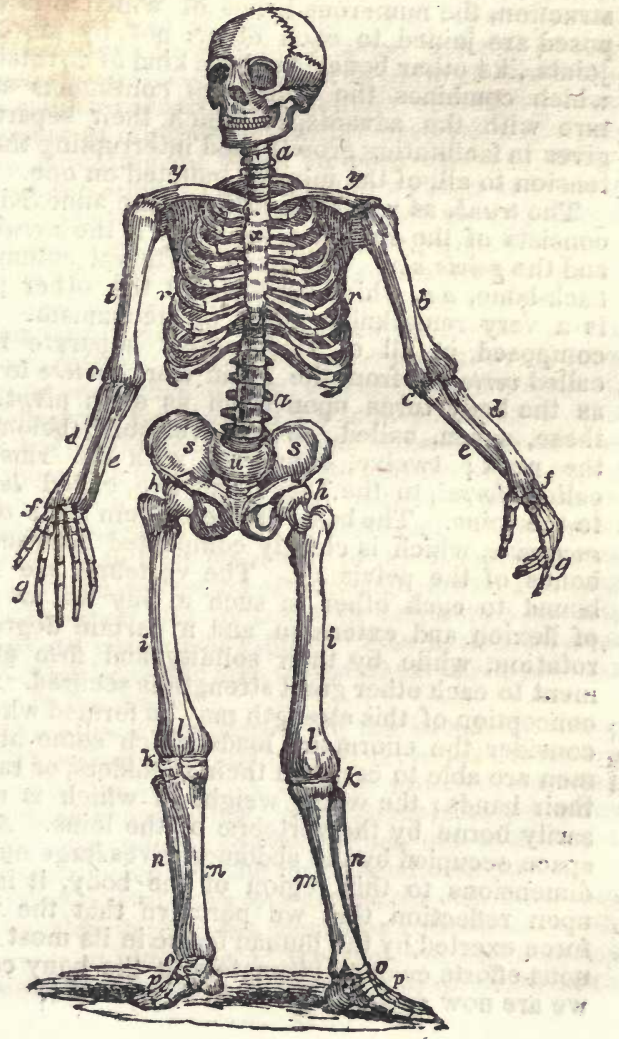


from all ordinary accidents, and also to the organs of hearing, seeing, smelling, and tasting. Protection and not motion being the sole object of its construction, the numerous bones of which it is composed are joined to each other, not by moveable joints s.ke other bones, but by a kind of dovetailing, which combines the solidity of continuous structure with the advantages which their separation gives in facilitating growth, and interrupting the extension to all, of the injuries inflicted on one.

The trunk, as will be seen from the aunexed cut, consists of the spine a a, the ribs $r$, the sternum $x$, and the pelvis $s$ s. The spine, vertebral column, or back-bone, $a$, which supports all the other parts, is a very remarkable piece of mechanism. It is composed in all of twenty-four separate bones called vertebra, from the Latin word vertere to turn, as the body turns upon them as on a pivot. Of these, seven, called cervical vertehræ, belong to the neck; twelve, connected with the ribs and called dorsal, to the back ; and five, called lumbar, to the loins. The base of the column rests on the sacrum $u$, which is closely compacted between the bones of the pelvis $s s$. The vertebræ are firmly bound to each other in such a way as to admit of flexion and extension and a certain degree of rotation, while by their solidity and firm attachment to each other great strength is secured. Some conception of this strength may be formed when we consider the enormous loads which some athletic men are able to carry on their shoulders, or raise in their hands; the whole weight of which is necessarily borne by the vertebræ of the loins. As the space occupied by the abdomen gives large outward dimensions to this region of the body, it is only upon reflection that we perceive that the whole force exerted by the human frame in its most strenuous efforts centres ultimately in the bony column we are now examining 
While the smooth or rounded forepart or body of the vertebræ affords support to the superincumbent parts, the projecting ridge behind, and rugged processes at the sides, combine with it to form a large tube or canal, extending from the top to the bottom of the column in which the spinal marrow is contained and protected. Between each of the vertebræ a thick compressible cushion of cartilage and ligament is interposed, which serves the triple purpose of uniting the bones to each other, of diminishing and diffusing the shock in walking or leaping, and of admitting a greater extent of motion than if the bones were in more immediate contact.

The ribs $r r$, twelve in number on each side, are attached by their heads to the spine, and by their other (cartilaginous) extremities to the sternum or breast-bone $x$. The seven uppermost are called true ribs, because each of them is connected directly with the sternum, by means of a separate cartilage. The five lower ribs are called false, because one or two of them are loose at one end, and the cartilages of the rest run into each other instead of being separately prolonged to the breast-bone. The use of the ribs is to form the cavity of the chest for the reception and protection of the lungs, heart, and great blood-vessels, and to assist in respiration by their alternate rising and falling. This action enlarges and diminishes the size of the chest and the capacity of the lungs.

The pelvis $s \boldsymbol{s}$ is formed by the broad flat bones which support the bowels and serve for the articulation of the thigh. A general notion of their appearance and uses may be obtained from inspection of the cut, which, however, does not with perfect accuracy represent the more minute structure.

The bones of the upper extremities are, the scapula or shoulder-blade; the clavicle or collar-bone $y$; the humerus or arm-bone $b$; the radius $d$, and ulna $e$, or bones of the forearm; and the small carpal and meta- 
carpal bones $f$ and phalanges $g$, forming the wrist, hand, and fingers.

The scapula is the broad flat bone lying at the upper part of the back, familiarly known as the shoulder-blade, and so troublesome to many young ladies by its unseemly projection. It serves to connect the arm with the trunk of the body, and gives origin to many of the muscles by which the former is put in motion. The collar-bone $y$ extends from the breast-bone outwards to the scapula. Its chief use is to prevent the arms from falling forward in front of the body ; and hence it is wanting in the lower animals, whose superior extremities are much closer to each other than those of man.

The humerus or arm-bone $b$ is adapted by a kind of ball and socket joint to a corresponding surface in the scapula, and hence enjoys great latitude of motion, and is somewhat liable to dislocation. The radius and $u l n a d e$, constituting the forearm, are connected with the humerus by a hinge-like joint, which admits readily of flexion and extension, but not of rotation ; and as the articulation is of a peculiar construction, it is rarely dislocated. The movements of pronation and supination, or turning round the hand, are effected, not by the elbow-joint, but by the radius $d$ moving upon the ulna $e$, by means of joints formed for this purpose. The wrist and finger joints are too complicated to admit of explanation here.

The lower extremities consist of the os femoris or thigh-bone $i$, the patella or knee-pan $l$, the tioia $m$ and fibula n, or leg bones; and the tarsal and metatarsal bones $o$, and phalanges $p$, composing the ankle, foot, and toes.

The thigh-bone $i$ is articulated by means of a large round head deeply sunk into a corresponding hollow in the pelvis at $h$, freedom of motion being thus combined with great security. The thigh may be moved backwards and forwards as in walking; and 
also outwards and inwards, as when sitting on horseback or with the legs crossed. The socket being much deeper than that of the shoulder-joint, the thigh-bone has not the same range of motion as the humerus, but it has proportionally greater security.

The patella or knee-pan $l$ is well known. It is a small bone, constituting the projection of the knee. It increases the power of the muscles which extend the leg, and protects the front of the knee-joint. The $t: b i a m$ is the principal bone of the leg, and is the only one articulated with that of the thigh. Its lower end forms the projection at the inner ankle. The fibula $n$ is the long slender bone at the outer side of the leg, the lower end of which forms the outer ankle. The tibia and fibula both contribute to the formation of the ankle-joint, which, like that of the knee, is almost limited to flexion and extension.

The tarsal bones constituting the foot display an admirable mechanism, but without plates any description of them would be unintelligible. My present aim being practical utility, I shall therefore pass over these details, and rather lay before the reader several considerations of a more general and directly useful nature.

Bones consist of two kinds of substances, viz. those of an animal and those of an earthy nature. To the former belongs every thing connected with the life and growth of bones, and to the latter the hardness and power of resistance by which they are characterized.

The animal portion of bones constitutes, according to the analysis of Berzelius, about 32.17 per cent. of their substance, and consists chiefiy of albumen, gelatine, cellular membrane, blood-vessels, nerves, and absorbents. Of the remaining 67 per cent. of earthy matter, nearly 52 parts consist of phosphate, and 11 of carbonate, of lime. The relative proportions of the animal and earthy constituents vary, 
however, according to the period of life. In infancy, the animal portion greatly predominates, and consequently the bones are at that age comparatively soft, yielding, and elastic. In middle life, the proportions are more equally balanced, and while the bones thereby acquire great hardness and solidity, they still preserve some elasticity. In old age, on the contrary, when the earthy constituents predominate, they become dry, brittle, and comparatively lifeless.

If a bone be subjected for a time to the action of muriatic acid, the earthy portion is gradually decomposed, and a cartilaginous-looking substance of the exact shape and size of the bone is procured, which is in reality its animal constituent. If, on the other hand, the bone be subjected to the action of fire, which decompases and dissipates the animal elements but scarcely affects the earths, a white, light, easily crumbled mass, of the exact shape and appearance of the original bone, is procured, which is simply the earthy part of bone, deprived of its connecting membrane. The latter is called the an. imal constituent of the bone, because it is the product of animal life, and does not exist in nature, except in the system of animals; and the former is called the earthy constituent, because it may and does exist in nature, without relation to life.

A very important purpose is served by the different proportions which the animal elements of bone bear to the earthy, at different ages. In early youth, when much strength is not wanted, as the body is never exposed to severe efforts, but when a great growth of bone is required to complete the development of the human frame, the animal or living part of the bone is observed to preponderate. But in middle life, when growth is finished, and the powers of resistance are at their maximum, and when nutrition is required only to repair waste, a larger proportion of the solid or earthy, and a smaller propor. 
tion of the vital constituents, becomes necessary In old age, again, when the wants of the system are reversed, and when positive diminution of existing masses is required to put the frame into harmony with the shrunk muscles and feebler powers of life, the absorbent vessels carry away more of the vital matter, leaving chiefly the earth, which, being less susceptible of change, requires scarcely any support from within; and hence the brittle and compact hardness of the bones, and their little capability of uniting when fracture happens at an advanced period of life.

At birth many of the bones are, properly speaking, of a cartilaginous nature. As ossification advances, the cartilage is removed by the absorbents, and its place supplied by a kind of cellular membrane, in the interstices of which the earthy particles are deposited; the two forming, by their union, the homogeneous whole called Bone. Although, therefore, it is to the softer material alone that vital properties essentially belong, it is usual to speak of the life, the vessels, and the nerves of bones, as if life belonged equally to the earthy and animal portions. This is correct enough in reality, because the union between the earthy and animal tissues is always the product of life; and the parts thus united are, to all intents and purposes, living parts.

To carry on the processes of waste and renovation, by which every living structure is distinguished, all parts of the body are provided, first, with arteries, conveying to them red or nutritive blood; secondly, with exhalants, by which the new matter is deposited, and which are believed to be the minute terminations of the arteries; thirdly, with veins by which the blood is carried back to the heart; fourthly, with absorbent vessels, which take up and carry away the waste particles to be thrown out of the system; and, lastly, with nerves to supply all these vessels. and the organs on which thev are dis- 
tributed, with that nervous energy which is essential to their vitality and to their connexion with other parts of the system. The bones, insensible as they may seem, possess all these attributes of living and organized parts. They are all provided with bloodvessels, with nerves, and with exhaling and absorbing vessels; and they are constantly undergoing the same process of decay and renovation to which all other living parts are subjected.

That bones are provided with blood-vessels is shown by the fact, that anatomists are able to trace these vessels into their substance, and to inject those of a young subject with wax, so minutely as to make the bones appear of a lively red colour. That they are provided also with nerves is evident, both from dissection and from the effects of injuries and disease. A healthy bone may be cut or sawn across without causing pain, but when the same bone becomes inflamed, the most excruciating torture is felt. And as sensation is the exclusive attribute of the nervous system, this fact alone would authorize us to assume their existence, even although nervous fibres could not be traced entering the osseous substance.

That the substance of the bones is continually undergoing a change, and that, while the old particles are withdrawn by absorbents, new particles are constantly deposited by the nutrient or exhalant vessels, is abundantly proved by the often repeated experiments of Duhamel. If madder be mixed with the food of fowls for a few days, and the fowls be then killed, the colouring matter deposited by the nutrient vessels will invariably be found to have died the bones of a deep red; and if the madder be withdrawn, the bones will then be found to be less and less red in proportion to the length of time which has been allowed to elapse-evidently showing that waste and renovation are constantly going on. It may be thought, that bones are, in their very 
essence, so hard and durable as to render any such supply of nourishment and change of parts altogether unnecessary. But if we look for a moment to the advantages consequent upon this order of things, we shall see abundant reason to abandon such an opinion.

It is only by means of the processes of growth and renewal that the bones can adapt themselves to the wants and state of the system. If the bones were not endowed with the principle of life, the stature of the infant must have been that of the future man. Or even supposing the osseous system to have grown to maturity, and then remained unchanged, the withered form of old age would necessarily have been oppressed and overcome by the large and massive bones which the vigorous muscles of manhood alone could easily put in motion. Had the bones been created unsusceptible of internal change and unendowed with life, it is obvious, that when broken by accident they must have remained for ever disunited, and therefore an encumbrance instead of an assistance to the animal. But from possessing bloodvessels of their own to supply them with nourishment, and nerves to give power of action to those blood-yessels, the very irritation of the broken ends is made to serve the purpose of increasing the vital powers of the injured parts, and producing that excitement which is necessary for the formation of a new bond of union, and for filling up the gap that would otherwise have remained.

In a state of health, the bones are insensible to pain; and here, also, the most provident benevolence appears. For, surrounded as they are by the softer and more sensitive parts, these afford them ample protection, while their insensibility enables them to act, for any length of time, without weariness or pain. But when a severe accident occurs to break them asunder or destroy their texture, pain then becomes their kindest anardian, and the surest pro. 
moter of their recovery. In such circumstances, indeed, nothing can be more truly benevolent than pain. It accompanies that inflammation and vascular activity without which the work of reunion of the broken part cannot be accomplished; and is the. means of securing the repose and quietude which are essential to the exact adaptation of the parts to each other, and which can be effected only by causing great pain to follow even the slightest motion. of such utility is the inflammation on these occasions, that when, as sometimes happens, the requisite degree of it, from want of nervous sensibility in the part, does not take place, and the bone remains disunited for many weeks, surgeons are in the habit of using violence to produce the necessary stimulus. In this case they either rub the broken ends rudely against each other, or introduce an instrument between them, by which pain and irritation may be excited; and then reunion is accomplished. On the other hand, if pain did not guard the limb from mo. tion when the process of recovery was going on, the union would be incessantly disturbed by every heedless and unavoidable start altering the relative positions of the parts. This, also, is occasionally exemplified in practice. Looking at these facts, it is impossible not to admire the wisdom and the benevolence manifested in the adaptation of the structure of bones in every particular to the circumstances and occurrences of life.

Another advantage arising from the vitality of bones is their susceptibility of change without injury to life. Thus it frequently happens, that, in infancy, water collects within the head in consider able quantity : but, in consequence of the law, that the form of the scull accommodates itself to the form and dimensions of its soft contents, the bones yield to the pressure from within, become larger, and, by forming a larger cavity, enable the brain to execute its functions, and life to go on; whereas, 
had the scull been incapable of undergoing change, death would have to a certainty ensued. The scull owes this power of adaptation entirely to its possessing vessels and nerves, and to its undergoing a constant decay and renewal, like the other parts of the system.

The same phenomena are exhibited by the bones of the chest. When tumours arise, or collections of fluid take place within that cavity, there is a constant effort on the part of nature to take advantage of this constitution of the bones, and to cause them so to expand, as to save the lungs and heart from hurtful pressure, and allow respiration and circulation to go on unimpaired.

In the opposite circumstances of diminished volume of the soft contents of the cavities, the same law enables the bone to decrease in a corresponding proportion, and consequently to continue the protection which it affords to its contained organs. Thus, were the bone to remsin unaltered, when, in cases of disease and in old age, the brain diminishes in size, the cavity of the scull would be only partially filled, and the brain, so far from being protected, would be jolted backwards and forwards, upwards and downwards by every motion of the head or body, till its structure should be utterly destroyed, and life itself extinguished.

To those who are unacquainted with the laws of nutrition of organized bodies, and who are accustomed to notice the hard and unyielding nature of bone, without having any adequate perception of the particular uses of the adaptation of the hard to the soft parts, this adaptation may seem strange and improbable ; but a little consideration will satisfy every one that it could not have been otherwise.

In infancy, when the lungs are imperfectly developed, the chest is narrow, flat, and confined, and the ribs almost in close juxtaposition. In youth and in middle age, when force and activity require ful- 
ness and vigour of respiration, the lvngs enlarge, and, to give thein scope, the chest br ones full, broad, and capacious. In old age, again, when the season of active exertion is over, and the strength decays, the broad shoulders and capacious chest of manhood gradually disappear, and a totally different form occupies its place. Now, at all these periods, the bones are the parts which, by their alteration, serve as an index of the changes going on within; and on this large scale, the difference in their form is so great that it must be obvious to all.

Where the whole of the soft contents of the bony cavity increase in size, as happens in the case of water in the head, the result is, as already mentioned, an expansion from interstitial growth of the osseous covering. But where the tumour or pressure is limited to a small part, a process of a different kind often takes place, which has also the preservation of life for its object, and which is accomplished by another of the natural actions,-absorption. When a bone, say of four inches square, is required gradually to expand itself, so as to protect a surface of six inches or of double the extent, this is accomplished by the gradual removal of the old, and the deposition of new and additional particles, on, as it were, a new and enlarged mould. But in the other case, where the pressure is very limited-where, for instance, a small tumour develops itself on the surface of the brain, which, if allowed to grow within unyielding walls, would soon cause death by pressure on the brain - the ordinary process of absorption becomes greatly excited, and gradually eats away the whole thickness of the bone over the tumour, which then protrudes externally, and relieves the brain within from pressure which would have been fatal to it.

I have already stated, that besides a large proportion of earthy matter, which gives to them dryness and hardness, bones contain a large quantity of animal matter, which is essential to their constitu- 
tion. In early life, this cartilaginous matter preponderates, and the bones are consequently less heavy, more pliable and elastic, and possessed of greater vitality. In old age, again, the earthy parts predominate, and with them fragility, insensibility, and a lower degree of life. It is from this difference that bones broken in youth reunite in one-third of the time necessary for their reunion in advanced life.

In some unhealthy states of the system, the pro. portion of earthy matter is greatly diminished, and in some parts it is even altogether removed. The bones become soft, compressible, and incapable of affording protection or support to other parts, to such a degree that instances have occurred in which the lower extremities could be twisted behind, as if made of wire. A slighter degree of the same affection is common in weak, rickety children; and hence the deformity of limbs so often occurring from absolute insufficiency of the bones to support the weight of the body.

The practical application to be made of our knowiedge of the constitution of the bones, as parts of our animal frame, and as governed by the ordinary organic laws, will now be obvious. Their health we have seen to depend on the regular supply of nourishment by the blood-vessels, on a due supply of nervous energy by the nerves, and on a due balance between the action of the nutrient and absorbent or removing vessels. To the steady observation of these conditions, therefore, we are bound to attend.

It is a common fault to consider the study of an organ or function complete, when we have viewed it on all sides as an isolated part, without regarding its external relations as constituting an essential portion of its history. Thus, although we examine the structure and functions of the heart, and see that it is a muscle, and that its office is to contract; 
our knowledge is incomplete if we do not go still further, and see that blood is the stimulant which causes its contractile power to act. And in like manner with the eye, whose relations to light are as essential a part of its constitution as the transparency of its membranes or the convexity of its lens. Now in the case of the bones we are apt to describe their hardness, their mobility, and other qualities, without sufficiently adverting to the fact that, being organs of resistance and motion, the frequent and regular performance of motion and resistance is as essential to their well-being as blood is to the heart, air to the lungs, or light to the eyes. And, accordingly, when that condition is not fulfilled, the bones become feeble, diseased, and unfit for their functions, just as the softer parts of the body do. In practice, it is of the utmost importance to be fully aware of this fact.

It is familiar to the professional mind, that a part deprived of that exercise or action which nature destined it to fulfil becomes weakened, diminishes in size, and at last shrivels and alters so much in appearance as not to be recognisable. Thus, if an arterythe large artery which supplies the arm with blood, for example-be tied, and the flow of blood obstructed, a change of structure immediately begins, and goes on progressively, till, at the end of a few weeks, what was formerly a hollow elastic tube presents the appearance of a ligamentous inelastic cord. A muscle condemned to inaction loses half its bulk in a comparatively short time ; and if long unexercised, at last loses entirely its power of contraction and muscular appearance. The same rule holds with all other parts of the system, and, in an especial manner, even with the hard and apparently unalterable fabric of the bones. It is ascertained by extensive experience, that complete inaction, besides diminishing the size, injures the structure of bone so much as to deprive it of its hardness, and 
sender it susceptible of being cut with a knife. Now, what is strongly marked in the extreme case is not less active, although it may be less palpably apparent in cases where there is great, though not total, deprivation of exercise : and hence one cause of the bad health, crooked spines, and deformed figures, of which the habitual restraint and condemnation to attitude in modern education lay so widespreading and so deep a foundation,--evils which could never stand for a moment before knowledge. or reason. The bones are the solid organs of motion; and unless they be duly exercised in effecting motion, they, like the muscles which move them, suffer and decay in virtue of that universal law which requires exercise as the condition of their well-being - as the stimulus necessary to their existence.

In early youth, in particular, when every part teems with life and activity, and is almost hourly acquiring an increase of dimensions, the nutrient system is in a state of unceasing and powerful action, and a rich and abundant supply of food is indispensable to health. Nature points out this fact; in the keen and vigorous appetite and strong powers of digestion which every healthy child uniformly manifests. To put ourselves in accordance with the intention of nature, at this period of life, it is, therefore, absolutely necessary to supply in abundance wholesome and nourishing food. The non-fulfilment of this condition, so often seen in times of distress among the labouring classes, gives rise to that tumid softness and consequent weakness of the bones and soft parts, which is known by the name of rickets; and which, if it continue till maturity, $i$. e. during the years of active nutrition, invariably leads to distortion and deformity.

The next requisite for the development and health of the osseous system is adequate exercise; and this condition cannot be infringed with impunity 
any more than the former. Wherever matter is the subject, action implies waste of materials, and unless this waste be made up by proportionate supplies, exercise leads to speedy decay, such as we'see take place where the exercise has been carried beyond the limits of nature, and beyond what any supply can compensate. Inaction, on the contrary, implies almost stagnation, and is always attended by diminution of the vital functions; as is exemplified, in the extreme degree, in hybernating animals, which pass months in sleep without food and almost without breathing,-and also in frogs found alive in stones and trees, where they must have been dormant for a great number of years. Inactive parts, then, require little nutrition, because there is little expenditure ; and they require little force or energy, because it would be not only useless but detrimental to them.

By a law of the constitution, manifestly arranged with relation to this principle, when any part of the system is active, it attracts to itself, by the simple stimulus of that activity, an increased supply of blood and nervous energy. The former enables it to repair the waste of substance which action produces, and the latter gives an increased tone in harmony with the greater call made on its powers. If the exercise is momentary and is not repeated, the extraordinary flow of blood soon disappears, and the nervous power falls to the usual standard: but if it is continued for a time, and is recurred to at regular intervals, a more active nutrition is established; a permanently greater supply of blood enters the vessels, even during the intervals of inaction; and an increase of development takes place, attended with increased facility and force of function.

If, again, any part is not duly exercised, there is no local stimulus to attract a large supply of blood or abundant flow of the nervous fluid; there is no 
activity of nutrition, no perfection of development, and no force of function. And hence, in partial exercise, there is always predominance of some part over others; the one too strong, the other too feeble. In the muscular system, the arms of a blacksmith, contrasted with those of a dancingmaster, are a sufficient-illustration.

This law of increased afflux of fluids and increased nutrition to exercised parts, and of diminished afflux and nutrition to inactive parts, is not only highly important in its practical consequences, but in exact and obvious accordance with the plainest principles of reason. By this benevolent arrangement, parts acting strongly receive large supplies, and parts doing nothing are left in the state of weakness befitting the demands made upon them. To every one who sees the principle, it must appear the height of folly to expect great nutrition and great energy to follow inaction, and vice vers $\hat{a}$; and yet this is what, in ignorance, is daily looked for by mankind at large.

This law of exercise, as influencing nutrition and function, is universal in its application, and applies to the osseous as much as to any other system. If the bones are duly exercised in their function of administering to motion, then active nutrition goes on, and they acquire dimensions, strength, and solidity. If they are not exercised, the stimulus required for the supply of blood to them becomes insufficient; imperfect nutrition takes place; and debility, softness, and unfitness for their office follow in the train. This cause of defective formation is most active and most commonly seen in the bones of the spine in growing girls, who are denied free exercise in that part; and the consequent weakness in the bones and cartilages, as well as in the muscles, is a very frequent cause of the swollen joints and curvature in the bones of the limbs in young people, which no subsequent care can ever remove. 
The beneficial effects of exercise and diet in imparting solidity to the bones have not escaped the observation of trainers. Sir John Sinclair expressly mentions that the bones become, in a remarkable degree, harder and tougher, and less liable to be injured by blows or accidents. Testimony of this kind ought to be of great weight, as based, not on theory, but on the broad and well-marked experience of practical men.*

It must be observed, however, that defective nutrition may arise from other causes than inadequate exercise ; but even then, the consequences attending it are analogous in their nature. $\Lambda$ mong the poor it often arises from deficiency of wholesome food, and from damp dark habitations; among the rich, from feeble digestive and-assimilating powers, and pampering in diet; and also from errors in clothing, and neglect of sufficient ventilation, and due exposure to the open air. Rickets, softness of the bones, and white swelling are accordingly observed to be almost confined to children belonging to one or other of these classes.

To understand more clearly the relative uses of bones and muscles, we may be allowed to use a comparison, although, like all other comparisons, it presents many points of difference. The bones are to the body what the mast and spars are to a ship; they give support and the power of resistance : and the muscles are to the bones what the ropes are to the masts and spars. It is to the muscles that the bones are indebted for the power of preserving or changing their relative position. If the bones or masts are too feeble in proportion to the weight which they are required to sustain, then a deviation from their shape and position takes place; and on the other hand, if the muscles or ropes are not sufficiently strong and well braced, then insufficiency of

* Code of Health, 5th edit. Appendix, p. 35. 
support must necessarily result. Early infancy affords an instance of both imperfections ; the bone being infirm, and the muscles small and destitute of true fleshy fibres. The diseased state, called mollities ossium, or softness of the bones, is an instance of what may be called a weak mast of the body, which must yield if its muscles be strongly drawn. The state of muscular debility consequent on fever and many acute diseases, or even on sudden fright, is, on the other hand, an instance of the inability of the bones alone to preserve an attitude, or execute motion, when the muscular system is weakened by disease. These differences merit attention.

In the regular order of nature, the maturity and perfection of all organs and functions are attained at the precise time at which each is required. The bones of the infant are soft, vascular, cartilaginous, full of life, and vigorous in growth ; but having no energetic motions to perform, they possess little power of solid resistance. In accordance with this condition of the bones, the muscles which move them are small, gelatinous, imperfectly fibrous, and little capable of powerful contraction. If the bones had been made solid and heavy from the beginning, they would not only have been inert and cumbrous masses, destitute of muscles to put them in motion; but, from being less vascular and less alive, they could not have grown with the rapidity necessary to adapt themselves to the growth of the other parts of the system. If, on the other hand, powerful muscles had existed from the first, they would have served only to twist the soft and yielding bones into fantastic shapes. Or, if both solid bones and strong muscles had been given from birth, then a complete power of locomotion would have been the result, which from the absence of intellect and of knowledge of the external world to direct it, would have led to incessant evils, if not to speedy destruction. But as things are arranged, the most profound wis- 
dom and the purest benevolence show themselves in the beautiful adaptation of all the parts and func. tions to each other and to one common end.

Knowledge of the condition of the bones at dif. ferent periods of life is not without its practical uses-particularly in regulating our treatment of children. Some fond parents, disregarding the fact that the bones are comparatively soft and pliable in infancy; and in their haste to see the little objects walk without support, are continually soliciting at. tempts at standing or walking, long before the bones have acquired sufficient power of resistance, and the muscles sufficient power of contraction, to cope with the laws of gravitation. The natural consequence is a curvature of the bone, which yields just like an elastic stick bending under a weight. The two ends approach nearer to each other than they ought to do; and to accommodate themselves to the change, the muscles become shorter on one side, and perhaps longer on the other, each losing part of its efficacy in the unnatural change which it undergoes.

From this view, it will be seen how hurtful leading-strings must be. In the first place, by their mechanical force, they compress the chest and impede respiration; and, in the second, by preventing the body from falling to the ground, or rather by preserving an upright position, they cause the whole weight to fall on the bones of the spine and lower extremities, which are not fitted by nature to bear the burden. From this noxious practice, flatness of the chest, confined lungs, distorted spine, and deformed legs too often originate.

The impropriety of an indiscriminate use of dumbbells, in early life, will also be easily understood. If the weight of these be disproportioned to the strength of the bones, it is obvious that we must produce the same kind of evil as by premature attempts to walk, viz. yielding of the bones, and stretching 
and relaxation of their connecting ligaments. If, again, they be disproportionate to the muscular power, their effect will be to exhaust instead of increasing the strength of the body.

From the exposition I have given of the laws of exercise, as affecting the muscular and osseous systems, the absurdity of expecting to strengthen either the one or the other by the use of stays, or by lying for hours on a horizontal or inclined plane, will be abundantly manifest. There is no royal road to health and strength, and no method by which, while exercise is dispensed with, its advantages can be obtained. In the intervals between exercise, reclining on a plane is very useful in delicate fast-growing girls; but it should be continued only till the feeling of fatigue goes off, and never be resorted to for hours in succession, as it often is on the false notion of its being conducive to strength.

In this chapter, as well as in that on the muscles, I have dwelt perhaps too long on the principles by which exercise ought to be regulated; but as the subject is little understood by those who have the direction of youth, and as it is of paramount importance, I am inclined to hope that the tediousness of repetition may be forgiven, if clearness and convic. tion are obtained. 


\section{CHAPTER VII.}

Arterial and venous Blood-Nature of Respiration-Structure of the Lungs-Conditions required for healthy RespirationSound original Constitution-Influence of hereditary Predis. position-Of wholesome Food, and good Digestion-Of the free Expansion of the Lungs - Of Exercise of the Muscles and Voice-Of Cheerfulness and Depression of Mind-Of pure Air and Ventilation-Examples of the bad Effects of vitiated Air-Respiration the Source of Animal Heat-Causes of deficient Generation of Heat-Removal of such Causes-Direct and indirect Exercise of the Lungs-Beneficial Effects of, and Rules for Exercise-Precautions to be observed in Diseases of the Lungs, and in Persons predisposed to Consumption.

WE come next to treat of the lungs and of the function of Respiration; but, in order to be clearly understood, I must premise a few observations on the circulation of the blood.

The blood circulating through the body is of two different kinds; the one red or arterial, and the other dark or venous blood. The former alone is capable of affording nourishment and of supporting life. It is distributed from the left side of the heart all over the body, by means of a great artery or blood-vessel called the aorta, which subdivides in its course, and ultimately terminates in myriads of very minute ramifications, closely interwoven with, and in reality constituting a large portion of, the texture of every living part. On reaching this extreme point of its course, the blood passes into equally minute ramifications of the veins, which, in their turn, gradually coalesce and form larger and larger trunks, till they at last terminate in two large veins, by which the whole current of the venous blood is brought back in a direction contrary to that in the 
arteries, and poured into the right side of the heart. On exanining the quality of the blood in these two systems of vessels, it is found to have undergone a great change in its passage from the one to the other. The florid hue which distinguishes it in the arteries has disappeared, and given place to the dark colour characteristic of venous blood. Its properties, too, have changed, and it is now no longer capable of sustaining life.

Two conditions are essential to the reconversion of venous into arterial blood, and to the restoration of its vital properties. The first is an adequate provision of new materials from the food, to supply the place of those which have been expended in nutrition ; and the second is the free exposure of the venous blood to the atmospheric air.

The first condition is fulfilled by the chyle or nutrient principle of the food being regularly poured into the venous blood, just before it reaches the right side of the heart; and the second, by the very important process of respiration, which takes place in the air-cells of the lungs, and which it is our present object to explain.

The venous blood, having arrived at the right side of the heart, is propelled by the contraction of that organ into a large artery, leading directly, by separate branches, to the two lungs, and hence called the pulmonary artery.* In the innumerable branches of this artery expanding themselves throughout the substance of the lungs, the dark blood is subjected to the contact of the air inhaled in breathing; and a change in the composition both of the blood and of

* Taking the nature of the blood for our guide, the pulmonary artery ought to be named the pulmonary vein, for it contains venous blood: but from its structure and office resembling those of the arteries, it has been called an artery. The pulmonary veins, on the other hand, contain arterial blood, although named veins. To prevent confusion, it is necessary to advert to this source of ambiguity. 
the inhaled air takes place, in consequence of which the former is found to have assumed its florid or arterial hue, and to have regained its power of supporting life. The blood then enters minute venous ramifications, which gradually coalesce into larger branches, and at last terminate in four large trunks in the left side of the heart; ' whence the blood in its arterial form is again distributed over the body, to pursue the same course and undergo the same changes as before.

There are thus two distinct circulations, each carried on by its own system of vessels : the one, from the left side of the heart to every part of the body, and back to the right side; and the other, from the right side of the heart to the two lungs, and back to the left. The former has for its object nutrition and the maintenance of life; and the latter the restoration of the deteriorated blood, and the animalization or assimilation of the chyle from which that fluid is formed.

As the food cannot become a part of the living animal, or the venous blood regain its lost properties until they have undergone the requisite changes in the air-cells of the lungs, the function of respiration, by which these are effected, is one of pre-eminent importance in the animal economy, and well deserves the most careful examination. The term respiration is frequently restricted to the mere inhalation and expiration of air from the lungs; but more generally it is employed to designate the whole series of phenomena which occurs in these organs. The words sanguification, and aerration of the blood are other forms of expression occasionally used to denote that part of the process in which the blood, by exposure to the action of the air, passes from the venous to the arterial state; and, as the chyle does not become assimilated to the blood until it has passed through the lungs, the term sanguification, or blood-making, is not unaptly applied. 
Ine quantity and quality of the blood have a most direcr and material influence upon the condition of every part of the body. If the quantity sent to the arm, for example, be diminished by tying the artery through which it is conveyed, the arm, being then imperfectly nourished, wastes away, and does not regain its plumpness till the full supply of blood be restored In like manner, when the quality of that fluid is impaired by deficiency of food, bad digestion, impure arr, or imperfect sanguification in the lungs, the body and all its functions become more or less disordered. Thus, in consumption, death takes place chietny in consequence of respiration not being sufficiently perfect to admit of the formation of proper blood in the lungs.

A knowledye of the structure and functions of the lungs, and of the conditions favourable to their healthy action, is, therefore, very important; for on their welfare depends that of every organ of the body. And wiren we recollect that, in the British Isles alone, nutrly fifty thousand persons fall victims annually to pulmonary consumption, and that these are chiefly among the young and most gifted, we cannot bur feel deeply interested in obtaining some acquaintance with the organization which is the seat of that affection, and with the conditions most conducive to the due performance of its functions and the preservation of its health.

The exposure of the blood to the action of the air seems to be indispensable to every variety of animated creatures. In man and the more perfect of the lower animals it is carried on in the lungs, the structure of which is admirably adapted for the purpose. In many animals, however, the requisite action is effected without the intervention of lungs. In fishes, for example, which live in a dense medium, and do not breathe, the blood circulates through the gills, which, being constantly and directly in contact with the water, are therefore more accessible 
to the action of the air which the water contains, and much better adapted than lungs would be to the medium in which fishes live. In worms, on the other hand, and many similar animals, no dis. tinct organ is set apart for the purpose, but the aerration of the blood takes place at the surface of the body by means of pores in the skin called spiras cula, specially adapted to this end, and which cannot be shut up or obstructed any more than the real lungs or gills without inducing death. So necessary, indeed, is atmospheric air to the vitality of the blood in all classes of animals, that its abstraction inevitably induces death; and a fish can no more live in water deprived of air than a man could do in an atmosphere devoid of oxygen. And thus the fish requires a renewal of air, and perishes when it is denied, exactly as man does in similar circumstances.

In man; the lungs are those large, light, spongy bodies which, along with the heart, completely fill the two lateral cavities of the chest. They vary much in size in different persons, and, as the chest is formed for their protection, we find it either large and capacious, or the reverse, according to the size which the lungs have attained. Their position relatively to the other viscera may be understood on reference to the subjoined woodcut, which represents the various organs of the chest and belly as they appear on removing the integuments, breastbone, and part of the ribs. The sketch is rather rude, but it will serve the purpose. The letters $\mathrm{R} L$ and $L \mathrm{~L}$ mark the right and left lungs, with $H$ the heart lying between them, but chiefly on the left side. $\quad V$ is an inaccurate representation of the large blood-vessels going to the head, neck, and superior extremities. Liv is the liver, lying in the abdomen or belly, and separated from the chest by the arched fleshy partition $\mathrm{D} D$, called the diaphragm or midriff. The stomach appears on 
the other side, marked $\mathrm{St}^{m}$, but both it and the liver are removed a little from their natural situation. G is the gall-bladder. II I are the various parts of the intestinal canal through which the fogd is passed on its way from the stomach, by what is called the peristaltic or vermicular motion of the bowel, one circle of fibres narrowing after another, so as to propel its contents slowly but steadily, and resembling in some $i$ egree the contraction of a common worm.

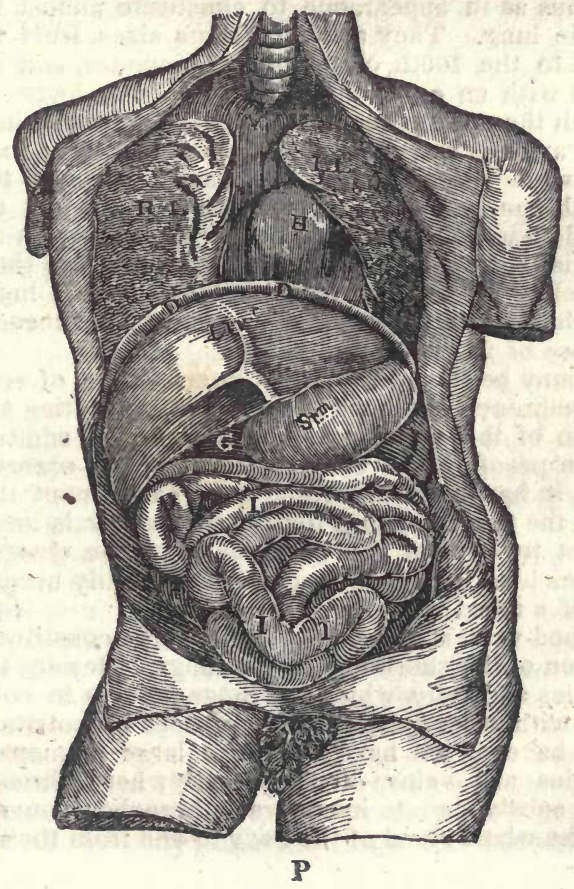


The substance of the lungs consists of bronchial tubes, air-cells, blood-vessels, nerves, and cellular membrane, or parenchyma. The first are merely continuations and subdivisions of the windpipe, and serve to convey the external air to the air-cells of the lungs. The air-cells constitute the chief part of the pulmonary tissue, and are in one sense the terminations of the smaller branches of the bronchial tubes. When fully distended, they are so numerous as in appearance to constitute almost the whole lung. They are of various sizes, from the 20 th to the 100th of an inch in diameter, and are lined with an exceedingly fine thin membrane, on which the minute capillary branches of the pulmonary arteries and veins are copiously ramified; and it is while circulating in the small vessels of this mernbrane, and there exposed to the air, that the blood undergoes the change from the venous to the arterial state. So prodigiously numerous are these air-cells that the aggregate extent of their lining membrane in man has been computed to exceed a surface of 20,000 square inches.

It may be thought that the interposition of such a membrane must have the effect of preventing any action of the air upon the blood. But, in addition to the proof to the contrary drawn from observation, it has been ascertained by experiment that even the thick and firm texture of bladder is insufficient to prevent the occurrence of the change; venous blood confined in a bladder speedily becom ing of a florid red, like arterial blood.

Blood-vessels necessarily form a large constituent portion of the substance of the lungs. Besides the arteries and veins which the lungs possess in common with other parts for the purposes of nutrition, they have, as we have seen, the large pulmonary arteries and veins, dividing everywhere through their substance into innumerable branches, conveying the whole blood of the body to and from the air- 
cells, and therefore of a magnitude proportioned to the quantity of blood which is destined to pass through them.

These two tissues, air-tubes and blood-vessels, together with the loose cellular texture or network which binds them together, called parenchyma, form the whole of the structure peculiar to the lungs. But, like all other living parts, they are provided also with nerves, without the active co. operation of which, in supplying the requisite ner vous stimulus, the special functions of the lungs, and consequently life itself, would speedily cease.

Every one must have remarked the copious exhalation of moisture which takes place in breathing, and which presents a striking analogy to the exhalation from the surface of the skin. In the former as in the latter instance, the exhalation is carried on by the innumerable minute capillary vessels, in which the small arterial branches terminate in the air-cells. This can be made evident after death, by injecting any of the arterial branches with water, turpentine, or quicksilver, when the injection will be seen to exude in minute points, on the surface of the lining membrane of the air-cells. The pulmonary exhalation, however, must not thence be supposed to be a mere physical or mechanical exudation. It is the result of a vital process, and is subject to the ordinary laws of vital action.

Absorption, in like manner, takes place from the lining membrane of the lungs, as we have seen it do $n$ the skin. When a person breathes an atmosphereloaded with fumes of spirits, of tobacco, of turpentine, or of any other volatile substance, a portion of the fumes is taken up by the absorbing vessels of the lungs, and carried into the system, and there produces precisely the same effects as if introduced into the stomach. It has occasionally happened that a person has unwarily become intoxicated in this way; and the lungs thus become a 
ready inlet to contagion, miasmata, and other poisonous influences diffused through the air which we breathe.

From this general explanation of the structure and uses of the lungs, it will be obvious, that several conditions, which it is our interest specially to know and observe, are essential to the healthy performance of the important function of respiration. FIRST among these we may rank a healthy original formation of the lungs. No fact in medicine is better established than that which proves the hereditary transmission from parents to children of a constitutional liability to pulmonary disease, and especially to consumption; yet no condition is less attended to in forming matrimonial engagements. The children of scrofulous and consumptive parents are generally precocious, and their minds being early matured, they engage early in the business of life, and often enter upon the married state before their bodily frame has had time to consolidate. For a few years every thing seems to go on prosperously, and a numerous family gathers around them. All at once, however, while still very young, their physical powers begin to give way, and they drop prematurely into the grave, exhausted by consumption, and leaving children behind them, destined in all probability either to be cut off as they approach maturity, or to run through the same delusive but fatal career as that of the parents from whom they derived their existence.

Many examples of this kind might be pointed out among the higher classes of society, who are not restrained from following their predominant inclinations, by any necessity of seeking subsistence in professional pursuits. And many instances might be referred to, in which no regard was shown to the manifest existence of the same disposition in the family of either parent, and in which, consequently, the marriage state was imbittered either by barren- 
ness, which is then the most favourable result, or by the prevalence of disease and delicacy in the progeny. It may not be easy to enforce upon the young and inexperienced the requisite degree of attention to these circumstances; but surely education, especially when backed by example, might do much, if the young were properly instructed, at an early period, in the leading facts and principles of the human constitution. Where there are hereditary precocity and delicacy of frame, marriage, instead of being hastened, ought invariably to be delayed at least till the fullest maturity and consolidation of the system : otherwise the consequences will be equally unhappy for the individual and for his future progeny. During growth, and for a considerable time after growth has ceased, the constitution is still imperfect, even in healthy subjects, and wants the enduring strength which it afterward acquires in mature age, and the possession of which marks the period which nature has fixed for the exercise of the functions of reproduction. Many young people of both sexes fall sacrifices to early marriages, who might have withstood the ordinary risks of life, and lived together in happiness, if they had delayed their union for a few years, and allowed time for the consolidation of their constitutions.

I have urged this point strongly, because hereditary predisposition is, avowedly and beyond all doubt, the most frequent source of the more serious forms of pulmonary disease, and it would be worse than folly to allow past and painful experience to go for nothing. Medical men have much in their power in preventing such violations of the laws of the Creator, at least where they are regarded, as they always ought to be, as the friends as well as the professional advisers of the family.

The sEcond requisite to the well-being of the lungs, and to the free and salutary exercise of respiration, is a due supply of rich and healthy blood. When, $\mathrm{P}_{2}$ 
from defective food, or impaired digestion, the blood is impoverished in quality and rendered unfit for adequate nutrition, the lungs speedily suffer, and that often to a fatal extent. So certain is this fact, that, in the lower animals, tubercles (the cause of incurable consumption) can be produced in the lungs to almost any extent, by withholding a sufficiency of nourishing food. The same circumstances operate to a lamentable extent among the poorly fed population of our manufacturing towns; whereas it is proverbial that butchers, - a class of men who eat animal food twice or thrice a day, and live much in the open air, are almost exempt from pulmonary consumption. Among the higher classes, again, the blood is impoverished, and the lungs are injured, not from want of food, but from want of the power of adequately digesting it; and hence we find in every treatise on consumption, a section devoted especially to "dyspeptic phthisis," as it is called, or simply "consumption from bad digestion." The late hours, heavy meals, and deficient exercise which are so generally complained of, but still so regularly adhered to in society, are the chief sources of the evils to which we are now alluding.

ThirdLy.-The free and easy expansion of the chest is obviously indispensable to the full play and dilatation of the lungs: whatever impedes it, either in dress or in position, is prejudicial to health; and, on the other hand, whatever favours the free expansion of the chest equally promotes the healthy fulfilment of the respiratory functions. Stays, corsets, and tight waist-bands operate most injuriously, by compressing the thoracic cavity and impeding the due dilatation of the lungs; and, in many instances, they give rise to consumption. I have seen one case, in which the liver was actually indented by the excessive pressure, and long continued bad health and ultimately death were the results. In allusion to this subject, Mr. Thackrah mentions, 
that men can exhale, at one effort, from six to ten pints of air, whereas in women the average is only from two to four pints. In ten females, free from disease, whom he examined, about the age of $18 \frac{1}{2}$, the quantity of air thrown out averaged $3 \frac{1}{2}$ pints; while, in young men of the same age, he found it amount to six pints. Some allowance is to be made for natural differences in the two sexes, but enough remains to show a great diminution of capacity, which can be ascribed to no other cause than the use of stays. But having discussed this matter when treating of the muscular system, it is unnecessary to enlarge on it again, further than to remark, that the constrained motionless attitudes enforced upon young females in the course of education are very unfavourable to the play of the lungs and to the full development of the chest.

The admirable harmony established by the Creator between the various constituent parts of the animal frame, renders it impossible to pay regard to or infringe the conditions required for the health of any one, without all the rest participating in the benefit or injury. Thus, while cheerful exercise in the open air and in the society of equals is directly and eminently conducive to the well-being of the muscular system, the advantage does not stop there ; the beneficent Creator having kindly so ordered it, that the same exercise shall be scarcely less advantageous to the proper performance of the important function of respiration. Active exercise calls the lungs into play, favours their expansion, promotes the circulation of the blood through their substance, and leads to their complete and healthy development. The same end is greatly facilitated by that free and vigorous exercise of the voice which so uniformly accompanies and enlivens the sports of the young, and which doubles the benefits derived from them considered as exercise. The excitement of the social and moral feelings among children 
engaged in play is another powerful tonic, the influence of which on the general health ought not to be overlooked; for the nervous influence is as indispensable to the right performance of respiration, as it is to the action of the muscles or to the digestion of food.

This latter principle explains the reason why the depressing passions predispose to pulmonary con sumption, a fact which has been remarked from a very early period. When the mind is in a state of depression, the whole nervous functions become enfeebled; and the stimulus to the other organs, on which so much of their vital power depends, is impaired, and a general want of tone pervades the system, rendering the principal organs of the body, and the lungs among the rest, unusually susceptible of disease. Here, again, we may perceive the beautiful adaptation of all the functions to each other, and the exquisite harmony of design.which has presided over the original construction of the body.

It is curious indeed to trace the relations in which the animal functions stand to each other. Grief, sorrow, fear, and other depressing passions of the mind, diminish the activity of the circulation, impair respiration, lower vitality, and consequently render the organization more than usually susceptible of diseases arising from diminished action. Anger, joy, and the other exhilarating passions, on the other hand, stimulate the circulation, quicken respiration, increase the vital powers, and create a proneness to inflammatory or excited action. At first sight, it may seem strange that such should be the results of different kinds of mental emotion. On examination, however, we perceive evident design in the arrangement. The tendency of grief, despondency, and sorrow is to produce meditative inaction. These emotions require no exertion of the bodily powers, and no unusual expenditure of vital energy: but rather the reverse. This, it will be observed, 
Is a condition incompatible with a quick supply of blood, or a high degree of respiration; for if these were conjoined, they would only give rise to an amount of bodily activity at variance with the absorbed and inactive state of the mind. The nature of the exciting passions, again, is to impel us vigorously to action; but action cannot be sustained without a full supply of highly oxygenated blood, and hence a very manifest reason for the quick respiration and accelerated circulation which attend mental excitement. Great depression of mind thus leads naturally to imperfect respiration, a more sluggish flow of blood, and the various diseases of diminished vitality; while great excitement induces full respiration, quickened circulation, and the various diseases of exalted vitality. These principles show the paramount importance, in the treatment of disease, of carefully regulating the mental state of the patient, according to the object we have in view.

A fourth essential condition of healthy respiration remains to be noticed, viz. a regular supply of vure fresh air, without which the requisite changes in the constitution of the blood, as it passes through the lungs, cannot be effected. To enable the reader to appreciate this condition, we must premise some remarks on the nature of the changes alluded to.

Atmospheric air consists of nearly 79 per cent. of nitrogen or azotic gas, 21 per cent. of oxygen, and not quite 1 per cent. of carbonic acid or fixed air: and such is its constitution when taken into the lungs in the act of breathing. When it is expelled from them, however, its composition is found to be greatly altered. The quantity of nitrogen remains nearly the same, but 8 or $8 \frac{1}{2}$ per cent. of the oxygen or vital air has disappeared, and been replaced by an equal amount of carbonic acid. In addition to these changes, the expired air is loaded with moisture. Simultaneously with these occurrences, the blood collected from the veins, which entered 
the lungs of a dark colour and unfit for the support of life, assumes a florid red hue, and acquires the power of supporting life.

It is not easy to offer a satisfactory explanation of the processes by which these changes are effected in the lungs. According to one view, the carbonic acid contained in expired air is formed by the secretion of carbon from the venous blood in its passage through the lungs, which immediately unites with the oxygen of the air, and forms carbonic acid, in which shape it is then thrown out in expiration. According to the other view, the carbonic acid exists in, and is separated from, the venous blood in the state of acid, and the oxygen which disappears is absorbed into the circulating current. The former explanation was long received, but Dr. Edwards has lately advanced very strong grounds for adopting the latter. Whatever may be the true theory, all physiologists are agreed as to the fact that the arterialization of the blood in the lungs is essentially dependent on the supply of oxygen contained in the air which we breathe, and that air is fit or unfit for respiration in exact proportion as its quantity of oxygen approaches to, or differs from, that contained in pure air. If, consequently, we attempt to breathe nitrogen, hydrogen, or any other gas not containing oxygen, the result will be speedy suffocation; whereas, if we breathe air containing a too high proportion of oxygen, the vital powers will speedily suffer from excess of stimulus. From oxygen being thus essential to life and respiration, it is often called vital air, in contradistinction to those gases which are incapable of supporting life.

We can now appreciate the importance of a due supply of fresh air wherever living beings are congregated. In man, the rate of vitiation produced by breathing, and the relative importance of ventilation, may be easily estimated. An individual is ascertained to breathe. on an average, from 14 to 20 
times in a minute, and to inhale from 15 to 40 cubic inches of air at each inspiration. Sir H. Davy and others rate the quantity so low as from 13 to 17 inches; but most observers agree with Dr. Menzies, who experimented with great care, in estimating it at 40 inches. The quantity, however, varies much in different individuals.

Even taking the consumpt of air at 20 inches, as a very low medium, and rating the number of inspirations at 15, it appears that, in the space of one minute, no less than 300 cubic inches of air are required for the respiration of a single person. In the same space of time, 24 cubic inches of oxygen disappear, and are replaced by an equal amount of carbonic acid; so that in the course of an hour one pair of lungs will, at a low estimate, vitiate the air by the subtraction of no less than 1440 cubic inches of oxygen, and the addition of an equal number of carbonic acid, thus constituting a source of impurity which cannot be safely overlooked.

The fatal effects of breathing highly vitiated air may easily be made the subject of experiment. When a mouse is confined in a large and tight glass jar full of air, it seems for a short time to experience no inconvenience ; but in proportion as the consump. tion of oxygen and the exhalation of carbonic acid proceed, it begins to show symptoms of uneasiness, and to pant in its breathing, as if struggling for air; and in a few hours it dies, convulsed exactly as if drowned or strangulated. The same results follow the deprivation or vitiation of air in man and in all animated beings; and in hanging, death results not from dislocation of the neck, as is often supposed, but simply from the interruption to breathing preventing the necessary changes taking place in the constitution of the blood.

The horrible fate of the Englishmen who were shut up in the Black Hole of Calcutta in 1756 is strikingly illustrative of the destructive conse- 
quences of an inadequate supply of air. 146 in number were thrust into a confined place, 18 feet square. There were only two very small windows by which air could be admitted, and as both of them were on the same side, ventilation was utterly impossible. Scarcely was the door shut upon the prisoners when their sufferings commenced, and in a short time a delirious and mortal struggle ensued to get near the windows. Within four hours, those who survived lay in the silence of apoplectic stupor ; and at the end of six hours, ninety-six were relieved by death! In the morning when the door was opened, 23 only were found alive, many of whom were subsequently cut off by putrid fever, caused by the dreadful effluvia and corruption of the air.

This tremendous example ought not to be lost upon us. If the results arising from the vitiation of the air to an extreme degree be so appalling, we may rest assured that those arising from every lesser degree, although they may be less obvious, are not less certain in their operation. It is, indeed, readily admitted in the abstract, that a constant supply of pure air is indispensable to the healthy performance of respiration; but if we inquire how far this condition is attended to by mankind at large, we shall have no reason to think the present warning unnecessary. I have already noticed (at p. 19) the case of Captain Ganson who was suffocated in the cabin of the Magnus Troil in Leith Harbour on 1st March, 1833, and whose brother was recovered with great difficulty from a state of stupor, induced apparently by an insufficient supply of respirable air. To these instances another may be added from the Globe newspaper of 1st April, in which it is mentioned, that the captain and mate of the French Chasse marée Royaliste lost their lives from suffocation in the harbour of Jersey, in a precisely similar way. In both vessels the cabin was very small, and the door having been carefully shut, the access of fresh ais was completely prevented. 
I do not mean to say, that in these cases the fatal results were attributable exclusively to vitiation of the air by breathing. Fixed air may have been dis. engaged also from some other source; but the deteriorating influence of respiration, where no ventilation is perceptible, cannot be doubted. According to Dr. Bostock's estimate, for example, an average sized man consumes about 45,000 cubic inches of oxygen, and gives out about 40,000 of carbonic acid in 24 hours, or 18,750 of oxygen and 16,666 of carbonic acid in ten hours, which was nearly the time which the sufferers had remained in the cabin before they were found. As they were two in number, the quantity of oxygen which would have been required for their consumption was of course equal to 37,500 cubic inches, while the carbonic acid given out would amount to upwards of 32,000 inches-a source of impurity manifestly quite equal to the production of serious consequences to those exposed to it ; and which no one, properly acquainted with the constitution of his own body and with the conditions essential to healthy respiration, would ever have willingly encountered. It is no argument to say that the cause of death must have been some disengagement of gas within the vessel: for, even granting this to have been the case, it is still certain that, had the means of ventilation been adequately provided, this gas would have been so much diluted, and so quickly dispersed, that it would have been comparatively innoxious.

In the construction of our houses, the laws of respiration are often glaringly infringed, especially in towns. The public rooms, which can be easily ventilated at any time, - which are in fact ventilated by the constant opening and shutting of the door, and by the draught of the chimney,-and in which, therefore, large dimensions are less necessary for salubrity, are always the most spacious and airy. The bed-rooms, on the other hand, in which, from 


\section{EFFECTS OF DEFICIENT VENTLLATION.}

the doors being shut, and from there being no current of air in the whole seven or eight hours during which they are occupied, the vitiation of the air is the greatest, and in which, consequently, size is most required, are uniformly the smallest and most confined; and, as if this source of impurity were not sufficient, we still farther reduce the already too limited space, by surrounding the bed closely with curtains, for the express purpose of preventing ventilation, and keeping us enveloped in the same heated atmosphere. Can any thing be imagined more directly at variance than this with the fundamental laws of respiration? Or could such practices ever have been resorted to, had the nature of the human constitution been regarded before they were adopted? In this respect we are more humane towards the lower animals than towards our own species; for, notwithstanding all the refinements of civilization, we have not yet aggravated the want of ventilation in the stable or the cow-house, by adding curtains to the individual stalls of the inmates.

So little, however, are we taught to think of the nature and wants of the human constitution, that in Edinburgh we have instances of large public rooms, capable of holding from 800 to 1000 persons, built within these few years, without any means of adequate ventilation being provided. This could not have happened, had either the architects or their employers known any thing of the laws of the human constitution. When these rooms are crowded, and the meeting lasts for some hours, especially if it be in winter, the consequences are sufficiently marked. Either such a multitude must be subjected to all the evils of a contaminated and unwholesome atnrosphere, or they must be partially relieved by opening the windows, and allowing a continued stream of cold air to pour down upon the heated bodies of those who are near them, till the latter are 
thoroughly chilled, and perhaps fatal illness is induced; and, unfortunately, even at such a price, the relief is only partial; for the windows being all on one side of the room, and not extending much above half-way to the ceiling, complete ventilation is impracticable.

In dwelling-houses lighted by gas, the frequent renewal of the air acquires increased importance A single gas-burner will consume more oxygen, an produce more carbonic acid to deteriorate the atmosphere of a room, than six or eight candles. - If, therefore, where several burners are used, no provision be made for the escape of the corrupted air, and for the introduction of pure air from without, the health will necessarily suffer. A ventilator placed over the burners, like an inverted funnel, and opening into the chimney, is an efficient and easy remedy for the former evil; and a small tube forming a communication between the external air and the room would supply fresh air, where necessary. The tube might be made to pass, like a distiller's worm, through a vessel containing hot water, by which means the air might be heated, in very cold weather, before being thrown into the room, and thus the danger arising from cold draughts and inequalities of temperature be avoided.

Many of our churches and schools are extremely IIl ventilated; and accordingly it is observed, that fainting and hysterics occur in churches much more frequently in the afternoon than in the forenoon, beause the air is then in its maximum of vitiation. Indeed, it is impossible to look around us in a crowded church, towards the close of the service, without perceiving the effects of deficient air in the expression of the features of every one present. Either a relaxed sallow paleness of the surface, or the hectic flush of fever, is observable; and, as the pecessary accompaniment, a sensation of mental 
and bodily lassitude is felt, which is immediately relieved by getting into the open air.

I have seen churches frequented by upwards of a thousand people, in which, in winter, not only no means of ventilation are employed during service, but even during the interval between the forenoon and afternoon services, the windows are kept as carefully closed as if deadly contagion lay outside, watching for an opportunity to enter by the first open chink, and where, consequently, the congregation must inhale, for two or three hours in the afternoon, an exceedingly corrupted air, and suffer the penalty in headaches, colds, bilious and nervous attacks.

Few of our schools are well regulated in this respect. It is now several years since, on the occasion of a visit to one of the classes of a great public seminary, my attention was first strongly attracted to the injury resulting to the mental and bodily functions from the inhalation of impure air. About 150 boys were assembled in one large room, where they had been already confined nearly an hour and a half when I entered. The windows were partly open; but, notwithstanding this, the change from the fresh atmosphere outside to the close contaminated air within was obvious to every sense, and most certainly was not without its effect on the mind itself, accompanied as it was with a sensation of fulness in the forehead, and slight headache. The boys, with every motive to activity that an excellent system and an enthusiastic teacher could bestow, presented an aspect of weariness and fatigue which the mental stimulus they were under could not overcome, and which recalled forcibly sensations long bygone, which I had experienced to a woful extent, when seated on the benches of the same school.

These observations stirred up a train of reflections ; and when I called to mind the freshness and alacrity with which, when at school, our morning 
operations were carried on, the gradual approach to languor and yawning which took place as the day advanced, and the almost instant resuscitation of the whole energies of mind and body that ensued on our dismissal, I could not help thinking that, even after making every necessary deduction for the mental fatigue of the lessons, and the inaction of body, a great deal of the comparative listlessness and indifference was owing to the continued inhalation of an air too much vitiated to be able to afford the requisite stimulus to the bloot, on which last condition the efficiency of the brain so essentially depends. This became the more probable, on recollecting the pleasing excitement occasionally experienced for a few moments, from the rush of fresh air which took place when the door was opened to admit some casual visiter. Indeed, on referring to the symptoms induced by breathing carbonic acid gas or fixed air, it is impossible not to perceive that the headache, languor, and debility consequent on confinement in an ill-ventilated apartment, or in air vitiated by many people, are nothing but minor degrees of the same process of poisoning which ensues on immersion in fixed air. Of this latter state, "great heaviness in the head, tingling in the ears, troubled sight, a great inclination to sleep, diminution of strength, and falling down," are stated by Orfila as the chief symptoms, ${ }^{*}$ and every one knows how closely these resemble what is felt in crowded halls,

Another instance of the noxious influence of vitiated air, which made a very strong impression on my mind, was during a three hours' service in a crowded country church, in a warm Sunday in July. The windows were all shut, and in consequence the open door was of little use in purifying the atn osphere, which was unusually contaminated, not ce ly by the respiration of so many people, but by ite

- Toxicologie, ii. 422.

Q 2 


\section{EFFECTS OF DEFICIENT VENTILATION.}

very abundant perspiration from the skin excited by the heat and confinement. Few of the lower classes, either in town or country, extend their cleanliness beyond the washing of the hands and face. Hence the cutaneous exudation, in such persons, is characterized by a strong and naur seous smell, which, when concentrated, as it was on this occasion, becomes absolutely overpowering. Accordingly, at the conclusion of the service, there was heard one general buzz of complaint of headache, sickness, and oppression; and the reality of the suffering was amply testified by the pale and wearied appearance even of the most robust.

One of the evils of ignorance is, that we often sin and suffer the punishment, without being aware that we are sinning, and that it is in our power to escape the suffering by avoiding the sin. For many generations, mankind have experienced the evil results of deficient ventilation, especially in towns, and suffered the penalty of delicate health, headaches, fevers, consumptions, cutaneous and nervous diseases ; and yet, from ignorance of the true nature and importance of the function of respiration, and of the great consumption of air in its performance, architects have gone on planning and constructing edifices and houses, without bestowing a thought on the means of supplying them with fresh air, although animal life cannot be carried on without it: and while ingenuity and science have been taxed to the uttermost to secure a proper supply of water, the admission of pure air, though far more essential, has been left to steal in like a thief in the night, through any hole it can find open. In constructing hospitals, indeed, ventilation has been thought of, because a notion is prevalent that the sick require fresh air, and cannot recover without it; but it seems not to have been perceived, that what is indispensable for the recovery of the sick may be not less advantageous in preserving from sickness those 
who are well. Were a general knowledge of the structure of man to constitute a regular part of a liberal education, such inconsistencies as this would soon disappear, and the scientific architect would speedily devise the best means for supplying our houses with pure air, as he has already supplied them with pure water.

That these remarks are not uncalled for, even as tegards hospitals, may be conceived from the subjoined quotations from the Lancet of 29 th December, 1832. After narrating a case of a patient who was carried off by pleurisy, while under treatment by Dr. Elliotson, in St. 'Thomas's Hospital, for disease of pylorus, the reporter gives his opinion, that the pleurisy " was most likely occasioned by the extreme draughts of this ward. There is a great current of air in the ward; and I have seen many persons in it suffer very much indeed." In a note, it is added, "The number of patients who are thus carried off yearly forms a startling list to be laid before the eyes of the governors of this institution. Such results are shamefully frequent." I fear there are many other hospitals as much in need of improvement in this respect as that of St. Thomas's.

As a contrast to the above case, it is gratifying to observe the care which has been taken to effect a thorough and safe ventilation in fitting up the new surgical wards of the Edinburgh Infirmary, which may serve as a specimen of what ought to be done, not only with all public institutions, but I may add with all private dwellings. In these wards fresh air is introduced by large circular openings in the floor, and the vitiated air escapes by similar openings in the roof. The apparatus is so constructed as to admit of the air being heated in winter before it enters the ward, by which means all danger from cold currents is prevented.

That the evils which sound physiology would lead us to anticipate from frequently breathing im- 
pure air actually occur, is not a matter of doubt. Among other writers, Mr. Thackrah, in his excellent little work on the effects of trades and professions on health, expresses himself strongly to this effect, and specially notices that dyspeptic symptoms are often the first indications of the commencing disease, and that the lungs suffer only after the digestive system has been for a time disordered. It may not be easy to explain why the stomach and bowels should suffer even sooner than the lungs themselves, from a cause which seems exclusively directed to the latter; but observation substantiates the fact, and it is one of much interest in enabling us to trace to their true sources many of the forms of bad health prevalent in the middle ranks of life.

Although, however, the first effects are so often referable to the stomach, the lungs and general system sooner or later become implicated. An individual possessing a strong constitution may indeed withstand the bad consequences of occasionally breathing an impure atmosphere, but even he will suffer for the time. He will not experience the same amount of mischief from it as the invalid, but will be perfectly conscious of a temporary feeling of discomfort, the very purpose of which is, like pain from a blow, to impel him to shun the danger, and seek relief in a purer air. The comparative harmlessness of a single exposure is the circumstance which blinds us to the magnitude of the ultimate result, and makes us fancy ourselves safe and prudent, when every day is surely though imperceptibly adding to the sum of the mischief. But let any one who doubts the importance of this condition of health watch the dyspeptic, the pulmonary, or the nervous invalid through a season devoted to attendance on crowded parties and public amusements, and he will find the frequency of headaches, colds, and other fits of illness increase in exact proportion to the accumulated exposure, till, at the end 
of spring, a general debility has been induced, which imperatively demands a cessation of festivity and a change of scene and air. This debility is often ignorantly ascribed to the unwholesome influence of spring,-a season extolled by the poet, not as a cause of relaxation and feebleness, but as the dispenser of renovated life and vigour to all created beings.

It is in vain to warn such persons beforehand that Nature is always consistent, and that if bad air be really unfit for healthy respiration, it must be detrimental to them, and to all who breathe it; and that its ill effects are not less real because at first gradual and unperceived in their approach. They know too little of the animal economy and of nature's laws, and are too much devoted to their own object, to be impressed by cautions of this kind; and, in looking forward to the ball-room or crowded evening-party, few of them will believe that any possible connexion can exist between breathing its vitiated atmosphere and the headaches, indigestion, and cutaneous eruptions which so frequently follow, and to be delivered from which they would sacrifice almost every other enjoyment.

If it be said that nobody will be troubled with all this trifling care, and that thousands who expose themselves in every way nevertheless enjoy good health and a long life, I can only answer that it is true ; but that an infinitely greater proportion pass through life as habitual invalids, and scarcely know, from experience, what a day of good health really is. The late discussions on the Factory Bill have demonstrated, by an unassailable mass of evidence, that many circumstances, rarely considered as injurious, because they have no immediate effect in suddenly destroying life by acute diseases, have nevertheless a marked influence in slowly undermining health and shortening humañ existence. There are trades, for example, at which workmen 
may labour for fifteen or twenty years without having been a month confined by disease during all that time, and which are therefore said to be healthy trades; and yet, when the investigation is pursued a little farther, it is found that the general health is so steadily, although imperceptibly, encroached upon, that scarcely a single workman survives his fortieth or fiftieth year.

It is this insidious influence of impure air to which I am anxious to direct attention. So long as delicacy is the rule, and robust health the exception, especially among females, and so long as fifty or sixty thousand persons perish annually in Great Britain from consumption alone, it will be difficult to persuade any rational and instructed mind that every cause of disease is already removed, and that further care is superfluous. My own conviction, on the contrary, is, that by proper care, and a stricter observance of the laws of the animal economy on the part of the parents and guardians of the young, the development of the disease might be prevented in a large proportion of the number, and that even the robust would enjoy health in a higher degree, and with increased security. It is an instructive proof of this, that those who have directed their chief attention to training either man or animals for athletic exercises, or the race-course, have been led, by observation, to attach the utmost importance to pure air. Sir John Sinclair has been at pains to collect the rules followed by Jackson, the celebrated trainer, and others of the same profession; and he tells us that, by all of them, the necessity of pure air is uniformly insisted upon. Sir John adds, that the same condition was deemed so essential by the ancients, that the Roman Athletæ established their principal schools at Capua and Ravenna, as the most pure and healthy air of all Italy; and that, in the training of race-horses, and even of game-cocks, 
the most sedulous attention is paid to the purity of the air in which they live.

The necessity for adequate ventilation is nowhere more urgent than in many of our manufactories, where, from the length of time (varying from 10 to 17 hours a day) during which the operatives are exposed to the evils of impure air, a great sacrifice , of health and happiness is constantly going on. The dust floating in the air in cotton manufactories and spinning-mills, and produced in many trades, is a very serious aggravation of their situation, as all foreign bodies thus inhaled into the lungs produce irritation in their structure, and sooner or later lead to the development of fatal pulmonary disease.

In the third chapter, I pointed out the necessity of protecting the skin by suitable clothing, and men tioned the intimate relation which subsists between its function and those of the lungs. We have now to consider this subject a little further, as regards the origin and regulation of the animal heat.

The true sources of animal heat are still imperfectly known, and any discussion concerning them would be too abstract for the present volume. Its regular production, however, is an essential condition of life. If the human body did not possess within itself the power of generating heat, so as to maintain nearly an equality of temperature in all climates, it could not long exist. In winter, and especially in the northern regions, the blood would speedily be converted into a solid mass, and life be extinguished, if no provision existed for replacing the caloric withdrawn from the system by the surrounding cold. In most parts of the globe, the heat of the atmosphere is, even in summer, inferior to that of the human body, and consequently a loss of caloric is always going on, which must be made up in some way, otherwise disease and death would speedily ensue. In cholera a very remarkable diminution of 
heat occurs, and a return to the natural temperature is an indispensable step towards recovery.

The relation between the production of animal heat, and the condition of the respiratory functions, is the most direct and remarkable. In general, other conditions being alike, heat is generated more or less freely, in proportion to the size and vigour of the lungs; and when these are impaired, the production of heat is diminished. Hence many persons with imperfectly developed lungs, and a predisposition to consumption, complain habitually of coldness of the surface and feet ; and many who were previously in good health become more and more sensible to cold, in proportion as the approach of disease weakens the functions of the lungs. I have noticed this increased sensibility to cold, as a precursor of chronic pulmonary disease, both in myself and others, before any other very ostensible symptonı had appeared, and think I have seen its farther progress arrested by the timely use of proper means, where much greater difficulty would have been experienced had the warning not been attended to.

The generation of heat in the living system being so immediately connected with the lungs, we find the temperature highest in those animals who possess them in the greatest perfection, viz. birds. In many species, the internal heat exceeds that of man by twenty or thirty degrees; while that of man ex ceeds, to as great an extent, the heat of such of the inferior animals as are remarkable for imperfect organs of respiration.

The next condition affecting the production of animal heat is the co-operation of the nervous system. If the mind be depressed by grief, tormented by anxiety, or absorbed in sedentary meditation, all the bodily functions become weakened, the circulation languishes, the breathing becomes slow and scarcely perceptible, digestion is ill performed, and 
coldness of the extremities ensues. If, on the other hand, the mind and nervous system be stimulated by cheerful exertion and agreeable emotions, a pleasant glow pervades the frame, and external cold is much more easily resisted.

The quantity and quality of the food and state of the digestive functions are also important conditions. This will be readily assented to, when the reader considers that a due supply of well-formed chyle is required to restore the nourishing properties of the blood, and that if, in consequence either of insufficient food or of weak digestion, this be rendered impossible, all the animal functions, among others the production of heat, must necessarily be impaired. This is the reason why cold is felt most severely in the morning before breakfast, and why coldness of the feet and chilliness of the surface are so generally complained of in indigestion and bilious complaints.

Everybody knows that exercise favours, and indolence obstructs, the development of animal heat. Exercise produces its effect by the general stimulus which it gives directly to the respiratory and circulating systems, and indirectly to the nervous and digestive functions.

In attempting, therefore, to increase the power of resistance to cold in the human body, we ought to take into account all the conditions which favour the generation of heat. Observation proves that the degree of cold required to overcome the internal generating power, and to extinguish life, varies in the same individual at different times; and therefore our protecting measures also ought to be varied according to the state of the constitution, the vigour of the respiratory and digestive functions, the kind of food, and the amount of exercise. When the food is inadequate, and the mind depressed, the system resists the impression of cold with great difficulty; and even in Scotland, where the tempera- 
ture is rarely very low, scarcely a winter passes without several instances of death occurring from exposure in ill-fed and ill-clothed individuals, even when the thermometer is above the freezing point. This happens usually when a high wind aids the rapid abstraction of heat. Well-fed and well-clothed guards of coaches, on the other hand, are remarkable examples of the power of withstanding low temperatures in very exposed situations, where the animal functions are in a state of vigour. The recent Arctic expeditions under Parry and Franklin afford similar instances.

Having already, when treating of the skin, sufficiently explained the principles on which clothing ought to be adjusted, it is unnecessary to recur to its utility as a means of regulating the temperature of the human body. If the use of suitable clothing is found insufficient to keep the body warm, we may infer with certainty, although no other sign of bad health has appeared, that some internal cause exists, affecting and impairing one or other of the sources of animal heat already mentioned, and that till the special cause be discovered and removed, the evil itself will continue undiminished.

In winter, young people often suffer from being daily confined for many hours in succession, without exercise, in rooms insufficiently heated. This is a constant subject of complaint in large acad. emies and boarding-schools, where economy in fuel is carried to its utmost limits. Nothing tends more than this to lower the general standard of health, and prepare the individual for the future inroads of insidious diseases. In scrofulous children especially, in whom the evolution of heat is rarely energetic, the evil is one of great magnitude, for the chilblains, colds, and headaches more immediately complained of are often its least important consequences. It is far from $\mathrm{my}$, wish to recommend that the young of either sex should be brought up in 
the relaxing atmosphere of overheated rooms. On the contrary, comfortable warmth ought, in every instance, to be drawn chiefly from its legitimate sources, free respiration in a pure air, abundant outdoor exercise, vigorous digestion, and an actively employed mind. If these conditions be observed, little fire will be required to supply warmth to the young. But if, as often happens, these be neglected, and the generation of animal heat be thereby reduced too low, we must either allow the mischief to go on increasing, or afford adequate warmth from without. It is in vain to think of rendering young creatures hardy by subjecting them to the continued influence of a depressing temperature. A few may escape, but the majority will certainly suffer.

In the heating of rooms and public halls, it is proper to be on our guard against rendering the air too dry, a condition which is hurtful in causing too rapid evaporation from the whole line of the airpassages, as well as from the surface of the body, and which is apt to produce considerable irritability in the general system. On the Continent, where stoves are much in use, a vessel containing water is commonly placed on a sand-bath on the top, that moisture may be generated quickly or slowly, according to the degree of heat, and diffused through the atmosphere. In such of our halls as are warmed by heated air or stoves, some such plan ought to be adopted.

Having thus examined the chief conditions required for healthy respiration, it only remains for us to throw out a few practical hints in regard to what may be called the education of the lungs, or the means by which their development may be favoured, and their functions improved in tone and extent. Most of these means have been already noticed at some length, and the only important one which still claims our attention is the exercise of the lungs. 
Judicious exercise of the lungs is one of the most efficacious means which we can employ for promoting their development and warding off their diseases. In this respect the organs of respiration closely resemble the muscles and all other organized parts. They are made to be used, and if they are left in habitual inactivity their strength and health are unavoidably impaired; while, if their exercise be ill-timed or excessive, disease will as certainly follow.

The lungs may be exercised indirectly by such kinds of bodily or muscular exertion as require quicker and deeper breathing; and directly by the employment of the voice in speaking, reading aloud, crying, or singing. In general, both ought to be conjoined. But where the chief object is to improve the lungs, those kinds which have a tendency to expand the chest, and call the organs of respiration into play, ought to be especially preferred. Rowing a boat, fencing, quoits, shuttlecock, and the proper use of dumb-bells and gymnastics are of this description. All of them employ actively the muscles of the chest and trunk, and excite the lungs themselves to freer and fuller expansion. Climbing up hill is, for the same reason, an exercise of high utility in giving tone and freedom to the pulmonary functions.

Where, either from hereditary predisposition or accidental causes, the chest is unusually weak, cvery effort should be made, from infancy upwards, to favour the growth and strength of the lungs by the habitual use of such of the above-mentioned exercises as can most easily be practised. The earlier they are resorted to, and the more steadily they are pursued, the more certainly will their beneficial results be experienced. In their employment, the principles explained in the chapter on the muscles ought to be adhered to.

Habitual exercise in a hilly country, and the fre- 
quent ascent of acclivities, especially in pursuit of an object, are well known to have a powerful effect in improving the wind and strengthening the lungs, which is just another way of saying that they increase the capacity of the chest, promote free circulation through the pulmonary vessels, and lead to the more complete oxygenation of the blood. Hence the vigorous appetite, the increased muscular power, and cheerfulness of mind so commonly felt by the invalid on his removal to the mountains are not to be wondered at. I was myself sensible of advantage from this kind of exercise during a Highland excursion. The necessity of frequent and deep inspirations, and the stimulus thus given to the general and pulmonary circulation, had an obvious effect in increasing the capacity of the ungs, and the power of bearing exertion without fatigue. Even when I was wearied, the fatigue went off much sooner than after a walk of equal length on a level road, and it was unattended with the languor which generally accompanied the latter. In fact, the most agreeable feeling which I experienced during the whole time was on resting after undergoing, in ascending a hill, a degree of exertion sufficient to accelerate the breathing, and bring out a considerable degree of perspiration. A lightness and activity of mind, and freedom about the chest which I never felt to the same extent at any other time, followed such excursions, and made the fatigue comparatively light.

Before such practices, however, can bé resorted to with advantage, or even with safety, there must be nothing in the shape of active disease existing. If there be, the adoption of such exercise will, in all probability, occasion the most serious injury. This also I experienced in my own case, as, for many months at an earlier stage of convalescence, going up a stair, ascending the most gentle acclivity, or speaking aloud for a few minutes, was equally R 2 
fatiguing and hurtful, and often bronght on cough, and occasionally a slight spitting of blood. At that time, riding on horseback, which exercises the body without hurrying the breathing, was especially useful. The advantage of these exercises in giving tone and capacity to the lungs, where debility rather than disease is complained of, is shown in their being regularly resorted to in preparing for the race-course and for the field. The true sportsman puts himself in training as well as his dog or his horse, and fits himself for the moors by regular excursions previous to the 12th of August. By so doing he improves his wind and increases his mus. cular strength to a remarkable extent in a very short time.

When no active pulmonary disease exists, these exercises may, with the best effects, be frequently carried so far as to induce free perspiration; only great care ought to be taken immediately after, to rub the surface of the body thoroughly dry, and to change the dress. It is quite ascertained, that with these precautions perspiration from exercise is the reverse of debilitating. It equalizes and gently stimulates the circulation, relieves the internal organs, improves digestion, and invigorates the skin. Jackson testifies strongly to these results when he declares that the severe exercise incurred in train. ing not only improves the lungs, but always renders the skin "quite clear, even though formerly subject to eruptions." "These assertions are, of course, to be received as the statements of a man partial to his own art; but they are in accordance with experience, and with the laws of the animal functions, so far as these are known. They therefore nierit the consideration of professional men, and of those whose features are often disfigured by eruptions

Code of Health, 5th edition. A ppendix, p. 37. 
which they find it difficult to remove by any kind of medicine.

I need hardly say, that when wishing to favour the development of the lungs, we ought to be scrupulous in avoiding such positions of the body as hinder their full expansion. Tailors, shoemakers, clerks at a writing-desk, and the like, are unfavourably situated in this respect, as their bent position constrains the chest, and impedes the breathing and circulation.

Direct exercise of the lungs, in speaking, reciting, singing, and playing on wind instruments, is very influential for good or for evil, according as it is indulged in with or without due reference to the constitution of the individual. If it is, nothing tends more to expand and give tone and health to these important organs; but if either ill-timed or carried to excess, nothing can be more detrimental.

The crying and sobbing of children contribute much to their future health, unless they are caused by disease, and carried to a very unusual extent. The loud laugh and noisy exclamations attending the sports of the young have an evident relation to the same beneficial end; and ought therefore to be encouraged instead of being repressed, as they are often sought to be, by those who, having forgotten that they themselves were once young, seek in childhood the gravity and decorum of more advanced age. I have already noticed, at page 109, an instance on a large scale, in which the inmates of an institution were, for the purpose of preserving their health, shut up within the limits of their hall for six months, and not allowed to indulge in any noisy and romping sports. The aim of the directors was undoubtedly the purest benevolence, but from their want of knowledge, their object was defeated, and the arrangement itself became the instrument of evil.

Beneficial as the direct exercise of the lungs is 
thus shown to be in strengthening the chest, its influence extends still farther. If we examine the position of the lungs as represented in the figure on page 169, we shall see, that, when fully inflated, they must necessarily push downwards and flatten the moveable arch of the diaphragm D D, by which they are separated from the belly or abdomen. This alteration, however, cannot take place without the diaphragm in its turn pushing down the liver, stomach, and bowels, which it accordingly does, causing them to project forwards and outwards. But no sooner are the lungs fully inflated than the contained air is again thrown out. The lungs diminish in size : the diaphragm rises, and with it all the contents of the abdomen return to their former position. The whole digestive apparatus is thus subjected to a continual pressure and change of place, and the stimulus thence arising is, in truth, essential to the healthy performance of the digestive functions, and is one of the means arranged by the Creator for the purpose. Consequently, if the lungs be rarely called into active exercise, not only do they suffer, but an important condition of digestion being withdrawn, the stomach and bowels also become weakened, and indigestion and costiveness make their appearance. I have already alluded to this subject in the chapter on muscular exercise; but the principle will now be better understood with the aid of the figure.

After this exposition, I need hardly say that the loud and distinct speaking enforced in many public schools is productive of much good to the young, and that in this respect the occasional songs in which all are required to join in the Infant Schools, and other institutions, are much to be commended. Let any one who doubts their efficacy as exercises of the lungs, attend to what passes in his own body on reading aloud a single paragraph, and he will find, not only that deep inspirations and full expira. 
tions are encouraged, but that a considerable impulse is communicated to the bowels, affording a marked contrast to the slight breathing and quiescent posture of those whose voices never rise above a whisper.

Reading aloud, public speaking, and lecturing are excellent exercises for developing the lungs and the chest. But, as they require some exertion, they ought to be indulged in with prudence, and with constant reference to the constitution and health of the individual. When early resorted to, and steadily persevered in, they are useful in warding off disease and communicating strength to an important function. But when begun suddenly, and carried to excess by persons with weak lungs, they are more directly injurious than almost any other cause. It is not uncommon for young divines to give themselves up to preaching, without any previous preparation for the effort which it requires, and to experience, in consequence, pains in the chest, spitting of blood, and other dangerous forms of disease, which often extinguish their brightest prospects in the morning of life. Sacrifices of this kind are the more to be lamented, because it is probable, that, by a well-planned system of gradual preparation, many who fall victims might find in their profession even a source of safety.

The late illustrious Cuvier, as was mentioned at page 135, is considered to have been saved from an early death by his appointment to a professorship leading him to the moderate and regular exercise of his lungs in teaching,-a practice which soon re. moved the delicacy of chest to which he was subject, and enabled him to pass uninjured through a long life of active usefulness. Other examples of the same kind might be mentioned. But it is important to observe, that in all of them the exercise was, at all times, accurately proportioned to the existing state of the lungs. Had active disease ex- 
isted, or the exertion required been beyond what the lungs were fully able to bear, the effect would have been, not to improve health, but to destroy life; and this condition of accurate relation between the amount of exercise and the state of the organization must never for a moment be overlooked. With a little care, however, the point at which direct exercise of the lungs ought to stop may easily be determined by observing its effects.

The same principle leads to another obvious rule. When disease of any kind exists in the chest, the exercise of the lungs in speaking, reading, and singing, and also in ordinary muscular exertion, ought either to be entirely refrained from or strictly regulated by professional advice. When a joint is sore or inflamed, we know that motion impedes its recovery. When the eye is affected, we, for a similar reason, shut out the light; and when the stomach is disordered, we have respect to its condition, and become more careful about diet. The lungs demand a treatment founded on the same general principle. If they are inflamed, they must not be exercised, otherwise mischief will ensue. Hence, in a common cold of any severity, silence, which is the absence of direct pulmonary exercise, ought to be preserved, and will in truth be its own reward. In severe cases, and in acute inflammations of the chest, this rule is of the greatest importance. It is common to meet with patients who cannot speak three words without exciting a fit of coughing, and who, notwithstanding, cannot be persuaded that peaking retards their recovery. In like manner, in spitting of blood, and in the early stage of tubercular consumption, when the breathing cannot be excited without direct mischief, it is often difficult to convince the patient of the necessity of silence. He perhaps does not feel pain on attempting to speak, and says that "it merely raises a short tickling cough, which is nothing." But if he persists, 
dearly-bought experience will teach him his error, and dispose him to regret, as did a lamented friend of the author, that a few weeks of the many years usually dedicated to the classics had not been devoted to communicating to him some knowledge of the structure and functions of his own body. In the instance alluded to, after spitting of blood had been induced by severe bodily labour, the patient continued talking almost the whole day to the visiters and inmates of a large public establishment, and believed himself all the time to be very careful, as he said he was no longer exerting his body. When the error was pointed out, and the mechanism of the lungs explained to him, he deeply bewailed the ignorance which had allowed him to act in a manner so pernicious.

All violent exercise ought, for similar reasons, to be refrained from, during at least the active stages of cold. Every thing which hurries the breathing, whether walking fast, ascending an acclivity, or reading aloud, has the same effect on the diseased lungs that motion of the bones has on an inflamed joint. It seems to me, that many people hurt themselves much more by the active exercise they take during a severe cold than by the mere exposure to the weather. It is well known, that a person when colded may go out for a short time, even in an open carriage more safely than on foot, and there is much reason to believe, that it is the absence of active exertion of the lungs in the former case which makes the exposure less hurtful.

After al' active disease has been subdued, or when nothing bun delicacy remains, the adequate exercise of the lungs is one of the best means of promoting effectual recovery. Those parents, therefore, act most erroneously, who, in their apprehensive anxiety for the protection of their delicate children, scrupulously prohibit them from every kind of exer. cise which requires the least effort, and shut them 


\section{PREVENTION OF DISEASE IN THE LUNGS.}

up from the open air during winter, with the false hope of thereby warding off colds and protecting their lungs. I have seen the greatest delicacy of constitution thus engendered, especially where an undue quantity of warm clothing was at the same time employed. When tested by the principles above explained, such conduct is found to be as ill adapted as possible to the end in view, and utterly at variance with all the laws of the animal economy.

Perhaps the most important time in the life of a person born with a predisposition to consumption is that of puberty, coniprising from the commencement of rapid growth to the full consolidation of the sys. tem about or after the twenty-first year. In most young people, the transition from adolescence to maturity is so rapid, that for two or three years all the animal powers are tasked to enable nutrition to keep pace with growth, and a corresponding debility of both body and mind is often observed to co-exist, indicating, in the clearest manner, the necessity of a temporary remission from such studies and occupations as require much mental exertion or confinement within doors. The development and health of the physical system ought then to be almost exclusively attended to; and when the bod- has acquired its solidity, the mental faculties will again become active. I have seen instances where a knowledge of the latter fact afforded substantial consolation to young men who, while their bodies were growing rapidly, were apt to become despondent, on account of the unusual sluggishness and inefficiency of their intellectual powers. In the course of a few years, when the growth and consolidation were completed, the brain vigorously resumed its functions.

In such circumstances, relaxation from study, residence in the country, exercise in the open air, plenty of food, and no care, will often do immense 
good, if sufficiently persisted in, and go far to protect the careful patient against the future invasion of consumption. Whereas, if, under the mistaken notion that such precautionary measures are a waste of time, a delicate growing youth is allowed to continue at his studies or his desk till disease has actually commenced, the disappointed parent will often discover that it is too late to take alarm when health * s gone.

It is at the approach of manhood, when both mind and body are in a state of transition, that dissipation is most indulged in, and presses with its deadliest force. Many delicate youths of both sexes are carried off, who would have escaped without injury, if they could have been persuaded to act with prudence during these two or three critical years. Many, I am constrained to say, first learn the means of their destruction in boarding-schools and places of public resort, and that often when no mischief is suspected by their respectable teachers. On this topic, however, the non-professional character of the present work precludes me from entering into details.

Before quitting this important subject, I may add another word of advice, in regard to those who are predisposed to consumption or weakness of chest. As soon as active growth commences, permanent benefit may be derived from removal, for a few years, to a milder and less variable climate. Many who are sent abroad only to die painfully in a foreign land, in the noonday of life, might have lived for years in the enjoyment of health and usefulness, had they been sent abroad before the appearance of disease, instead of after its unequivocal commencement. The previous delicacy, whence the susceptibility to colds and pulmonary affections arises, ought to attract the earliest attention, and excite the most persevering efforts for its removal. If it be allowed to make progress till consumption has 
commenced, medicine may come armed with its most powerful remedies, and directed by the most consummate skill, but it will too often come in vain, for the patient will be no longer within its reach.

\section{CHAPTER VIII.}

Nervous System-Structure of the Brain-lts FunctionsConnexion between the Mind and Brain-Conditions of Health in the Brain-Hereditary Predisposition-Influence of the Blood on the Brain-Influence of Exercise on the Brain-Effects of insufficient Exercise-Effects of excessive Exercise at different Ages-Case of Sir H. Davy-Rules for the proper Exercise of the Brain-Best Time for Mental Exertion-Regularity essential-Repetition-Every Mental Power to be exercised directly on its own Objects-Illustrations-Influence of the Nervous System on the general Health-Fixamples.

Is man and the higher order of animals, the nervous system is composed of, 1 st, the brain; $2 \mathrm{~d}$, the spinal marrow; and, $3 \mathrm{~d}$, the nerves. But, on the present occasion, it will be necessary to confine our remarks chiefly to the brain; and, even regarding it, to offer observations only on such points as all are agreed upon, and the general reader can easily comprehend.

The brain is that large organized mass which, along with its enveloping membranes, completely fills the cavity of the scull. It is the seat of thought, of feeling, and of consciousness, and the centre towards which all impressions made on the nerves distributed through the body are conveyed, and from which the commands of the will are transmitted to put the various parts in motion.

The structure of the brain is so complicated, that less is known of its true nature than of that of almost 
any other organ. It would therefore be entirely out of place to attempt to describe it here, further than by stating generally its principal divisions. On sawing off the top of the scull, and removing the firm tough membrane called dura mater (hard mother), which adheres closely to its concave surface, the cerebrum, or brain proper, presents itself, marked on the surface, with a great variety of undulating windings or convolutions, and extending from the fore to the back part of the head, somewhat in the form of an ellipse. In the middle line, a deep fissure is perceived, into which dips a fold of the dura mater, named the falx, separating the brain, in its whole length, into two halves, or hemispheres, as they are called. Each hemisphere is, in its turn, divided,-but in a less marked way, as the divisions are observable only on its inferior surface,-into three portions, called, from their situations, the anterior, middle, and posterior lobes, each occupying nearly a third of the whole length of the brain. The anterior lobe occupies the forehead; the middle is all the portion of brain lying above and a little in front of the ears; and the posterior fills the back part of the head.

Beneath the posterior lobe, a strong fold of the dura mater, called the tentorium, is extended horizontally to support and separate it from the cerebellum, or little brain lying below it. The cerebellum forms the last great division of the contents of the scull. Its surface is marked by convolutions, dilfer$\mathrm{ng}$, however, in size and appearance from those observed in the brain.

Adhering to the surface of the convolutions, and consequently dipping down into and lining the sulci or furrows between them, another membrane, of a finer texture, and great vascularity, called the pic mater, is found. The blood-vessels going to the brain branch out so extensively on the pia mater, that, when a little inflamed, it seems to constitute a per. 
fect vascular net-work. This minute subdivision is of use in preventing the blood from being impelled with too great force against the delicate tissue of the brain.

A third covering, called the arachnoid membrane, from its fineness resembling that of a spider's web, is interposed between the other two, and is frequently the seat of disease.

On examining the convolutions in different brains, they are found to vary a good deal in size, depth, and general appearance. In the various regions of the same brain they are also different, but preserve the same general aspect. Thus they are always small and numerous in the anterior lobe, larger and deeper in the middle, and still larger in the posterior lobe.

The brain receives an unusually large supply of blood, in comparison with the rest of the body ; but the nature of its circulation, although a very interesting subject of study, being only indirectly connected with our present purpose, cannot now be discussed.

Most physiologists are agreed that the different parts of the brain perform distinct functions, and that these functions are the highest and most important in the animal economy; but there is great discrepancy of opinion as to what the function of each part is, and as to the best mode of removing the obscurity in which the subject is involved. It would be useless to examine here the merits of the respective theories and modes of inquiry, as the attempt would lead us too far from the practical aim of the work. Suffice it to say, that all physiologists and philosophers regard the brain as the organ of mind; that most of them consider it as an aggregate of parts, each charged with a specific function; and that a large majority, with Gall and Cuvier at their head, regard the anterior lobe as more immediately the 
seat of the intellectual faculties.* Further, by nearly universal consent, the brain is held to be also the seat of the passions and moral feelings of our nature, as well as of consciousness and every other mental act, and to be the chief source of that nervous influence which is indispensable to the vitality and action of every organ of the body. There are so few exceptions to the general belief of these propositions, that I consider myself fairly entitled to hold them as established.

Many animals possess individual senses or instincts in greater perfection than man, but there is not one which can be compared with him in the number and range of its faculties; and, as a necessary consequence, there is not one which approaches him in the development and perfection of its nervous system. No organ can execute more than a single function ; and, accordingly, even the Edinburgh Review admits, that, in precise proportion as we ascend in the scale of creation, and the animal acquires a sense, a power, or an instinct, do its nerves multiply and "its brain improve in structure and augment in volume, each addition being marked by some addition or amplification of the powers of the animal, until in man we behold it possessing some parts of which animals are destitute, and wanting none which they possess," so that "we are enabled to associate every faculty which gives superiority, with some addition to the nervous mass, even from the smallest indications of sensation and will, up to the highest degree of sensi-; bility, judgment, and expression." $\dagger$

It is extremely important to bear in mind this con-

* In speaking of the cerebral lobes being the place "where ali the sensations take $a$ distinct form and leave durable impressions," Cuvier adds, "L'anatomie comparée en offre une autre confirmation dans la proportion constante du volume de ces lobes avec le degré d'intelligence des Animaux."-Vide Report to the Institute on Flourens's Experiments in 1822.

† Edinburgh Review, No. xciv. p. 442-3. 
stant relation between mental power and develop. ment of brain. It not only explains why capacities and dispositions are so different, but shows incontrovertibly that the cultivation of the moral and intellectual faculties can be successfully carried on only by acting in obedience to the laws of organization, and associating together those faculties, the organs of which are simultaneously progressive in their growth. It is a law, for instance, that alternate periods of activity and repose conduce to the strength and development of every organ, and to the easy performance of its function, and that excess in either is alike hurtful in its consequences. If, therefore, in our anxiety for the advancement of a child in a favourite pursuit, we urge it to incessant and unvaried exertion of the same kind for many hours a day, we violate this law in neglecting the necessary intervals of rest, and thus run the risk of injuring the health of the brain, and entirely defeating our object. And, on the other hand, if we withdraw the child altogether from the pursuit, for weeks or months at a time, as happens during the vacation of a school, we violate the law again, in depriving the faculties of their necessary exercise, and thus run the risk of sacrificing the improvement already gained, and of diminishing the mental power. In neither case is the brain exercised in conformity with the organic laws, and consequently we look in vain for the same amount of improvement which would have followed their fulfilment ; and yet, so far is the physiology of the brain from being considered as the only sound basis on which the science of education can rest, that very few teachers or moralists are aware that the organic laws have any connexion with the operations of mind, and still fewer have ever thought of adapting their practice to the dictates of these laws; although no truth in education or philosophy can be more clearly proved, or 
CONNEXION BETWEIN THE MIND AND BRATN. 211

more beneficially applied, than that on which I am now insisting.

In thus treating of the brain as the indispensable instrument or organ of the mental faculties, I must not be understood as representing mind and brain to be one and the same thing. I mean only that the brain is necessarily engaged in every intellectual and moral operation, exactly as the eye is in every act of vision ; and that, as the mind cannot see without the intervention of the eye, so neither can it think or feel, during life, except through the instrumentality of the brain. Consequently, it would be as reasonable and logical to infer, from the former proposition, that the eye is the mind, or the mind the eye, as to infer from the latter that the brain is the mind, or the mind the brain.

It requires, however, to be distinctly understood, that activity of mind and activity of brain are inseparable, and that every change in the one is attended by a corresponding change in the condition of the other. If, by the excessive use of stimulants, the brain be highly excited, the mind will be disturbed in an equal degree, as is exemplified every day in the phenomena of intoxication; and if, on the other hand, the mind be suddenly roused by violent passions, the vessels of the brain will instantly take on increased action, redness will suffuse the face, and excitement of the brain will show itself in characters as legible as if produced by a physical cause.

The mind and brain being thus inseparably asso. ciated during life, it becomes an object of primary importance to discover the laws by which their healthy action is regulated, that we may yield them willing obedience, and escape the numerous evils consequent on their violation. To this inquiry the following pages shall be devoted.

The brain being a part of the animal system, and subject to the same general laws as every other organ, the reader will not be surprised that I should, 
as in the case of the lungs, state a sound original constitution as the first condition of its healthy action. If the brain possess from birth a freedom from all hereditary taints and imperfections, and have acquired no unusual susceptibility from injudicious treatment in infancy, it will withstand a great deal in after-life before its health will give way. But if, on the other hand, either it inherit deficiencies, or early mismanagement have subsequently entailed upon it an unusual proneness to morbid action, it will give way under circumstances which would otherwise have been perfectly innocuous: and, accordingly, it may be truly said, that the most powerful of all the causes which predispose to nervous and mental disease is the transmission of a hereditary tendency from parents to children, producing in the latter an unusual liability to the same naladies under which the parents have laboured.

Even where the defect in the parent is merely some peculiarity of disposition or temper, amounting perhaps to eccentricity, it is astonishing how clearly its influence on some one or other of the progeny may be traced, and how completely a constitutional bias of this description may interfere with a man's happiness or success in life. I have seen instances in which it pervaded every member of a family, and others in which it affected only one or two. When the original eccentricity is on the mother's side, and she is gifted with much force of character, the evil extends more widely among the children than when it is on the father's side. Where both parents are descended from tainted families, the progeny is of course more deeply affected than where one of them is from a pure stock; and, seemingly for this reason, hereditary predisposition is a more usual cause of nervous disease in the higher classes, who intermarry much with each other, than in the lower, who have a wider choice.

Unhappily, it is not merely as a cause of disease 
that hereditary predisposition is to be dreaded. The obstacles which it throws in the way of permanent recovery are even more formidable, and can never be entirely removed. Safety is to be found only in avoiding the perpetuation of the mischief; and, therefore, if two persons, each naturally of an excitable and delicate nervous temperament, choose to unite for life, they have themselves to blame for the concentrated influence of similar tendencies in destroying the health of their offspring, and subjecting them to all the miseries of nervous disease, madness, or melancholy.

Even where no hereditary defect exists, continued excitement of the nervous functions in the mother, from anxiety, grief, or other causes, during pregnancy, has often a striking effect on the future mental health and constitution of the offspring. Many authors testify to the truth of this fact, which has not escaped the penetration of some mothers. The Margravine of Anspach observes justly, that " when a female is likely to become a mother, she ought to be doubly careful of her temper; and, in particular, to indulge no ideas that are not cheerful, and no sentiments that are not kind. Such is the connexion between the mind and body, that the features of the face are moulded commonly into an expression of the internal disposition; and is it not natural to think that an infant, before it is born, may be affected by the temper of its mother?"-Memoirs, vol. ii. chap. viii.

The second condition required for the health of the brain is a due supply of properly oxygenated blood. The effects of slight differences in the quality of the blood are not easily recognised, but when extreme they are too obvious to be overlooked. If the stimulus of arterial blood be altogether withdrawn, the brain ceases to act, and sensibility and consciousness become extinct. Thus, when fixed air is inhaled, the blood circulating 


\section{INFLUENCE OF THE BLOOD ON THE BRAIN.}

through the lungs does not undergo that process ot oxygenation which is essential to life; and as it is in this state unfit to excite or support the action of the brain, the mental functions become impaired, and death speedily closes the scene. If, on the other hand, the blood be too highly oxygenated, as by breathing oxygen gas instead of common air, the brain is too much stimulated, and an intensity of action, bordering on inflammation, takes place, which also soon terminates in death.

Such are the consequences of the two extremes; but the slighter variations in the state of the blood have equally sure, although less palpable, effects. If its vitality be impaired by breathing an atmosphere so much vitiated as to be insufficient to produce the proper degree of oxygenation, the blood then affords an imperfect stimulus to the brain; and as a necessary consequence, languor and inactivity of the mental and nervous functions ensue, and a tendency to headache, syncope, or hysteria makes its appearance. This is seen every day in the listlessness and apathy prevalent in crowded and illventilated schools; and in the headaches and liability to fainting which are so sure to attack persons of a delicate habit in the contaminated atmosphere of crowded theatres, churches, and assemblies. It is seen less strikingly, but more permanently, in the irritable and sensitive condition of the inmates of cotton-manufactories and public hospitals. In these instances, the operation of the principle cannot be disputed, for the languor and nervous debility consequent on confinement in ill-ventilated apartments, or in air vitiated by the breath of many people, are neither more nor less than minor degrees of the same process of poisoning to which I have formerly alluded. It is not real debility which produces them; for egress to the open air almost instantly restores activity and vigour to both mind and body, unless the exposure has been very long, in which 
case more time is required to re-establish the exhausted powers of the brain. A good deal of observation has convinced me, that the transmission of imperfectly oxygenated blood to the brain is greatly more influential in the production of nervouis disease and delicacy of constitution than is commonly imagined; and I am delighted to see the same truth so powerfully insisted on by Mr. Thackrah from extensive experience in the manufacturing dis. trict about Leeds. Having, however, dwelt on this subject in the preceding chapter, I need not repeat the observations already made.*

Although, in delicate constitutions, the health of the brain and nervous system is often impaired by inadequate nutrition, and a sufficient supply of nourishing food is therefore indispensable to their wellbeing, yet, as this condition is implied in the preceding, and its separate consideration would lead us too far from our main object, I shall not dwell upon it here. I shall merely state, that starvation often affects the brain so much as to produce ferocious delirium, and that, in the Milanese, a species of insanity arising from defective nourishment is very prevalent, and is easily cured by the nourishing diet provided in the hospitals to which the patients are sent. I have seen the mental functions weakened, and the brain disordered, by the same causeinadequate nutrition - at the period of rapid growth. This defective nutrition, however, it must be observed, does not always depend on want of proper

* An intelligent teacher in Edinburgh, to whom I communi cated the above views, and who immediately set about acting on them by turning his pupils out to play, and throwing open the door and windows for ten minutes at the end of the first hour's confinement, assures me that the difference between the languor and little power of sustained attention exhibited under the old system, and the activity shown under the new, is very marked, and that the interval of relaxation is most profitably spent time both to his pupils and himself, as they return to work with new life. 


\section{INFLUENCE OF EXERCISE ON THE BRAIN}

food. On the contrary, it is often the result, among the higher classes, of too much or too stimulating food over-exciting and ultimately impairing the digestive powers. The proneness to morbid excitement in the brain, induced by insufficient food, is one cause why, in times of public distress, the lower orders are so apt to resort to violence to remove the sources of their discontent.

"The THIRD condition of health in the brain and nervous system, and that to which it is the chief object of these pages to direct attention, is the regular exercise of their respective functions, according to the laws already so frequently referred to, and so fully explained in one of the preceding chapters.*

The brain, being an organized part, is subject, in so far as regards its exercise, to precisely the same laws as the other organs of the body. If it be doomed to inactivity, its functions languish, and its health decays. If it be duly exercised, after regular intervals of repose, its functions acquire readiness and strength; and, lastly, if it be over-tasked, either in the force or duration of its activity, its functions become impaired, and irritability and disease take the place of health and vigour.

The consequences of inadequate exercise may be first explained.

We have seen that, by disuse, muscle becomes emaciated, bone softens, blood-vessels are obliterated, and nerves lose their characteristic structure. The brain is no exception to this general rule. Of it also the tone is impaired by permanent inactivity, and it becomes less fit to manifest the mental powers with readiness and energy. Nor will this surprise any reflecting person, who considers that the brain, as a part of the same animal system, is nourished by the same blood, and regulated by the same vital laws, as the muscles, bones, and nerves.

* See Chapter IV., and also p. 156. 
It is the weakening and depressing effect upon the brain of the withdrawal of the stimulus necessary for its healthy exercise, which renders solitary confinement so severe a punishment even to the most daring minds. It is a lower degree of the same cause which renders continuous seclusion from society so injurious to both mental and bodily health, and which often renders the situation of governesses one of misery and bad health, even where every kindness is meant to be shown towards them. In many families, especially in the higher ranks, the governess lives so secluded that she is as much out of society as if she were placed in solitary confinement. She is too much above the domestics to make companions of them, and too much below her employers to be treated by them either with confidence or as an equal. With feelings as acute, interests as dear to her, and a judgment as sound as those of any of the persons who scarcely notice her existence, she is denied every opportunity of gratifying the first or expressing the last, merely because she "is only the governess ;" as if governesses were not made of the same flesh and blood, and sent into the world by the same Creator, as their more fortunate employers. It is, I believe, beyond question, that much unhappiness, and not unfrequently madness itself, are unintentionally caused by this cold and inconsiderate treatment. For the same reason, those who are cut off from social converse by any bodily infirmity often become discontented and morose in spite of every resolution to the contrary. The feelings and faculties of the mind, which had formerly full play in tlieir intercourse with their fellow-creatures, have no longer scope for sufficient exercise, and the almost inevitable result is irritability and weakness in the corresponding parts of the brain.

This fact is particularly observed among the deaf and blind, in whom, from their being cut off 
from a full participation in the same sources of in terest as their more favoured brethren, irritability, weakness of mind, and idiocy are known to be much more prevalent than among other classes of people. In the Dictionnaire de Médècine (vol. xx. p. 87), Andral gives a description of the deaf and dumb, every word of which bears a direct reference to the above principle; and a nearly similar account has been lately given of the blind by an equally intelligent observer. "The deaf and dumb," says Andral, "presents, in his intelligence, character, and the development of his passions, certain modifications which depend on his state of isolation in the midst of society. He remains habitually in a state of half-childishness, is very credulous, but, like the savage, remains free from many of the prejudices acquired in society. In him the tender feelings are not deep; he appears susceptible neither of strong attachment nor of lively gratitude; pity moves him feebly; he has little emulation, few enjoyments, and few desires. This is what is contmonly observed in the deaf and dunib, but the picture is far from being of universal application; some, more happily endowed, are remarkable for the great developnent of their intellectual and moral nature, but others, on the contrary, remain immersed in complete idiocy." Andral adds, that we must not infer from this that the deaf and dumb are therefore constitutionally inferior in mind to other men. "Their powers are not developed, because they live isolated from society: place them, by some means or other, in relation with their fellow-men, and they will become their equals." This is the cause of the rapid brightening up of both mind and features, which is so often observed in blind or deaf children, when transferred from home to public institutions, and there taught the means of converse with their fellows. In these instructive instances, the whole change is from a state of inactivity 
of the mind and brain to that of their wholesome and regular exercise.

Kueping the above principle in view, we shall not be surprised to find, that non-exercise of the brain and nervous system, or, in other words, inactivity of intellect and of feeling, is a very frequent predisposing cause of every form of nervous disease. For demonstrative evidence of this position, we have only to look at the numerous victims to be fouud among females of the middle and higher ranks, who have no call to exertion in gaining the means of subsistence, and no objects of interest on which to exercise their mental faculties, and who consequently sink into a state of mental sloth and nervous weakness, which not only deprives them of much enjoyment, but lays them open to suffering, both of mind and body, from the slightest causes.

If we look abroad upon society, we shall find innumerable examples of mental and nervous debility from this cause. When a person of some mental capacity is confined for a long time to an unvarying round of employment, which affords neither scope nor stimulus for one-half of his faculties, and from want of education or society has no external resources, his mental powers, for want of exercise to keep up due vitality in their cerebral organs, become blunted, and his perceptions slow and dull, and he feels any unusual subjects of thought as disagreeable and painful intrusions. The intellect and feelings, not being provided with interests external to thenselves, must either become inactive and weak, or work upon themselves, and become diseased. In the former case, the mind becomes apathetıc, and possesses no ground of sympathy with its fellow-creatures; in the latter, it becomes unduly sensitive, and shrinks within itself and its own limited circle, as its only protection against every trifling occurrence or mode of action which has not relation to itself. A desire to continue an 
unvaried round of life takes strong possession of the mind; because to come forth into society requires an exertion of faculties which have been long dormant, and cannot be awakened without pain, and which are felt to be feeble when called into action. In such a state, home and its immediate interests become not only the centre which they ought to be, but also the boundary of life; and the mind originally constituted to embrace a much wider sphere is thus shorn of its powers, and the tone of mental and bodily health is lowered, till a total inaptitude for the business of life and the ordinary intercourse of society comes on, and often increases till it becomes a positive malady.

But let the situation of such persons be changed; bring them, for instance, from the listlessness of retirement to the business and bustle of a town,-give them a variety of imperative employments,-and place them in society so as to supply to their cerebral organs that extent of exercise which gives them health and vivacity of action,-and, in a few months, the change produced will be surprising. Health, animation, and acuteness will take the place of former insipidity and dulness. In such instances it would be absurd to suppose that it is the mind itself which becomies heavy and feeble, and again revives into energy by these changes in external circumstances: the effects arise entirely from changes in the state of the brain; and the mental manifestations and the bodily health have been improved solely by the improvement of its condition.

Examples of this kind are not rare among retired officers, annuitants, merchants, and other persons living on certain incomes, without fixed occupations to interest them ; and a curious enough instance occurred lately in a young military officer, who spent three years in Canada, commanding a small detachment, in a remote station, where he was completely separated from all society of his own rank. During 
all that period he spent his time in sauntering, shooting, or fishing, without that excitement to his various faculties which is afforded by the society of equals. The consequence of this compulsory mental apathy, and the corresponding inactivity of brain, was, that on returning to England his nervous system had become so weak and irritable, that, although by nature fond of society, he feared to meet even with the members of his own family, and for many weeks would never venture to walk out to take necessary exercise, except in the dark. And it was only at the end of several months that the renewed stimulus of society and employment restored the tone of his nervous system so far as to allow him to regain his natural character of mind, and to return to his usual habits of life. In this predisposed state of the system, a very slight cause would obviously have sufficed to convert the depression into absolute derangement.

But, as mentioned at first, the most frequent victims of this kind of predisposition are females of the middle and higher ranks, especially those of a nervous constitution and good natural abilities; but who, from ill-directed education, possess nothing more snlid than mere accomplishments, and have no materials of thought or feeling, and no regular or imperative occupations, to excite interest or demand attention. Such persons have literally nothing on which to expend half the nervous energy which nature has bestowed on them for better purposes. They have nothing to excite and exercise the brain, -nothing to elicit activity; their own feelings and personal relations necessarily constitute the grand objects of their contemplations; these are brooded over till the mental energies become impaired, false ideas of existence and of Providence spring up in the mind, the fancy is haunted by strange impressions, and every trifle which relates to self is exaggerated into an ohject of immense importance. The 
brain, having almost no employment, becomes weak, and the mental manifestations are enfeebled in proportion; so that a person of good endowments, thus treated, will often not only exhibit'somewhat of the imbecility of a fool, but gradually become irritable, peevish, and discontented, and open to the attack of every form of nervous disease and of derangement from causes which, under different circumstances, would never have disturbed her for a moment.

That the liability of such persons to melancholy, hysteria, hypochondriasis, and other varieties of mental disease, really depends on a state of irritability of brain, induced by imperfect exercise, is proved by the vast and rapid improvement we often witness from the sudden supervention of occurrences which excite and employ the mental powers and their cerebral organs. Nothing is more usual than to see a nervous young lady, who for years had been unfit for any thing, while ease and indolence were her portion, deriving the utmost advantage from apparent misfortunes, which throw her upon her own resources, and force her to exert her utmost energies to maintain a respectable station in society. Where, as in such circumstances, the mental faculties and brain, the intellect and moral and social feelings, are blessed with a stimulus to act,- the weakness, the tremors, and the apprehensions, which formerly seemed an inborn part of herself, disappear as if by enchantment, and strength, vigour, and happiness take their place; solely because now God's law is fulfilled, and the brain with which He has connected the mind is supplied with that healthful stimulus and exercise which $\mathrm{He}$ ordained to be indispensable to its healthy existence.

An additional illustration, and I venture upon it because the principle is an important one in the production of many distressing forms of disease, will be found in the case of a man of mature age and of active habits, who has devoted his life to the toils 
of business, and whose hours of enjoyment have been few and short. Suppose such a person to retire to the country in search of repose, and to have no deep moral, religious, or philosophical pursuits to occupy his attention, and keep up the active exercise of his brain,- the latter will lose its health, and the invariable result will be ennui, weariness of life, despondency, or some other variety of nervous disease.*

One great evil attending the absence of some imperative employment or object of interest to exercise the mind and brain, is the tendency which it generates to waste the mental energies on every trifling occurrence which presents itself, and to seek relief in the monientary excitement of any sensation, however unworthy. Not only does painful instability of purpose and interest arise from this cause, especially among females, but, by degrees, enjoyment is sought for more from the indulgence of the sensual appetites of eating and drinking than from any higher occupation; till, at last, the habit is established, and quantities of food and wine are daily swallowed, which add disease to indolence, and oppress both mind and body. Patients labouring under this form of indisposition complain much of debility, and of the exhaustion left by every exertion. It is common to hear them defending the excesses which they commit, by affirming that with less support they would die of weakness; but the plea, though plausible, is not less groundless than injurious. No doubt, they may feel stronger after a good dinner and a few glasses of wine, but the strength is that of feverish excitement, and the sub. sequent languor is proportionally great. Ere long,

* It may be proper to state, that several of the preceding pages have been taken, with little alteration, from iny "Observations on Mental Derangement," published some time ago. But as that work is designed for the profession, and not for the general reader, I have thought it necessary to repeat them here. 
too, the power of mental application gives way; the digestive organs fail under the task imposed upon them; and headache, flushing, sickness, and bilious attacks ensue in such rapid succession, that life at last becomes a state of habitual indisposition.

The best remedy for these evils is to create occupation to interest the mind, and give that wholesome exercise to the brain which its constitution requires. Unless this can be done, the services of the physician will be available only so long as their novelty continues a source of excitement; and then, in all probability, he will be discharged to make way for another, who will, in his turn, be dismissed to give place to a third. The principle on which this is done is perfectly sound, and, in such cases, no sensible physician will take it amiss that his assistance is declined. The error lies in the patient seeking the necessary mental stimulus in a change of attendant, instead of in a change of occupation. But there cannot be a doubt, that where the patient is either unable or unwilling to seek recovery from engaging in proper employment, the mere change of physician is often of temporary service.

The evils arising from excessive or ill-timed exercise of the brain or any of its parts, are numerous and equally in accordance with the ordinary laws of physiology. When we use the eye too long, or in too bright a light, it becomes bloodshot, and the increased action of its vessels and nerves gives rise to a sensation of fatigue and pain requiring us to desist. If we turn away the eye, the irritation gradually subsides, and the healthy state returns; but if we continue to look intently, or resume our employment before the eye has regained its natural state by repose, the irritation at last becomes pernianent, and disease, followed by weakness of sight or even blindness, mav ensue : as often happens to 
glass-blowers, smiths, and others, who are obliged to work in an intense light.

Precisely analogous phenomena occur when, from intense mental excitement, the brain is kept long in a state of excessive activity. The only difference is, that we can always see what happens in the eye, but rarely what takes place in the brain. Occasionally, however, cases of fracture of the scull occur, in which, from part of the bone being removed, we can see the quickened circulation in the vessels of the brain as easily as in those of the eye. Sir Astley Cooper had a young gentleman brought to him who had lost a portion of his scull just above the eyebrow. "On examining the head," says Sir Astley, "I distinctly saw the pulsation of the brain was regular and slow; but at this time he was agitated by some opposition to his wishes, and directly the blood was sent with increased force to the brain, the pulsation became frequent and violent; if, therefore," continues Sir Astley, "you omit to keep the mind free from agitation, your other means will be unavailing" in the treatment of injuries of the brain.* We are conscious, indeed, of a flow of blood to the head when we think intently, or are roused by passion; and the distension of the small vessels of the brain is not the less real or influential on account of its being hidden from our view. Too often it reveals itself by its effects when least expected, and leaves traces after death which are but too legible. How many public men, like Whitbread, Romilly, Castlereagh, and Canning, urged on by ambition or natural eagerness of mind, have been suddenly arrested in their career by the inordinate action of the brain induced by incessant toil! And how many more have had their mental power for ever impaired by similar excess! When tasked beyond its strength, the eye becomes

* See Sir A. Cooper's Lecture on Surgery, by Tyrrel, vol. i. p. 279 . 


\section{EXCESSTVE EXERCISK OF THE BRA1N.}

insensible to light, and no longer conveys any impressions to the mind. In like manner, the brain, when much exhausted, becomes incapable of thought, and consciousness is almost lost in a feeling of utter confusion.

At any time of life, excessive and continued mental exertion is hurtful; but in infancy and early youth, when the structure of the brain is still immature and delicate, permanent mischief is more easily inflicted by injudicious treatment than at any subsequent period; and, in this respect, the analogy is complete between the brain and the other parts of the body, as we have already seen exemplified in the injurious effects of premature exercise of the bones and muscles. Scrofulous and rickety children are the most usual sufferers in this way. They are generally remarkable for large heads, great precocity of understanding, and small delicate bodies. But, in such instances, the great size of the brain and the acuteness of mind are the results of morbid growth; and, even with the best management, the child passes the first years of its life constantly on the brink of active disease. Instead, however, of trying to repress its activity, the fond parents, misled by the early promise of genius, too often excite it still fartlier, by unceasing cultivation and the never-failing stumulus of praise and emulation; and, finding its progress for a time equal to their warmest wishes, they look forward with ecstasy to the day when its talents will break forth, and shed a lustre on its name. But, in exact proportion as the picture becomes brighter to their fancy, the probability of its being realized becomes less; as the brain, worn out by premature exertion, either becomes diseased or loses its tone, leaving the mental powers slow and depressed for the remainder of life. The expected prodigy is thus ultimately and easily outstripped in the social race by many whose apparently dull outset promised him an easy victory. 
Taking for our guide the necessitics of the consti. tution, it will be obvious that the modes of treatment commonly resorted to ought to be reversed, and that, instead of straining to the uttermost the already irritable powers of the precocious child, and leaving his dull competitor to ripen at leisure, a systematic attempt ought to be made, from early infancy, to rouse to action the languid faculties of the latter; while no pains ought to be spared to moderate and give tone to the activity of the former. Instead of this, however, the prematurely intelligent child is generally sent to school, and tasked with lessons at an unusually early age; while the healthy but more backward boy, who requires to be stimulated, is kept at home in idleness, perhaps for two or three years longer, merely on account of his backwardness. A double error is here committed, and the consequence to the clever boy is frequently the permanent loss both of health and of his envied superiority of intellect.

In youth, too, much mischief is done by the long school-hours, and continued application of mind, which the present system of education requires. The law of exercise, that long-sustained action exhausts the vital powers of an organ, applies equally to the brain as to the muscles; and hence the necessity of varying the occupations of the young, and allowing frequent intervals of active exercise in the open air, instead of enforcing the continued confinement now so common. This exclusive attention to mental culture fails, as might be expected, even in its essential object; for experience shows that, with a rational distribution of employment and exercise, a child will make greater progress than in double the time employed in continuous mental exertion. If the human being were made up of nothing but a brain and nervous system, it would be very well to content ourselves with sedentary pursuits, and to confine education entirely to the mind. But when 
observation tells us that we have numerous other important organs of motions, sanguification, digestion, circulation, and nutrition, all demanding exercise and the open air as essential both to their. own health and to that of the nervous system, it is worse than folly to shut our eyes to the fact, and to act as if we could, by denying it, alter the constitution of nature, and thereby escape the consequences of our misconduct.

Reason and experience being thus set at naught both by parents and teachers, in the management of the young, the latter naturally grow up with the notion that no such influences as the laws of organization exist, and that they may follow any course of life which inclination leads them to prefer, without injury to health, provided they avoid what is called dissipation. It is owing to this ignorance, that we find young men of a studious or literary habit enter heedlessly upon an amount of mental exertion, unalleviated by bodily exercise or intervals of repose, which is quite incompatible with the continued enjoyment of a sound mind in a sound body. Such, however, is the effect of the total neglect of all instruction in the laws of the organization during early education, that it becomes almost impossible to warn an ardent student against the dangers to which he is exposing himself, and nothing but actual experience will convince him of the truth.

In the first number of the "American Annals of Education," the reader will find an instructive article on the necessity of combining bodily with mental exercise. "For twenty years and more," says the writer, "the unnatural umion of sedentary with studious habits, contracted by the monastic system, has been killing in the middle age. The Register of Education shows, in one year, 120 deaths. Examine into the particular cases, and these will be found the undoubted effects of sedentary habits. Look at one name there. He had valuable gifts, perfected 
by two years' academic, four years' collegiate, and three years' theological studies. He preached, gave much promise, and then died of a stomach disease. $\mathrm{He}$ contracted it when a student. $\mathrm{He}$ did not alternate bodily with mental labour, or he had lived and been a blessing to the church. When he entered on his sludies, he was growing into full size and strength. He sat down till his muscles dwindled, his digestion became disordered, his chest contracted, his lungs congested, and his head liable to periodical pains. He sat four years in college, and three years in theological application. Look at him nov. He has gained much useful knowledge, and has improved his talents; he has lost his health. The duties of his mind and heart were done, and faithfully so; but those of his body were left undone. Three hundred and seventyfive muscles, organs of motion, have been robbed of their appropriate action fornine or ten years, and now they have become, alike with the rest of his frame, the prey of near one hundred and fifty diseased and irritable nerves." - "Look at another case. Exposure incident to the parson or missionary has developed the disease in his chest, planted there while fitting himself for usefulness. He contracted a sedentary, while he was gaining a studious habit. That which he sows, that also shall he reap. The east winds give him colds ; a pulpit effort causes hoarseness and cough, oppression and pain. He becomes alarmed and nervous. His views of usefulness begin to be limited. He must now go by direction, and not so much to labour where otherwise he would have been most wanted, as to nurse his broken constitution. He soon adds to the number of mysterious providences, to the number of innocent victims, rather, of cultivating the mind and heart, at the unnecessary and sinful expense of the body, - to the number of loud calls to alternate mental and corporeal action daily, for the reciprocal sanity and vigour of both mind and body." 
To renedy these evils, and introduce a better system of training, so as to make bodily health and mental and rational cultivation go hand in hand, an establishment called the Manual Labour Academy was opened near Philadelphia in 1829, and has already proved the soundness of its principles by the success of its results. The usual branches of study in classical schools, with the addition of the Bible, are pursued; and "the hours of recreation are employed in useful bodily labour, such as will exercise their skill, make them dexterous, establish their health and strength, enable each to defray his own expenses, and fit him for the vicissitudes of life." From this systematic union of bodily labour in gardening, farming, carpentry, and other work, with the usual academic studies, many comforts are said to have arisen. The health of the inmates has been uninterrupted, except in a few who were ill when received; and, at the date of the report, in 1830, "every invalid remaining there had been restored to health." Young men thus trained to practical obedience to the organic laws are much less likely to run into excess in after-life, than those who have been left in ignorance of the constitution of their own bodies. "When thought shall need no brain," the report continues, "and nearly four hundred organs of motion shall cease to constitute the principal portion of the human body, then may the student dispense with muscular exertion ;" but, till then, let him beware what he does, and look to the laws which the Creator has established for his guidance, and seek his happiness, not in denying their existence, but in yielding them willing and cheerful obedience.

In early and middle life, fever, with an unusual degree of cerebral disorder, is a common consequence of the excessive and continued excitenient of the brain, which is brought on by severe study, unremitting mental exertion, anxiety, and watching. 
Some very marked cases of this kind have come under my observation, but that of Sir Humphry Davy is so strikingly illustrative of the dangers alluded to, that I cannot do better than lay it before the reader. In November, 1807, Sir Humphry Davy was seized with very severe fever, in consequence of the excitement and fatigue which he underwent when engaged in his splendid discovery of the alkaline metals. "The laboratory of the institution was crowded with persons of every rank and description; and Davy, as may be readily supposed, was kept in a continued state of excitement throughout the day. This circumstance, co-operating with the effects of the fatigue he had previously undergone, produced a most severe fit of illness, which, for a time, caused an awful pause in his researches, broke the thread of his pursuits, and turned his reflections into different channels." Davy ascribed his illness to contagion caught in experimenting on the fumigation of hospitals. "Upon conversing, however, with Dr. Babington, who, with Dr. Frank, attended Davy throughout this illness, he assured me that there was not the slightest ground for this opinion, and that the fever was evidently the effect of fatigue and an over-exciled brain. The reader will not feel much hesitation in believing this statement, when he is made acquainted with the habits of Davy at this period. His intellectual exertions were of the most injurious kind, and yet, unlike the philosophers of old, he sought not to fortify himself by habits of temperance." "Such was his great celebrity at this period of his career, that persons of the highest rank contended for the honour of his company at dinner, and he did not possess sufficient resolution to resist the gratification thus afforded, although it generally happened that his pursuits in the laboratory were no. suspended until the appointed dinner hour had passed On his return in the evening, he resumed his chymica. labours, and commonly continued them till three or fous 
o'clock in the morning, and yet the servants of the establishment not unfrequently found that he had risen before them." Such was the alarming state of Davy, that for many weeks his physicians regularly visited him four times in the day; and the housekeeper, Mrs. Greenwood, never retired to bed, except one night, during eleven weeks. In the latter part of -his illness, ' he was reduced to the extreme of weakness, and is mind participated in the debility of his body."*

Instances occasionally occur of persons exhausted by anxiety and long attendance on others, being themselves attacked by fever, and dying, more from the unfavourable state to which previous exhaustion had reduced them, than from the intensity of the fever itself.

Nervous disease from excessive mental labour and exaltation of feeling sometimes shows itself in another form. From neglecting proper intervals of rest, the vascular excitement of the brain, which always accompanies activity of mind, has never time to subside, and a restless irritability of temper and disposition comes on, attended with sleeplessness and anxiety, for which no external cause can be assigned. The symptoms gradually become aggravated, the digestive functions give way, nutrition is impaired, and a sense of wretchedness is constantly present, which often leads to attempts at suicide. While all this is going on, however, the patient will talk or transact business with perfect propriety and accuracy, and no stranger could tell that any thing ails him. But in his intercourse with his intimate friends or physician, the havoc made upon the mind becomes apparent; and, if not speedily arrested, it soon terminates, according to the constitution and circumstances of the individual case, in derangement, palsy, apoplexy, fever, suicide, or permanent weakness.

* Paris's Life of Sir H. Davy, p. 183. 
As age advances, moderation in mental exertion becomes still more necessary than in early or mature years. Scipion Pinel, in adverting to the evil consequences of excessive moral or intellectual excitement, acutely remarks, that while in youth and manhood the wear of the brain thus induced may be repaired, no such salutary result follows over-exertion in the decline of life: "what is lost then is lost for ever. At that period we must learn to wait for what the brain is willing to give, and allow it to work at its own time; to attempt to force it is to weaken it to no purpose; it becomes excited and quickly exhausted when forced to vigorous thinking." - "Men of exalted intellect perish by their brains, and such is the noble end of those whose genius procures for them that immortality which so many ardently desire."*

Who can peruse these lines without the fate of Scott instantly occurring to his mind, as a practical illustration of their truth? In the vigour of manhood few ever wrote so much, or with greater ease. But when, on the verge of old age, adversity forced him to unparalleled exertion, the organic waste could no longer be repaired, and perseverance only "weakened the brain to no purpose," till morbid irritability became the substitute of healthy power, and he perished by that brain which had served him so faithfully and so efficiently, but which could no longer withstand the gigantic efforts which he continued to demand from it.

Where a predisposition to insanity exists, the cerebral excitement induced by excessive activity of mind often leads to disease. Examples of this kind abound in the works of authors. Pinel mentions several. One of theni was the case of a young man, distinguished for his talents and his profound knowledge of chymistry, who was occupied with a

* Physiologie de l'Homme Aliéné, p. 177. U 2 


\section{EXCESSIVE EXERCISE OF THE BRAIא.}

discovery which he hoped would lead him to fortune and distinction. To effect it the sooner, he resolved to shut himself up in his laboratory for several successive days; and, the better to banish sleep and to raise himself to the level of his labours, he prepared a variety of stimulants. A singing girl shared his retreat; he drank spirits, smelled frequently odoriferous substances, and sprinkled the room with eau de Cologne. The combined action of all these means, added to the heat of his furnace, caused such a degree of cerebral excitement that, at the end of eight days, the most furious delirium took place, followed by a regular attack of mania If any thing can demonstrate the mutual influence of mind and brain, it is surely a case like this,-a case which it is impossible to read without perceiving how easily the cerebral affection might have been of the violent inflammatory character, which terminates, in a few days, in life or in death; or of the felorile character, that lasts for one or two months, and leaves the mind for ever reduced in tone and vigour.

It is well remarked by Tissot, that the disorders produced by the efforts of the mind fall soonest upon such as are incessantly engaged in the contem plation of the same object. In this case, he adds, there is only one part of the sensorium (brain) acted upon, and that is kept always on the stretch; it is not relieved by the action of the other parts; and therefore is sooner fatigued and injured; the same rule holding with the brain as with the muscles, that the exercise which, if divided among the different parts of which it is composed, will strengthen them, will, il confined to a few, exhaust and impair them. Boerhave himself, after a long period of intense thinking, suffered for six weeks from excitement of the brain, bordering on madness, and characterized by that want of sleep, irritability, and indifference to 
ordinary interests, which so often appear as the harbingers of insanity.

The number of literary and public men, students, and persons in business, who do themselves irreparable injury in this way, is so great, that few of my readers who have had experience of the world will be at a loss for examples even among their own acquaiutances. In addition to Davy, Scott, and others, already mentioned, Sir Isaac Newton may be referred to ; as it is now certain that his mind was for a time disordered by excessive application, and there is much reason to believe that he never altogether recovered the shock. The premature extinction of early "prodigies" of genius is also generally traceable to the operation of the same cause. The wonder excited by their performances stimulates them to incessant and severe exertion, unrelieved either by adequate repose or by variety of pursuit; and the exhausted brain either sinks at the period of growth, or becomes so much weakened as to be unfit for the same splendour of manifestations. The more limited the sphere of talent, the greater the danger of its being over-exercised; and hence the frequency of nervous affections in musicians, and others who dedicate their lives to the exclusive cultivation of their arts. It is said that Gretry not only ruined his own health, but lost three highly-gifted and beautiful daughters in succession, from over-excitement of the nervous system thus induced; and there can be no doubt that the melancholy fate of Weber was greatly hastened by intense application. He continued deeply engaged in musical composition long after his health was undermined; and, even when the hand of death was almost upon him, his avocations pressed so heavily that he could not help exclaiming, "Would that I were a tailor, for then I should have a Sunday's holyday!" The philanthropic physician will rather oe inclined to exclaim, "Would that mankind would 
study their bodily structure and functions, and thus learn to preserve longer the health and existence of those whose genius is the source of so many pleasures to the world at large !"

Having thus pointed out the evils arising both from inadequate and from excessive mental exertion, it remains for me to direct attention to some of the conditions required for the proper exercise of the brain.

It seens to be a law of the animal economy, that two clusses of functions cannot be called into vigorous action at the same time, without one or other, or both, sooner or later sustaining injury. Hence the important rule, never to enter upon continued mental exertion, or to rouse deep feeling, immediately after a full meal, as the activity of the brain is sure to interfere with that of the stomach, and - disorder its functions. Even in a perfectly healthy person, unwelcome news, sudden anxiety, or mental excitement, occurring after eating, will put an entire stop to digestion, and cause the stomach to loathe at the sight of food. In accordance with this, we learn by experience, that the worst forms of indigestion and nervous depression are those which arise from excessive application of nind, or turmoil of feeling, conjoined with unrestrained indulgence in the pleasures of the table. In such circumstances, the stomach and brain react upon and disturb each other, till all the horrors of nervous disease make their unwelcome appearance, and render life miserable. Literary men and hard students know this fact from sad experience; but as they are not aware of the incompatibility of the two processes of active thinking and active digestion going on at the same time, it is extremely difficult to give them a sense of their danger, and to convince them that an hour, or an hour and a half, after a meal is more profitably spent in easy relaxation than in the 
abour of composition. As regards the lower animals, indeed, we are careful enough to observe this organic law; for we do not allow our horses or dogs to be actively exercised till digestion is in some degree completed.

It may be said that mechanics, labourers, and others hurry away to work immediately after meals, and that, in the United States, the practice of hastily swallowing dinner and instantly returning to business is proverbially common. My answer to this objection is simply, that experience proves the fact, that digestion goes on better when exertion is refrained from and repose is enjoyed, and that the tendency to sleep and inactivity which besets most animals after a full meal shows repose to be, in such circumstances, the intention of nature. It must be observed also, that the bad effects of immediate exertion are not of that description which ensue instantly, or are felt from day to day. These may show themselves only at the end of months or years, when the influence has, as it were, accumulated by repetition. Although, therefore, the system possesses a certain power of resistance, and many persons seem to escape even for years, it cannot be doubted that opposition to the law of nature will eventually prove injurious. The extreme prevalence of dyspeptic complaints and of insanity among the Americans is, in all probability, partly owing to the very practice which is supposed by some to be harmless to them.

The time best adapted for mental exertion falls next to be considered. Nature has allotted the darkness of night for repose, and the restoration by sleep of the exhausted energies of mind and body. If study or composition be ardently engaged in towards that period of the day, the increased action in the brain which always accompanies activity of mind requires a long time to subside; and, if the individual be at all of an irritable habit of body, he 
will be sleepless for hours after going to bed, or perhaps be tormented by unpleasant dreams. If, notwithstanding, the practice be continued, the want of refreshing repose will ultimately induce a state of morbid irritability of the nervous system, not far distant from insanity. It is therefore of great advantage to engage in severer studies early in the day, and devote the two or three hours which precede bedtime to lighter reading, music, or amusing conversation. The vascular excitement previously induced in the head by study has then time to subside, and sound refreshing sleep is much more certainly obtained. 'This rule is of great consequence to those who are obliged to undergo much mental labour.

There are, no doubt, individuals so happily constituted, and whose natural sphere is so essentially that of activity, that they are able to think and work, early and late, for years in succession, with very little sleep, and with little regard to diet and regimen; but they are so obviously exceptions to the general rule, that we cannot for a monient hold them up as models for imitation; and even they would enjoy their astonishing gifts with greater security, were they to conform more completely with the laws of their organization.

Periodicity, or the tendency to resume the same mode of action at stated times, is peculiarly the characteristic of the nervous system; and, on this account, regularity is of great consequence in exer cising the moral and intellectual powers. All nervous diseases have a marked tendency to observe regular periods, and the natural inclination to sleep at the approach of night is but another instance of the same fact. It is this principle of our nature which promotes the formation of what are called habits. If we repeat any kind of mental effort every day at the same hour, we at last find ourselves entering upon it, without premeditation, when the time 
approaches; and, in like manner, if we arrange our studies in accordance with this law, and take up each regularly in the same order, a natural aptitude is soon produced, which renders application more easy than by taking up the subjects as accident may direct. Nay, the tendency to periodical and associated activity occasionally becomes so great, in the course of time, that the faculties seem to go through their operations almost without conscious effort, while their facility of action becomes so prodigiously increased, as to give unerring certainty where at first difficulty and doubt were the only results.*

In thus acquiring readiness and forming habits, we merely turn to account that organic law which associates increased aptitude, animation, and vigour with regular exercise. It is not the soul or abstract principle of mind which is thus changed, but simply the organic medium through which it is destined to act ; and, when we compare the rapid and easy eloquence of the practised orator with the slow and embarrassed utterance which distinguished him at the outset of his career, we have merely a counterpart, in the organ of mind, of what is effected in the organs of motion, when the easy and graceful novements of the practised dancer, writer, or piano-forte player take the place of his earliest and rudest attempts.

The necessity of judicious repetition in mental and moral education is in fact too little adverted to, because the principle on which it is effectual has not

* These remarks are curiously confirmed by an anecdote of Silvio Pellico, which I read in the Foreign Quarterly Review (No. xxii. p. 478), when this sheet was passing through the press. When first imprisoned, Pellico was " allowed the use of a copy of Dante and the Bible. Of the f́nrmer, he used to cornmit a canto to memory every day, till a last the exercise became so mrchanical that it ceased to afford any interruption to the train of melancholy thought." I need scarcely point out the coincidence between this and the remarks in the text. 
been understood. To induce facility of action in the otgans of the mind, practice is as essential as it is in the organs of motion. The idea or feeling must not only be communicated, but it must be reproduced and represented, in different forms, till all the faculties concerned in understanding it come to work efficiently together in the conception of it. We often blame servants for not doing a thing every day, because they were once told to do so. The organic laws, however, teach us that we are presumptuous in expecting the formation of a habit from a single act, and that we must reproduce the associated activity of the requisite faculties many times before the result will certainly follow. We find, on turning to a new subject, that however well we may understand it by one perusal, we do not fully master it, except by dwelling upon it again and again.

Repetition is thus necessary to make a durable impression on the brain; and, according to this principle, it follows that, in learning a language or science, six successive months of application will be more effectual in fixing it in the mind, and making it a part of its furniture, than double or triple the time, if interrupted by long intervals. Hence it is a great error to begin any study, and then break off to finish at a later period. The ennui is thus doubled and the success greatly diminished. The best way is to begin at the proper age, and to persevere till the end is attained. This accustoms the mind to sound exertion, and not to fits of attention. Hence the mischief of long vacations, and hence the evil of beginning studies before the age at which they can be understood, as in teaching the abstract rules of grammar to children; to succeed in which implies in them a power of thinking, and an amount of general knowledge, which they cannot possess.

In physical education, we are quite alive to the advantages of repetition and practice. We know 
that if practice in dancing, fencing, skating, and riding be persevered in for a sufficient length of time to give the muscles the requisite promptitude and harmony of action, the power will be ever afterward retained, although little called into use. Whereas, if we stop short of this point, we may reiterate practice by fits and starts, without any proportionate advancement. The same principle applies equally to the moral and intellectual powers, because these operate by means of material organs.

The necessity of being in private what we wish to appear in public springs from the same rule. If we wish to be polite, just, kind, and sociable, we must habitually act under the influence of the corresponding sentiments in the domestic circle and in every-day life, as well as in the company of strangers and on great occasions. It is the daily practice which gives ready activity to the sentiments, and marks the character. If we indulge in vulgarities of speech and behaviour at home, and put on politeness merely for the reception of strangers, the former will shine through the mask which is intended to hide them ; because the habitual association to which the organs and faculties have been accustomed cannot be thus controlled. As well may we hope to excel in elegant and graceful dancing by the daily practice of every awkward attitude. In the one case, as in the other, the organs must not only be associated in action by the command of the will, but they must be habituated to the association by the frequency of the practice ; a fact which exposes the ignorant folly of those parents who habitually act with rudeness and caprice towards their children, and then chide the latter for unpolite behaviour towards strangers.

The same principle, of repetition being necessary to make a durable impression on the brain and constitute a mental habit, also explains the manner in which natural endowments are modified by external 
situation. Taking the average of mankind, the limits to which this modification may be carried are not narrow. Place a child, for example, of average propensities, sentiments, and intellect, among a class of people-thieves-in whom the selfish faculties are exclusively exercised; by whom gain is worshipped as the end of life, and cunning and cheating as the means, and among whom it never hears one word of disapprobation or moral indignation against either crime or sentiment; and its lower faculties will be exclusively exercised and increase in strength, while the higher will be left unemployed and become weak. A child so situated will consequently not only act as those around do, but insensibly grow up resembling them in disposition and character, because, by the law of repetition, the organs of the selfish faculties will have acquired proportionally greater aptitude and vigour, just as the muscles of the fencer or dancer. But suppose the same individual placed from infancy in the society of a superiorly endowed moral and intellectual people; the moral faculties will then be habitually excited and their organs invigorated by repetition, till a greater aptitude, or. in other words, a higher moral character, will be formed. There are, of course, limits set to this modification by the natural endowments of the individual : but where the original dispositions are not strongly marked, the range is still a wide one.

From this source arise many differences, not only of individual, but of national character, and such differences as we observe take place from changes of fortune and condition. The Negro free in Africa differs widely from the Negro subjected to the scourge of the colonist.

The truth of these remarks is confirmed by $M$. Aragn, in his account of Freycinet's Voyage round the World in 1818-19-20. In speaking of the different results of the same education in the Isle of France and in the mother country, he observes, that 
the professors, the methods, and the subjects taught are quite on a par with those of Paris; but that, nevertheless, from the very early maturity of the human being in that climate, the pupils are removed from school so soon that the impression made on their minds is speedily obliterated; on which account, he adds, the only really educated and wellinformed men whom he met with are those who had been sent to France very young, and retained there till a later age and more thorough grounding had been attained, after which the risk of losing their acquirements was greatly diminished.

The next rule to be observed in the cultivation of the brain and mental faculties, is founded on that law of our constitution, which directs each organ to be exercised directly upon its own objects, and not merely roused or addressed through the medium of another organ. We have said, that when we wish, for example, to teach the graceful and rapid evolutions of fencing, we do not content ourselves with merely giving directions, but our chief attention is employed in making the muscles themselves go through the evolutions, till, by frequent repetition and correction, they acquire the requisite quickness and precision of action; or when we wish to teach music, we do not merely address the understanding and explain the qualities of sounds, but we train the ear to their attentive discrimination, and the hand to the reproduction of the motions which call them into existence. We follow this plan, because the laws of organization require direct practice, and we feel instinctively that we can succeed only by obey ing them. Now, the purely mental faculties, being connected during life with material organs, are subjected to precisely the same law; and therefore if we wish to improve the reasoning powers, we must exercise them regularly in tracing the causes and relations of things. And, in like manner, if our aim 
is to develop the sentiments of Attachment, Benevolence, Justice, or Devotion, we must exercise each of them directly and for its own sake, otherwise neither it nor its organ will ever acquire promptitude or strength.

It ought never to be forgotten, that in education it is the brain, or organ of mind, and not the abstract immaterial principle, which requires cultivation, and that hence education operates invariably in subjection to the laws of organization. In improving the $e x$ ternal senses, we admit this principle readily enough; but whenever we come to the internal faculties of thought and feeling, it is either denied or neglected. With gross inconsistency, we admit that the superior quickness of touch, sight, and hearing, consequent upon judicious exercise, is always referable to increased facility of action in their appropriate organs ; but when we explain, on the same principle, the superior development of the reasoning powers, or the greater warmth of feeling produced by similar exercise in these and other internal faculties, few are inclined to listen to our proposition, or allow to it half the weight or attention which its importance requires, although every fact in philosophy and experience concurs in supporting it. We see the mental powers of feeling and of thought unfolding themselves in infancy and youth in exact accordance with the progress of the organization,-we see them perverted or suspended by the sudden inroad of disease, and as suddenly restored : nay, we sometimes observe every previous acquirement obliterated from the adult mind by fever or by accident, leave education to be commenced anew, as if it had never been; and yet, with all these evidences of the organic influence, it is still a novelty in education to propose that the established laws of physiology, as applied to the brain, should be considered as our best and surest guide; and scarcely a volume can be pointed out in which it is even hinted that these laws have 
the slightest influence over mental or moral improvement.

Were a general acquaintance with the laws of organization to be held as an indispensable part of a liberal education, we would then be able to inculcate, with tenfold force and success, the necessity of actively exercising every faculty, whether of thought, feeling, or motion, directly on its own objects, and at once to explode the mistake of supposing that any organ or function may be efficiently exercised through the medium of another, and that, to produce high moral feeling, it is sufficient to address ourselves to the intellect alone. The merest savage, following the footsteps of nature, would pity the philosopher who would seriously assure him that, to cultivate acuteness of hearing or of vision, it was sufficient to be told how to listen or to look. The savage goes more directly and surely to work. If he wants physical strength, agility, and swiftness of foot, he sets himself to develop the muscular system of his child by ample muscular exercise, by constant repetition of the movements and acts he wishes him to perform, and by causing him to run, to leap, or to swim; and he rests in well-founded hope of accomplishing his purpose. Following the same rule when he seeks acuteness of hearing, he does not merely tell his child how to listen, but he lays him with his ear to the ground, and teaches him, by practice, to distinguish the qualities of sounds. If he wishes him to excel in hunting, in fishing, in lying in ambush, or in scenting the approach of an enemy, he expects to be successful only in proportion as he finds occasion to employ him in the prac. tice of these pursuits. If he wishes to inculcate courage in battle, contempt of pain, endurance of fatigue, obedience to chiefs, or revenge upon enemies, he chooses the sure way, and cultivates each of these qualities by calling it into direct action on its own objects; and we all know the success which 
the savage meets with in the education which he bestows.

With this experience before our eyes, then, let us, who pretend to superior wisdom and civilization, show ourselves also consistent, and ready to receive instruction from whatever quarter it may come. As God has given us bones, and muscles, and bloodvessels, and nerves, for the purpose of being used, let us not despise the gift, but consent at once to turn them to account, and to reap health and vigour as the reward which $\mathrm{He}$ has associated with moderate labour. As he has given us lungs to breathe with, and blood to circulate, let us give up our folly of shutting ourselves up with so little intermission in rooms in inactive study and sedentary occupations, and consent to inhale copiously and freely that wholesome atmosphere which $\mathrm{His}$ benevolence has spread around us. As $\mathrm{He}$ has given us appetites and organs of digestion, let us profit by $\mathrm{His}$ bounty, and earn their enjoyment by healthful exercise. As He has given us a moral and a social nature, which is invigorated by activity, and impaired by solitude and restraint, let us cultivate good feeling, and act towards each other on principles of kindness, justice, forbearance, and mutual assistance; and as $\mathrm{He}$ has given us intellect, let us exercise it in seeking a knowledge of His works and of His laws, and in tracing out the relation in which we stand towards Him, towards our fellow-men, and towards the various objects of the external world; and, in perfect faith and sincerity, let us rely upon His promise, that, in so doing, we shall have a rich reward-a reward a thousand times more pure, more permanent, and more delightful, than we can ever hope to experience in following our own blind devices, regardless of $\mathrm{His}$ will and intentions towards us.

So little, however, are even educated men familiar with the influence and laws of the organization, that, 
even in our best directed establishments, as well as in private families, cultivation is still in a great measure confined to intellect alone; and the direct exercise and training of the moral and religious sentiments and affections upon their own objects are rarely thought of as essential to their full and vigorous development. Moral precepts are no doubt offered in abundance; but these address themselves chiefly to the intellect. We must not be satisfied with merely exclaiming, "Be kind, just, and affectionate," when perhaps at the very moment we are counteracting the effect of the advice by our own opposite conduct. Parents and teachers too often forget that the sentiments feel, and do not reason, and that, consequently, a mere child may, by the instinctive operation of its moral nature, at once detect and be revolted at the immorality of practices, the true character of which its reason is unable to penetrate or expose. What kind of moral education is that, for instance, which, while the instructress vilifies the physical appetites of hunger and thirst, and preaches disregard of their cravings and of the gratifications of taste, leads her to set down a meal to her boarders, from partaking in which she betrays the strongest desire to escape, on account of its inferiority to that which is provided for herself and the few at the head of the establishment? What advances in morality and religion can be expected under the charge of one, who says, "Do unto others as you would be done by," and then leaves his dependants to suffer pain, chilblains, and disease, from want of fire to warm the room in which they sit, he himself coming into it with features fiushed by the heat of the blazing fire, which, for weeks, has been provided for his comfort in his own apartment? What generosity of feeling can arise from the superintendence of a teacher, who, though liberally paid for the food of her pupils, and with moral precepts on her lips, satisfies the cravings of nature in the 
long intervals between meals, only at the expense of the pence constituting the pocket-money of tho scholar? - the food in this case being denied, not because it is considered improper,-for were that the case, it would be a dereliction of duty to give it on any terms,-but from sheer meanness and cupidity. What kind of moral duties does the parent encourage, who, recommending kindness, openness, and justice, tricks the child into the confession of faults, and then basely punishes it, having previously promised forgiveness? And how is openness best encouraged,- by practising it in conduct, or by neglecting it in practice, but praising it in words? Is it to be cultivated by thrusting suspicions in the face of honest intentions? And how is justice to be cultivated by a guardian who speaks about it, recommends it, and in practice charges each of four pupils the whole fare of a hackney-coach? Or what kind of moral education is that which says, "Do as I bid you, and I will give you sweetmeats or money, or I will tell your mamma how good you were ;" holding out the lowest and most selfish propensities as the motives to moral conduct! Did space permit, I might indeed pursue the whole round of moral and religious duties, and ask similiar questions at each. But it is neeuless. These examples will suffice; and I give them, not as applicable generally either to parents or teachers, but simply as individual instances from among both, which have come within the sphere of my own knowledge, and which bear directly upon the principle under discussion.

The moral sentiments, it may be observed, are so many determinate impulses given us by the Creator to act in a certain way towards those around us, and it is not necessary that some extraordinary situation should be waited for to give them full employment. Benevolence, no doubt, is strongly excited by the aspect of misery and unhappiness, and im. pels strongly to the relief of the suffering object 
but this is not its most common or its most useful field. In ordinary life, it finds ample scope in charity to our neighbours, and in contributing to the happiness of our fanily circle and of our assnciates and dependants. Benevolence is much better occupied in adding a gleam of enjoyment, in removing little sources of irritation, in promoting concord among relatives, and in other kind offices of a similar nature, than in giving alms indiscriminately to all who de mand them, or even in relieving occasional distress, where this is held to dispense, as it too often is, with all obligation to habitual forbearance and Christian good-will in the private relations of life. But how little is this most important faculty directly attended to or cultivated, in the way we see done with the faculties necessary for the practice of drawing or music, which, by incessant exercise procured at a great sacrifice of time, money, and labour, are brought into such a state of activity as ever after to enable their possessors to derive delight from their exercise, where the talents are possessed in any considerable degree! And what might we not expect from the systematic training of the higher sentiments on a similar plan, in improving society and exalting the happiness of the race! But it is evident, that the objects of benevolence are our fellow-creatures; and consequently, if we restrict our intercourse and our sympathies to the limits of our own drawing-rooms, and take no interest in the progress of the race, or of the individuals composing it, we leave our best faculties in abeyance, and reap the reward of bodily debility and mental weakness and monotony.

Conscientiousness is another principle of the mind that requires direct cultivation, and that rarely receives it. It holds the balance between man and man, and is excited by the presentment of any difference of right between individuals, of any injusiice, of any temptation offered by the other faculties, 
which may lead us to encroach on others. It gives a strong sense of duty, with which it is agreeable to act in conformity, but which it is painful and injurious to oppose. It gives weight and force to the impulses of the other sentiments, and, joined with intellect and the sentiment of devotion, gives that faith in the beneficence and equity of the Deity, and in the immutability of all his laws, that forms the strongest encouragement to virtuous conduct and temporary self-denial. And here again, living in society, engaging in the active duties of life, and acting justly amid the conflicting interests of others, and not seclusion and privacy, are manifestly intended by the Creator as our proper sphere.

I need not follow out this exposition in detail. The above illustrations will suffice to explain the principle; and to exceed this limit would withdraw attention too much from the matters more directly before us.

For the same reason that every faculty ought to be exercised directly upon its own objects, the exclusive use of book-education as a means of conveying instruction, is manifestly unnatural as well as inefficient. If allowed to handle and examine a new object, a child will pursue the investigation with pleasure, and in five minutes will acquire more correct knowledge than by a whole hour's reading about its qualities without seeing it. In the one instance its perceptive powers are stimulated by the direct presence of the qualities of which they are destined to take cognizance; while, in the other, they are roused only through the imperfect medium of artificial language, and the child has to create the object in his own mind before he can take notice of its qualities. When we recollect the different ideas which the same written language suggests to different mature minds, we may form some conception of the impossibility of a child making progress in this way, and of the weariness and ennui which the 
thankless effort must always induce; and yet, at the present day, in nineteen out of twenty schools, all the knowledge that is offered is through the medium of books and language alone!

Adequate exercise of the perceptive powers would require a certain amount of muscular exertion, and of daily exposure to the open air, in going about to collect and examine the varied objects of interest with which creation abounds. In other words, the perceptive faculties cannot be successfully cultivated, without at the same time benefiting the muscular system, and the organs of respiration, circulation, and digestion; and this grand recommendation in the eye of reason, viz. pursuing study in the field of nature instead of in books, is actually, though not avowedly, the circumstance which retards its adoption in ordinary education.

What, therefore, is wanted is a system of education in harmony with the constitution of the human mind, and a mode of life and of occupation which shall give, not only full play to the intellectual powers, but also healthy excitement and activity, and a right direction, to the moral, religious, and effective feetings.

The details of such a system do not fall under the scope of a treatise like this; and I must, for the present, content myself with the exposition of the general principle. A serious obstacle to entering upon the regular exertion here recommended requires to be noticed, as it arises from a feeling in the patient against which he cannot be too much on his guard. Where the nervous system is weak, and where it, of course, requires most to be strengthened, there is often a retiring sensitiveness of disposition, leading its possessor rather to avoid than to seek intercourse with society. Feeling the irksomeness of present exertion, the nervous invalid is apt to form the secret resolution to live in solitude till the mind shall become stronger, and then to seek society when it will no longer be a burden. Unhappily, 
however, this feeling leads only to delusion, and the wished-for result becomes every day more distant, the longer retırement and indolence are persevered in. It is by activity, and not by repose, that strength is to be acquired. We do not expect to increase bodily strength by lying in bed, but by stirring about ; and, in like manner, we shall never succeed in strengthening the nervous system by indulging in mental indolence. Many are led astray by the false expectation of acquiring strength without using the natural means from which alone strength can be procured.

It may be remarked, that in the preceding pages I have made no allusion to the doctrines of Phrenology. My reasons are simply, that, for the object I had in view, a special reference to them was not necessary, and that, in a work written for the general reader, and for practical purposes, I was naturally anxious to avoid every contested point. Accordingly, in limiting myself to the statement that different parts of the brain perform different functions, without specifying those connected with any particular part, farther than that they are all concerned in the mental operations, I am not venturing beyond what most eminent anatomists and physiologists in the past or present times have taught before me. My own sentiments on the subject are already before the public ;* and I am bound to say that every day's experience increases my conviction of the truth of Phrenology, and deepens my sense of its practical value. Those who desire to prosecute the inquiry will find ample assistance in the numerous works already published, both in England and in France. The splendid work of Vimont would do honour to any age or country.

* Vide Observations on Mental Derangement; being an application of the Principles of Phrenology to the elucidation of the Causes, Symptoms, Nature, and Treatment of Insanity. 1 vol. post 8vo, 1831 . 
I have already had frequent occasion to notice the direct influence exercised by the mind and brain over all the bodily functions, and over the general health. As the subject is an important one, and has not received all the attention which it deserves, it may be proper, before concluding, to offer a few remarks on it.

The nervous fluid or influence presents many phenomena allied to those of electricity, but its real nature is not yet known. All that can be said is, that it is an influence of a peculiar kind, originating in the brain and nervous system; and that, like the blood, it is essential to the vital action of every animal organ. When I move the hand in writing, the muscles of the arm are called into play by an influ. ence transmitted to them from the brain, by means of the soft white cords called nerves. This stimulus is so indispensable, that if the communication between the brain and the muscles be cut off, by dividing or tying the nerve, no effort of the mind will longer suffice to excite them to action. In like manner, if the nerves of the lungs and stomach be cut through, so as to interrupt the flow of nervous influence, respiration and digestion will cease, although in every other respect their respective organs remain uninjured.

Changes in the quality or amount of the nervous influence transmitted from the brain to any organ have thus a direct power of modifying its function. If, from a peculiar state of the brain, the nervous influence sent to the stomach be impaired, the tone of that organ will be also impaired, and digestion become imperfect ; whereas if, in consequence of pleasing excitement, the nervous stimulus be increased, a corresponding activity will be com municated to the stomach, and digestion will be facilitated, as is experienced after a dinner in pleasant society. But if, by a violent burst of pas: sion or grief, the brain be inordinately excited, 50 


\section{INFLUENCE OF THE BRAIN ON HEALTH.}

as to send forth a stimulus vitiated in quality, the stomach which receives it will partake in the disorder, and hence the sudden loathing and sickness so often induced by unexpected bad news, vexation, or alarn.

Something analogous to this is still more visibly exhibited in the case of the muscles. If the mind be active and decided, the muscles, receiving a strong stimulus, move with readiness and force ; but if the cerebral activity be impaired by bilious de. pression, muscular action becomes slow, infirm, and indolent : whereas, if the brain be excited by strong passion, and the stimultis be impetuous, the movements instantly become energetic and decided; and, if the excitement be carried still farther, the regulated muscular contraction passes the limits of health, and becomes involuntary and convulsive.

As the quality of the nervous influence depends on the condition of the brain, that which springs from a brain of which all the parts are in sound and vigorous action is the best. Mental indolence and high mental excitement are alike inimical to bodily health; and consequently our great aim ought to be to secure for every mental power, moral as well as intellectual, that equal and regular exercise from which alone the proper nervous stimulus can spring.

It is indeed interesting to observe the various effects of the nervous influence, according to the faculties in predominant action at the time it is produced. If the higher feelings have the ascendency, and the more selfish propensities be merely sufficiently active to give force to the character, without exciting contention in the mind itself, the nervous influence is the most grateful and efficient which can be imagined for sustaining the healthy co-operation of the whole body. This result follows, because the Creator evidently designed such a state of mind to be the best and happiest for man himself, and therefore took care to surround him with every motive to induce him to enter into it. 


\section{INYLUENCE OF THE BRAIN ON HEALTH. 255}

If, however, the lower feelings be in great activity, and the mind be at variance with itself, and filled with designs and emotions repulsive to our moral sentiments ; or if it be oppressed with grief, anxiety, or remorse, the stinulus which it communicates is far from beneficial, being no longer in accordance with the conditions designed by the Creator. It is in such circumstances, accordingly, that bad health is so often seen to arise from the state of the mind, and that suffering is produced which no art can relieve till the primary cause be removed.

The same result follows over-exercise of intellect, and the non-activity of the feelings. From the concentration of vital action in one part of the brain, the stomach and other organs are unprovided with the requisite nervous stimulus, and become impaired in their functions; and hence the dyspeptic and hypochondriacal symptoms which so often render life a burden to literary men. Persons so situated, when advised to attend to diet, often answer that it is in vain, and that, while at times nothing can be digested, at other times, perhaps within a few hours or days, nothing comes amiss, - the power of digestion varying thus quickly, according to their mental condition. Whereas, when indigestion arises from a primary affection of the stomach, the least deviation in the way of indulgence proves injurious. In both instances, attention to diet is beneficial, but in the one it is less rigidly important than in the other.

The influence of the brain on the digestive organs is so direct, that sickness and vomiting are among the earliest symptoms of many affections of the head, and of wounds and injuries of the brain; while violent emotions, intense grief, or sudden bad news sometimes arrest at once the progress of digestion, and produce squeamishness or loathing of food, although an instant before the appetite was 
keen. Narcotics, the direct action of which is on the brain, have a similar effect on the stomach.

The influence of the mind and brain over the action of the heart and lungs is familiar to every one. The sighing, palpitation, and fainting, sc often witnessed as consequences of emotions of the mind, are evidences which nobody can resist. Death itself is not a rare result of such excitement in delicately organized persons.

This law of our constitution, whereby the regulated activity of both intellect and feeling is made essential to sound bodily health, seems to me one of the most beautiful arrangements of an all-wise and beneficent Creator. If we shun the society of our fellow-creatures, and shrink from taking a share in the active duties of life, mental indolence and physical debility beset our path. Whereas if, by engaging in the business of life and taking an active interest in the advancement of society, we duly exercise our various powers of perception, thought, and feeling; we promote the health of the whole corporeal system, invigorate the mind itself, and at the same time experience the highest mental gratification of which a human being is susceptible, viz. that of having fulfilled the end and object of our being, in the active discharge of our duties to God, to our fellow-men, and to ourselves. If we neglect our faculties or deprive them of their objects, we weaken the organization, give rise to distressing diseases, and at the same time experience the bitterest feelings that can afflict humanity-ennui and melancholy. The harmony thus shown to exist between the moral and physical world is but another example of the numerous inducements to that right conduct and activity, in pursuing which the Creator has evidently destined us to find terrestrial happiness.

The reader will now understand why the state of the mind is so influential in the production and pro- 
gress of disease. In the army this principle has often been exemplified in a very striking manner, and on so large a scale as to put its influence beyond a doubt. Sir George Ballingall mentions, in his excellent lectures on Military Surgery, that the proportion of sick in garrison in a healthy country, and under favourable circumstances, is about five per cent.; but that, during a campaign, the usua average is nearer ten per cent. So marked, however, are the preservative effects of cheerfulness and the excitement of success, that, according to Vaidy, the French army cantoned in Bavaria, after the battle of Austerlitz, had only 109 sick in a division of 8000 men, being little more than one in the hundred. When, on the other hand, an army is subjected to privations, or " is discouraged by defeat or want of confidence in its chiefs," the proportion of sick is "often fearfully increased." *

The same principle explains why it is so important for the physician to carry the feelings of the patient along with him in his curative measures. It is well known, for example, that those who live in constant apprehension of fever, cholera, or other ailment are generally among its first victims when exposed to its cause. The reason is obvious. The depressing nervous influence resulting from the painful activity of the selfish feelings affects all the functions of the body, and places them on the brink of disease, even before any external cause is in operation; and hence the easy inroad the latter makes when it comes into play.

So efficacious, on the other hand, is a more cheerful state of mind, from the more healthful nervous influence which it diffuses through the frame, that surprising recoveries occasionally happen, which can be ascribed to no other cause but this. A singular but instructive instance fell under the observa-

- Medico-Chirurgical Review, No. xxxvi. p. 430. 


\section{INFLUENCE OF THE BRAIN ON HEALTH.}

tion of Sir Humphry Davy, when, early in life, he was assisting Dr. Beddoes in his experiments on the inhalation of nitrous oxide. Dr. Beddoes having inferred that the oxide must be a specific for palsy, a patient was selected for trial, and placed under the care of Davy. Previously to administering the gas, Davy inserted a small thermometer under the tongue of the patient to ascertain the temperature. The paralytic man, wholly ignorant of the process to which he was to submit, but deeply impressed by Dr. Beddoes with the certainty of its success, no sooner felt the thermometer between his teeth than he concluded the talisman was in operation, and in a burst of enthusiasm declared that he had already experienced the effects of its benign influence throughout his whole body. The opportunity was too tempting to be lost. Davy did nothing more, but.desired his patient to return on the following day. The same ceremony was repeated, the same result followed; and at the end of a fortnight he was dismissed cured, no remedy of any kind, except the thermometer, having ever been used.* Quacks profit largely by taking advantage of this principle of our nature ; and regular practitioners would do well to bestow more pains than they do in assisting their treatment by well-directed moral influence, Baglivi was deeply impressed with this sentiment when he said, "I can scarcely express how much the conversation of the physician influences even the life of his patient, and modifies his complaints. For a physician powerful in speech, and skilled in addressing the feelings of a patient, adds so much to the power of his remedies, and excites so much confidence in his treatment, as frequently to overcome dangerous diseases with very feeble remedies, which more learned doctors, languid and indifferent

\section{- Paris's Life of Davv, p. 51}


in speech, could not have cured with the best remedies that man could produce."

Every one, indeed, who has either attended invalids, or been an invalid himself, must often have remarked, that the visit of a kind and intelligent friend is highly useful in dispelling uneasy sensations, and in promoting recovery by increased cheerfulness and hope. The true reason of this is simply, that such intercourse interests the feelings, and affords an agreeable stimulus to several of the largest organs in the brain, and thereby conduces to the diffusion of a healthier and more abundant nervous energy over the whole system. The extent of good which a man of kindly feelings and a ready command of his ideas and language may do in this way, is much beyond what is generally believed; and if this holds in debility arising from general causes, in which the nervous system is affected, not exclusively, but only as a part of the body, it must hold infinitely more in nervous debility and in nervous disease ; for then, indeed, the moral management is truly the medical remedy, and differs from the latter only in this, that its administration depends on the physician, and not on the apothecary,- on the friend, and not on the indifferent attendant.

The powerfully stimulating effect of mental excitement on the bodily functions is familiar to every one, and is duly noticed in the works of the novelist and poet. In nine cases out of ten, a visit to a watering-place, or a journey through an in teresting country, does more good by the beneficial excitement which it gives to the mind and brain, than by all the other circumstances put together. It is indeed greatly to the credit of the medical departments of both army and navy, that the influence of the mind in preserving and restoring health is more correctly appreciated and provided for than it is even in private practice. In the late expeditions of discovery to the Northern Regions. the utmost 


\section{INFLUENCE OF THE BRAIN ON HEALTH.}

attention was bestowed by the enlightened com. manders to keep up a healthful vivacity of intellect and feeling among their men, by constant occupation, intellectual instruction, the representation of plays, masquerades, and other amusing and exciting exertions; and there cannot be a doubt, that their remarkable immunity from disease was in no small degree owing to these admirable arrangements : and hence the immense importance which attaches to the selection of a humane and considerate as well as scientific commander.

In the second volume of Captain Basil Hall's first series of Fragments of Voyages and Travels, the reader will find a chapter on "The Effects of being well commanded," which illustrates, very amusingly, many of the principles explained in the preceding pages. "People," he says, " who have no acquaintance with the intricacies of naval discipline can scarcely comprehend how vast a difference is made in the efficiency of a man-of-war by the character of the commander."- "Early in the year 1805, we were made abundantly sensible of the truth of this remark, by an important change which took place in the highest office on board. From a state of languid inefficiency, we started in a single moment into the most vigorous activity, and from being almost the laughing-stock of the fleet, for the clumsiness of our gait, and the want of success which attended our cumbrous exertions, we soon outstripped them all, not only in the activity, but in the useful result of our services."-(p. 2.)

The new captain was a man who knew his profession, and possessed that decision of character which makes its weight instinctively felt. Betwcen certain disgrace and punishment to offenders, and "high favour to those who took pains to do right, the ship was speedily brought into proper trim. Every thing now seemed alive, and moved smartly ; no time ran to waste; even the indolent and the ill- 
disposed found their best interest in working well. The decks became cleaner than they had ever been before; the people dressed themselves more tidily; the sails looked better furled; the yards better squared; the complaints of inatlention and drunkenness grew daily less frequent, and an air of general happiness, as well as new-born energy, spread itself over the whole ship." - "So magical indeed was the effect of this change, that I dare swear we should then have engaged and beaten an enemy, whom it might not have been considered by any means prudent to have brought to action a week before."-(p. 17.)

Captain Hall gives other examples of the same principle, and remarks, that in this way the simple fact of Nelson joining the fleet off Trafalgar was almost equivalent to double manning every ship in the line. The explanation which he gives of the " mys" terious agency" by which the genius of a commanding officer imparts a portion of its spirit to every one under his orders is perfectly philosophical. "When a person of talents is placed under an able commander, he feels confident that nothing he does will be passed without notice, and consequently that his exertions must tell to his advantage, exactly in proportion as their utility makes itself felt. This consciousness will, of course, stimulate him to fresh endeavours to excel; and, from thus feeling sure that his conduct is duly appreciated, he has an immediate motive to bring his whole strength into play-an exercise which must ever produce good results."

But "suppose the case differently put, and let the superior in station be the inferior in abilities or experience, or not so zealous in the execution of his duty as the men he commands. The situation of the inferior is now far from being so independent, or so well calculated to draw forth his powers, as it was in the first case. The subordinate officer has no longer the same animated stimulus to exertion; 


\section{INFLURNCE OF THE BRAIN ON HEALTH.}

for, his labours being generally unnoticed, or their results unappreciated, he is left without much encouragement to proceed in fresh endeavours to excel; while his faculties, instead of improving, through generous exercise, are often deteriorated by the languid manner in which they are brought into play."-(p. 6.)

Captain Hall justly observes, that the influence of the commander on men of moderate talents is still more striking, as they stand more in need of a stimulus to duty. "If a commander has skill enough to enlist the sympathies of those placed under his orders, they will feel insensibly drawn on to make common cause with him, and will afterward exert themselves strenuously to maintain that degree of importance derived from this implied companionship in ability which they could hardly hope to reach single-handed." - "The invariable effect of these efforts is to improve the character. Such training will certainly not make a clever man out of a stupid one ; but it may often render a discontented or useless man of service to himself and the state : and, instead of his continuing a wretched and hopeless being, may convert him into one who is happy and confident of success."

"I suspect, however, that no one who has not been an eye-witness of the condition of a ship under the command of an ignorant, trifling, or otherwise inefficient captain, can have any notion of the mischievous effects of his misrule, or rather of his no rule. Perhaps, in the long-run, almost every degree of consistent severity is preferable to the uncertain, higgledy-piggledy kind of discipline on board a man-ofwar in what is called slack-order. The moderately gifted persons feeling that, in these circumstances, they have no chance of notice by any exertions of their own, speedily degenerate into a sort of vegetables, so incapable of any useful exertion that they infest the ship like the fungus called the dry-rot. This chaotic period is the holyday season of the 
scamps and skulkers, who then fancy their game the surest. These fellows certainly succeed in working as little as possible, and in making those about them unhappy ; but, after all, without any great accession to their own comfort."

"This system," continues Captain Hall, "discourages the cheerful and willing workers by the oppression of its injustice-a feeling which speedily takes away or deadens some of the best motives to improvement. Such a captain, unwilling to see that he himself is in fault, ascribes the evil to others ; and, "by his unfair censure of those who, in fact, are the most deserving of commendation, he scatters the seeds of discouragement over all the different classes exposed to his unskilful handling, and every thing falls into confusion worse confounded."(p. 10.) The loss of the French frigate Medusa, on the coast of Africa, in 1817, and the tremendous suffering which instantly ensued from the state of anarchy and uproar which took place among the crew, are well known to have arisen entirely from the insufficiency and headstrong conceit of a weak and ig. norant commander, and afford a strong contrast to the admirable coolness and high-toned moral feeling displayed on the similar occasion of the wreck of the Alceste, on her return from China with Lord Amherst, and which also made a deep impression, but of a widely different description, on the public mind.

From the above quotations, the influence which he qualities of the commander may exert on the health, as well as the discipline, of those under his orders, may easily be inferred. So important, indeed, are cheerfulness and confidence, as conditions of health, that if two ships were to be sent out to circumnavigate the globe, each equal to the other in every respect, except the one being under the direction of a humane, vivacious, and considerate man, and the other of a lymphatic, selfish, and tyrannical 
commander, though both were equal in talent, it is quite certain that the fate of the crews would be widely different, and that sickness would prevail much more in the one than in the other.

\section{CHAPTER IX.}

Causes of had Health-Not always the Result of moral or immoral Conduct-Nor of Accident-But of the Infringement of the Laws of Organization-Proofs from past HistoryDiminished Mortality from Incr3ase of Knowledge, and better Fulfilment of the Conditions of Health-The Expeditions of Anson and Cook contrasted-Gratifying Results of the Sanatory Arrangements of Ross, Parry, and Franklin-Pulnorary Diseases in the Channel Fleet, from Ignorance of Physiology -Rates of Mortality in different Ages and Countries-Causes of late Improvements-Condition of wealthier and poorer Classes compared-Good done by the Apprehension of Cholera-Influence of Habit-Neglect of organic Laws in Recruiting Service-Examples-Conclusion.

The reader will now be prepared to take a correct view of a question on which it especially interests us to have true and precise notions. I allude to the real origin of bad health. On this point very vague and contradictory opinions are prevalent; and, as our conduct in life must necessarily be closely dependent on our views in regard to this subject, I cannot do better, before concluding, than devote a chapter to its consideration.

Setting aside, for the present, hereditary tendencies to disease (which must have begun at first with some progenitor, from ordinary causes, and which, therefore, are not really unconnected with the inquiry), bad health may be regarded in three different lights: First, As having no necessary connexion with our conduct, but as being the result of circum- 
stances entirely beyond our knowledge and control, and sent by a superintending Providence, not to urge us to more rational care, but to soften our hearts, and warn us from sin; Secondly, As the result of accident alone, or of external influences which we can appreciate, but from which it is impossible to withdraw ourselves ; and, ThIRDLY, As, in every instance, the result of the direct infringement of one or more of the laws or conditions decreed by the Creator to be essential to the well-being and activity of every bodily organ, and the knowledge and observance of which are to a great extent within our own power.

According as one or other of those views shall be adopted, the most opposite practical results will follow. If the first be received as the truth, and health and sickness be viewed as dispensed without reference to our bodily conduct, but solely as a means of reclaiming us from sin, attention to our moral and religious improvement alone will be our best protection; and any attempt to avert bad health, by studying and obeying the laws which regulate the bodily functions, will be entirely useless. If, again, the second principle be correct, and disease arise from accident and from influences beyond our control, then neither our moral nor our bodily conduct will avail us as a protection, and our only resource will be humble resignation to the will of God. But if the third be true, and the human frame be constructed by the Creator on principles calculated to carry on life for seventy years, and if de facto a large proportion of the race perish before attaining ten years of age, chiefly from infringing the conditions on which the due performance of the various vital functions depends, it then becomes an object of great interest to us to study the structure of our organs, to discover the laws which regulate their functions, and to yield to those laws that implicit obedience from which alone health can spring.

That the strictest observance of the moral laws, 
and the purest devotion of which human nature is capable, are insufficient to secure health to the body, without a simultaneous observance of the organic laws, is too clearly proved by the instances already adduced, and by the history of mankind, to require any demonstration here. The biographies of the pious and excellent furnish abundant examples to the contrary ; while the annals of crime afford numerous instances of men of the most depraved characters enjoying unbroken health. If, indeed, the organic conditions be fulfilled, the upright man will enjoy a serenity of health which the criminal can never know ; but the moral observance alone will not avail him, if he at the same time neglect the organic laws.

In regard to the second proposition, a little reflection will satisfy every intelligent mind that it is equally untenable, and that disease is not always the result of accident or circumstances which cannot be modified. There are causes of bad health against which even the most stupid and prejudiced take some precautions, and with success; and the whole art of medicine would be a grosser delusion than ever romancer believed it to be, if health were not influenced by circumstances within our control. All our remedies, and all the effects of diet, clothing, and regimen, are indications of the contrary persuasion. There are, indeed, agencies from which we shall probably never be able entirely to protect ourselves. Such are variations in the state of the atmosphere, epidemic and contagious causes, and necessary exposure, in pursuance of higher duties, to known unhealthy influences; but, allowing for all these, ample scope remains, within which man may, by an extension of his knowledge and industry, provide himself with safe-guards far beyond what he has ever yet done, or has ever dreamed of accomplishing.

The third view, or that which ascribes bad health to the infringement of some one or more of the organic 
laws, thus presents itself as the only one in accordance with observation and past experience; and, after the full exposition I have already given of the conditions of health of various important organs, I trast little further proof will be required. At the same time, as the principle is full of practical value, I will take a short review of some facts which go far to establish its accuracy.

Considering that the human frame is constructed to endure, in many cases, for sixty, seventy, or eighty years, it must seem extraordinary to a reflecting mind that, in some situations, one-half of all who are born should die before attaining maturity; and that, of 1000 infants born and reared in London, 650 die before the age of ten years. It is impossible to suppose that such a rate of mortality was designed by the Creator as the unavoidable fate of man; for, by the gradual improvement of society and a closer observance of the organic laws, the proportion of deaths in early life has already been greatly reduced. A hundred years ago, when the pauper infants of London were received and brought up in the workhouses, ?mid impure air, crowding, and want of proper food, not above one in twentyfour lived to be a year old; so that out of 2800 received into them, 2690 died yearly. But when the conditions of health came to be a little better understood, and an act of Parliament was obtained obliging the parish officers to send the infants to nurse in the country, this frightful mortality was reduced to 450 , instead of upwards of 2600 ! Can evidence stronger than this be required to prove that bad health frequently arises from causes which man may often be able to discover and remove, and which, therefore, it is his bounden duty to investigato and avoid by every means which Providence has placed within his reach?

The different rates of mortality in crowded cities and country villages equally demonstrate the influ. 
ence of bad air, crowding, and imperfect food, in abridging life. Even in the best-managed communities, the number, not only of the sick of all ages, but of those who are cut off in early youth, is so prodigious as to show that we are far from having arrived at the maximum of health of which the race is susceptible; while the advance we have already made gives us every reason to hope that, by perseverance and the extension of our knowledge, we may continue to improve for many centuries to come.

The progress of knowledge, and the increasing ascendency of reason, have already delivered us from many scourges which were regarded by our forefathers as unavoidable dispensations of an inscrutable Providence. In the days of the ancient Romans, their capital and territories were frequently almost depopulated by visitations of plague and pestilence, from which the present generation is, by a stricter observance of the conditions of health, entirely exempted. In London, in like manner, the same contempt of cleanliness, ventilation, and comfort which was so fatal to the Romans produced similar results, and swept off its thousands and tens of thousands, till a fortunate disaster-the great firecame in the place of knowledge, and, by destroying the crowded lanes and other sources of impurity, which man had shown himself so little solicitous to remove, procured for its inhabitants a perfect and permanent immunity from one of the deadliest forms of disease,-and taught them the grand practical truth, that such awful visitations are not wanton inflictions of a vengeful Providence, but the direct consequences of our non-observance of those conditions by which the various vital functions are regulated, and by conforming to which alone health can be preserved. Accordingly, by greater attention to proper food, cleanliness, and pure air, London, with its gigantic. population, now flourishes in comparative security, 
and scarcely feels the rayages of an epidemic which has inflicted a blow on some less fortunate cities, the effects of which will be long remembered.

Small-pox is another scourge which annually carried off its thousands, and from which modern science bids fair to protect us; although half a century ago, any one who might have ventured to express such an expectation would have been ridiculed for his credulity. Even before Jenner's immortal discovery of vaccination, the improvement of medical science consequent on a better knowledge of the structure and functions of the human body had greatly mitigated the fatality of small-pox. Formerly the patients were shut up, loaded with bedclothes, in heated rooms, from which every particle of fresh air was excluded, and stimulants were administered, as if on purpose to hasten the fate of the sick. But sounder views of the wants of the animal economy at last prevailed; and, by the admission of fresh air, the removal of every thing heating or stimulating, and the administration of cooling drinks and other appropriate remedies, thousands were preserved whose lives would have been lost under the mistaken guidance of the older physicians.

As late as the middle of the last century, ague was so prevalent in many parts of Britain, where it is now never seen, that our ancestors looked upon an attack of it as a kind of necessary evil, from which they could neve: hope to be delivered. In this instance also, farther experience has shown that Providence was not in fault. By draining the land, removing dunghills, building better houses in better situations, and obtaining better food and warmer clothing, it appears that generations now succeed each other, living on the very same soil, without a single case of ague ever occurring, where, a century ago, every man, woman, and child was almost sure to suffer from it at one time or other of their lives; thus again showing how much man may do for the pres- 
ervation of his health and the improvement of his condition, when his conduct is directed by knowledge and sound principles.

If we wish for a still more admirable proof of the same practical truth, we have only to compare the condition of our seamen, in maritime expeditions undertaken a century ago, with their lot in the present day,- the expedition against Carthagena, or that of Anson, for instance, with those of Coak, Parry, and Ross; or the health enjoyed by the crew of the Valorous, with that of the seamen in the other vessels lying in the same harbour.*

Anson set sail from England, on 13th September, 1740 , in the Centurion, of 60 guns and 400 men, accompanied by the Gloucester, of 50 guns and 300 men ; the Pearl, of 40 guns and 250 men; the Wager, of 28 guns and 160 men ; the Tryal sloop, of 8 guns and $100 \mathrm{men}$, and two victuallers, one of 400 , and the other of 200 tons. They had a long run to Madeira, and thence to the coast of Brazil, where they arrived on the 18th December; but, by this time, the crews were remarkably sickly, so that many died, and great numbers were confined to their hammocks. The commodore now ordered "six airscuttles to be cut in each ship, to admit more air between the decks," and took other measures to correct the "noisome stench on board," and destroy the vermin, which nuisances had become "very loathsome ;" "and, besides being most intolerably offensive, they were doubtless, in some sort, productive of the sickness under which we had laboured." Such is the mild language used by the chaplain, Mr. Walter, in communicating these appalling truths! On anchoring at St. Catharine's, 80 patients were sent on shore from the Centurion alone, of whom 28 soon died, and the number of sick increased to 96 . Although this was nothing compared to what took

- Vide, p. 68. 
plave afterward, it is nevertheless worthy of remark, for as yet they had suffered no privations or unusual hardships, except from contrary winds. The causes of disease lay entirely within themselves.

After a stormy and tedious navigation of three months round Cape Horn, scurvy carried off $\mathbf{4 3}$ more in the month of April, and double that number in May, 1741. Those who remained alive now became more dispirited and melancholy than ever; which "general dejection added to the virulence of the disease, and the mortality increased to a frightful degree." On 9 th June, when in sight of Juan Fernandez, the debility of the people was so great that, 200 being already dead, the lieutenant could muster only two quarter-masters and six foremast men able for duty in the middle watch; so that, had it not been for the assistance of the officers; servants, \&c. they would have been unable to reach the island,-to such a condition was a crew of $\mathbf{4 0 0}$ men reduced in the course of a few months!

I have noticed the cutting of holes for the admission of air between decks, and the dejection of the men. The narrative proceeds to say, that the commodore's principal attention was now devoted to getting the sick on shore, as they were dying fast on board, " the distemper being doubtless considerably augmented by the stench and filthiness in which they lay, for few could be spared to look after them, which rendered the ship extremely loathsome between decks." The officers suffered least, as being the best fed and best lodged. Within a year, out of upwards of 1200 men, composing the crews of the squadron who had sailed from England, 335 alone remained.

The fate of the Spanish squadron which sailed nearly at the same time was still more horrible. The Esperanza, of 50 guns, lost 392 out of 450 men, and the other ships almost as large a proportion. It is true that, in doubling Cape Horn, they encountered the severest weather and the greatest privations. 
and that their deplorable fate was aggravated by these causes. But when we look to the conduct of later navigators, in circumstances equally trying, it is impossible to resist the gratifying conviction, that mortality like this forms no part of the designs of a beneficent Providence, and that, for the best of purposes, our safety is placed, to a great extent, within the limits of our own power. The late memorable expeditions of Parry, of Franklin, and more especially of Ross, who, with few resources, spent upwards of four years in the desolate regions of the north, with scarcely any loss of life, are examples pregnant with meaning to all who are interested in the future progress of man.

It may be said that the climate and situation of the two parties were dissimilar. In some respects the objection is well founded; but Cook's second voyage round the world, in 1772, affords a parallel presenting so many points of resemblance to that of Anson, that no one can reasonably object to their comparison. On this occasion, the vessels selected were the Resolution, carrying 112 men, and the Adventure, with a crew of 81 . Enlightened by former experience, Cook spared no pains to effect his equipment in the completest manner, and to lay in such stores of clothing and provisions as he knew to be useful in preserving the health of those under his command. Among these were malt, sour krout, portable broth, sugar, and wheat. Care was taken to expose the men to wet as little as possible, to make them shift themselves after being wet, and to keep their persons, hammocks, bedding, and clothes perfectly clean and dry. Equal attention was paid to keep the ship clean and dry between decks; once or twice a week it was aired with fires; and a fire was also frequently made at the bottom of the well, which was of great use in purifying the air in the lower parts of the ship. To the last precaution too great attention cannot be paid; as the least neglect 
occasions a putrid and disagreeable smell below which nothing but fires can remove. Fresh water, vegetables, and fresh provisions were also eagerly sought for at every opportunity; and these it was Captain Cook's practice to oblige his people to make use of by his own example and authority. The results of these measures we shall now see.

The two ships sailed on 13th July, 1772. Towards the end of August, when advancing towards the south, the rain "poured down, not in drops but i. streams; and the wind at the same time being variable and rough, the people were obliged to attend so constantly upon the deck, that few of them escaped being completely soaked;" but although rain is a great promoter of sickness in warm climates, the airing by fires between decks, and the other precautions, were so effectual, that, on arriving at the Cape of Good Hope, only one man was on the sick-list; whereas we have seen that, after a similar voyage, the Centurion arrived on the coast of Brazil with 80 sick, of whom 28 soon died. As we proceed, the contrast becomes still more striking. On 22d November, Cook sailed from the Cape in search of a southern continent. On the 29th, a violent storm, attended with hail and rain, came on, and caused the loss of most of their live-stock; and a sudden transition took place from warm and mild to extremely cold and wet weather, which was severely felt by the people. On 10 th December they met with islands of ice; and, from that time till the middle of March, continued their search for land with unremitting diligence, amid cold, hardships, and dangers, such as we can form a very imperfect idea of; and, at last, on 26th March, after being 117 days at sea, during which they had sailed 3660 leagues, they came to anchor in Dusky Bay, NewZealand. "After so long a voyage," says Dr. Kippis, from whose Life of Cook these particulars are taken, "in a high southern latitude, it might cer. 


\section{EXCELLENT HEALTH IN COOK'S VOYAGES.}

tainly have been expected that many of Caplain Cook's people would be ill of scurvy. This, however, was not the case. So salutary were the effects of the sweetwort and several articles of provision, and especially of the frequent airings and sweetening of the ship, that there was only one man on board who could be said to be much afflicted with the disease; and even in that man it was chiefly occasioned by a bad habit of body, and a complication of other disorders."

Can any thing be conceived more demonstrative of the advantages to be derived from investigating and obeying the laws of health, than these splendid results, when contrasted with those on board of the Centurion? In the Resolution, cheerful activity, cleanliness, dry pure air, adequate clothing, and a suitable regimen were found to carry man unscathed through hardships and exposure, which, in the Centurion, from neglect of the same protective means, were severe enough to sweep off a large proportion of her crew. And, as if on purpose to place the efficacy of these measures beyond a doubt, it appears, that, in the month of July, 1773, the Adventure had many sick, and twenty of her best men incapable of duty from scurvy and flux, when the Resolution, with a larger crew, had only three men sick, and only one of them from scurvy. This difference in the state of health of the two ships was distinctly traced to the crew of the Adventure having eaten few or no vegetables when in Queen Charlotte's Sound, while, on board of the Resolution, Cook was most particular in enforcing attention to this part of their dietetic regimen.

By this admirable care and unwearied watchfulness on the part of Cook and his officers, the Reso. lution performed a voyage of three years and eigh. teen days, through all climates, from $52^{\circ}$ north to $71^{\circ}$ south, with the loss of only one man by disease out of 112 ! And in his last voyage, so efficaciously 
were the same means put in practice, that his ship was brought home, after an absence of four years, without the loss of a single man by disease !

Similar results were obtained by the able commanders of our more recent expeditions to the Northern Regions. The Fury and Hecla were, at one time, no less than twenty-seven months entirely dependent on their own resources, before scurvy began to make its appearance; and at the end of $28 \frac{1}{2}$ months, both ships returned home (in September, 1823) with the loss of only five men,-a result which, a century ago, could hardly have occurred, and which, even at the present day, is a remarkable indication of the talent and humanity of the officers by whom it was effected.

Nothing, in fact, could have been better devised than the means practised in these expeditions to preserve the health of the people; and did my limits permit it, I might illustrate almost every principle in this volume by a reference to its actual efficacy as displayed in these voyages. Not only were the conditions of health attended to as regarded the skin, the muscles, the bones, the lungs, and the digestive organs; but the health of the all-important nervous system was sedulously provided for by the constant and cheerful occupation of the people in their various duties and amusements; and so judiciously were these planned, that a spirit of life and activity extremely favourable to the preservation of health was constantly kept up, and had, no doubt, great influence in producing that concord and unity of feeling among them which were so conspicuous amid all their privations.

In looking forward to a still greater diminution of disease in the human family, it is cheering to fix ittention to what has been thus already accomplished by the hand of authority. Had the same individuals who circumnavigated the globe with Cook, or braved the northern winters with Ross 
and Parry, been left for the same number of years to undergo the ordinary vicissitudes of life at home unrestrained in their inclinations and conduct by the constantly operating and beneficent influence of a superior mind, it is morally certain that disease and death would have made greater havoc among them than actually occurred amid physical privations and sufferings much greater than they were likely to have encountered at home. Hence the obvious and pressing necessity which exists of diffusing widely among society that species of knowledge which has proved beneficial in the hands of those who are fortunate enough to possess it. If human health and happiness may be thus effectually promoted by increased attention to the conditions which regulate the vital and animal functions, nothing can be more useful than to communicate to every intelligent being such a measure of knowledge as will enable him to do that for his own safety and improvement which government now does for those whose services it requires.

With these successful and cheering results of knowledge, it will be instructive to contrast the fatal influence of ignorance in a situation where knowledge might have been effectual in preserving life and sparing suffering. I shall take the example from an early work of Dr. James Johnson,* who has devoted much attention to the subject of health and the causes by which it is affected, and whose work contains much valuable matter connected with hygiène, as well as with the history and cure of disease. In treating of exercise, and the evils of its excess, Dr. Johnson says, "I shall exemplify this reasoning by an instructive lesson. During the late war, it was observed, that in its earlier periods fever, fluxes, and scurvy made the greatest havoc; while, in its midale and ulterior periods, these diseases

- On the Influence of the Atmosphere on the Health and Functions of the Human Frame, \&c. 8vo, $2 d$ edition, p. 193. 
almost disappeared, and pneumonia (inflammation of the lungs), with its too frequent consequence, PHTHIsis, became infinitely more prevalent and fatal. The facts were apparent to all, but the causes few could divine. Some of our chymical wiseacres attributed the pneumonic diathesis to the lime-juice served out; but this hypothesis need not detain us, for I think a more rational explanation can be offered. As the period of warfare was lengthened out, discipline gradually became more perfect, and, at length attained its acmé. Every evolution was now performed with a rapidity and precision that seemed the effect almost of magic. All machinery and apparatus were not only so arranged as to give human power its greatest force and facility of application, but human strength was put to its ultimatum of exertion, and every muscular fibre of the frame called into furious action, during each manœuvre of navigation or war. Thus, in exercising great guns, the heaviest pieces of artillery were made to fly out and in, or wheel round, with almost the celerity of a musket in the hands of a fugleman. The most ponderous anchors were torn from their beds with astonishing velocity; while the men were often seen lying about the decks breathless and exhausted after such ultra-human exertions !"

"But reefing and furling sails were still worse. Here, as in all other operations, there was a constant struggle against time. The instant that the word "alof $t$ " was given, the men flew up the shrouds with such agility, that, by the time they were on the yards, the respirations were nearer fifty than fifteen in a minute! In this state of anhelation they bent across the yards, and exerted every atom of muscular energy in dragging up the sails and securing the reef-lines, while the thorax was strained and compressed up against the unyielding wood! What were the consequences? The air-cells were frequently torn; blood extravasated : and the origins 
of cough and hemoptoes continually laid. The lungs were now in a proper state for receiving the impression of aërial vicissitudes ; and constant exposure to night air, to rain, and every inclemency of the season, soon evolved the long black catalogue of pulmonic and phthisical maladies, which swept off our men in vast numbers, to the no small surprise of the officers, who could not divine the cause of this new and destructive enemy.

"But it was not the lungs alone that suffered here. The central organ of circulation bore a part of the onus, and a host of anomalous and otherwise inexplicable symptoms were produced, which completely puzzled the naval practitioners, who rarely suspected any lesion of the heart. These last affections both aggravated, and were in their turn aggravated by, the depressing passions engendered during the long confinement on ship-board and separation from friends and native home."

I need hardly stop to point out to what extent the fatal results above mentioned might have been prevented, had the officers been possessed even of a superficial acquaintance with the laws of respiration and of muscular action. A perusal of the chapters on these subjects will enable the reader to judge for himself, and to determine whether the cause of the destruction was really difficult to be divined. Dr. Johnson, it may be mentioned, has the Channel and North Sea fleets chiefly in view in his remarks.

Increased attention to the organic laws has greatly reduced the annual rate of mortality in Europe, even within the last forty years, and it cannot be supposed that farther improvement is impracticable. Dr. Hawkins, in his Medical Statistics, states, that in $\mathbf{1 7 8 0}$ the annual mortality in England and Wales was 1 in 40 ; in 1790 it was 1 in 45 ; in 1801 it was 1 in 47 ; in 1811,1 in 50 ; and in 1821 it had sunk so low as 1 in 58 . In cities, the diminution 
is still more remarkable. In London, 80 years ago, the annual mortality was 1 in 20 ; it is now as 1 in 40. In Manchester, Glasgow, and other places, a similar improvement has taken place; but, in some instances, the decrement in the rate of mortality has been so much exaggerated that the deaths are stated at only 1 in $74-a$ proportion which is altogether incredible as occurring in any community.

In France, the average mortality is 1 in 40 ; in Austria, 1 in 38; in Russia, 1 in 41 ; and in the United States, 1 in 40 ; whereas it is rated by Hunboldt as 1 in 30 in South America. In Paris it is rated 1 in 32 .

From the greater accuracy with which statistical returns are obtained and preserved in France and on the Continent, and the inadequate means which we have in this country of procuring correct tables, as well as the great disparity between the results obtained here and abroad, there is every reason to suspect, that in England, sources of error have been overlooked, and that the rates are consequently too favourable. It is difficult to believe, for example, that with us the rate of mortality should be so low as 1 in 58; when in France, Russia, and Austria it is ascertained to be so high as 1 in 40,1 in 41 , and 1 in 38. Still, however, the returns, such as they are, show a manifest improvement in the value of life within the last forty years, which can be ascribed only to a greater degree of comfort among the people, and a more skilful treatment of their diseases.

The principle which I am advocating is established even by many of the continental returns, which are more trust-worthy than our own. In France, the annual deaths in 1781 were 1 in 29 ; in 1802,1 in 30 , and in 1823, 1 in 40 ; and in Paris the mortality has diminished, in seventy years, from 1 in 25 to 1 in 32 ; so that, though we neglect altogether the more than doubtful statements as to Manchester and other 
places, with an annual mortality of only 1 in 60 or 70 , evidence enough exists to prove the proposition that health is intimately connected with, and dependent on, man's own conduct ; and that when the conditions of health shall be better understood, we may reasonably look forward to still brighter results.

It was very common at one time to eulogize the simple food and hardy habits of the poor and labouring classes as eminently conducive to health, when contrasted with the debilitating effects of the cares and luxuries of the rich. Experience unfortunately reverses the picture, and shows, by arithmetice] arguments, that the excess of work and the privations to which the poor are habitually exposed, produce a much higher rate of mortality among them, especially in seasons of scarcity or commercial depression, than among the richer classes of society; and the same thing is farther proved by the fact, that in the army and navy the officers almost invariably suffer less than the men from changes of climate, and from the fatigues and calamities of war. In France, the mortality among the infants of the poorer classes is said to be nearly double that occurring among those in more affluent circumstances; while, in the wealthier departments, the average of life is twelve years greater than in those which are poor In London, according to Dr. Granville's tables, only 542 infants out of every 1000 births among the poor survive their second year; and in Paris, also, the mortality in the quarter inhabited by the working classes is nearly double that which occurs among the more wealthy.

If, as seems to be the case, a corresponding disproportion occur between the rates of mortality in the different classes of society in Great Britain, it suggests some most important considerations, the first of which is the simple question, Whether that condition of the lower orders can be regarded as eminently 
prosperous or natural, which subjects them to be cut off by death so many years before the term allotted to those by whom they are employed? It also illustrates, strikingly, what I have said about bad health being more frequently the result of gradual causes long in unperceived operation, than of any sudden or accidental exposure; and proves that a mode of life or degree of labour is not to be rashly pronounced harmless, merely because its injurious effects are not immediately seen, and because years may elapse before it breaks down the constitution. It is blindness to the perception of this principle which still misleads mankind, and renders them in. sensible to the agency of numerous hurtful influences from which, by a little exertion, they might easily be relieved.

Much angry discussion lately took place as to the reality of the mischief inflicted by the long hours and unremitting exertion required in our factories and spinning-mills, where an unerring test might easily have been found. If those who contended that the hours of labour were not too long, either for the children or adults, could have produced evidence to show that, among operatives, the average of life was equally high as among the apparently more favoured classes, there would have been, at once and for ever, an end of the argument; while, had the result proved different, the system of labour might justly have been deemed oppressive in the precise ratio in which the mortality among the operatives exceeded that among their wealthier countrymen. No criterion could be so infallible as the one now proposed; and if government possessed the means of obtaining accurate returns, it seems to me that the expense of procuring them would be well bestowed, as, whatever might be the result, if could not fail to produce greater harmony of views and purpose than now unhappily prevails between the different classes of society. 


\section{GOOD DONE BY APPREHENSION OF CH DLERA.}

Every thing which tends strongly to call attention to the conditions which influence public and individual health is calculated to do great good to the community. In this point of view I am disposed to consider the visitation of cholera to the British Isles rather as one of those remarkable instances in which a beneficent Providence brings good out of evil, and converts an apparent calamity into a positive blessing, than as the public scourge which it has been generally proclaimed. True it is, that many individuals have perished, and others suffered by it in their affections, and in their worldly circumstances ; but I question if any thing short of the dread which cholera produced, could have combined all classes so efficiently and ardently in their efforts to discover and remove every thing in the condition of the poor and labouring portions of the community, which could prove detrimental to health. In the season of apparent danger, the importance of cleanliness, ventilation, warmth, clothing, and nourishment as preservatives of health, not only became manifest to minds on which nothing else could have made an impression, but their experienced efficacy gave an impetus to the exertions of the lower orders in their own behalf, which will continue to be productive of good, long after the cause from which it sprung shall be forgotten.

The comparative exemption of the wealthier classes from cholera is itself sufficient to show how much it is in the power of man, by the proper exercise of reason in the application of his knowledge, to obviate the dangers to which his health is exposed; how closely his bodily welfare is dependent on his own conduct and external situation; and how very little, comparatively, it is the result of circumstances which he cannot control or modify. In fact, every one who has investigated the subject with attention will readily testify, that, but for the establishment of soup-kitchens, the supplies of warm 
clothing, and the whitewashing, cleaning, and ventilating of the houses of the poor classes, before and during the epidemic, a much greater number would have fallen victims to its ravages. And it is consoling to know, that even those who regard such visitations as direct inflictions of a vengeful Providence, and as nowise connected with mere neglect of the laws of health, were, nevertheless, not the least active in enforcing and superintending the removal of every external cause of disease, and promoting the comforts and supplying the wants of the needy and destitute ; so that, whatever differences in mere belief there might be, all parties were content to act as if the Creator had intended the health of the race to depend, in a very high degree, on the care which was taken to fulfil the conditions which he has decreed to be essential to the due action and preservation of the various bodily organs.

Many individuals exist who, from hereditary deficiencies, can scarcely attain tolerable health, even with the best care; and many more are to be met with, who are exposed to bad health from the hurtful nature of the professions in which they are engaged. Many suffer, also, from vicissitudes of weather and other causes, which we may never be able entirely to guard against; but all these united are few, when compared to the number of those whose health is ruined by causes capable of removal or of modification, and to which they are now exposed from ignorance of their nature, from apathy, or from the want of the coinforts and necessaries of life. If I have succeeded in calling attention to this important truth, the great object of these pages will be accomplished; and I cannot help repeating the remark already made more than once, that health is more frequently undermined by the gradual operation of constant though unperceived causes, than by any great and marked exposures of an accidental kind, and is, consequently, more effectually to be preserved. 
by a judicious and steady observance of the organic laws in daily life, than by exclusive attention to any particular function to the neglect of all the rest.

It may be said that I allow nothing for the influence of habit in rendering situations and causes comparatively innocuous, which were at first dangerous. It is quite true that the human constitution possesses a power of adapting itself, within certain linits, to a change of circumstances; but it is not less true, that sudden and extreme changes often destroy health and life before the system can adapt itself to the exigency, and that after making the most ample allowance for this source of safety, the protection which it affords against the active causes of disease is comparatively trifling.

Where the change is sudden, as in passing from a temperate to a tropical climate, or even from very ine to very inconstant weather, the consequences to ealth are well known to be highly injurious. But where it is gradual and not extreme in degree, as in passing from winter to summer, health is not much endangered, because the system has time to accommodate itself to its new circumstances. Different organs predominate in activity in different climates and seasons, and time is thus required to admit of the requisite changes taking place, without disturbing the general balance of the circulation. In hot countries, for example, the skin predominates greatly in activity in comparison with the kidneys ; whereas, in a cold country the case is precisely reversed. If, therefore, a sudden transition be made from the one to the other without due preparation, the rapid change in the distribution of the blood from the surface to the internal organs, or from the latter to the surface, consequent on such change, is likely to be attended with danger; although the same change gradually effected would be unattended with any injurious results. 
If, again, the change be from a healthy situation to one only a little less favourable, the consequences to the system will be also gradual and progressive. No immediate injury to health may be apparent, and the body may be said to adapt itself to the circumstances, but, in reality, health will be lowered in tone, and life shortened, in exact proportion to the amount of the injurious exposure, and the state of the system at the time. Individuals of a peculiar constitution may live long, but the average of health and life will be positively lowered,-a fact which shows that the apparent exception is more a fallacy than a reality, and that, cateris paribus, the highest health and greatest vigour will always be on the side of those who make the nearest approach to the fulfilment of the organic laws.

It is, therefore, a glaring perversion of logic and reason to infer that we may safely rest satisfied with a limited portion of evil, on the plea that the constitution will adapt itself to its presence. The argument ought to be turned in exactly the opposite direction. If the constitution possesses this power of adaptation to the extent supposed, it becomes doubly incumbent on us to have it always surrounded with beneficial influences, seeing that, when the laws of health shall be fulfilled, the same tendency to adaptation will then operate with equal force in permanently ameliorating the constitution. In every point of view it is, therefore, an object of much consequence to us to become acquainted with and to obey all the laws which regulate the functions of the human body.

It would be easy, were it consistent with the limits and purpose of the present volume, to show that although great advances have been made of late years, both in physiological knowledge and in its applications to the advancement of human hapt piness, many of the usages current in society, and many of the practices resorted to in education, are 
still far from being in harmony with the laws of the human constitution, and that much good may be done by diffusing among the reflecting portion of mankind more accurate notions of the structure and uses of the various bodily organs, and of the conditions required for their healthy action. Illustrations in proof of this position, drawn from individual cases, may be cavilled at as incomplete, or regarded as accidental coincidences; but when the principle is exhibited in active operation on a large scale, minor qualifications fall into the shade, and leave the evidence absolutely unassailable. On this account I prefer selecting an example from the records of the army, both as being striking in its features, and as being one in which the public interest is deeply involved.

A few years ago, young growing lads were uniformly selected for the army in preference to men of a mature age, on the supposition that, because their habits were not formed, they could be more easily converted into good soldiers than if taken a few years later. Many officers still entertain and act on this opinion, and the period at which, by law, liability to military service commences in this country, remains fixed at eighteen years of age, although it has been raised to twenty by most of the conti. nental governments.

Examined physiologically, the practice of enlisting juvenile recruits seems peculiarly irrational. During growth, the conditions required for the healthy development of the body are, moderate and regular exercise, plenty of nourishing food, abundance of sleep, and a cheerful state of mind. In making the transition from boyhood to maturity, the equilibrium of action between the different parts of the system is so much disturbed, that, even under the most favourable circumstances, an unusual susceptibility of disease prevails, which renders that period of life particularly dangerous. By consult- 
ing the statistical tables prepared by Mr. Finlayson, it will be seen, that in all classes of society, the rate of mortality suddenly increases from the age of fourteen, when rapid growth may be said to commence, to that of twenty-three, when it is nearly completed. In Paris, for example, the tables for the year 1820 exhibit only 395 deaths as occurring between the ages of 10 and 15 ; whereas those between 15 and 20 amount to no less than 703, being nearly double while in the five years immediately subsequent they rise to 1339 , and afterward begin again to decrease.

Viewing these results in connexion with the laws of the animal economy, and bearing in mind that, even in peace, military service implies broken sleep, separation from friends, and occasional exposure to fatigue and privation, we must consider it almost self-evident, that an army composed of young lads belonging to this hazardous period of life must be sickly and inefficient, and that a large portion of the expense and trouble bestowed in enlisting and training them must be entirely thrown away. That such is actually the fact has unfortunately been proved too often by fatal experience. Mr. Marshall, Deputy Inspector of Hospitals, in his late excellent work "On the Enlisting, the Discharging, and the Pensioning of Soldiers," adduces an irresistible mass of evidence to show, that till the growth is completed, it is impossible to form any correct estimate of the probable efficiency of a recruit, as numbers of apparently promising young men are cut off by affections of the chest, and other acute diseases, be: fore attaining maturity, and before being exposed to any unusual privations or fatigue. So literally accurate is this statement, that Coche, a high French authority quoted by Mr. Marshall, mentions distinctly, that even in time of peace, when no great hardships are to be encountered, volunteers received into the army at the age of eighteen or twenty pass two, three, or four years of their period of servies 
(eight years) in hospital, solely from inability to bear ap under difficulties which scarcely affect those who are a few years older.

9 If such be the result during peace, I need hardly say, that in time of war the practice of enlisting very young men is not less fatal to the individual than costly to the country. It appears, accordingly, that in the army in Spain, sickness and inefficiency prevailed almost in proportion to the youth and recent arrival of the soldiers. Sir James Macgrigor cites the 7th regiment as an illustration, and adds, that between 9th August, 1811, and 20th May, 1812, it Iost 246 men, of whom 169 were recruits landed in the preceding June; while only 77 were old soldiers. The original number of this detachment of recruits was 353 , so that more than one-half died within the first eleven months. The total number of old soldiers, on the vther hand, was 1143 , and of them only 77 perished in the same time! So convinced, indeed, is Sir James of growing "lads being unequal to the harassing duties of the service," that in making calculations for measures in the field, he thinks that 300 men who had served five years would be found more effective than 1000 newly arrived, not simply from their greater experience, but chiefly from the additional stamina proceeding from maturity.*

In a note subjoined to the preceding opinion of Sir James Macgrigor, Mr. Marshall says, "numerous examples might be quoted to show that young lads are much less able to endure the fatigue of marching than men a little more advanced in life. During the winter of 1805 , a French army, which was stationed on the coast in the neighbourhood of Boulogne, marched about 400 leagues to join the grand arrny before the battle of Austerlitz, which it effected without leaving almost any sick in the hospitals on the route. The men of this army had served two

* Marshall, lib. cit., p. 3 . 
years, and were rot under twenty-two years of age. The result of the march of this army may be compared with that of another under different circum. stances. In the campaign of the summer of 1809 , the troops cantoned in the north of Germany marched to Vienna, but by the time they arrived at the place of their destination, all the hospitals on the road were filled with sick. More than one-half of the men composing this army were under twenty years of age, the usual levy of conscripts having been anticipated. After the battle of Leipsic, Napoleon made great exertions to recruit his army, and called upon the legislative senate to give him their assistance, to which they showed some reluctance. - Shame on you !' cried the emperor * * *, 'I demand a levy of 300,000 men, but I must have grown men, BOYS SERVE ONLY TO ENCUMBER THE HOSPITALS AND ROAD-SIDES." "

In similar defiance of the laws of physiology, halfgrown lads were at one time preferred for the East India service, on the false supposition that their unconsolidated constitutions would more easily adapt themselves to the climate than those of men already arrived at maturity, - a proposition very nearly equivalent to saying, that because a person is already enfeebled, exposure to the causes of disease will therefore have less effect on him than after his strength shall be restored! Palpably fallacious as this kind of logic now appears to be, it nevertheless reigned for years with undisputed sway, and it was only in September, 1829, that an order was issued from the Horse Guards that no recruits under twenty should be received for regiments serving in tropical climates; and so late as the year 1826, nearly 15 per cent. of the king's troops in Bengal were under that age.

In touching upon this question also, Mr. Marshall supports his positions by a reference to facts of a very conclusive kind, and to authors whose opinions $\mathbf{B}$ b 
ought to have great weight. Among other evidence, he quotes the register of a regiment employed in the Burmese territory in 1824-5, from which "it appears that, in 1824 , the ratio of mortality among the young men who went out with the corps was 38 per cent., or 1 in every $2 \frac{1}{3}$; while, among the volunteers who were considerably older, the mortality was 17 per cent., or only 1 in 6 . In 1825 , it was 30.5 per cent., or 1 in $3 \frac{1}{3}$, among the younger lass, and only 6 per cent., or 1 in 16, among the older." -(p. 10.)*

Some other instances might be quoted in proof of the greatest mortality being always among the youngest men: and I might refer to a regiment mentioned by Dr. Davies, in which, when it was sent out to Bombay in 1808 , there was not a single private above 22 years of age, and in which, out of 550 men, nearly 300 required medical assistance within six weeks after he joined it; but it is unnecessary, as, although individual officers still prefer young men, government is at last awakened to their unfitness. A vague opinion that growing lads do not bear fatigue is indeed prevalent enough; but I venture to say, that if those by whom the age of enlistment was first determined had been thoroughly acquainted with the laws of physiology, and had possessed a clear perception of the conditions of

* In availing myself of Mr. Marshall's labours, I may be allowed to express my opinion of the benefit he is conferring by his statistical researches, not only on the service with which he bas been so long and honourably connected, but also on the public at large. There are many practical questions deeply concerning publis health, which can only be fully elucidated by such masses of facts being grouped together as shall destroy all minor inequalities, and place the operation of principles prominent'y in view. But to effect this object with due regard to accuracy requires an acquaintance with details, an acuteness of observation, and a power of successful generalization, which are rarely found in combination with adequate zeal and industry. It would be very useful if similar researches were instituted in rogard to the occurrences in our public haspitals. 
healthy growth, the practice of receiving recruits at 17 or 18 years of age would never have been sanctioned, and the country would have been saved the pain and the expense of sending thousands of young men to "encumber the hospitals and the road-sides" of the Peninsula, or to perish under the exhausting influence of a tropical climate.

I have dwelt at some length on this subject, both because the practice which I condemn was lately in full operation, and is even yet not entirely exploded, and because, from the magnitude of its results, and the clearness with which they can be traced to a direct violation of a natural law of the constitution, it affords an instructive example of the evils arising from ignorance of the structure and functions of the human body, and of the aid which might be derived from a general acquaintance with physiology in preserving health, and promoting the happiness of the race.

It was my intention to analyze, in the same way, various other practices in which public or private health is concerned, and to offer some suggestions for improving the treatment of the insane, by a more extensive observation of the conditions required for the healthy exercise of the mental functions; but I have already so far exceeded the limits originally proposed, that I must now draw to a conclusion, and judge, by the reception of the present volume, how far I am right in believing that information of the kind now communicated will be acceptable or useful to the public 




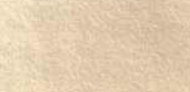





\section{U.C. BERKELEY LIBRARIES}

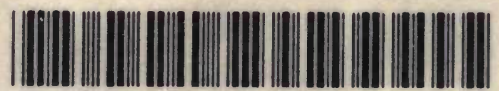

C006?10119

1) 1 


\section{HARPEK S FAMILY LIBRARY.}

Aps. 3, 2, 3. Milm is History of the Jews. brin f'ates $3 y$.

4, 5. Lockhart's I.feoi Napo. Leon Bongyart. Plales.. 2v.

6. Southey's hif uf Nelson $1 \mathrm{v}$.

7. Willams's L hie bi Atexan. der the drobat, Mares... I

3. Natanal Hist of Insects, last $\nabla_{5}$

7. Galt's Lite of Lord Byron Iv.

16. Bush's Lific of Mol numed iv:

11. Seot on Demonology and Witeloruft. Plate....... It

12, 10 Gieig's Bible History.. 2 v.

14. Discovery and Adventure in the Polar Seas, \&e ... I $\mathrm{y}_{\text {. }}$

15. Croly's Life of George IV: Iv.

15. Discuvery anc Adventure in Africa. Engravings... 1v.

17, 18, 19. Cunainghum is lives of Painters. Seulptors, sec. $3 \mathrm{v}$.

20. Chivaliry atid the L rusades iv. 21, 22. Hell's tifte of Mary, Queen of Seots. Portrait $2 \mathrm{v}$.

23. I issell's A nelent and Mod? cm Egypt. With Hates.. Iv.

24. History of Jeand ,....... iv $v$.

25. Snith'e Fetivals, Ganjes, and A insuse haents........ is,

26. Life al Sir Lsagc Newton.. I v.

97. Russell's Palestine, of the Holy Land. Wicl Plaies 1 v.

28. Mautes's Manoirs of Sinuress Josr phime. $r$ whe.. iv.

29. The $\mathrm{C}$ and Cam of Bonaglarte. Witis Plates $1 \mathrm{v}$.

30 Lires of Fimly No iors ir.

31. Fespription af Piteal n's Esland, dee. Engravings. Iv.

68. Purner's Sacred Historv, ist $\mathrm{v}$.

33. 34 Hemoirs of Celebraced

Fensile sovereigns....... $\& \mathrm{v}$.

25,30 asderst Africa , . . . 2 $\mathrm{y}$.

37. Inteviertuht Powers, \&c... iv

38,40 , Chltivind Travellers $3 v$.

41, 42. Lite of : deric II.... $2 v$.

Si Yentian iistory...... $2 v$.

45. 10. Whateher's Iadian Lives $2 \mathrm{v}$. 4t, 48,49. History of India.... 3v 50. Brewster on Natural Magie I v. 3L, 52. Hlistory of Ireland...... 2v. 53. Discoveries on the Narthern Cimsis of Amertea... I $\%$. 51. Humbuldits Travels.o.n. iv 55, Ef Buler's Nat. Thilosuphy $2 \%$ 57. Mudie is Caribe to tha Olo servacion of Nature....... 1

58. A bercran bie or this Philesopsy of the Minus Feetinus 1 .

50. Hifk on the Improvement of society, Eduearion, sce. iv. 60. James' hile of elianlenagne iv. 61. Nubia and shysainir...... I $y$, 62 , b*. Lifo of Cromwell..... 2v o4 Mongotnery's Lectures ... I v. 05. Peter the Great............ iv. 66, 6\%. Eminent fainterk..... $2 \mathrm{v}$. 68,69 . theiory of A rabia..... $2 \div$ 70. History of Persia........ I v 1. Combers Phystatogy ...... iv. 72. Tumer's kaved History, id vol. 73. History of Barbary sintes. I v, 74. Natup! History or ilisects, $2 d \mathrm{v}$ 73,7 . Life of Wi hington... $2 \mathrm{y}$

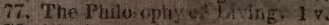
78. Higgins on tha garth... Iv. 79. Histo: cithly .... I v 80,81. The Chisese ...... $2 \mathrm{v}$.

\section{CLASEFAL EI IL.}

1, F. Xenophen Wortrat ... 2v, 3, 4. Leluticto Demosthenes. $2 v$ 5 Tose's Ballust fortrait... IV 6. 7 Cursut's Com mentu jes. . $2 v$. $8,9,10$. Cicere. Porrait.... 3 F. 11, 12 Viruit Portrais..... 2v: 13. Aschylus.............. I v is Sophocles............. I v, $15,16,17$. Euripiates......... $3 \mathrm{v}$, 18, 19 . Horace ats Pledrus... 2v. 30,21 . Ovid. Fartrait...... $8 v$. 22, a3. Thueydides.......... $2 \mathrm{v}$. $24,25,26,27,28$. Livy,....... 5 v. 29. 30, 31. Herodotus........ $3 \mathrm{v}$. $32,33,34$. Hamer.......... $3 v$.

\section{Boys? and Glyls' Library.}

1. Ives or the A postiles, \& c. 1 v. 16. Caroline Westerley .... I v 2,3. Swios Fanily Robinson.. 2v. 17. Clergyman's Orphan..... iv 4 Sunday Eveaings, tst vol.. Iv. 18. Sunday Lvenangs, last vol. Iv 5. Son of a Genius ......... 1v. 19. Omainents Diseovered.. I v 6. Unete I'k 's Conversations Iv. 20. Unele Philijus Christianity Lv. 7,8 Indiau Tralts........... $2 v$. 21, Uncle Philip's Virginia.... iv 9. 10,11 American Higtory,.. $3 \mathrm{v}$. 22. Uncle Philip on Treses... I v.

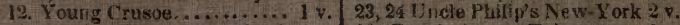
13. Sunday Evenings, 2 d vol. 1 v. 25 . Revolutionary Tales...... I v. 14. Perils of the sea......... I v. 26, 27 . Unele Ebilp on the 15. Feusale Biography ....... Iv. Whalo fishery.......... . 25. 